\title{
Contributions to the Measurement and Control System Design of the Carleton Supercritical Fluid Heat Transfer Test Loops
}

\author{
By
}

\author{
Yi-Li Jin \\ A Thesis submitted to \\ the Faculty of Graduate and Postdoctoral Affairs \\ in partial fulfillment of \\ the requirements for the degree of \\ Master of Applied Science
}

Ottawa-Carleton Institute for Mechanical and Aerospace Engineering

Department of Mechanical and Aerospace Engineering

Carleton University

Ottawa, Ontario, Canada

February 2014

Copyright (C)

$2014-$ Yi-Li Jin 
The undersigned recommend to the Faculty of Graduate and Postdoctoral Affairs acceptance of the Thesis

\title{
Contributions to the Measurement and Control System Design of the Carleton Supercritical Fluid Heat Transfer Test Loops
}

\author{
Submitted by \\ Yi-Li Jin \\ in partial fulfillment of the requirements for the degree of \\ Master of Applied Science
}

M.I. Yaras, Supervisor

M.I. Yaras, Chair of the Department of Mechanical and Aerospace Engineering

Carleton University

2014 


\begin{abstract}
Two thermalhydraulic test facilities, namely the Carleton Supercritical Water Loop (C-SCW Loop) and the Carleton R-134a Loop (C-R134a Loop) are currently being designed for experimentally investigating the convective heat transfer characteristics of supercritical fluids.
\end{abstract}

As part of the design efforts, flow control devices, namely two control valves and a centrifugal pump have been selected for the purpose of delivering a water mass flow rate of $0.113-0.365 \mathrm{~kg} / \mathrm{s}$ through the test section of the C-SCW Loop. The selected control valves and the centrifugal pump are designed to withstand a temperature of $260^{\circ} \mathrm{C}$ and a pressure of up to $27 \mathrm{MPa}$ of C-SCW Loop.

To regulate the test loops' system pressures and to accommodate the excessive working fluids caused by the temperature variation during the operation of the two test loops, two pressure control modules are designed. Two pressure control modules are designed to relevant standards so that they can be certified by the Technical Standards and Safety Authority (TSSA) to ensure the safe operation of the test loops. Numerical simulations are carried out to investigate the performance of the Shear-Stress-Transport turbulence model in modeling convective heat transfer problems.

Sensors and control devices are also installed on the two test loops to monitor and control the operation of the loop. A number of $\mathrm{N}$ type thermocouples with a sheath diameter of $1.59 \mathrm{~mm}$ are selected and installed on two tubular test sections. They are used to collect the wall temperature data at the test section. A data acquisition system capable of collecting sensor measurements from both test loops is designed. Two virtual control panels, one for each of the test loops, are designed using LabVIEW ${ }^{\mathrm{TM}}$ version 2010 . The 
virtual control panels are designed using the ergonomic principles to avoid as much human-error as possible. 


\section{$\underline{\text { Acknowledgements }}$}

First of all, I would like to thank my thesis supervisor, Dr. Metin I. Yaras, for his support and guidance through my research work. I would extend my thanks to my colleagues Masih N. Balouch, Alex Picard and Camelia Nisioiu, for their help during the course of this work. I would also like to thank Dr. Richard Kind for taking time reviewing my thesis. I also owe a great debt to my family and my best friends, Mr. Richard Huyda and Mrs. Elaine Huyda. Finally, I would like to thank Carleton University and AECL Ltd. for their funding of my research. 


\section{Table of Contents}

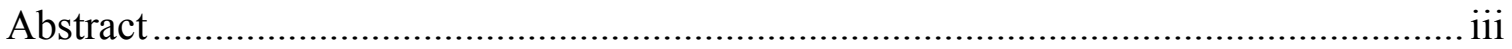

Acknowledgements ................................................................................................... V

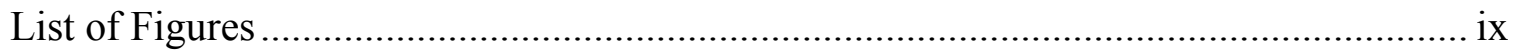

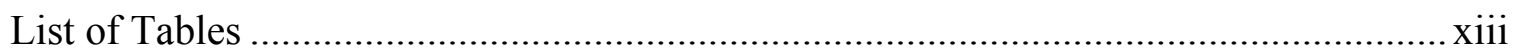

Nomenclature

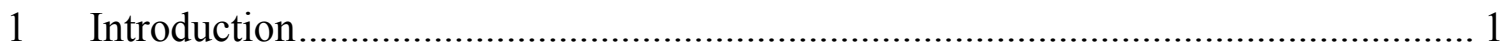

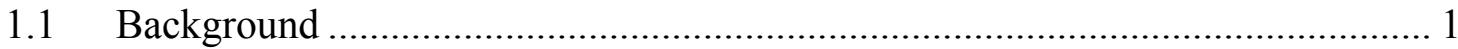

1.2 Scope and Organization of the Thesis .............................................................. 1

2 Review of the Design Work for the C-SCW and C-R134a Loops ............................. 3

3 Flow Control Devices on the C-SCW Loop ………............................................ 7

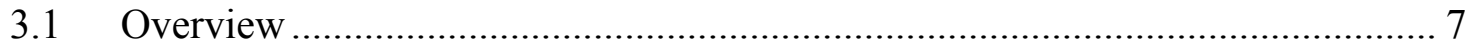

3.2 Sizing of the Pump on the C-SCW Loop ………......................................... 7

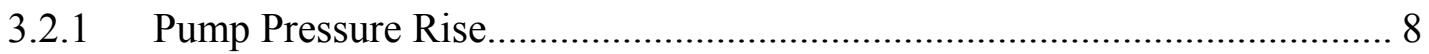

3.2.2 Pump Type Selection and Sizing .......................................................... 16

3.3 C-SCW Loop Flow Control Valves ……………...................................... 22

3.3.1 Valve Selection and Sizing …………………...................................... 22

4 Design of the Pressure Control Modules on the C-SCW Loop and the C-R134a

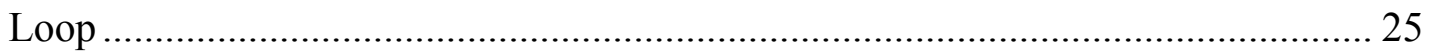

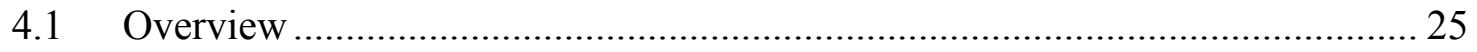


4.2 Selection and Sizing of the Accumulator for the C-SCW Loop and the C-R134a

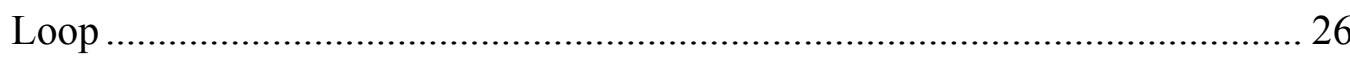

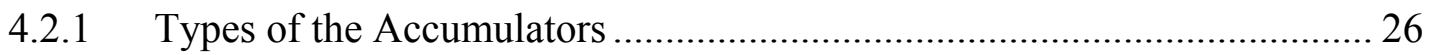

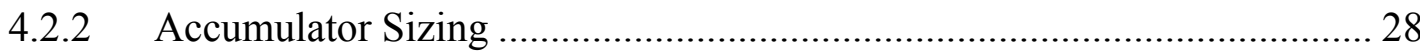

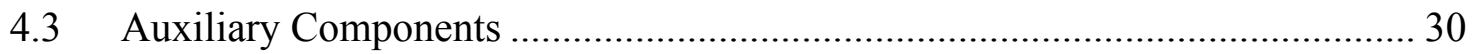

4.3.1 Cooling Tube for the Accumulator ............................................................ 31

5 Instrumentation, Data Acquisition System (DAQ) and Virtual Control Panel

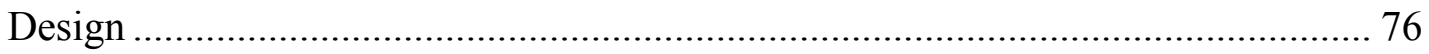

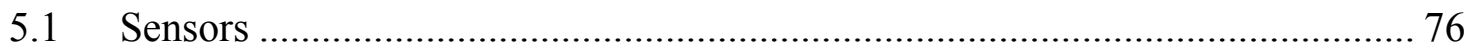

5.1.1 Selection of Temperature Sensors ......................................................... 79

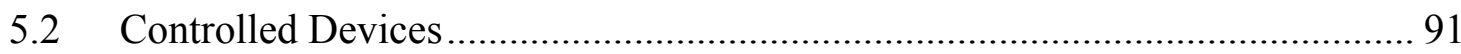

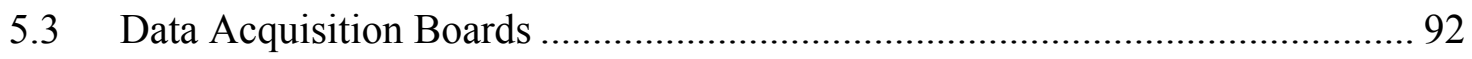

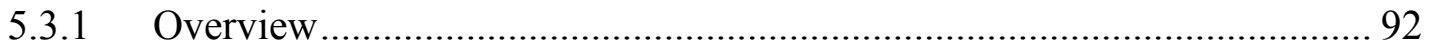

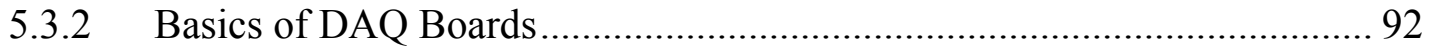

5.3.3 Selection of DAQ Boards for Use with the C-SCW and C-R134a Loops.. 96

5.4 Measurement Uncertainties and Propagated Uncertainties for the Selected Thermalhydraulic Parameters ........................................................................... 106

5.4.1 Uncertainties for the Sensor Measurements ............................................. 108

5.4.2 Error Propagation for the Convection Heat Transfer Coefficient.............. 110

5.5 Design of the Virtual Control Panel ............................................................. 125 
5.5.1 Overview.

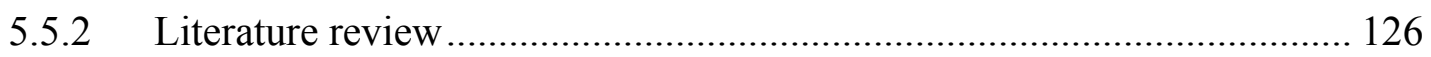

5.5.3 Design of the Virtual Control and Monitoring panel............................. 130

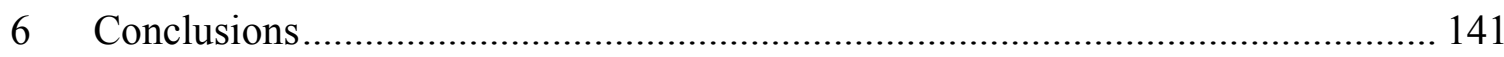

6.1 Flow Control Devices on the C-SCW Loop............................................. 141

6.2 Pressurization Modules for the Two Test Loops ........................................ 142

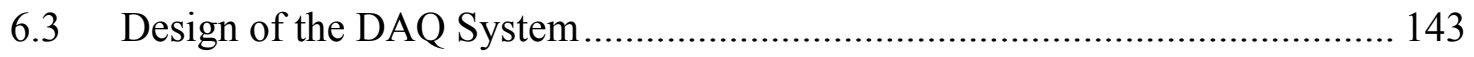

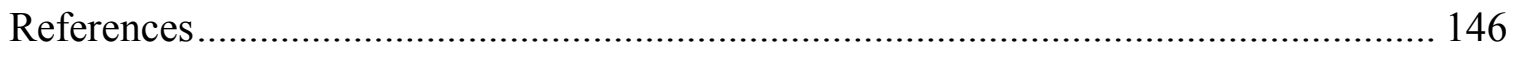

Appendix 1: Total Pressure Loss in the Subsections of the C-SCW Loop.................... 152

Appendix 2: Operating Flow Coefficients of the Two Control Valves Installed on the C-

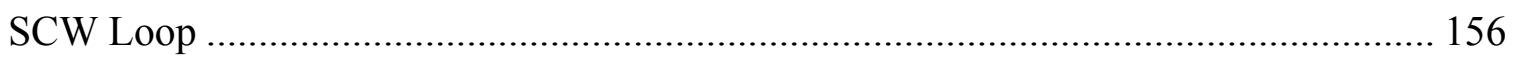

Appendix 3: Sizing of the Cooling Tube and the Pressure Relief Valves .................... 157

Appendix 4: Specifications for the Fans Selected of the Pressure Control Module of the

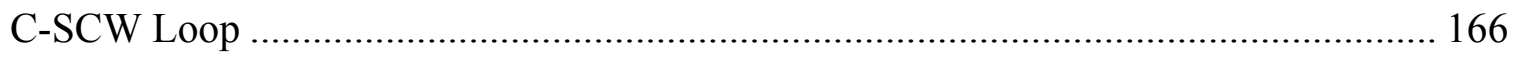




\section{List of Figures}

Figure 1: Test loop installations in the laboratory space [2] ......................................... 3

Figure 2: Schematics of the (a) C-SCW Loop and (b) C-R134a Loop [2] ........................ 4

Figure 3: Cross sections of the three types of test sections [2] ...................................... 5

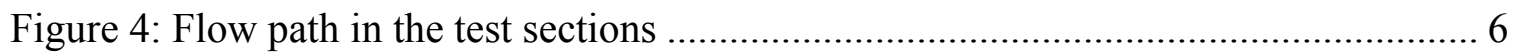

Figure 5: Locations of the pump and the control valves (CV 1 and $\mathrm{CV} 2)$ on the C-SCW Loop

Figure 6: Subsections of the C-SCW Loop................................................................. 9

Figure 7: Total pressure losses within the subsections of the C-SCW Loop for the expected operating pressures and test section outlet temperatures ................................. 13

Figure 8: Required pump mechanical power in the C-SCW Loop for the operating

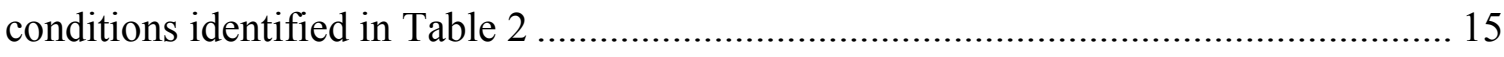

Figure 9: Specific speed charts for selection of the pump type [7] ................................ 18

Figure 10: Cordier diagram [8] ....................................................................... 20

Figure 11: Schematic of the pressure control modules on the C-SCW Loop and C-R134a

Loop

Figure 12: Thermal conduction through the cooling tube ………………………......... 33

Figure 13: Simulation domain and boundary conditions for the cooling-tube heat transfer

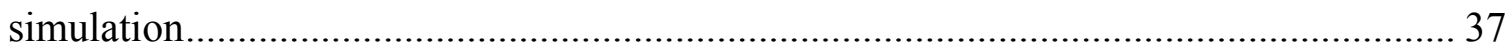

Figure 14: Illustration of the construction of a control volume around a mesh node and

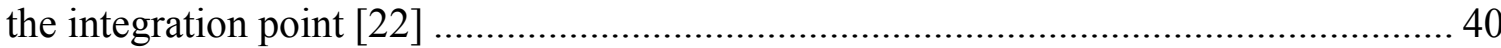

Figure 15: View of mesh for the most refined mesh generated for the cooling tube and the accumulator assembly 
Figure 16: Layout for forced convection over the cooling tubes................................ 50

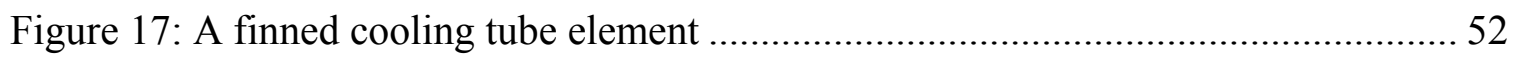

Figure 18: Simulation domain for the convective heat transfer simulation inside the

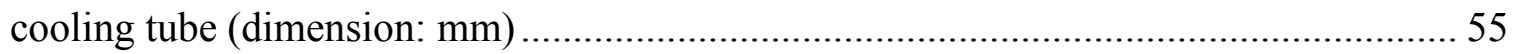

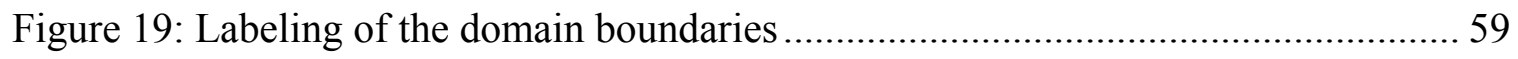

Figure 20: The combined thermal resistance for heat conduction through the wall and convective heat transfer between the ambient and the external wall of the tube............. 62

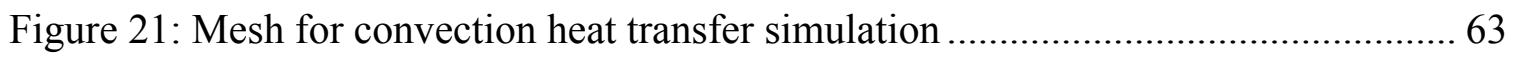

Figure 22: A view of the mesh for Case 3 for a small section of the simulation domain

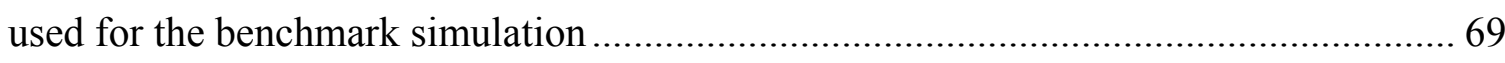

Figure 23: Comparison of benchmark simulation streamwise-velocity profile with semi-

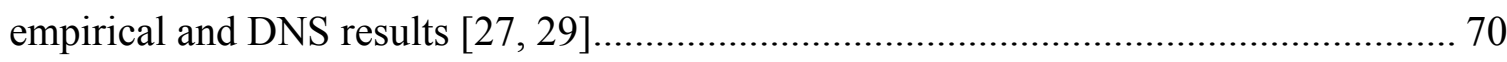

Figure 24: Comparison of benchmark simulation temperature profile results with the

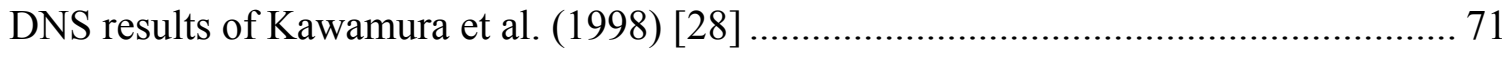

Figure 25: Comparison of the Nusselt numbers obtained from the simulation results and those from an empirical Nusselt number correlation (Eqn. (28)) ................................ 73

Figure 26: Sensor layout for the C-R134a Loop.................................................... 76

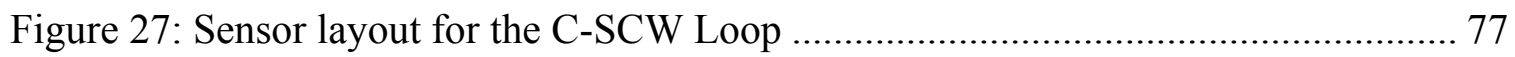

Figure 28: Three designs of thermocouple measuring junction [41] ........................... 83

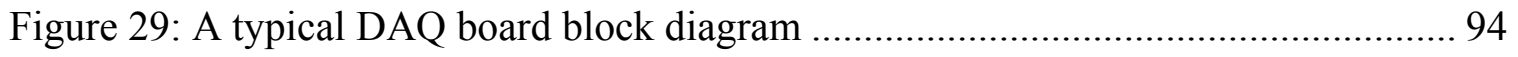

Figure 30: Illustration of an aliased signal due to undersampling .............................. 96

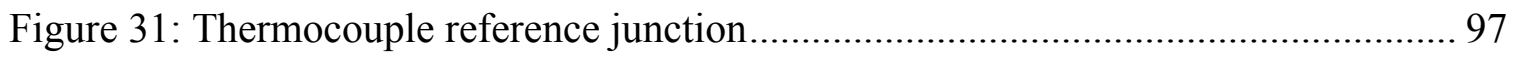


Figure 32: Uncertainty in the absolute pressure measurements due to signal conditioning 102

Figure 33: Uncertainty in the differential pressure measurements due to signal conditioning

Figure 34: Uncertainty in the flow rate measurements due to signal conditioning ........ 103

Figure 35: Uncertainty in temperature measurements due to signal conditioning ......... 103 Figure 36: Uncertainty in electric current measurements of the $300 \mathrm{~kW}$ AC-to-DC electric transformer due to signal conditioning 104

Figure 37: Screw terminal and the ribbon cable with multi-pin connector 106 Figure 38: Total uncertainty of the absolute pressure measurement of the working fluid 108 Figure 39: Total uncertainty in differential pressure measurements across the tubular test section 109

Figure 40: Total uncertainty in flow-rate measurements 109

Figure 41: Total uncertainty of the temperature measurements 110

Figure 42: Relative uncertainty for the convection heat transfer coefficient in the test section for the C-SCW Loop with the tubular test section installed

Figure 43: Relative uncertainty for the convection heat transfer coefficient in the test section for the C-SCW Loop with the annular test section installed.

Figure 44: Relative uncertainty for the convection heat transfer coefficient in the test section for the C-SCW Loop with the 7-rod bundle test section installed.

Figure 45: Relative uncertainty for the convection heat transfer coefficient in the test section for the C-R134a Loop with the tubular test section installed 
Figure 46: Relative uncertainty for the convection heat transfer coefficient in the test section for the C-R134a Loop with the annular test section installed

Figure 47: Relative uncertainty for the convection heat transfer coefficient in the test section for the C-R134a Loop with the 7-rod bundle test section installed.

Figure 48: Setup of the differential pressure transducer on the two test loops

Figure 49: Relative uncertainty for the total pressure loss in the test section for the C-

SCW Loop with the tubular test section installed.

Figure 50: Relative uncertainty for the total pressure loss in the test section for the C-

SCW Loop with the annular test section installed

Figure 51: Relative uncertainty for the total pressure loss in the test section for the CSCW Loop with the 7-rod bundle test section installed

Figure 52: Relative uncertainty for the total pressure loss in the test section for the C-

R134a Loop with the tubular test section installed

Figure 53: Relative uncertainty for the total pressure loss in the test section for the C-

R134a Loop with the annular test section installed

Figure 54: Relative uncertainty for the total pressure loss in the test section for the C-

R134a Loop with the 7-rod bundle test section installed....................................... 125

Figure 55: Health monitoring virtual panel for the C-R134a Loop ............................ 132

Figure 56: Health monitoring virtual panel for the C-SCW Loop............................. 133

Figure 57: Virtual control panel for the C-R134a Loop ........................................ 135

Figure 58: Virtual control panel for the C-SCW Loop........................................... 136

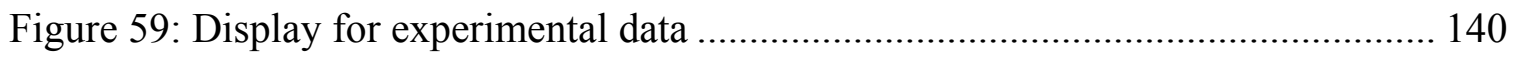




\section{List of Tables}

Table 1: Geometric information relevant to the pressure loss calculations on the C-SCW Loop [2] 10

Table 2: Experimental conditions of system pressure, test section outlet temperature and

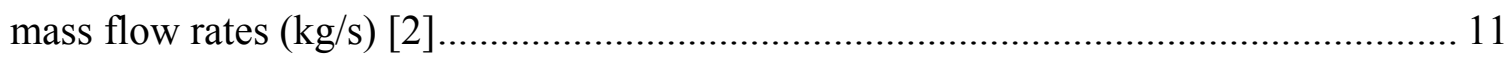

Table 3: Pressure-loss coefficients for the pipe fittings .......................................... 11

Table 4: Friction factor range for the pipe segments in each subsection........................ 12

Table 5: Selected C-SCW Loop operating point for the sizing of the pump ................... 15

Table 6: Specifications for the C-SCW Loop Pump................................................ 20

Table 7: The initial and final loop conditions for the C-SCW Loop and the C-R134a Loop which causes the maximum discharge of hydraulic fluids .......................................... 28

Table 8: Nusselt numbers for natural convection at different circumferential positions over a horizontal cylinder for a range of Rayleigh numbers and a constant Prandtl number

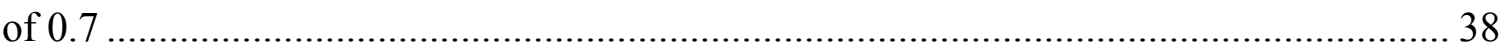

Table 9: Number of elements for the meshes generated for the mesh sensitivity study... 43 Table 10: Length of the cooling tube at which the temperature of tube reaches $90^{\circ} \mathrm{C}$ at the

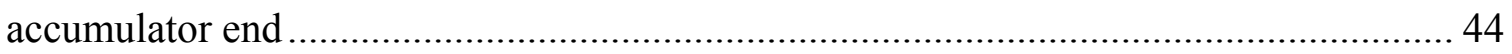

Table 11: Specifications for the finned cooling tube .............................................. 51

Table 12: Turbulence model constants for the SST turbulence model ........................... 58

Table 13: Boundary conditions for the cooling-tube water flow simulation .................... 60

Table 14: Statistics of the mesh for the three cases of the benchmark simulation ........... 68

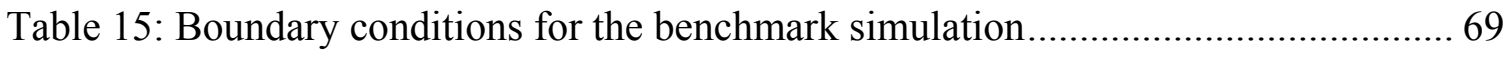

Table 16: Summary of the results on the sizing for required length of cooling tube ....... 74 
Table 17: Summary of the specifications for the finned cooling tube 75

Table 18: Number of sensors and their signal types [31 - 37] $\ldots$ 78

Table 19: Thermocouple measurement range, uncertainty and sensor sensitivity (the relative uncertainty is expressed as the percentage of temperature reading with units in ${ }^{\circ} \mathrm{C}$ )

Table 20: Typical temperature limits for different types of thermocouples at the selected sensing element sizes (the listed wire sizes are obtained based on the standard American

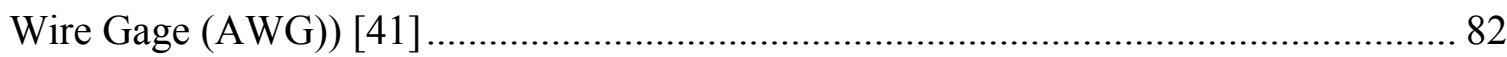

Table 21: Test loop operating scenarios created for the transient heat transfer analysis.. 89

Table 22: Values of the constants $C$ and $n$ in Eqn. (70) at different Reynolds number [18]

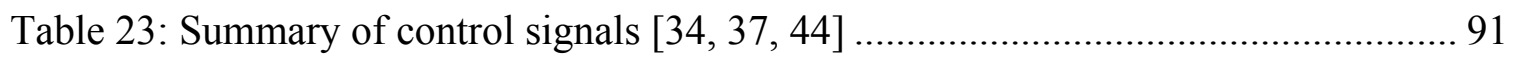

Table 24: Uncertainties resulted from the digitization of the analog input signals ......... 95

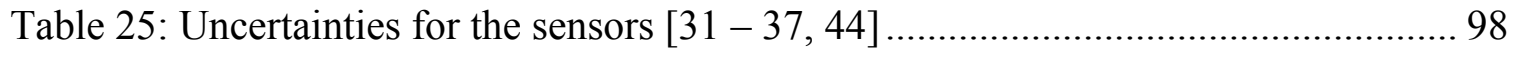

Table 26: Response time of the pressure transducers and the flow meters $[31-33,36]$

Table 27: Parameters of interest for the experiments performed on the C-SCW and C-

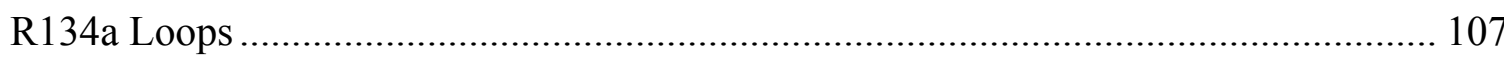

Table 28: Independent variables and partial derivatives for evaluating the propagated uncertainties for convection heat transfer coefficient ......................................... 111

Table 29: C-R134a Loop operating scenarios considered for the error propagation...... 113

Table 30: List of independent variables and their partial derivatives ......................... 122 


\section{Nomenclature}

\section{Latin letters}

A

$A_{b, f}$

$A_{\text {flow }}$

$A_{i}$

$a$

$a_{1}$

$\arg _{1}$

$\arg _{2}$

b

C

$C_{v}$

$c$

$c_{p}$

D

$D_{h}$

d

$e_{j}$

$e_{p}$

$e_{p, h}$
Area

Tube surface area covered by the fin for the finned cooling tube

Flow area of the test section

Internal wall surface area of the cooling tube

Matrix coefficients generated by ANSYS CFX ${ }^{\circledR}$

Turbulence model constant

Turbulence model constant

Turbulence model constant

Right-hand-side term for resolving the governing equations in the ANSYS CFX $^{\circledR}$ algorithm

Outside circumference of the cross section of the tube;

turbulence model constant; Nusselt number correlation constant

Valve flow coefficient

Specific heat capacity

Isobaric specific heat capacity

Diameter of the pump impeller; outside diameter of the cooling tube

Hydraulic diameter

Internal diameter of the cooling tube

Measurement uncertainty from source $j$

Propagated uncertainty

Total uncertainty of the convection heat transfer coefficient in the 
test section

$e_{p, p}$

$e_{r p, h}$

$e_{r p, p}$

$e_{\text {total }}$

$F_{1}$

$F_{2}$

$f$

$f_{\min }$

$g$

$\Delta H$

$h$

$h_{\text {air }}$

$h_{\text {eff }}$

$h_{e q}$

the effect of the heat conduction through the wall and that of the
forced-convection heat transfer on the outer peripheral of the finned
cooling tube
Total specific enthalpy
$h_{\text {tot }}$
$h_{w a t e r}$

Total uncertainty of the total pressure loss in the test section

Relative uncertainty of the convection heat transfer coefficient in the test section

Relative uncertainty of the total pressure loss in the test section

Combined uncertainty for the sensor measurements

Turbulence model constant

Turbulence model constant

Friction factor

Minimum required sampling rate

Gravitational acceleration

Pump pressure rise expressed in height of the working fluid column

Specific enthalpy; convection heat transfer coefficient

Convection heat transfer coefficient on the outer perimeter of the

cooling tube

Effective heat transfer coefficient for the finned section of a finned tube element, $\varepsilon_{f} h_{\text {air }}$

Equivalent convection heat transfer coefficient, which incorporates the effect of the heat conduction through the wall and that of the forced-convection heat transfer on the outer peripheral of the finned

Convection heat transfer coefficient for water flow in the cooling 
tube

$I$

$i$

$K$

$k$

$L$

$L_{e}$

$L_{e, t h}$

$L_{\text {tube }}$

$m$

$m$

$N$

$N_{S}$

$n$

$\Delta n$
Turbulence intensity; electric current through the heater of the test section

Number of channels on the DAQ board

Turbulence kinetic energy

Coefficient accounting for the pressure losses in pipe fittings;

thermal conductivity

Length of the pipe; length of the test section; length of the cooling

tube

Hydrodynamic entry length

Thermal entry length

Length of the tube segment

Parameter for calculating temperature profile along a bar connected to an isothermal heat source

Mass flow rate

Shape function generated by ANSYS CFX ${ }^{\circledR}$ for the mesh element; pump speed; DAQ board throughput rate

Specific size of the pump calculated using a custom unit system An exponent in the Nusselt number correlation; number of bits for the DAQ board; number of samples taken to be averaged to form one output for the DAQ board

Outward pointing normal unit vector of the surface of the control volume around a mesh node 


\begin{tabular}{|c|c|}
\hline$P$ & Static pressure \\
\hline$\Delta P_{o}$ & Total pressure loss \\
\hline$\Delta P_{o, t e s t}$ & Total pressure loss in the test section \\
\hline$\Delta P_{\text {measured }}$ & Readings from the differential pressure transducer \\
\hline$P_{o l}$ & Maximum total pressure rise of a pump \\
\hline$P_{o 2}$ & Minimum total pressure rise of a pump \\
\hline$Q$ & Volume flow rate \\
\hline$\dot{Q}$ & Rate of heat transfer \\
\hline$\dot{Q}^{\prime \prime}$ & Wall heat flux \\
\hline$R$ & Thermal resistance; electric resistance of the test section heater \\
\hline$R_{e q}$ & Combined thermal resistance \\
\hline$r_{i}$ & Inner radius of the cooling tube \\
\hline$r_{o}$ & Outer radius of the cooling tube \\
\hline$S$ & Vorticity magnitude \\
\hline S.G. & Specific gravity \\
\hline$S_{E}$ & Heat source or sink \\
\hline$T$ & Temperature \\
\hline$T^{+}$ & Normalized temperature, $\frac{T-T_{\text {wall }}}{\dot{Q}^{\prime \prime} / \rho c_{p}} \sqrt{\frac{\tau_{\text {wall }}}{\rho}}$ \\
\hline$T_{o}$ & Initial temperature \\
\hline$t$ & Time \\
\hline$U$ & Velocity component \\
\hline
\end{tabular}




$\begin{array}{ll}U^{+} & \text {Normalized velocity, } U / \sqrt{\frac{\tau_{\text {wall }}}{\rho}} \\ V & \text { Fluid velocity } \\ \dot{W}_{\text {fluid }} & \text { Volume } \\ X & \text { Pump power input imparted to the fluid } \\ X_{j} & \text { Axial location on the cooling tube; Cartesian spatial coordinate } \\ Y & \text { Independent variable } j, \text { of which the uncertainty affects the } \\ y & \text { Phcertainty of the sensor measurement } \\ & \text { Distance between the mesh node and the nearest solid boundary; } \\ y_{l} & \text { normal distance measured from the wall } \\ y^{+} & \text {Nirst mesh node from the wall of the internal tube wall }\end{array}$

Greek letters

$\beta$

Thermal expansion coefficient

$\beta_{3} \quad$ Turbulence model constant

$\beta^{*} \quad$ Turbulence model constant

$\Delta$

Specific size parameter

$\delta_{i j} \quad$ Kronecker delta

$\varepsilon$

Surface roughness of the pipe 


$\begin{array}{ll}\varepsilon_{f} & \text { Fin effectiveness } \\ \Phi & \text { Generic turbulence model constant } \\ \phi & \text { Variable stored at the mesh nodes in ANSYS CFX } \\ \gamma_{3} & \text { Turbulence model constant } \\ \eta & \text { Pump efficiency } \\ \mu & \text { Dynamic viscosity } \\ \mu_{T} & \text { Turbulent viscosity } \\ v & \text { Kinematic viscosity } \\ \theta & \text { Angular position of the test section } \\ \rho & \text { Density } \\ \sigma_{\omega 3} & \text { Turbulence model constant } \\ \sigma_{\omega 2} & \text { Turbulence model constant } \\ & \text { Turbulence model constant } \\ & \end{array}$

Shear stress

Nondimensional

parameters

$\begin{array}{ll}\mathrm{Bi} & \text { Biot number } \\ \mathrm{Nu} & \text { Nusselt number } \\ \mathrm{Pr} & \text { Prandtl number }\end{array}$




$\begin{array}{ll}\operatorname{Pr}_{T} & \text { Turbulent Prandtl number } \\ R a & \text { Rayleigh number } \\ \operatorname{Re} & \text { Reynolds number }\end{array}$

\section{Superscript}

$n b$

Neighbouring nodes

\section{Subscripts}

$\begin{array}{ll}\text { air } & \text { Air } \\ \text { bare } & \text { Bare tube part } \\ \text { bulk } & \text { Bulk fluid property } \\ \text { components } & \text { Piping components } \\ \text { cross } & \text { Cross-section } \\ \text { D } & \text { Outside diameter } \\ d & \text { Inside diameter } \\ \text { element } & \text { Finned cooling-tube element } \\ f & \text { Finned cooling-tube section; flow meter } \\ \text { film } & \text { Film property } \\ \text { fin } & \text { Fin property } \\ i & \text { Index for piping components; index for mesh nodes; index for } \\ & \text { surfaces constituting a control volume around a mesh node; index } \\ & \text { for Cartesian spatial coordinates }\end{array}$

impulse Average fluid property in the impulse tube connecting the ports of 
the differential pressure transducer

in

$\infty$

ip

j

out

source

tube

wall

\section{Abbreviations}

ANSI

AP

API

ASME

$C-S C W$

$C-R 134 a$

CV

$D A Q$

$D P$

F

$M A W P$
Inlet

Ambient

Integration point

Index for spatial coordinates; error source $j$

Outlet

Isothermal heat source

Tube without fin

Fluid property near the test section heater/cooling tube wall;

properties of the test section heater/cooling tube wall

American National Standard Institute

Absolute pressure transducer

American Petroleum Institute

American Society of Mechanical Engineers

Carleton Supercritical Water Loop

Carleton R-134a Loop

Control valve

Data acquisition

Differential pressure transducer

Flow meter

Maximum allowable working pressure 


$\begin{array}{ll}\text { NPS } & \text { Nominal Pipe Size } \\ R P & \text { Recommended Practice } \\ T & \text { Thermocouple } \\ \text { TSSA } & \text { Technical Standard Safety Authority }\end{array}$




\section{Introduction}

\subsection{Background}

Carleton University has taken part in a joint research project for addressing the uncertainties in heat transfer characteristics of supercritical fluid flows. A concept has been proposed by Atomic Energy Canada Ltd. to use supercritical water as the coolant for the Generation IV nuclear reactor [1]. The intention of the research is to understand the heat transfer characteristics of supercritical water and to develop reliable prediction methods for use in the safe design of Generation IV nuclear reactor.

Two thermalhydraulic test facilities, a Carleton Supercritical Water Loop (C-SCW Loop) and a Carleton R-134a Loop (C-R134a Loop), are currently being designed for conducting forced convection heat transfer experiments on two types of fluids: water and R-134a refrigerant. Major design work of the loops has been carried out by another Master's student in the author's research group, and the design work is detailed in his dissertation [2].

\subsection{Scope and Organization of the Thesis}

This thesis work focuses on the design and selection of some of the crucial components for the two experimental loops. The work can be divided into four parts.

The first part of the work involves the preliminary sizing of hydraulic components that are to be installed directly on the loop. These components consist of a pump and control valves on the C-SCW Loop. Chapter 3 of the thesis discusses this part of the work. 
The second part of the work is to design pressure control modules for regulating the system pressure for the C-SCW and C-R134a Loops. Chapter 4 of the thesis discusses this part of the work.

The third part of the work is to design a data acquisition system for acquiring the analog signals from sensors installed on the two loops and for sending digital signals to control the flow control devices installed on the two loops, the power supply to the test section, and the preheater. Some of the work in this part also involves the selection of temperature sensors for the test sections that will be interchangeably used on the two experimental loops. This part of thesis work is addressed in Chapter 5.

Lastly, conclusions and recommendations are given in Chapter 6. 


\section{Review of the Design Work for the C-SCW and C-R134a Loops}

The C-SCW and C-R134a Loops and the supporting infrastructures are located in a laboratory in the Visualization and Simulation (VSIM) building on the Carleton University campus. Figure 1 and 2 respectively show the layout of the two experimental facilities within the lab and the detailed schematics of the design of the two loops.

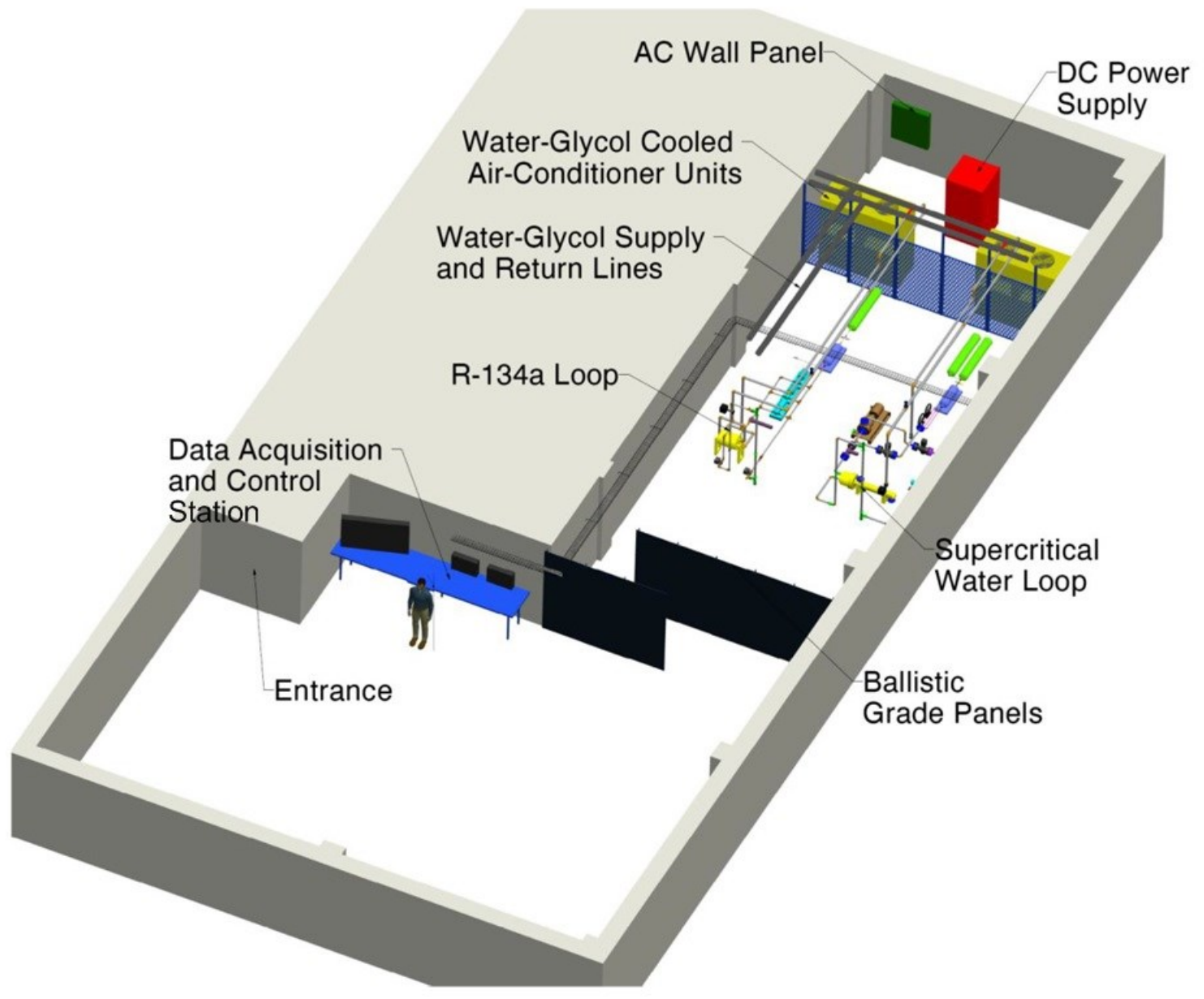

Figure 1: Test loop installations in the laboratory space [2] 


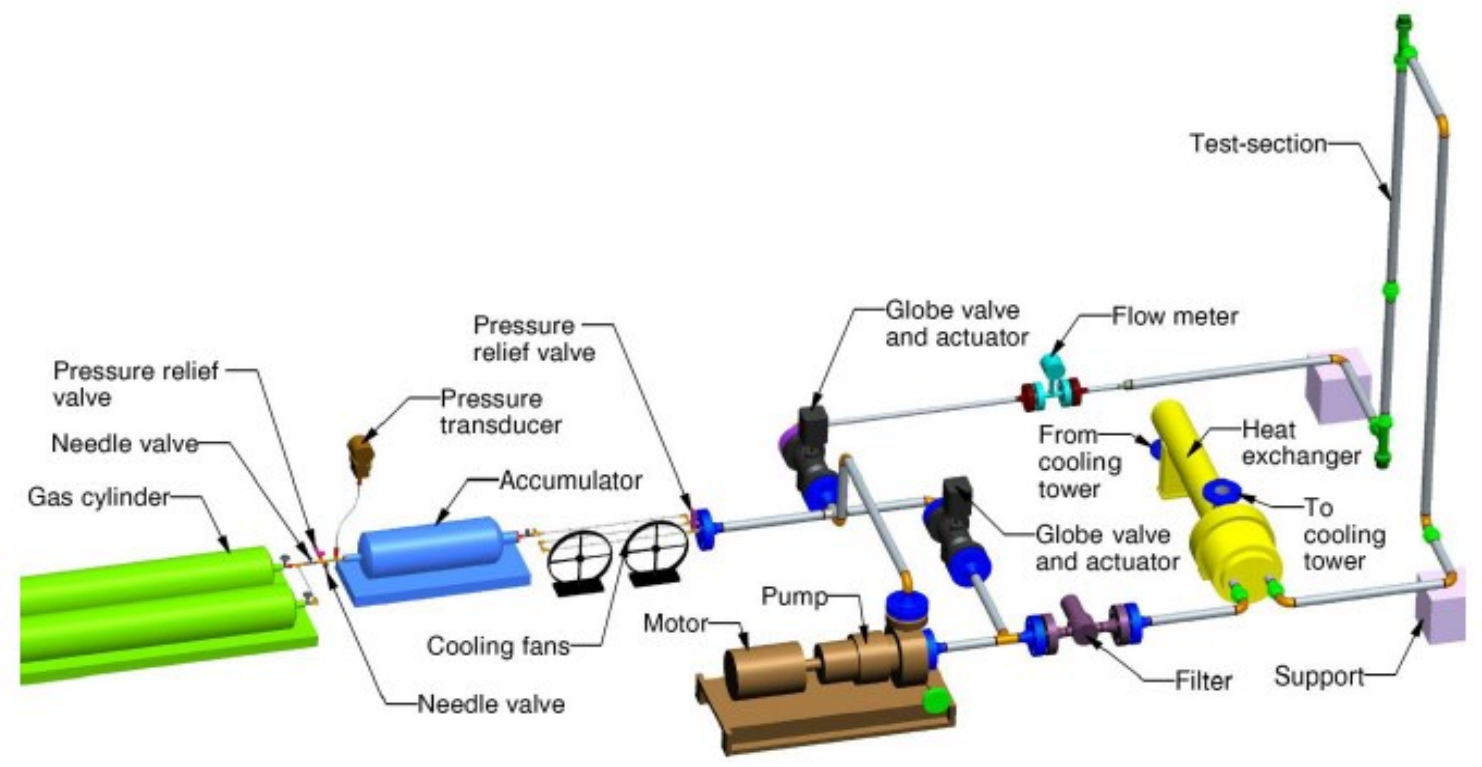

(a)

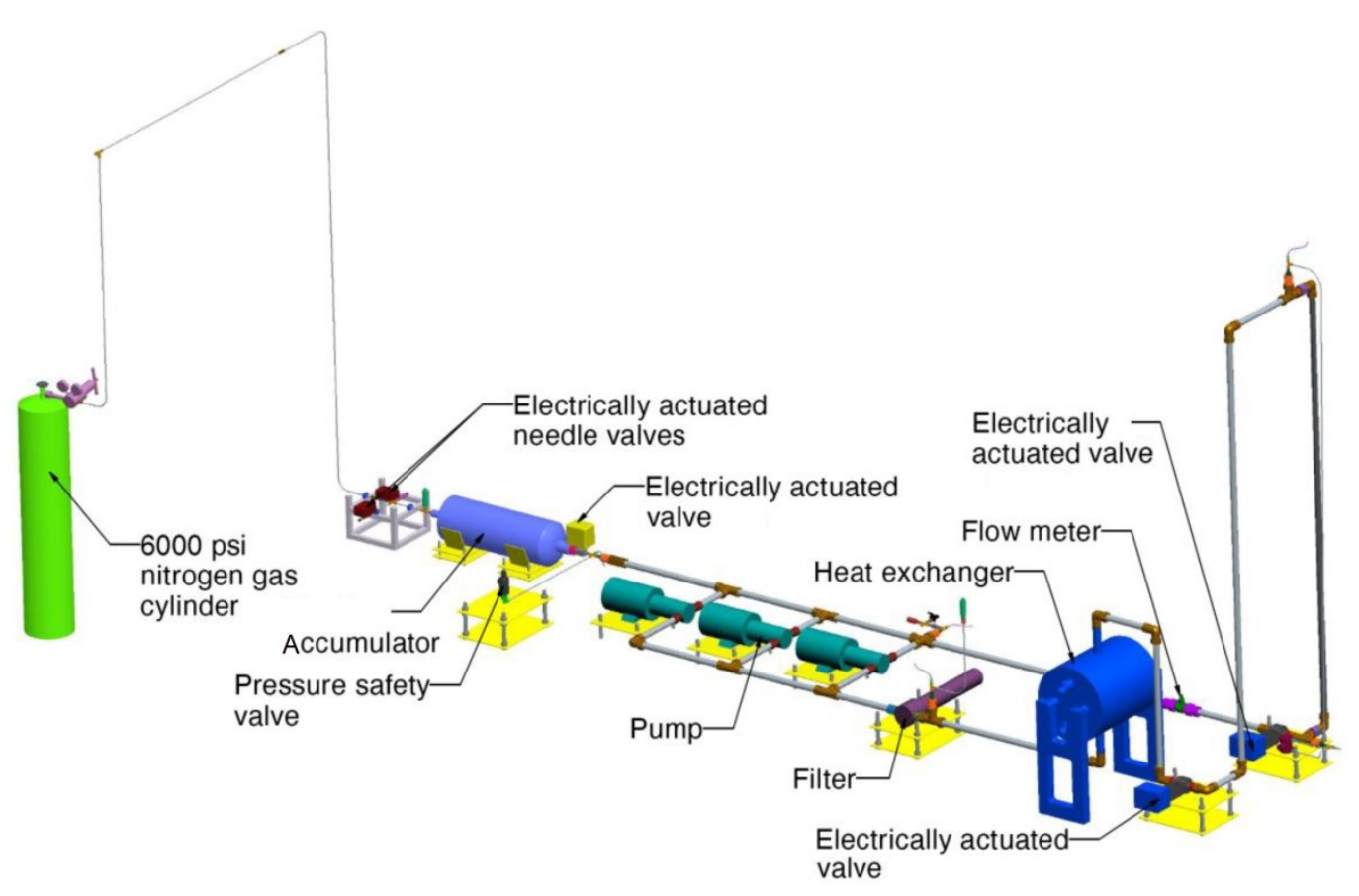

(b)

Figure 2: Schematics of the (a) C-SCW Loop and (b) C-R134a Loop [2] 
The C-SCW Loop is a high temperature and pressure heat-transfer experiment setup utilizing water as the working fluid. The operating pressure of this setup varies from $23 \mathrm{MPa}$ to $27 \mathrm{MPa}$ with a maximum test section outlet temperature of $600^{\circ} \mathrm{C}$. The C-R134a Loop operates at substantially lower pressure and temperature levels. The operating pressure of this loop varies from $4.4 \mathrm{MPa}$ to $6 \mathrm{MPa}$ and the maximum test section outlet temperature is $140^{\circ} \mathrm{C}$ [2]. An AC-to-DC transformer with a maximum power output of $300 \mathrm{~kW}-\mathrm{DC}(2000 \mathrm{~A}$ at $150 \mathrm{~V})$ is installed in the lab to provide the electric power to the two loops for resistive heating in the test section of each loop that is intended to simulate a nuclear fuel-bundle core in an idealized setting.

There are three different types of test sections for the two loops: a 7-rod bundle test section, an annular test section and a tubular test section. The test sections are interchangeable between the two loops. Figure 3 shows the cross sections of the test sections and Figure 4 shows the flow path within the test sections.

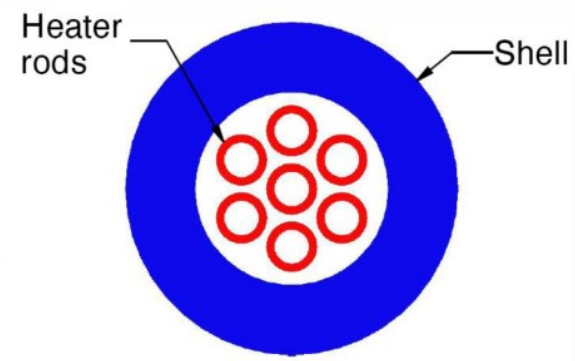

Bundle Assembly

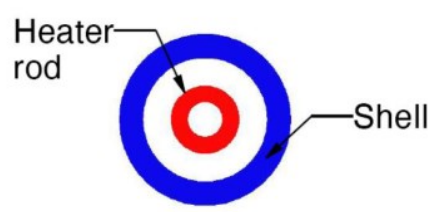

Annular

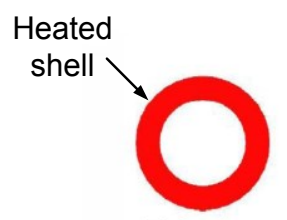

Tubular

Figure 3: Cross sections of the three types of test sections [2] 


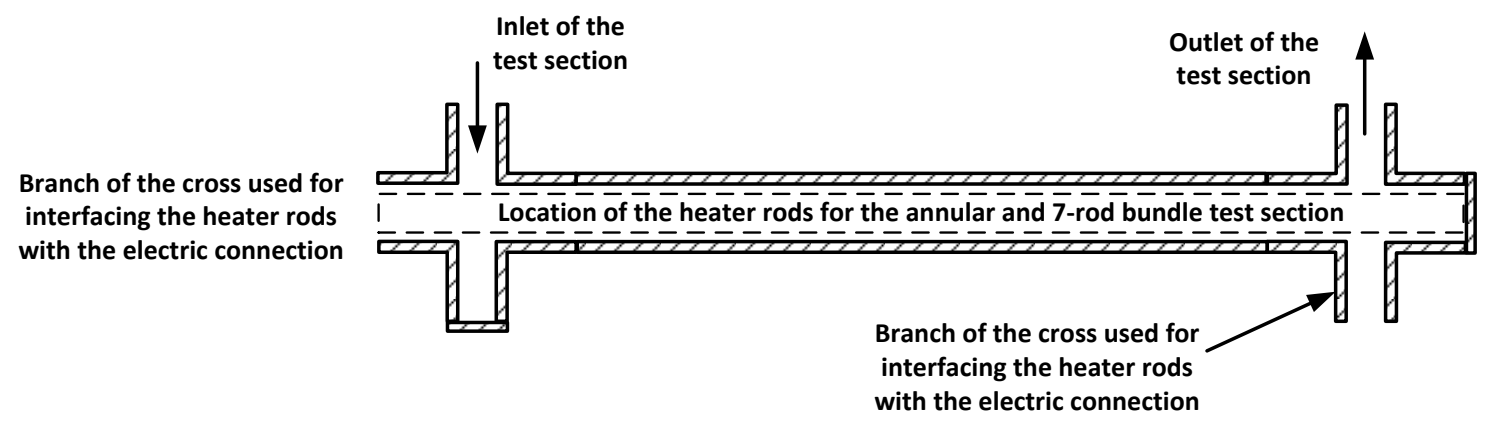

\section{Figure 4: Flow path in the test sections}

As these loops operate at high temperature and pressure, caution is needed to prevent unsafe conditions in case the loop undergoes a structural failure. As shown in Figure 1, the control station is set up at the entrance of the lab to avoid the operator being exposed to the direct line of sight with either loop. In addition, several ballistic-grade panels are put in place to enhance the protection measures. More details on this heat transfer research facility can be found in a conference paper published by the author's research group [3]. 


\section{Flow Control Devices on the C-SCW Loop}

\subsection{Overview}

There are three devices on the C-SCW Loop that affect the flow rate: a centrifugal pump and two control valves. The pump is used to provide the necessary pressure rise to keep the water flowing at the desired flow rate and the two control valves are used to regulate the water flow rate through the test section. Figure 5 is a schematic for the CSCW Loop with these two sets of equipment highlighted.

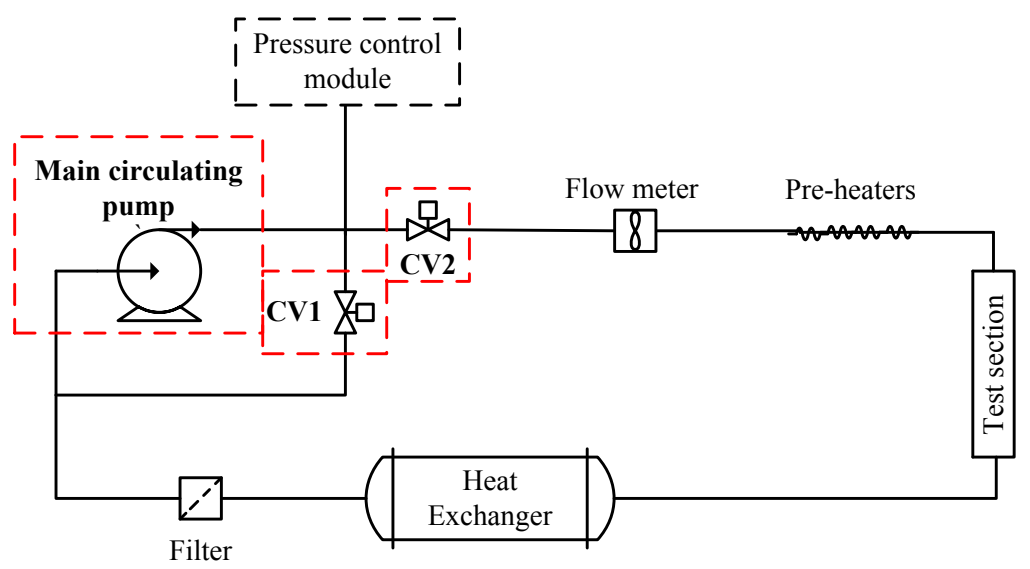

Figure 5: Locations of the pump and the control valves (CV 1 and CV 2) on the CSCW Loop

\subsection{Sizing of the Pump on the C-SCW Loop}

In the preliminary stages of the design of the C-SCW loop, the pump type and approximate size was determined by the author to help establish the component layout on the C-SCW loop. The pump must be able to withstand the maximum system pressure, 27 $\mathrm{MPa}$ and temperature of $260^{\circ} \mathrm{C}$ that is expected at the discharge of the heat exchanger. To properly size the pump for the C-SCW Loop, it is necessary to establish the total pressure 
losses for the intended range of flow rates. Two parameters, specific speed and specific size are used to determine the type and the size of the pump.

\subsubsection{Pump Pressure Rise}

The total pressure rise across the pump should match the total pressure loss along the full length of the loop. The following subsections present the total pressure loss estimates for the various components of the loop.

\subsubsection{Calculation of Pressure Loss in Ducted Flows}

The total pressure loss for a ducted flow can be determined using [4]:

$$
\Delta P_{o}=\sum_{j}\left(\left(f_{j} \frac{L_{j}}{D_{h, j}}+k_{j}\right) \frac{1}{2} \rho_{j} v_{j}^{2}\right)+\sum \Delta P_{o, \text { components }}
$$

where $\Delta P_{o}$ is the total pressure loss $(\mathrm{Pa}) ; f$ is the pipe friction factor; $L$ is the pipe length (m); $D_{h}$ is the hydraulic diameter (four times the flow area divided by the wetted perimeter) (m); $\rho$ is the bulk fluid density $\left(\mathrm{kg} / \mathrm{m}^{3}\right) ; v$ is the area-averaged velocity of the flow $(\mathrm{m} / \mathrm{s}) ; k$ is the pressure-loss coefficient accounting for the pressure losses in pipe fittings; $\Delta P_{o, \text { components }}$ is the total pressure losses across the components (in this case the filter) on the loop for which the pressure-loss coefficient does not provide suitable representation $(\mathrm{Pa})$; and subscript $j$ is an index used to identify segments of pipes and pipe fittings.

To simplify the proceeding analysis, Eqn. (1) is manipulated and turned into an expression based on the mass flow rate through the pipe system:

$$
\Delta P_{o}=\sum_{j}\left[\left(f_{j} \frac{L_{j}}{D_{h, j}}+k_{j}\right) \frac{1}{2} \frac{1}{\rho_{j}}\left(\frac{\dot{m}}{A_{j}}\right)^{2}\right]+\sum \Delta P_{o, \text { component }}
$$


where $\dot{m}$ is the mass flow rate $(\mathrm{kg} / \mathrm{s})$ and $A_{j}$ is cross-sectional flow area of pipe fitting $j$ $\left(\mathrm{m}^{2}\right)$

The friction factor is related to the Reynolds number, $R e$, and the surface roughness of the internal pipe surface, $\varepsilon$, normalized by the hydraulic diameter of the pipe [4]:

$$
f=f n\left(\operatorname{Re}, \frac{\varepsilon}{D_{h}}\right)
$$

The surface roughness for the stainless steel pipes used on the present test loops is set to $0.002 \mathrm{~mm}$ [4]. The following sections provide information on the various parameters appearing in Eqn. (2).

\subsubsection{Geometry of the C-SCW Loop}

In support of the pressure-loss calculations, this section lists the relevant geometric information on the C-SCW Loop. For presentation purposes, the test loop is divided into subsections as shown in Figure 6 and detailed geometric information on each of the subsections is listed in Table 1 .

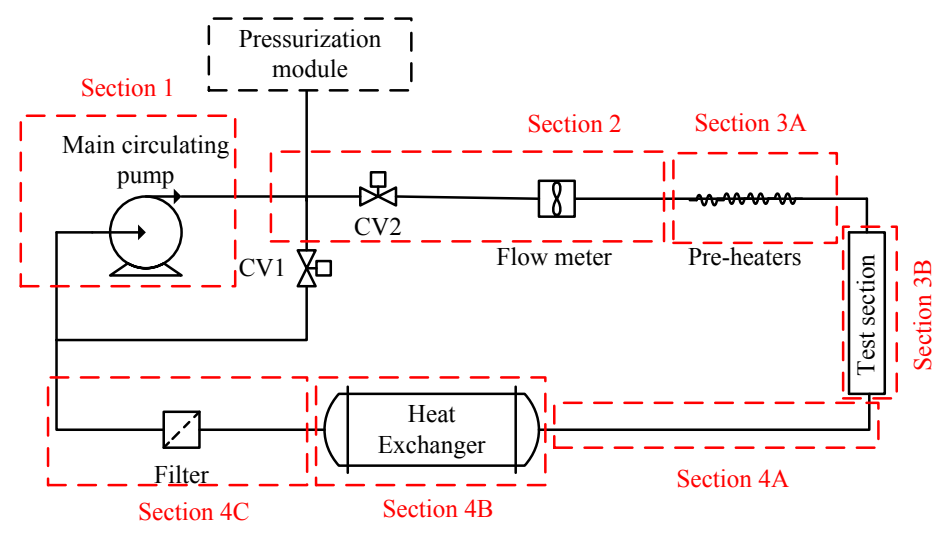

Figure 6: Subsections of the C-SCW Loop 
Table 1: Geometric information relevant to the pressure loss calculations on the CSCW Loop [2]

(a) Geometry of the piping on the C-SCW Loop

\begin{tabular}{|c|c|c|c|c|}
\hline \multirow[b]{2}{*}{ Subsection } & \multicolumn{2}{|c|}{ Pipes } & \multicolumn{2}{|c|}{ Pipe fittings } \\
\hline & $\begin{array}{l}\text { Diameter } \\
\text { (m) }\end{array}$ & $\begin{array}{l}\text { Length } \\
\text { (m) }\end{array}$ & Fitting type & $\begin{array}{l}\text { Number of } \\
\text { components }\end{array}$ \\
\hline \multirow{2}{*}{ Section 1} & \multirow{7}{*}{0.0279} & \multirow{2}{*}{2.44} & $90^{\circ}$ Elbow & 3 \\
\hline & & & Cross & 1 \\
\hline \multirow{2}{*}{ Section 2} & & \multirow{2}{*}{1.40} & $90^{\circ}$ Elbow & 1 \\
\hline & & & Cross & 1 \\
\hline Section $4 A$ & & 1.26 & $90^{\circ}$ Elbow & 2 \\
\hline \multirow{2}{*}{ Section $4 C$} & & \multirow{2}{*}{1.00} & $90^{\circ}$ Elbow & 1 \\
\hline & & & Tee & 1 \\
\hline
\end{tabular}

(b) Geometry of Sections 3A and 3B

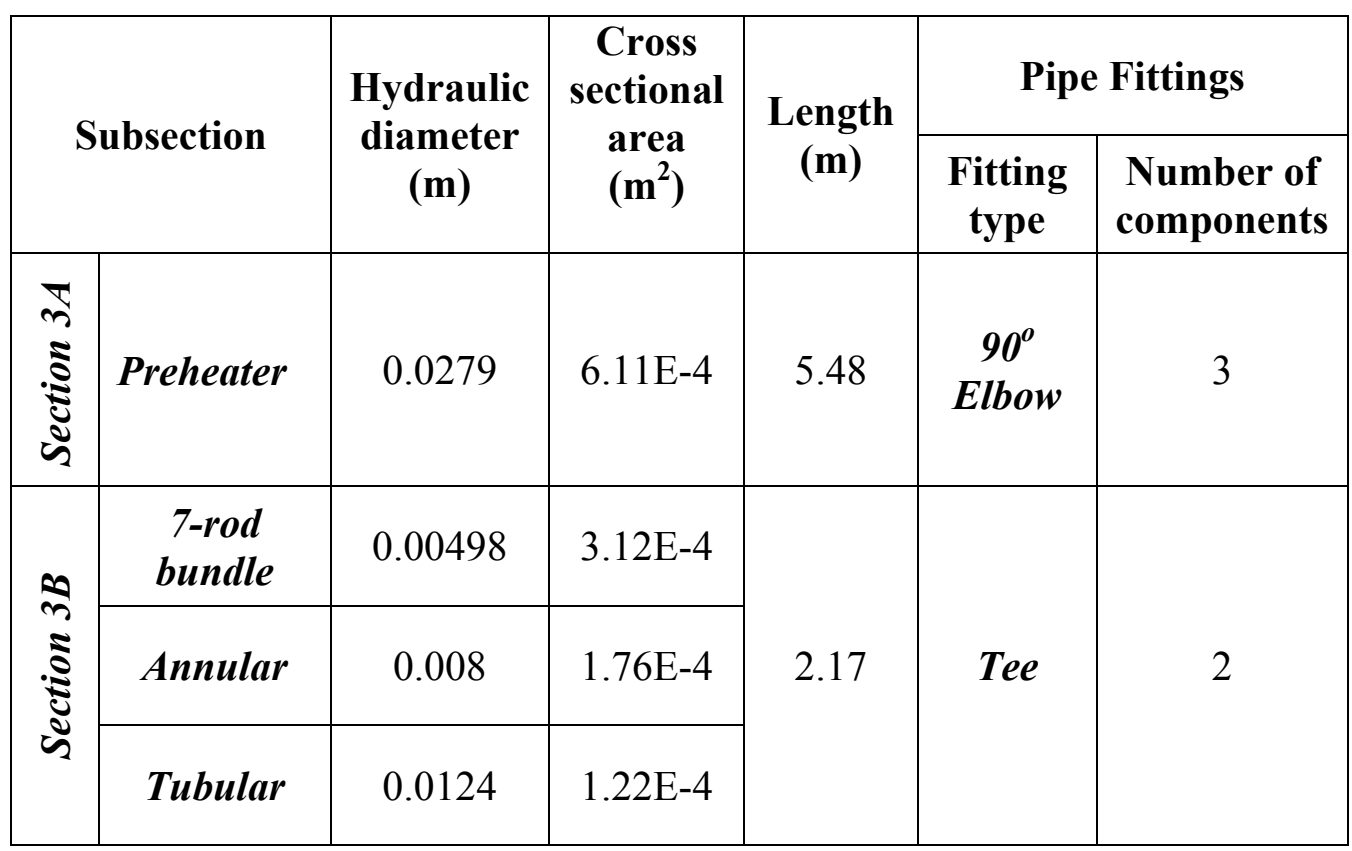




\subsubsection{Operating Conditions of the C-SCW Loop}

The operating conditions of the test loop affect the thermodynamic state of the working fluid and thus the pressure losses in the loop as per Eqn. (2). The planned operating conditions of the loop are summarized in Table 2.

Table 2: Experimental conditions of system pressure, test section outlet temperature and mass flow rates $(\mathrm{kg} / \mathrm{s})[2]$

\begin{tabular}{|c|c|c|c|}
\hline & $\boldsymbol{P}_{\text {loop }}=\mathbf{2 3} \mathbf{~ M P a}$ & $\mathbf{2 5} \mathbf{~ M P a}$ & $\mathbf{2 7} \mathbf{M P a}$ \\
\hline $\boldsymbol{T}_{\boldsymbol{m a x}}=\mathbf{3 8 0}^{\mathbf{C}} \mathbf{C}$ & $\dot{m}=0.219 \mathrm{~kg} / \mathrm{s}$ & 0.336 & 0.362 \\
\hline $\mathbf{4 0 0}^{\mathbf{C}} \mathrm{C}$ & 0.173 & 0.186 & 0.208 \\
\hline $\mathbf{5 0 0}^{\mathbf{C}} \mathbf{C}$ & 0.131 & 0.133 & 0.135 \\
\hline $\mathbf{6 0 0}^{\circ} \mathbf{C}$ & 0.113 & 0.114 & 0.115 \\
\hline
\end{tabular}

\subsubsection{Pressure Loss Analysis}

The pressure-loss coefficients for the various pipe fittings identified in Table 1 are listed in Table 3 and were obtained from a handbook and the manufacturer of the heat exchanger [5].

Table 3: Pressure-loss coefficients for the pipe fittings

\begin{tabular}{|l|c|}
\hline Type of pipe fittings & $\begin{array}{c}\text { Pressure-loss } \\
\text { coefficient }\end{array}$ \\
\hline $\mathbf{9 0}^{\mathbf{0}}$ Elbow & 0.4 \\
\hline Cross (line) & 0.095 \\
\hline Tee (line) & 0.095 \\
\hline Tee (branch) & 1.53 \\
\hline Heat exchanger (Section 4B) & 410 \\
\hline
\end{tabular}


The pressure-loss coefficients listed in Table 3 are applicable to ducted flows with Reynolds number larger than $10^{4}$ [5]. Since, given the flow conditions listed in Table 2, the minimum Reynolds number for the flow in the C-SCW loop is $1.79 \times 10^{4}$, the pressure-loss coefficients listed in Table 3 are applicable to the flow in the C-SCW Loop [5].

The pipe friction factor, $f$, values are listed in Table 4 and were estimated from Haaland's formula, which is valid for the Reynolds number range from 4000 to $10^{8}$ [4]:

$$
f=\left\{-1.8 \log \left[\frac{6.9}{\operatorname{Re}}+\left(\frac{\varepsilon / D_{h}}{3.7}\right)^{1.11}\right]\right\}^{-2}
$$

Table 4: Friction factor range for the pipe segments in each subsection

\begin{tabular}{|l|c|c|c|}
\hline Subsection & $\begin{array}{c}\text { Hydraulic } \\
\text { diameter } \\
(\mathbf{m})\end{array}$ & $\begin{array}{c}\text { Reynolds number } \\
\text { range }\end{array}$ & Friction factor range \\
\hline Section 1 & & $4.8 \times 10^{4}-1.5 \times 10^{5}$ & $0.0167-0.0210$ \\
\cline { 1 - 1 } Section 2 & \multirow{2}{*}{0.0279} & $7.6 \times 10^{4}-2.4 \times 10^{5}$ & $0.0159-0.0192$ \\
\cline { 1 - 1 } Section 4C & & $1.5 \times 10^{5}-3.3 \times 10^{5}$ & $0.0148-0.0168$ \\
\hline Section 3A & & $5.6 \times 10^{4}-6.2 \times 10^{5}$ & $0.0146-0.0214$ \\
\hline Section 4A & & & \\
\hline Section 3B & $0.008-0.0124$ & &
\end{tabular}

Fluid properties required for these calculations were obtained from NIST fluid thermodynamic property tables [6]. In instances where the thermalphysical property variations are significant along the length of a subsection, the averaged properties of the fluid at the inlet and the outlet of the section are used. This was implemented for the preheaters, the test section and the heat exchanger (Sections 3A, 3B and 4B in Figure 6). 
The resultant pressure losses are shown in Figure 7. The total pressure loss in the filter shown in this figure was provided by the manufacturer.

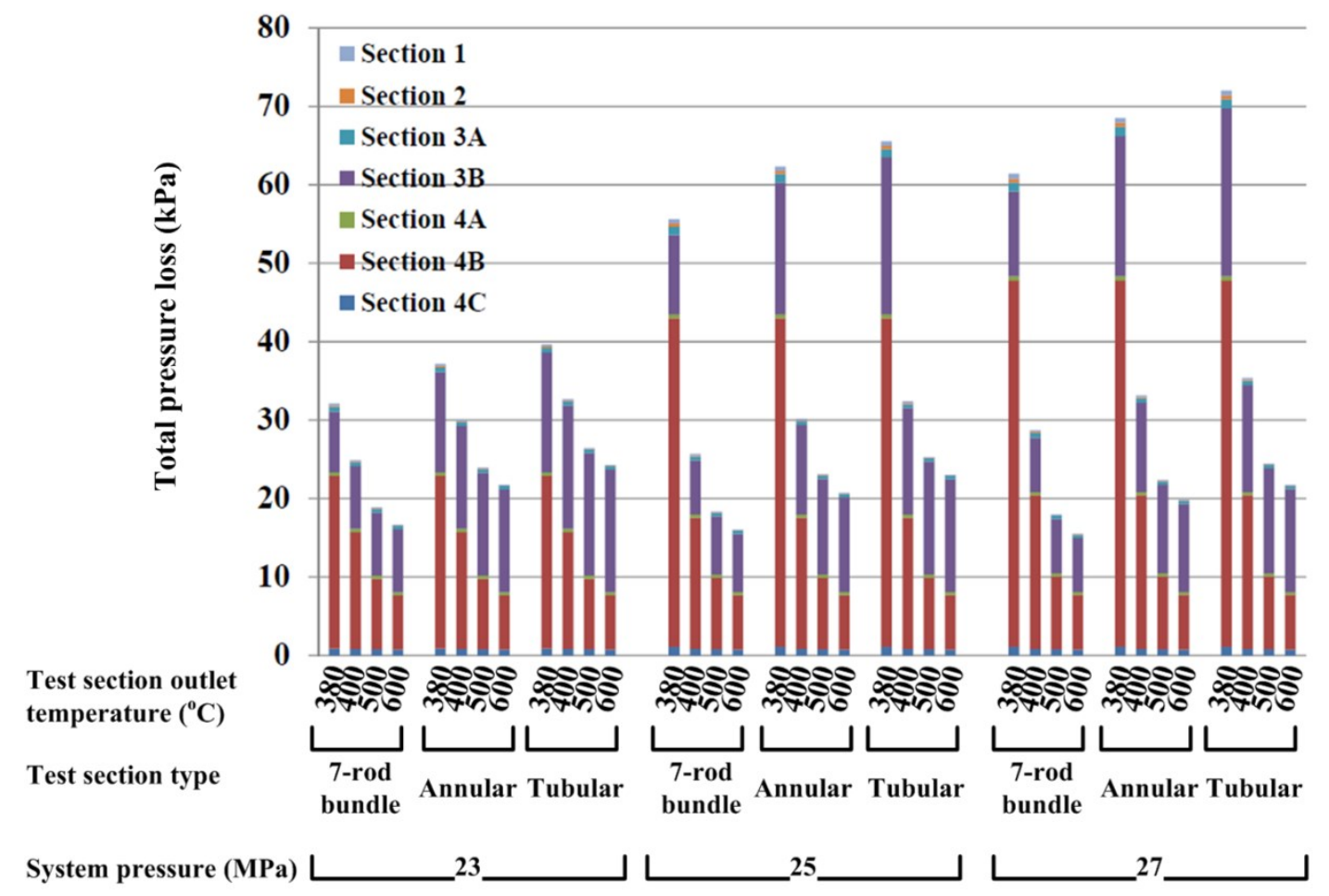

Figure 7: Total pressure losses within the subsections of the C-SCW Loop for the expected operating pressures and test section outlet temperatures

The corresponding $\mathrm{C}-\mathrm{SCW}$ Loop operating conditions and the installed test section types are indicated along the horizontal axis in Figure 7. As shown in this figure, majority of the total pressure loss is incurred by Section 3B (the test section) and Section 4B (the heat exchanger). The total pressure losses in the heat exchanger tend to be much higher than that in the test section at low test section outlet temperature. As the test section outlet temperature increases the total pressure losses in these two sections tend to equalize. 
Thus, most of the pump power is contributed to offset the total pressure losses in these two subsections. Detailed data for total pressure losses within the subsections of the C-SCW Loop are presented in Appendix 1.

The mechanical power required to overcome these total pressure losses can then be calculated using:

$$
\dot{W}_{\text {fluid }}=\Delta P_{o} Q
$$

where $\dot{W}_{\text {fluid }}$ is the required mechanical power and $Q$ is the volume flow rate at the pump inlet. The power requirements corresponding to the conditions of Figure 7 are illustrated in Figure 8. It is noted here that the calculated mechanical power, $\dot{W}_{\text {fuid }}$ does not take the pump efficiency into account.

The corresponding C-SCW Loop operating conditions are indicated at the bottom in Figure 8. The maximum power requirement occurs at $27 \mathrm{MPa}$ with test section outlet temperature being $380^{\circ} \mathrm{C}$ for the tubular test section at the maximum flow rate. Therefore, this operating point is used to size the pump for the C-SCW Loop. Table 5 summarizes the condition under which this pressure loss is obtained. 


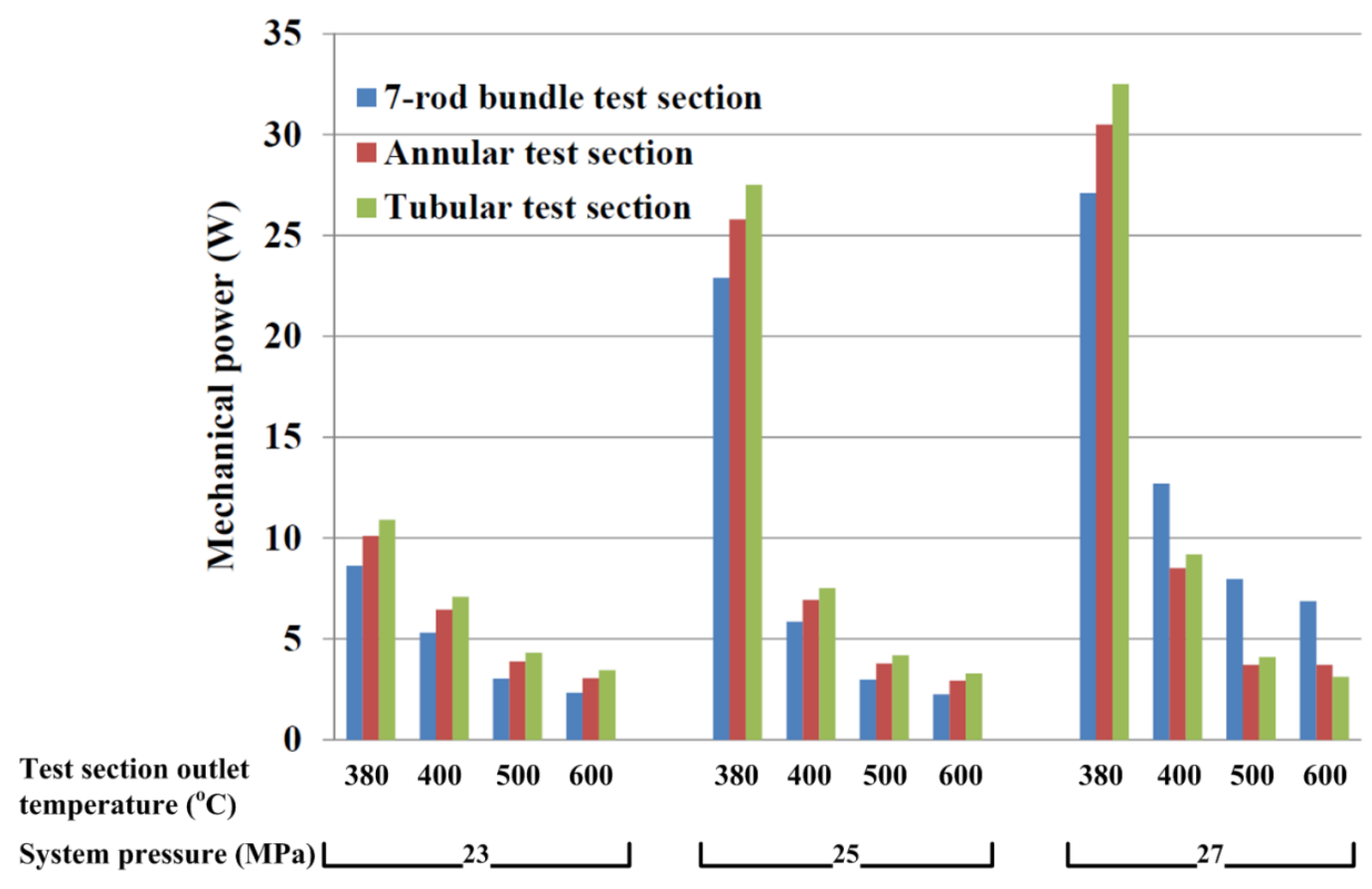

Figure 8: Required pump mechanical power in the C-SCW Loop for the operating conditions identified in Table 2

Table 5: Selected C-SCW Loop operating point for the sizing of the pump

\begin{tabular}{|l|c|}
\hline Type of test section & Tubular \\
\hline System pressure (MPa) & 27 \\
\hline Test section outlet temperature $\left.\mathbf{~}^{\mathbf{0}} \mathbf{C}\right)$ & 380 \\
\hline Mass flow rate $(\mathbf{k g} / \mathbf{s})$ & 0.365 \\
\hline $\begin{array}{l}\left.\text { Volume flow rate } \mathbf{( m}^{\mathbf{3}} / \mathbf{s}\right) \\
\text { (based on a water pressure of } \mathbf{2 7} \mathbf{~ M P a ~ a n d ~} \\
\left.\text { temperature of } \mathbf{2 6 0}^{\mathbf{0}} \mathbf{C}\right)\end{array}$ & $4.51 \times 10^{-4}$ \\
\hline Required pressure rise for the pump (kPa) & 72.1 \\
\hline Required fluid power input $\mathbf{( W )}$ & 32.5 \\
\hline
\end{tabular}




\subsubsection{Pump Type Selection and Sizing}

Specific speed and specific size are the two nondimensional parameters for determining the pump type and size respectively that are most suitable for a particular load as quantified by the required values of pressure rise and flow rate at a given rotational speed for the pump [7]. The selection procedure starts off by calculating the specific speed based on the required pressure rise at the corresponding flow rate to establish the pump type that will perform most efficiently at the stated load. Then, the specific size parameter is used to determine the size of the pump impeller.

The specific speed, $\Omega_{s}$, is defined as [7]:

$$
\Omega_{s}=\frac{\omega \sqrt{Q}}{(g \Delta H)^{0.75}}
$$

where $\omega$ is the rotational speed of the pump $(\mathrm{rad} / \mathrm{s}) ; Q$ is the volume flow rate of the working fluid $\left(\mathrm{m}^{3} / \mathrm{s}\right) ; g$ is the gravitational acceleration $\left(\mathrm{m} / \mathrm{s}^{2}\right)$ and $\Delta H$ is the pressure rise of the pump expressed in height of the working fluid column (m).

Based on a broad range of pumps that have been designed and tested to date, Figure 9 shows the expected pump performance level, and identifies the best pump type for given values of specific speed [7]. As observed in Figure 9 (a), for very low values of specific speed, $\Omega_{s}$, positive-displacement pumps (piston and gear designs) are most suitable. For $\Omega_{s}$ values in the range of 0.1 to 1.0 , centrifugal pumps should be selected. For higher values of $\Omega_{s}$, mixed flow and axial pumps are to be preferred. These choices are based on achieving the highest pumping efficiency for a given load. The hydrodynamic efficiencies that can be expected for each pump type are shown in Figure 9 
(b). In addition to the non-dimensional specific speed, $\Omega_{s}$, Figure 9 also provides a dimensional version, $N_{s}$, that is frequently used in industry.

Choosing a typical electric motor speed of $1800 \mathrm{rpm}$ to drive the pump for the CSCW Loop, with the pressure rise and flow rate requirements identified in Table 5, the specific speed parameter is calculated as $\Omega_{s}=0.13$. This specific speed value corresponds to the range for which a centrifugal pump is most efficient. The value of this hydrodynamic efficiency is estimated from Figure 9 (b) as 35\%. The corresponding shaft power for the pump can be determined through the expression:

$$
\dot{W}=\frac{\Delta P_{o} Q}{\eta}
$$

as $92 \mathrm{~W}$. This value does not include losses in the pump due to mechanical friction and disc losses. As such, the electric motor to drive the pump is conservatively selected to provide $113 \mathrm{~W}$ of shaft power (choosing a typical pump mechanical efficiency of $90 \%$ and an overall electric motor efficiency of $90 \%$ ). 


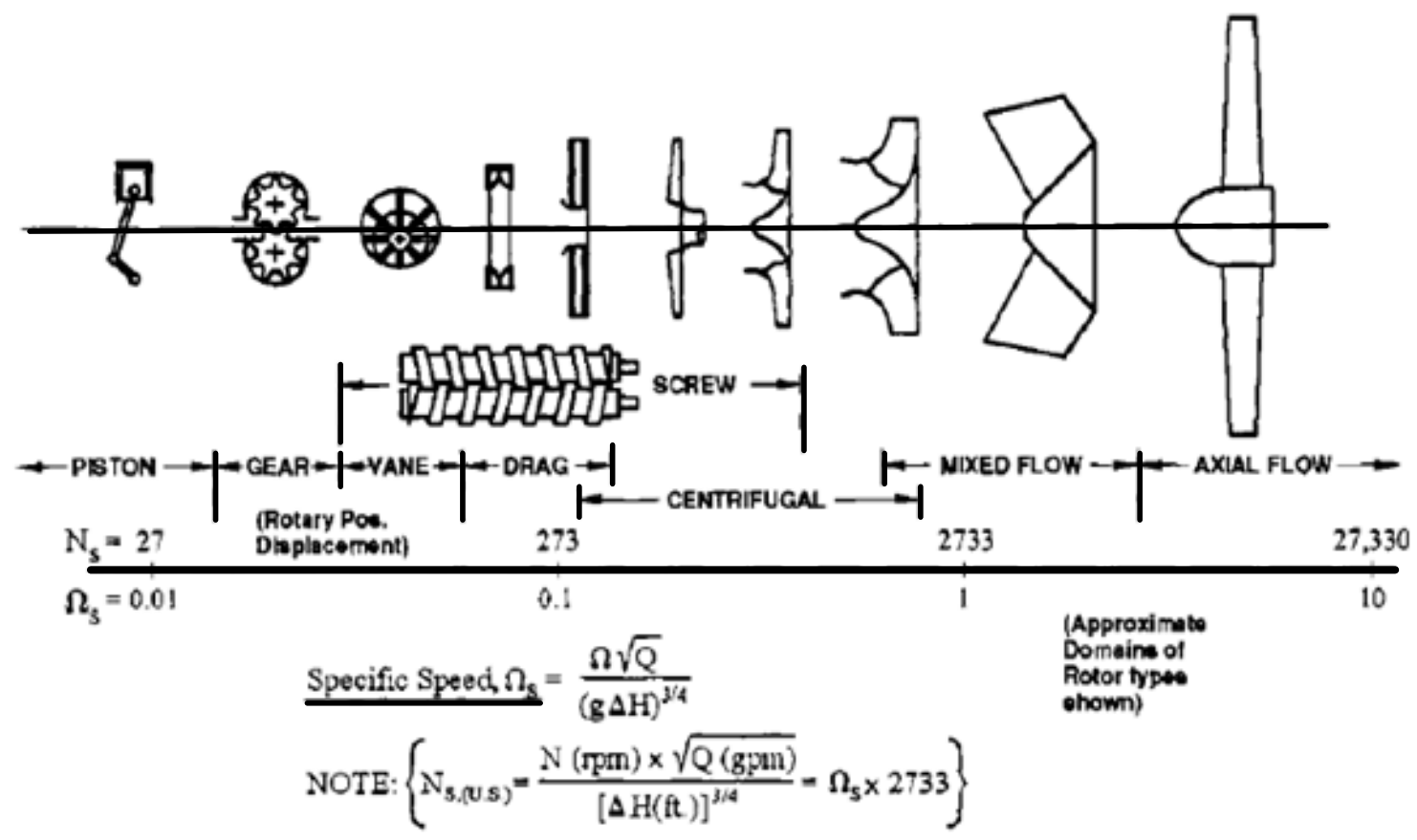

(a)

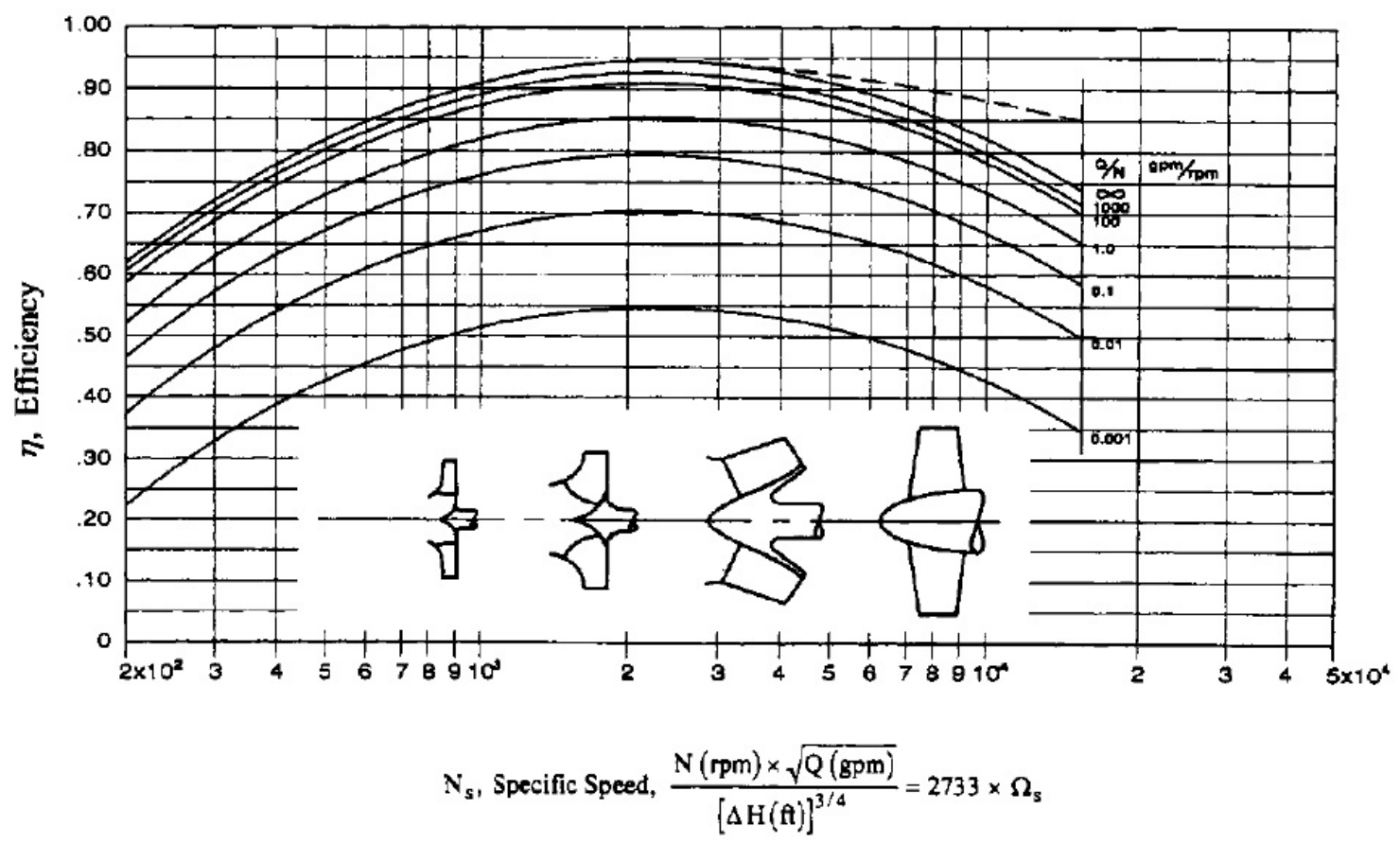

(b)

Figure 9: Specific speed charts for selection of the pump type [7] 
With the pump type having been established, its impeller size can be estimated through the nondimensional specific size parameter, $\Delta$, defined as [8]:

$$
\Delta=\frac{D(g \Delta H)^{0.25}}{\sqrt{Q}}
$$

where $\Delta$ is the specific size parameter; $D$ is the diameter of the impeller (m); $\Delta H$ is the head rise across the pump expressed as height of the working fluid column (m); $g$ is the gravitational acceleration $\left(\mathrm{m} / \mathrm{s}^{2}\right)$ and $Q$ is the volume flow rate $\left(\mathrm{m}^{3} / \mathrm{s}\right)$.

The specific size parameter is correlated to the specific speed parameter through the Cordier diagram shown in Figure $10[8]$. A specific speed value of $\Omega_{s}=0.13$ corresponds to a specific size value of 20, which yields an impeller diameter of $0.138 \mathrm{~m}$. The design of a pump for the pressure rise, flow rate and fluid properties of the C-SCW Loop was performed by Klaus Union Gmbh \& Co. The manufacturer indeed chose a centrifugal design that is driven by a $1.11 \mathrm{~kW}(1.5 \mathrm{hp})$ squirrel-cage induction motor via a magnetic drive. The pump data as supplied by the manufacturer is listed in Table 6 . The impeller diameter chosen by the manufacturer is close to the diameter that was estimated through the specific size parameter. 


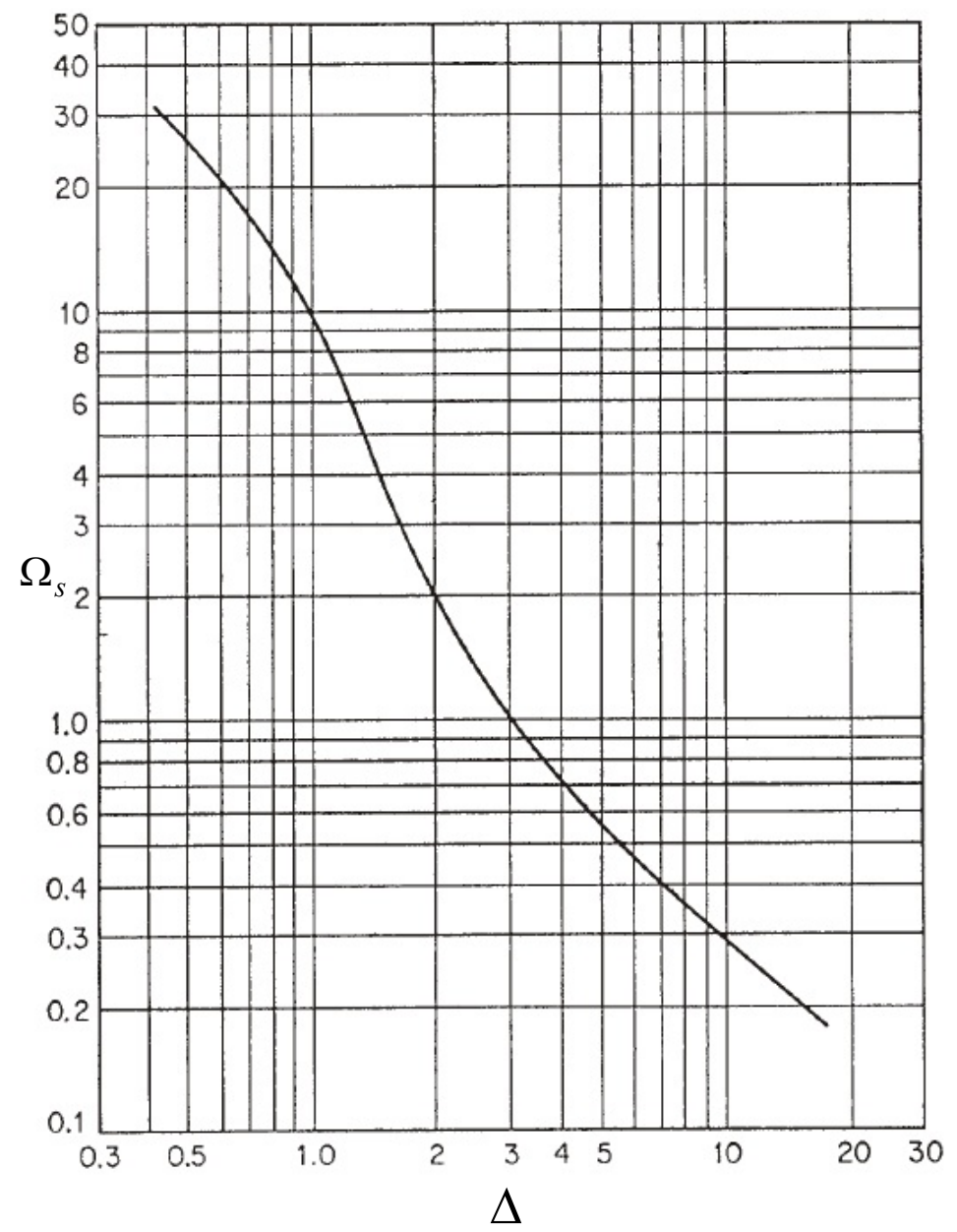

Figure 10: Cordier diagram [8]

Table 6: Specifications for the C-SCW Loop Pump

\begin{tabular}{|l|c|}
\hline \multicolumn{1}{|c|}{ Parameters } & From manufacturer \\
\hline Maximum system pressure $(\mathrm{MPa})$ & 28 \\
\hline Maximum system temperature $\left({ }^{\circ} \mathrm{C}\right)$ & 260 \\
\hline Range for the water volume flow rate $\left(\mathrm{m}^{3} / \mathrm{s}\right)$ & $5.0 \times 10^{-4}-2.0 \times 10^{-3}$ \\
\hline Maximum pressure rise $(\mathrm{kPa})$ & 101 \\
\hline Pump speed range $(\mathrm{rpm})$ & $1200-1800$ \\
\hline Impeller diameter $(\mathrm{m})$ & 0.16 \\
\hline $\begin{array}{l}\text { Overall efficiency at the design point }(\mathrm{at} \mathrm{1} \mathrm{bar} \\
\left.\text { pressure rise and a flow rate of } 5 \times 10^{-4} \mathrm{~m}^{3} / \mathrm{s}\right)\end{array}$ & $7.7 \%$ \\
\hline Inlet and outlet connections & $\begin{array}{l}\text { ANSI Class } 2500 \mathrm{NPS} \\
1-1 / 2 \text { " raised face flange }\end{array}$ \\
\hline
\end{tabular}


The manufacturer designed the pump for a volume flow rate range that is notably higher than the required volume flow rate range on the C-SCW Loop. This resulted in the pump requiring significantly larger shaft power input $(1110 \mathrm{~W})$ than the aforementioned value of $113 \mathrm{~W}$ that was determined on the basis of the anticipated flow rate range in the test loop. A bypass line was therefore incorporated in the design of the C-SCW Loop that redirects part of the pump discharge flow to the pump inlet across a globe valve. Furthermore, another globe valve was included on the pipe feeding the pump discharge flow to the rest of the test loop to allow for additional control on the pressure load. These globe valves are identified in Figure 2 (a). Engineering calculation on these valves is provided in the next section.

It is noteworthy that even when the mechanical losses and the electric motor efficiency are included, the predicted overall efficiency of the pump is still substantially higher than the overall efficiency claimed by the manufacturer. The discrepancy is mainly caused by the fact that the prediction of the mechanical losses discussed earlier in this section is based on a centrifugal pump design which does not use magnetic drive to connect the pump motor and its impeller. When the magnetic drive is used, the rotating magnets connected to the shaft of the motor create a varying magnetic field around the metallic pressure shell, which houses the pump impeller. Based on the law of induction, this varying magnetic field induces eddy currents within the pressure shell provoking mechanical power loss through resistive heating. According to Karassik et al. (2008), the mechanical power loss incurred by eddy currents within a magnetic-drive pump can become as high as $20 \%$ of the overall mechanical power input depending on the design of the pump [7]. 


\subsection{C-SCW Loop Flow Control Valves}

As discussed in Section 3.2.2, two control valves are to be installed on the C-SCW loop to enable operation of the loop over the intended range of flow rates.

\subsubsection{Valve Selection and Sizing}

\subsubsection{Types of Control Valves}

There are two groups of valves that are most commonly used for flow control purposes: linear motion valves and rotary valves [9]. Globe valves and piston valves are the most common examples for the linear-motion valves [9]. They realize their flow control by the reciprocating linear motion of the valve closure member. Ball, butterfly and plug valves are common examples of rotary valves [9]. Unlike linear-motion valves, flow control in rotary valves is realized by adjusting the level of flow restriction in the valve flow path through the rotating motion of an obstruction (ball, butterfly-plate or plug).

According to Zappe et al. (2004), linear-motion valves are recommended for flow control services, as the opening of this type valve is directly proportional to the travel of the valve closure member [10]. The rotary type valves, although also offering good flow throttling capability, only provide good flow controllability over a limited range of valve opening [10]. Thus, linear-motion valves are preferred for the C-SCW Loop.

\subsubsection{Valve Selection}

Hydrodynamic features of a control valve are characterized by the flow coefficient, $C_{v}$, which is a function of the valve opening only [10]: 


$$
C_{v}=41340\left(Q \sqrt{\frac{S . G .}{\Delta P_{o}}}\right)
$$

where $Q$ is the volume flow rate in $\left(\mathrm{m}^{3} / \mathrm{s}\right)$; S.G. is the specific gravity and $\Delta P_{o}$ is the pressure loss across the valve $(\mathrm{kPa})$.

The function of the first valve on the C-SCW Loop, CV 1, is to vary the total pressure losses in the bypass line in accordance with the pressure losses occurring within the main branch of the C-SCW Loop (i.e. the branch containing the test section). Using the total pressure losses shown in Figure 7 and the flow rates in the bypass line (i.e. the difference between the minimum flow rate of the pump and the required flow rate within the main branch), the operating flow coefficient range for CV 1 was found to be between 2.1 and 4.3. Detailed data for the operating $C_{v}$ of $\mathrm{CV} 1$ are presented in Appendix 2.

The function of the second valve on the C-SCW Loop, CV 2, is to dissipate the excessive total pressure rise delivered by the pump. The minimum pressure rise of the pump can be estimated through an affinity law [7]:

$$
\frac{\Delta P_{o 1}}{\Delta P_{o 2}}=\left(\frac{\Omega_{2}}{\Omega_{1}}\right)^{2}
$$

Given the maximum total pressure rise of the pump, $\Delta P_{o 1}$, is $101 \mathrm{kPa}$, the maximum speed of the pump, $\Omega_{1}$, is $188 \mathrm{rad} / \mathrm{s}(1800 \mathrm{rpm})$ and the minimum speed of the pump, $\Omega_{2}$, is $125 \mathrm{rad} / \mathrm{s}(1200 \mathrm{rpm})$ as listed in Table 6 , the minimum total pressure rise was estimated to be $44 \mathrm{kPa}$ using Eqn. (10). Using the overall total pressure losses shown in Figure 7 and the flow rates presented in Table 2, the total pressure to be dissipated by CV 2 is found to be varying between $18.1 \mathrm{kPa}$ and $35.4 \mathrm{kPa}$. Thus, using Eqn. (9), the 
operating flow coefficient range for CV 2 is found to be varying between 1.07 and 4.87. Detailed data for the operating $C_{v}$ of CV 2 are presented in Appendix 2.

To maintain good controllability over the flow through the valve, it is recommended by Towler et al. (2009) that the operating range of the valve flow coefficient should be roughly $50 \%$ of the maximum flow coefficient of the valve [11]. Thus, based on the calculated operating flow coefficient range of the two control valves, the maximum flow coefficient of the two valves should be chosen around 6 for both control valves.

Based on this preliminary selection and sizing, two Class 2500 globe valves with a maximum flow coefficient of 6 were selected from the valves manufactured by EnerFest Inc. The Class 2500 valve rating allows the valve to operate under a pressure up to 27.07 $\mathrm{MPa}$ at $260^{\circ} \mathrm{C}$, which is beyond the maximum operating pressure of the $\mathrm{C}-\mathrm{SCW}$ Loop [12]. In addition, both valves are equipped with an electric actuator (Model number: SAREx12-LTU12-4) allowing the valves to be remotely controlled by a computer. 


\section{Design of the Pressure Control Modules on the C-SCW Loop and the C-R134a Loop}

\subsection{Overview}

Figure 11 schematically shows the design of the pressure control module used to control the system pressure for the C-SCW Loop and C-R134a Loop. The major component of the pressure control module is an accumulator which is used to regulate the system pressure and store the excess working fluid from the main loop. Pressurized inert gas is used to pressurize the accumulator. The gas flowing in and out of the accumulator is regulated through two control valves (CV 3 and $\mathrm{CV} 4$ ). Two pressure relief valves are used to prevent the over-pressurization of the loop. Instrumentation of this module includes an absolute pressure transducer, which monitors the pressure of the gas in the accumulator, and a thermocouple, which measures the temperature of the working fluid entering the accumulator from the main loop. As the C-SCW loop is operating at a substantially higher temperature than the rated temperature of the accumulator, a set of cooling tubes is installed to cool down the water discharge flow from the main loop and thus entering the accumulator. 
CV Control valve

PRV Pressure relieve valve

PT Absolute pressure transducer

TC Thermocouple

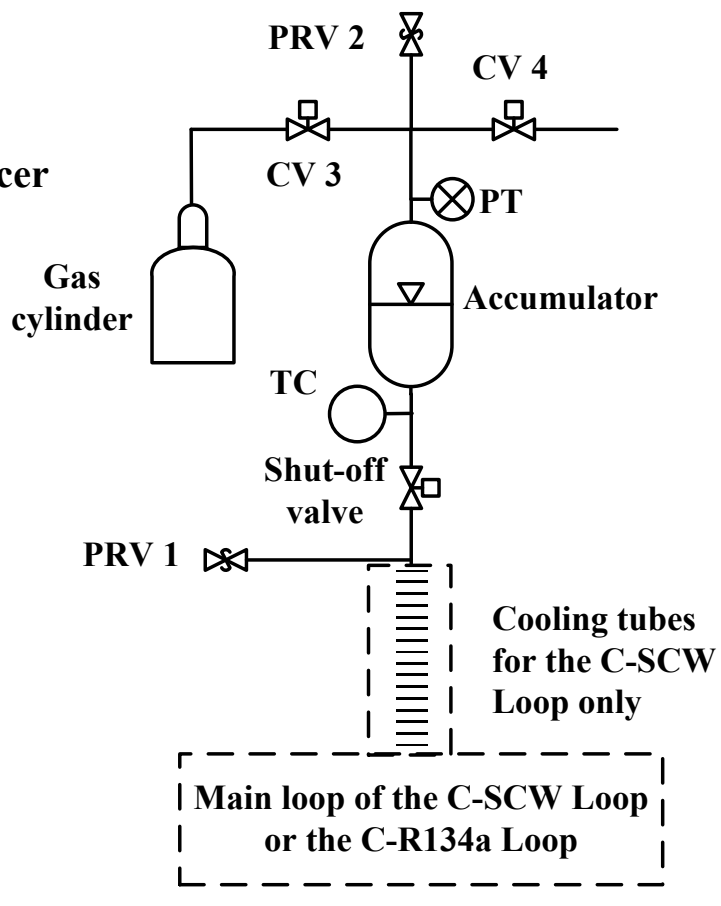

Figure 11: Schematic of the pressure control modules on the C-SCW Loop and CR134a Loop

\subsection{Selection and Sizing of the Accumulator for the C-SCW Loop and the C-R134a Loop}

\subsubsection{Types of the Accumulators}

There are several different types of commercially-available accumulator designs. Basically, the types of the accumulator can be divided into two categories based on the methods of pressurization: gas pressurized accumulators or mechanically pressurized accumulators [13, 14]. Since a gas pressurized accumulator allows the user to conveniently control the system pressure dynamically by adjusting the amount of gas stored in the accumulator during the operation of the test loops, it becomes the preferred 
type of accumulator. Thus, only the gas pressurized accumulators are studied here. They are briefly introduced through the remainder of this section.

There are two types of gas pressurized accumulator: separated type accumulator in which the gas and the working fluid are separated by a diaphragm and non-separated type accumulator in which there is no physical boundary between the gas and the working fluid. Since the non-separated type accumulators may risk mixing of the working fluid with the pressurization gas, the separated type accumulators are preferred [13].

There are three different designs for the separated type accumulators: the bladder type accumulator, the diaphragm type accumulator and the piston type accumulator. The bladder and diaphragm type accumulators are very similar. Both of them separate the gas and working fluid with a flexible membrane. The application of the bladder type accumulator is versatile and the diaphragm type accumulator is a replacement for the bladder type accumulator where the weight of the accumulator needs to be reduced [13, 15]. The major drawback of these two types of accumulators is that the service temperature of the accumulator is limited by the material used for the bladder or diaphragm [13]. On the other hand, the piston type accumulator uses a free moving piston to separate the fluid and gas chamber of the accumulator. The piston type accumulator is often used for extreme service conditions (e.g. corrosive working fluid or extremely high service temperature). The drawback of the piston accumulators is that they are prone to leakage problems due to the deterioration of the piston seal over time.

In conclusion, all three types of separated-fluid accumulators are appropriate for the service on the C-SCW Loop and the C-R134a Loop. The choice on the type of 
accumulator depends on the availability and cost. The bladder type accumulators are chosen for the two loops for their wide availability.

\subsubsection{Accumulator Sizing}

The objective of the accumulator sizing is to find out the necessary total internal volume of the accumulator. To establish the volumetric demand on the accumulator, it is necessary to find out the maximum amount of fluid that is to be discharged from the loop. This can be done by comparing the initial amount of fluid pre-charged in the two loops and the amount of fluid in the two loops when they are running under the experimental conditions. For the two loops, the maximum amount of working fluid discharge happens when the two loops undergo the transients between the initial and final loop conditions shown in Table 7 with the 7-rod bundle test section installed.

Table 7: The initial and final loop conditions for the C-SCW Loop and the C-R134a Loop which causes the maximum discharge of hydraulic fluids

\begin{tabular}{|c|c|c|c|c|c|}
\hline & \multicolumn{2}{|c|}{ Initial conditions } & \multicolumn{3}{|c|}{ Experimental conditions } \\
\hline \multirow{3}{*}{ نُ } & $\begin{array}{l}\text { Pre-charge } \\
\text { pressure (MPa) }\end{array}$ & $>7.6$ & $\begin{array}{l}\text { Pressure } \\
\text { (MPa) }\end{array}$ & \multicolumn{2}{|c|}{23} \\
\hline & \multirow{2}{*}{$\begin{array}{l}\text { Temperature } \\
\left({ }^{C}\right)\end{array}$} & \multirow{2}{*}{25} & \multirow{2}{*}{$\begin{array}{l}\text { Test section } \\
\text { temperature } \\
(\mathrm{C})\end{array}$} & Inlet & Outlet \\
\hline & & & & 260 & 600 \\
\hline \multirow{3}{*}{ 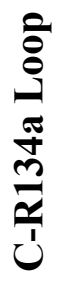 } & $\begin{array}{l}\text { Pre-charge } \\
\text { pressure (MPa) }\end{array}$ & $>1$ & $\begin{array}{l}\text { Pressure } \\
\text { (MPa) }\end{array}$ & \multicolumn{2}{|c|}{1.7} \\
\hline & \multirow{2}{*}{$\begin{array}{l}\text { Temperature } \\
\left({ }^{C} C\right)\end{array}$} & \multirow{2}{*}{25} & \multirow{2}{*}{$\begin{array}{l}\text { Test section } \\
\text { temperature } \\
(\mathrm{C})\end{array}$} & Inlet & Outlet \\
\hline & & & & 60 & 100 \\
\hline
\end{tabular}


The total amount of fluid discharge is found to be about $6 \mathrm{~kg}$ for the C-SCW Loop and about $18 \mathrm{~kg}$ for the C-R134a Loop. Using the fluid density at an elevated room temperature, $30^{\circ} \mathrm{C}$, under the respective final system pressure of the two loops, the volume of the discharged fluid to be stored in the accumulators is found to be $0.0059 \mathrm{~m}^{3}$ and $0.015 \mathrm{~m}^{3}$ for the C-SCW Loop and the C-R134a Loop, respectively.

In order to maximize the life span of the bladder, the operational range of the accumulator is recommended to be maintained such that the volume of the inert gas in the bladder is between approximately $1 / 3$ and $2 / 3$ of the total volume of the accumulator [13]. Thus, the total volume of the accumulator should be $0.0089 \mathrm{~m}^{3}$ and $0.022 \mathrm{~m}^{3}$ for the CSCW Loop and the C-R134a Loop, respectively.

Based on the volumetric demand, two bladder type accumulators with similar total volumes of $18.9 \mathrm{~L}$ were found from the inventory of the Accumulator Inc. The accumulator selected for the C-SCW Loop is rated for $40.8 \mathrm{MPa}$ and the one selected for the C-R134a Loop is rated for $20.4 \mathrm{MPa}$. Both pressure ratings are applicable for temperatures up to $93^{\circ} \mathrm{C}$. Nitrogen gas is selected to charge the accumulator. It is an inert gas which is safe and economic for high pressure applications [13].

It is noted that the accumulator selected for the C-SCW Loop is larger than the result of the preliminary sizing. The reason for selecting a larger accumulator is because of the temperature rating of the accumulator. For the C-SCW Loop, the lowest operating temperature is $260^{\circ} \mathrm{C}$. As will be shown in the next section, some cooling tubes must be installed at the inlet of the accumulator to cool down the working fluid to the rated temperature of the accumulator. A larger accumulator volume is used as an additional safety factor as it provides increased surface area for heat transfer to the surroundings. 
Since the operation of the loop covers a wide range of temperatures and pressures, based on the ideal gas law, the amount of gas used to pressurize the accumulator must be adjustable. Therefore, as shown in Figure 11, a gas cylinder with two control valves is installed for this purpose. The next section discusses the details of these components.

\subsection{Auxiliary Components}

As shown in Figure 11, auxiliary components are added to control the gas pressure in the accumulator. These components include a gas cylinder, two control valves, two pressure relief valves and a shut-off/control valve for each of the pressure control module.

Both loops share the same type of gas cylinder and control valves. K-type gas cylinders are used to supply nitrogen gas to pressurize the accumulators. The gas cylinder has an internal volume of $0.0499 \mathrm{~m}^{3}$ and the nitrogen inside has a maximum pressure of 40.8 MPa. Two small needle valves used as control valves (CV 3 and CV 4 in Figure 11) with a flow coefficient of 0.09 are installed on each of the pressure control modules to control the gas flowing in and out of the accumulator. Electric actuators are installed on these valves such that the nitrogen gas flow can be regulated from a remote computer workstation. An absolute pressure transducer is installed at inlet of the gas side of the accumulator to monitor the pressure inside the accumulator.

For the C-R134a Loop, two conventional ASME D-type pressure relief valves are installed on the fluid side (PRV 1 in Figure 11) and gas side (PRV 2 in Figure 11) of the accumulator to prevent the over-pressurization of the loops. For the C-SCW Loop, two ASME D-type pilot operated pressure relief valves are required. The pressure relief valves are set to relieve the nitrogen gas and working fluid at the maximum allowable working pressure (MAWP) (27.07 MPa and 6.2 MPa for the C-SCW Loop and the C- 
R134a Loop, respectively) [16]. The reason for using pilot operated pressure relief valves on the $\mathrm{C}-\mathrm{SCW}$ is because the MAWP of the C-SCW Loop is very close to the maximum operating pressure of the loop, and a pilot operated pressure relief valve can prevent premature gas venting. All the pressure relief valves are sized in accordance with the guidelines detailed in API RP 520 [16]. Sample sizing calculations for the pressure relief valves can be found in Appendix 3.

Tubes made of 316 stainless steel with an outside diameter of $6.25 \mathrm{~mm}$ (1/4 inch) and a wall thickness of $1.24 \mathrm{~mm}(0.049 \mathrm{inch})$ are used to connect the components of the pressure control module. The thickness of the tube is sized in accordance with ASME B31.1 Power Piping Code and the sizing calculations can be found in Appendix 3 [17]. This tube specification ensures that the tube can withstand the pressure exerted by the nitrogen gas flow and the working fluid discharged from the main loop. The tubes and the components of the pressure control modules are connected via compression fittings and NPT threaded connections. A shut-off/control valve is installed near the working-fluid port of the accumulator to enable control of the working-fluid access to the accumulator. As shown in Figure 11, a thermocouple is installed near the shut-off valve to monitor the bulk temperature of the working fluid entering the accumulator.

\subsubsection{Cooling Tube for the Accumulator}

As mentioned earlier, the minimum temperature for the water circulating in the $\mathrm{C}$ SCW Loop is $260^{\circ} \mathrm{C}$. However, the accumulator is rated for a maximum temperature of $93^{\circ} \mathrm{C}$. Therefore, it is necessary to install a section of cooling tube to ensure that the accumulator will not become overheated. The objective of the sizing of the tube is to 
obtain the required length for the cooling tube such that the fluid temperature at the outlet of the cooling tube (i.e. at the inlet of the accumulator) is below $93^{\circ} \mathrm{C}$.

A two-part heat transfer analysis is conducted on the accumulator and the line connecting the accumulator to the main loop based on two phases during the operation of the C-SCW Loop. The first part of the analysis is to find out the required length of cooling tube when the loop is operating at steady temperature and system pressure. In this case, since water is not exchanged between the accumulator and the main loop, the heat transfer between the main loop and the accumulator is mainly through heat conduction along the metallic wall of the tube and water in the tube. The second part of the analysis is to find out the required cooling tube length during the thermal transients of the $\mathrm{C}-\mathrm{SCW}$ Loop. In this case, the operation scenario considered is one where water at $260^{\circ} \mathrm{C}$ is discharged from the main loop to the accumulator. The purpose of the second part of the heat transfer analysis is to select and size the cooling tube to reduce the bulk temperature of the water from $260^{\circ} \mathrm{C}$ to the rated temperature of the accumulator, $93^{\circ} \mathrm{C}$, as the water flows from the main loop into the accumulator.

The analytical calculation is followed by numerical heat transfer simulations for the first part of the heat transfer analysis. This approach serves to validate the numerical approach. For the second part of the heat transfer analysis, a numerical heat transfer simulation is performed to study the convective heat transfer of the water flow in the cooling tube using a turbulence model. Both numerical heat transfer simulations are performed on a computer with an Intel ${ }^{\circledR} \mathrm{Core}^{\mathrm{TM}} 2$ Duo CPU with a clock rate of 2.13 GHz and a total physical memory of 4 GB. The simulation software is ANSYS CFX ${ }^{\circledR}$ 12.0. 


\subsubsection{Analytical Calculations for the Required Cooling Tube Length When the C- SCW Loop is Operating at Steady System Pressure and Temperature}

A simplified scenario is created to mimic the conductive heat transfer between the main loop and the accumulator:

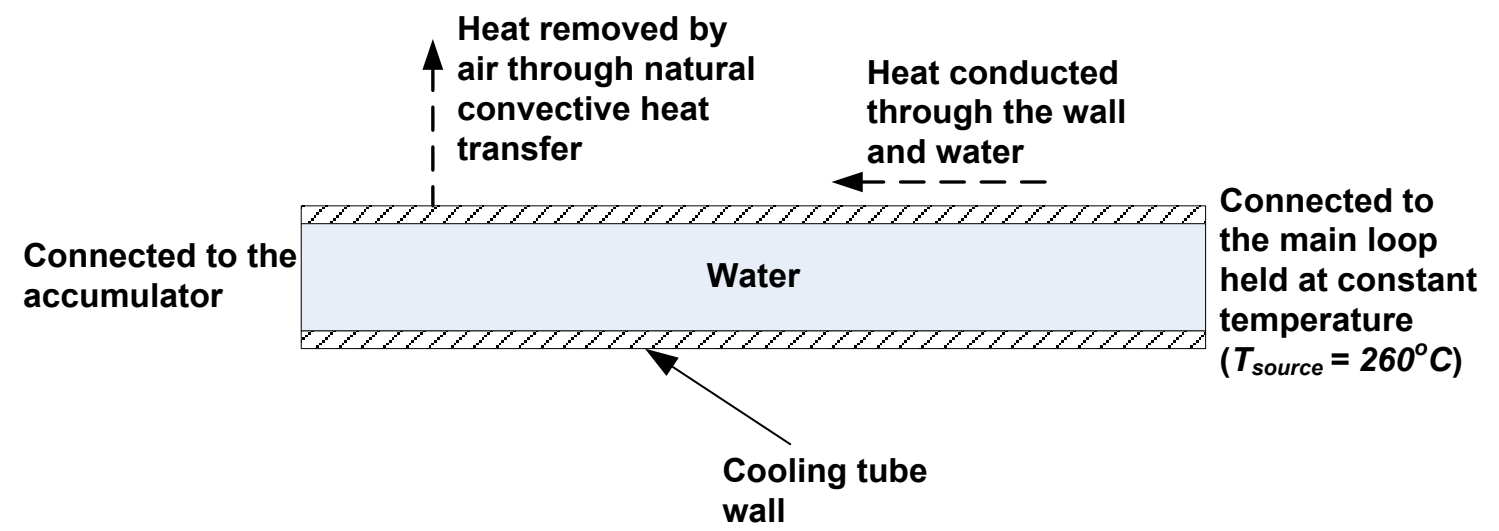

Figure 12: Thermal conduction through the cooling tube

As shown in Figure 12, there are two modes of heat transfer involved: the heat conduction through the cooling tube wall and water and the natural convective heat transfer between the outer surface of the tube and the surrounding air. Since the stainless steel wall is thermally 39 times more conductive than water, the heat conduction through the water is neglected in the heat transfer analysis. In this case, the comparison is made based on the thermal resistance for heat conduction, which is defined as:

$$
R=\frac{1}{k A_{\text {corss }}}
$$

where $k$ is the thermal conductivity $\left(\mathrm{W} / \mathrm{m}{ }^{\circ} \mathrm{C}\right)$ which in this case is the thermal conductivity of the tube wall or the water and $A_{\text {cross }}$ is the cross-sectional area of the wall or the water in the cooling tube $\left(\mathrm{m}^{2}\right)$. 
Thus, the resultant local temperature profile along the wall of the cooling tube can be found analytically using [18]:

$$
\frac{T-T_{\infty}}{T_{\text {source }}-T_{\infty}}=\frac{\cosh [m(L-x)]}{\cosh (m L)}
$$

where $T$ is the circumferentially-averaged temperature of the tube wall at location $\mathrm{x}$ measured form the source of the heat $\left({ }^{\circ} \mathrm{C}\right) ; T_{\infty}$ is the ambient temperature, which is conservatively assumed to be $30^{\circ} \mathrm{C} ; T_{\text {source }}$ is the temperature of the isothermal heat source $\left({ }^{\circ} \mathrm{C}\right) ; L$ is the total length of the cooling tube $(\mathrm{m})$ and $m$ is a parameter defined as:

$$
m=\sqrt{\frac{h_{\text {tube }} C}{k A_{\text {cross }}}}
$$

where $h_{\text {tube }}$ is the natural convective heat transfer coefficient at the outer surface of the tube $\left(\mathrm{W} / \mathrm{m}^{2}{ }^{\circ} \mathrm{C}\right) ; C$ is the tube circumference based on the tube outside diameter $(\mathrm{m}) ; k$ is the thermal conductivity of the stainless steel $316\left(16.3 \mathrm{~W} / \mathrm{m}{ }^{\circ} \mathrm{C}\right)$ and $A_{\text {cross }}$ is the cross sectional area of the wall of the cooling tube.

The only unknown parameter in Eqn. (13) is the heat transfer coefficient, $h_{\text {tube }}$, which can be calculated using a Nusselt number correlation for natural convection from a horizontally-oriented cylinder [18]:

$$
N u_{D}=0.36+\frac{0.518 R a_{D}^{1 / 4}}{\left[1+(0.559 / \operatorname{Pr})^{9 / 16}\right]^{4 / 9}}
$$

where $D$ is the outside diameter of the cooling tube (m). The Nusselt number, $N u_{D}$, Prandtl number, $P r$, and Rayleigh number, $R a_{D}$, are defined as:

$$
N u_{D}=\frac{h_{\text {tube }} D}{k_{\text {air }}}
$$




$$
\begin{gathered}
\operatorname{Pr}=\frac{c_{p \text { air }} \mu_{\text {air }}}{k_{\text {air }}} \\
R a_{D}=\frac{\rho_{\text {air }} g \beta_{\text {air }} c_{p \text { air }}\left(T_{\text {wall }}-T_{\infty}\right) D^{3}}{k_{\text {air }} \nu_{\text {air }}},
\end{gathered}
$$

where $T_{\text {wall }}$ is the wall temperature $\left({ }^{\circ} \mathrm{C}\right) ; T_{\infty}$ is the ambient temperature, which is conservatively taken as $30^{\circ} \mathrm{C} ; k_{\text {air }}$ is the thermal conductivity of air $\left(\mathrm{W} / \mathrm{m}{ }^{\circ} \mathrm{C}\right) ; c_{p}$ is the isobaric specific heat capacity $\left(\mathrm{J} / \mathrm{kg}{ }^{\circ} \mathrm{C}\right) ; \mu_{\text {air }}$ is the dynamic viscosity of air $(\mathrm{Pa} \mathrm{s}) ; \rho_{\text {air }}$ is the density of air $\left(\mathrm{kg} / \mathrm{m}^{3}\right) ; v_{\text {air }}$ is the kinematic viscosity $\left(\mathrm{m}^{2} \mathrm{~s}\right)$, and $\beta_{\text {air }}$ is the thermal expansion coefficient for air which can be calculated through:

$$
\beta_{\text {air }}=\frac{1}{T_{\text {film }}+273.15}
$$

where $T_{\text {film }}$ is the air film temperature $\left({ }^{\circ} \mathrm{C}\right)$ defined as:

$$
T_{\text {film }}=\frac{T_{\text {wall }}+T_{\infty}}{2}
$$

All thermophysical properties of air required in the expressions presented thus far are to be evaluated at the film temperature. The Nusselt number correlation given in Eqn. (14) is valid for Rayleigh number $\left(R a_{D}\right)$ values between $10^{-6}$ and $10^{9}[18]$.

$93^{\circ} \mathrm{C}$ is taken as the temperature of the tube outside surface, $T_{\text {wall }}$ for this heat transfer analysis. In reality, only the tube surface temperature at the accumulator end is $93^{\circ} \mathrm{C}$; the surface temperature elsewhere along the tube length will be higher. This, in turn, would produce increased rates of cooling along the length of the tube through natural convection. Thus, the present assumption of $93^{\circ} \mathrm{C}$ surface temperature is conservative. The resultant Rayleigh number value for the cooling tube is found to be 898 
and the Prandtl number value is 0.7 . These values of $R a_{D}$ and $\operatorname{Pr}$ yield a Nusselt number value of 2.5 through Eqn. (14). Using this result in Eqn. (13) produces an $m$ value of 26, and using this $m$ value in Eqn. (12) together with a temperature value of $93^{\circ} \mathrm{C}$ at the accumulator end yields a tube length of $7.5 \mathrm{~cm}$.

\subsubsection{Numerical Calculations for the Required Cooling Tube Length When the C-SCW Loop is Operating at Steady System Pressure and Temperature}

The purpose of this simulation is to provide further support for the analytical results presented in the preceding section and to help validate the numerical approach in preparation for the second part of the heat transfer analysis involving transient conditions.

\subsection{Simulation Domain and Boundary Conditions}

The simulation domain includes a section of the accumulator, which is about $1 / 3$ of the actual accumulator and a $15 \mathrm{~cm}$ long stainless steel cooling tube section. The geometry and the type of boundary conditions applied to the surfaces of the simulation domain are illustrated in Figure 13. 


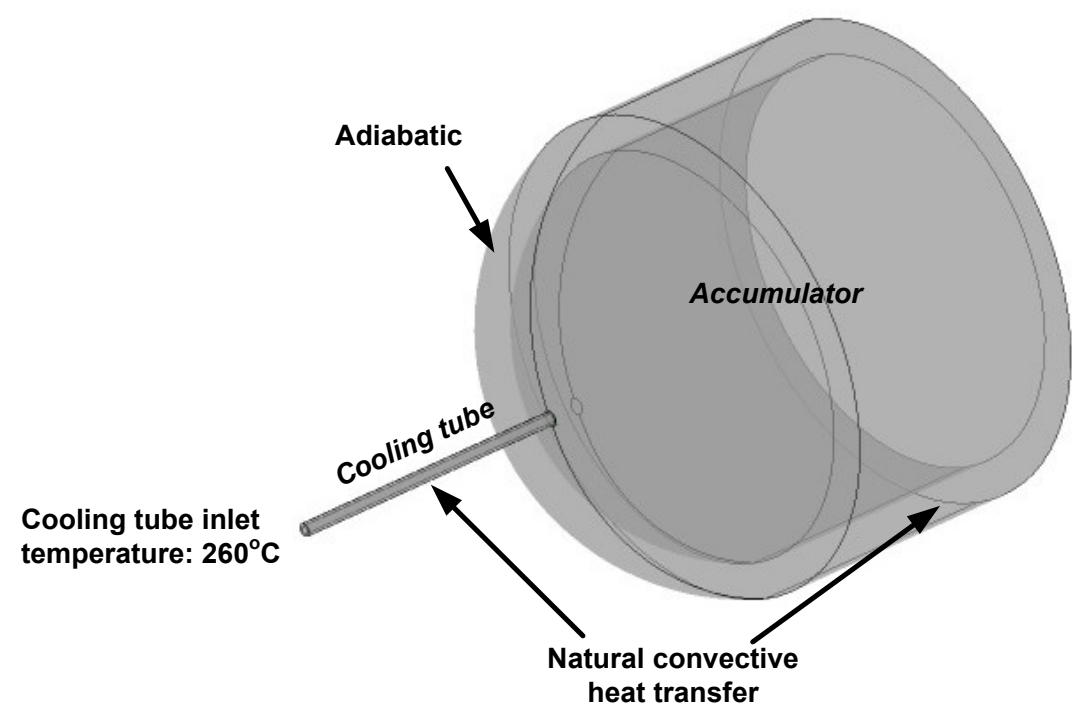

Figure 13: Simulation domain and boundary conditions for the cooling-tube heat

\section{transfer simulation}

The reason to include part of the accumulator in the simulation is that, due to the large size of the accumulator, it can act as a heat sink and increase the heat transfer surface area.

The boundary conditions not shown in Figure 13 are the ones applied to the open end of the accumulator and to the internal surfaces of the accumulator and the cooling tube. These boundaries are conservatively set to adiabatic conditions.

For the heat transfer on the outside surface of the accumulator and the cooling tube, pre-calculated local convective heat transfer coefficients are used to simplify the heat transfer simulation in ANSYS $\mathrm{CFX}^{\circledR}$. To estimate the convective heat transfer coefficients, the similarity criteria, namely, Prandtl number and Rayleigh number were used to identify dynamically similar scenarios for natural convective heat transfer around a horizontal cylinder in the existing literature. The local Nusselt numbers presented in the literature can then be used to calculate the local convective heat transfer coefficients. 
Given that the outside surface temperature of the cooling tube and accumulator varies between $30^{\circ} \mathrm{C}$ and $260^{\circ} \mathrm{C}$, the Prandtl number of air is 0.7 and the Rayleigh number of air varies from $3.2 \times 10^{6}$ to $4.8 \times 10^{6}$ on the accumulator case and from 67.9 to $1.23 \times 10^{3}$ on the cooling tube. Nusselt numbers corresponding to these ranges of Prandtl and Rayleigh number are listed in Table 8 . The data were obtained from three different sources:

1. Kuehn et al. (1980); 2. Saitoh et al. (1993) and 3. Wang et al. (1990) [19-21].

Table 8: Nusselt numbers for natural convection at different circumferential positions over a horizontal cylinder for a range of Rayleigh numbers and a constant Prandtl number of 0.7

\begin{tabular}{|c|c|c|c|c|c|c|c|c|c|}
\hline \multirow{2}{*}{$R a$} & \multirow{2}{*}{$\begin{array}{l}\text { Source of } \\
\text { the data }\end{array}$} & \multicolumn{8}{|c|}{$N u$} \\
\hline & & $\theta=0^{\circ}$ & $30^{\circ}$ & $60^{\circ}$ & $90^{\circ}$ & $120^{\circ}$ & $150^{\circ}$ & $180^{\circ}$ & Avg. \\
\hline $10^{1}$ & 1 & 1.83 & 1.79 & 1.67 & 1.47 & 1.21 & 0.94 & 0.81 & 1.40 \\
\hline $10^{2}$ & 1 & 2.71 & 2.66 & 2.51 & 2.23 & 1.80 & 1.27 & 0.97 & 2.05 \\
\hline \multirow{3}{*}{$10^{3}$} & 1 & 3.89 & 3.85 & 3.72 & 3.45 & 2.93 & 2.01 & 1.22 & 3.09 \\
\hline & 2 & 3.81 & 3.77 & 3.64 & 3.37 & 2.87 & 1.98 & 1.22 & 3.02 \\
\hline & 3 & 3.86 & 3.82 & 3.70 & 3.45 & 2.93 & 1.98 & 1.20 & 3.06 \\
\hline \multirow{3}{*}{$10^{4}$} & 1 & 6.24 & 6.19 & 6.01 & 5.64 & 4.82 & 3.14 & 1.46 & 4.94 \\
\hline & 2 & 6.00 & 5.94 & 5.75 & 5.41 & 4.76 & 3.31 & 1.53 & 4.83 \\
\hline & 3 & 6.03 & 5.98 & 5.80 & 5.56 & 4.87 & 3.32 & 1.50 & 4.86 \\
\hline \multirow{2}{*}{$10^{7}$} & 1 & 29.41 & 29.02 & 27.95 & 26.20 & 23.46 & 16.48 & 2.51 & 23.32 \\
\hline & 3 & 28.27 & 27.98 & 26.95 & 25.40 & 23.00 & 19.68 & 4.20 & 23.29 \\
\hline
\end{tabular}

The heat transfer coefficients corresponding to the Nusselt numbers listed in Table 8 are used to form a data file that can be imported into the ANSYS CFX ${ }^{\circledR}$ to be used as a convection heat transfer coefficient boundary condition on the outer surface of the cooling tube and the accumulator. In the case of dealing with discrepancies for the data obtained from different sources, the lowest Nusselt number is used as a conservative estimate (e.g. for $R a=10^{3}$ and $\theta=0^{\circ}, N u=3.81$ is used to calculate the convective heat 
transfer coefficient). During the simulation, ANSYS CFX ${ }^{\circledR}$ interpolates the given data file, based on the spatial coordinates of the nodes on the circumference and the local temperature at the nodes, to obtain the local convection heat transfer coefficients.

It should be noted that, in the transition region, where the body of the accumulator with large diameter shrinks into a smaller diameter to interface with the cooling tube, the imposed boundary condition is adiabatic for the simulation. Due to the variation of diameter, the convection heat transfer coefficient data file must contain convection heat transfer coefficients evaluated at all possible surface temperatures for a range of selected diameters. This would significantly increase the size of the data file. Thus, in order to simplify the simulation, the boundary condition is conservatively set to the adiabatic boundary condition at this location.

\subsection{Governing Equation}

The governing equation used in ANSYS CFX ${ }^{\circledR} 12.0$ for heat conduction in solid media is given by [22]:

$$
\frac{\partial}{\partial t}(\rho c T)=\nabla \cdot(k \nabla T)+S
$$

where $\rho$ is the density $\left(\mathrm{kg} / \mathrm{m}^{3}\right) ; c$ is the specific heat capacity $\left(\mathrm{J} / \mathrm{kg}{ }^{\circ} \mathrm{C}\right) ; T$ is the local temperature $\left({ }^{\circ} \mathrm{C}\right) ; k$ is the thermal conductivity $\left(\mathrm{W} / \mathrm{m}{ }^{\circ} \mathrm{C}\right)$ and $S$ is the local heat generated/removed by a heat source/sink $\left(\mathrm{W} / \mathrm{m}^{3}\right)$.

\subsection{Solution Method}

In order to solve the governing partial differential equation, ANSYS CFX ${ }^{\circledR}$ uses an element-based finite volume method to discretize the spatial domain [22]. Figure 14 illustrates the construction of the control volume around a mesh node. 


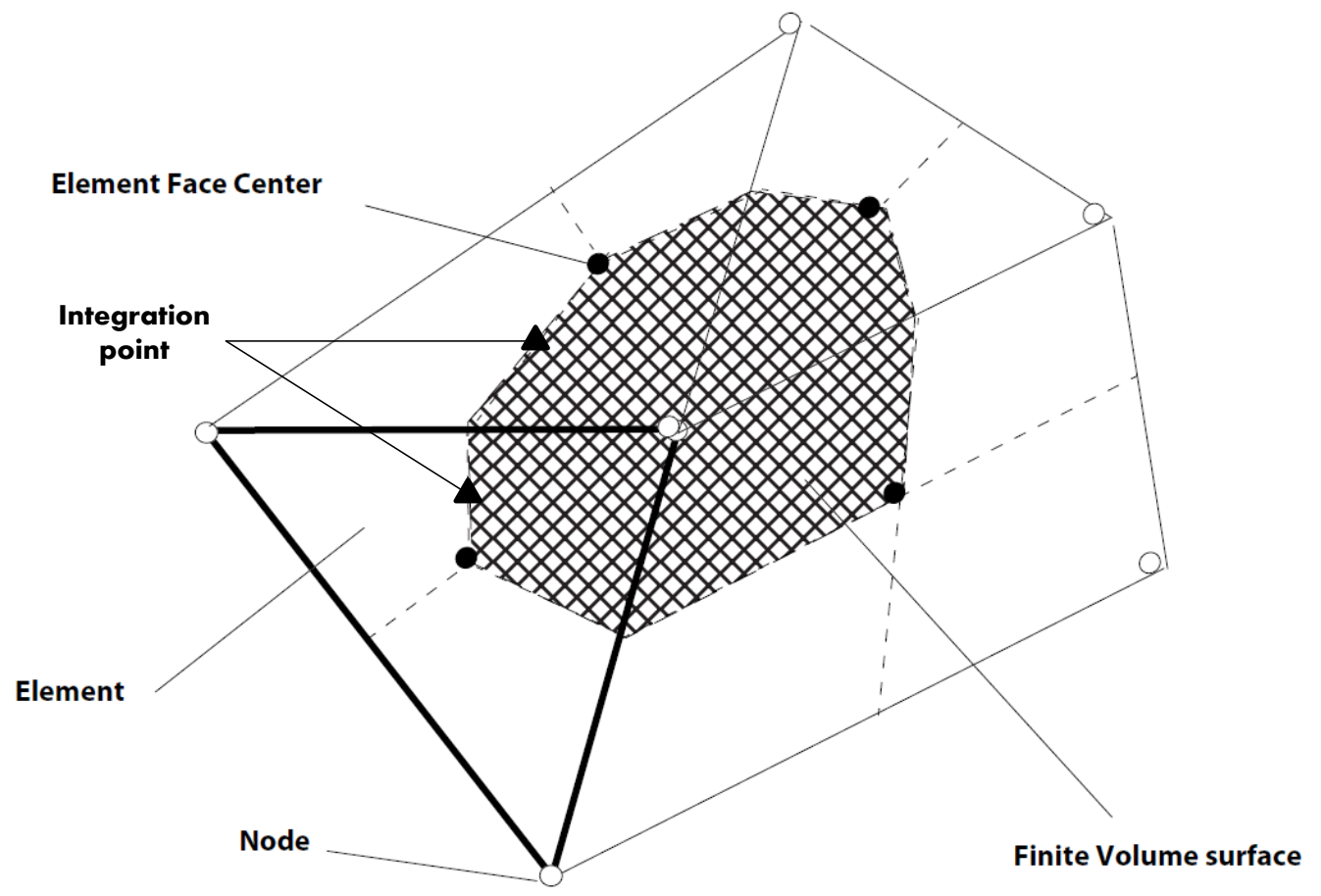

Figure 14: Illustration of the construction of a control volume around a mesh node and the integration point [22]

As shown in this figure, the control volume is constructed around each node by joining the center of the edges and the center of the mesh element. The integration point (ip), which is defined as the centroid of each of the constituent surfaces of the control volume, is where the surface integrals are to be evaluated [22]. Based on this, the governing equation can be integrated over the control volume as a discrete summation, which can be expressed as:

$$
\frac{\partial}{\partial t} \int_{V}\left(\rho c_{p} T\right) d V=\sum_{i p}(k \nabla T) \Delta n_{i}+S V
$$

where $V$ is volume of the control volume $\left(\mathrm{m}^{3}\right)$ and $\Delta n_{i}$ is the discrete outward-pointing normal unit vector of the surfaces of the control volume. 
The volume integral (i.e. the source term) is evaluated for each of the threedimensional sectors constituting the control volume and summed over all these sectors [22]. All property data required for the integration are stored at the mesh nodes, and they are interpolated to the integration points by introducing a finite-element based shape function, $N_{i}$, defined based on the parametric coordinates of the local mesh element. Thus, the variation of a parameter, $\phi$, within the mesh element can be expressed as [22]:

$$
\phi=\sum_{i} N_{i} \phi_{i}
$$

where $N_{i}$ is the shape function for node $i$ of the mesh element and $\phi_{i}$ is the value of the parameter at the same node. Thus, at the integration point, the diffusion term of the governing equation here can be evaluated via [22]:

$$
\left.\frac{\partial T}{\partial x_{j}}\right|_{i p}=\left.\sum_{i} \frac{\partial N_{i}}{\partial x_{j}}\right|_{i p} T_{i}
$$

where $x_{j}$ represents the spatial coordinates $(\mathrm{m})$.

The transient term is kept for the steady-state simulation as a means of underrelaxation as the governing equation iterates towards the final solution [22]. An automatic timescale is used by ANSYS CFX ${ }^{\circledR}$, under which an internally calculated physical time scale (called a false time step) is used to march the solution to the steady state [22]. The transient term is discretized using the First Order Backward Euler scheme [22].

Applying the finite volume method to all elements in the computational domain, the governing equation can be expressed in the form [22]:

$$
\sum_{n b_{i}} a_{i}^{n b} T_{i}^{n b}=b_{i}^{n b}
$$


where $T$ is the temperature solution; $b$ is the right-hand-side term and $a$ is the coefficient of the equation; $i$ is the index for the node/control volume in question and the superscript, $n b$, implies that the solution of temperature at location $i$ depends on the neighbouring nodes.

ANSYS CFX ${ }^{\circledR}$ initializes the solution by generating an approximate solution for the computational domain based on the boundary conditions and physics of the simulation. The solution is then iterated using a W-type Algebraic Multigrid method through an inner loop which is embedded in an outer loop between each timestep. The outer loop seeks to update the coefficient of Eqn. (24) until the error of solution (which is referred to as residuals) becomes lower than the convergence criterion specified by the user. For the current simulation for the conduction heat transfer analysis, a root-meansquare residual of $10^{-4}$ is used as the convergence criterion, which is a recommended value for general engineering application [22]. In general, a total number of 2 to 3 outer loop iterations are performed to reach convergence. Only one inner loop iteration is performed per outer loop iteration for steady state simulations [22].

\subsection{Spatial Mesh}

A hybrid mesh is mapped onto the computational domain. For the cooling tube section a structured mesh consisted of prisms and hexahedral elements is used, whereas an unstructured mesh consisting of tetrahedral elements is used for the more complicated geometry of the accumulator. A mesh sensitivity study is carried out to study the impact of the size of the mesh elements on the simulation results. Three cases are created for the mesh sensitivity study as listed in Table 9. The refinement of the mesh mainly focuses on the mesh of cooling tube, because, based on the first simulation, a large temperature 
gradient was observed along the axis of the tube while the temperature of the accumulator remains close to room temperature. Figure 15 shows the pattern of the mesh generated for the simulation domain in Case 3.

Table 9: Number of elements for the meshes generated for the mesh sensitivity study

\begin{tabular}{|c|c|c|c|}
\hline \multirow{2}{*}{} & \multicolumn{2}{|c|}{$\begin{array}{c}\text { Maximum element edge length } \\
\text { \% of the thickness of the wall of } \\
\text { the tube and the accumulator) }\end{array}$} & \multirow{2}{*}{$\begin{array}{c}\text { Total number } \\
\text { of elements }\end{array}$} \\
\cline { 2 - 2 } & Cooling tube & Accumulator & \\
\hline Case 1 & $48 \%$ & & 103,400 \\
\hline Case 2 & $40 \%$ & \multirow{2}{*}{$58 \%$} & 155,461 \\
\hline Case 3 & $32 \%$ & & 346,192 \\
\hline
\end{tabular}

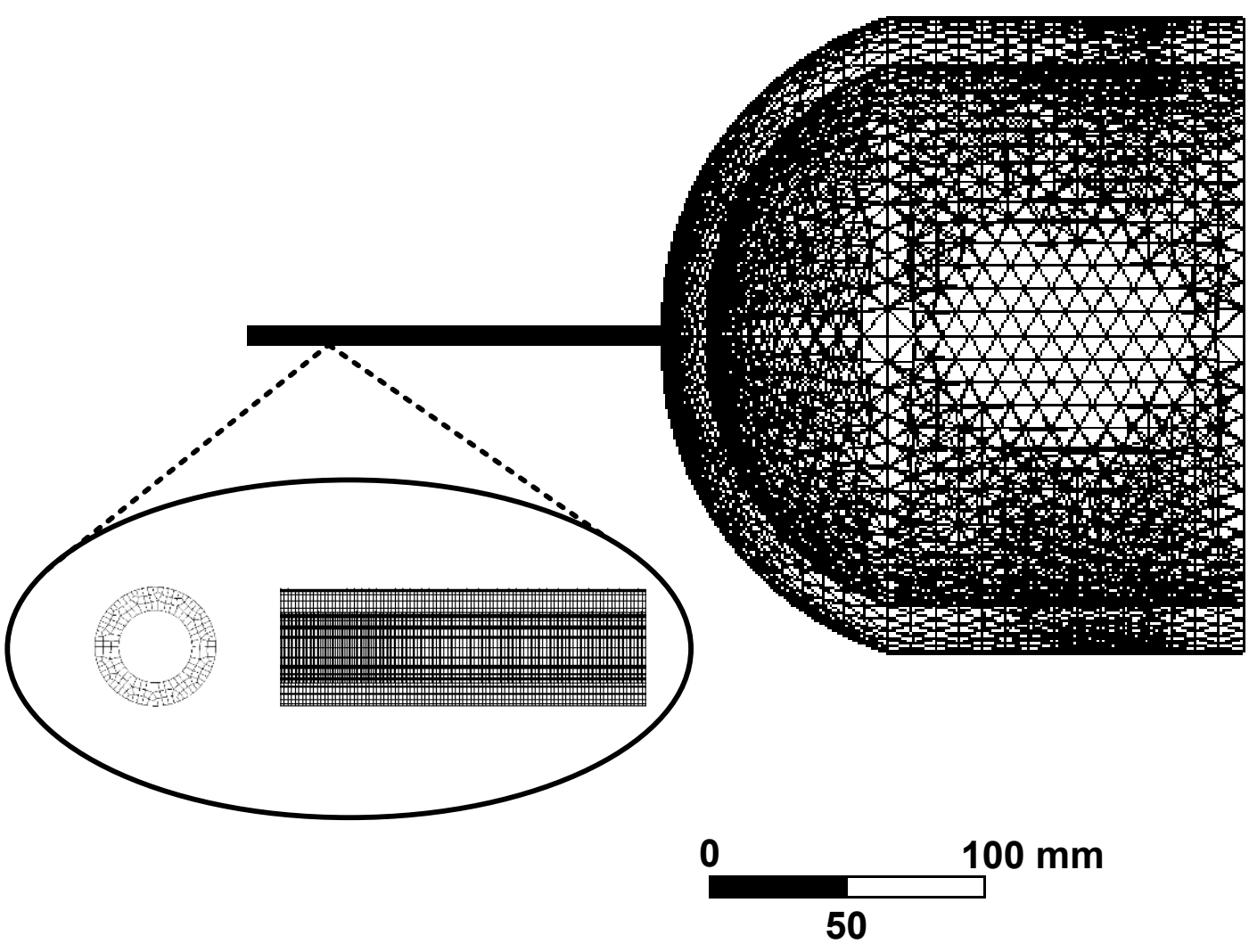

Figure 15: View of mesh for the most refined mesh generated for the cooling tube and the accumulator assembly 


\subsection{Simulation Results}

All three simulations show that the $15 \mathrm{~cm}$-long tube adopted here for the simulation domain is more than sufficient to prevent the accumulator from being overheated. Table 10 shows the length of the tube at which the temperature of the tube near the accumulator end reaches a value of $90^{\circ} \mathrm{C}$ in the three cases identified in Table 9.

Table 10: Length of the cooling tube at which the temperature of tube reaches $90^{\circ} \mathrm{C}$ at the accumulator end

\begin{tabular}{|c|c|}
\hline & $\begin{array}{c}\text { Length of the } \\
\text { cooling tube } \mathbf{( m )}\end{array}$ \\
\hline Case 1 & 0.078 \\
\hline Case 2 & 0.075 \\
\hline Case 3 & 0.07 \\
\hline
\end{tabular}

As shown in Table 10, the predicted lengths of the cooling tube at which the temperature of tube reaches $90^{\circ} \mathrm{C}$ in each of the simulations are very similar to each other. Therefore, the simulation results can be considered as being independent of the size of the mesh element. The results also agree favorably with the analytically-determined cooling-tube length of $0.075 \mathrm{~m}$ documented in the preceding section. Thus, it can be concluded that approximately $0.08 \mathrm{~m}$ of cooling tube made of 316 stainless steel is required to prevent the accumulator from being overheated when the loop is operating at a steady temperature of $260^{\circ} \mathrm{C}$. 


\subsubsection{Analytical Calculation for the Required Cooling Tube Length during Thermal Transients of the C-SCW Loop}

Water is discharged from the main loop to the accumulator under transient operating regimes such as start-up of the C-SCW Loop. The possibility exists that water at $260^{\circ} \mathrm{C}$ may enter the cooling tube, flowing towards the accumulator while losing heat to the surroundings. It is important that the cooling tube be designed to ensure sufficient heat loss from the water as it flows through the tube to ensure a discharge temperature that is no greater than the accumulator temperature limit of $93^{\circ} \mathrm{C}$. For the purpose of the heat transfer calculation for such a transient scenario involving fluid flow in the cooling tube, the tube is divided into equal-length segments with each segment having a uniform temperature distribution. The energy balance for the water flowing through each such segment is given by:

$$
\dot{Q}=\dot{m}\left(h_{\text {out }}-h_{\text {in }}\right)
$$

where $\dot{Q}$ is the rate of heat transfer to the water (W); $\dot{m}$ is the water mass flow rate through the cooling tube $(\mathrm{kg} / \mathrm{s}) ; h_{\text {out }}$ and $h_{\text {in }}$ are the bulk water specific enthalpy at the outlet and inlet of the segment, respectively $(\mathrm{J} / \mathrm{kg})$.

The mass flow rate in the cooling tube is in fact the rate of mass change in the main loop. The mass change in the main loop mainly depends on temporal change of the water density, which, in turn is a function of the net rate of heat input to the water in the test loop. Such information is yet to be established for the C-SCW Loop. As such, the mass flow rate of water in the cooling tube is estimated based on the startup duration of a similar supercritical water heat transfer test facility at the University of Wisconsin. The startup procedure for this facility adopts a temperature increment rate of $1^{\circ} \mathrm{C} / \mathrm{min}$ [23]. 
Unfortunately, this procedure is not practical on the C-SCW Loop, as this temperature increment rate would result in a startup duration of 6 to $10 \mathrm{hr}$. However, with this rate, a reasonable temperature increment rate for the C-SCW Loop can be estimated based on the order of magnitude. To balance the startup duration and thermal stresses associated with rapid transients, $5^{\circ} \mathrm{C} / \mathrm{min}$ shall be used as the temperature increment, which would result in a startup duration ranging from 1 to $2 \mathrm{hr}$ for the C-SCW Loop depending on the desired test section outlet temperature. To account for the non-linear change of water density with respect to temperature, the startup duration used for calculating the mass flow rate in the cooling tube is conservatively chosen as $30 \mathrm{~min}$. Thus, the average mass flow rate for the discharged water flow in the cooling tube is $3.29 \times 10^{-3} \mathrm{~kg} / \mathrm{s}$.

The rate of radial heat transfer from the water in each tube segment is given by:

$$
\dot{Q}=\frac{T_{b u l k}-T_{\infty}}{R_{\text {tot }}}
$$

where $T_{\text {bulk }}$ is the bulk water flow temperature $\left({ }^{\circ} \mathrm{C}\right) ; T_{\infty}$ is the ambient temperature, which was conservatively chosen as $30^{\circ} \mathrm{C}$; and $R_{\text {tot }}$ is the combined thermal resistance due to convective motion on the inside and outside of the tube wall and the thermal conductivity of the tube material $\left({ }^{\circ} \mathrm{C} / \mathrm{W}\right)$ and it can be estimated using [18]:

$$
R_{\text {tot }}=\left(\frac{1}{h_{\text {water }} A_{i}}+\frac{\ln \left(\frac{r_{o}}{r_{i}}\right)}{2 \pi L_{\text {tube }} k}+\frac{1}{h_{\text {air }} A_{o}}\right)
$$

where $h_{\text {water }}$ is the forced convection heat transfer coefficient for the water flow $\left(\mathrm{W} / \mathrm{m}^{2}\right.$ $\left.{ }^{\circ} \mathrm{C}\right) ; r_{o}$ and $r_{i}$ are the tube outside and inside radii, respectively (m); $A_{i}$ and $A_{o}$ are the inside and outside heat transfer surface areas $\left(\mathrm{m}^{2}\right) ; k$ is the thermal conductivity of the 
tube material $\left(\mathrm{W} / \mathrm{m}{ }^{\circ} \mathrm{C}\right) ; h_{\text {air }}$ is the convection heat transfer coefficient on the outside surface of the cooling tube $\left(\mathrm{W} / \mathrm{m}^{2}{ }^{\circ} \mathrm{C}\right)$, and $L_{\text {tube }}$ is the length of the tube segment (m).

The two convection heat transfer coefficients in Eqn. (27) can be obtained via an empirical Nusselt number correlation. For the transient water flow scenario considered in this analysis, the Reynolds number value in the cooling tube varies between 3500 and $10^{4}$ and Prandtl number value varies between 0.7 and 2, respectively. For these ranges of the Reynolds number and Prandtl number, a Nusselt number correlation applicable to pipe flows is given as [24]:

$$
N u_{d}=\frac{(f / 8)\left(\operatorname{Re}_{d}-1000\right) \operatorname{Pr}}{1+12.7\left(\frac{f}{8}\right)^{0.5}\left(\operatorname{Pr}^{2} / 3-1\right)}
$$

where $d$ is the internal diameter of the cooling tube (m) and $f$ is the friction factor, which can be determined using Eqn. (4). It should be noted that the velocity profile in the tube will likely not correspond to fully developed conditions for some portion of the tube length. As such, the use of values corresponding to fully-developed flow conditions for parameters such as $f$ is an approximation. This approximation should tend to produce heat transfer rates that are lower than those corresponding to developing flow conditions, as such should yield a conservative length for the cooling tube.

For $h_{\text {air }}$, the choice of the Nusselt number correlation depends on the cooling methods used. Three different cooling methods are investigated for the sizing of the cooling tube to find the optimized cooling solution.

\section{Case 1. Cooling via natural convective heat transfer}

In this case, the horizontally-oriented cooling tube releases heat to the surrounding air via natural convection. Since the temperature on the outside surface of 
the cooling tube is expected to vary between $93^{\circ} \mathrm{C}$ and $260^{\circ} \mathrm{C}$, the resulting Rayleigh number varies between $1.2 \times 10^{3}$ and 898 . Thus, the same Nusselt number correlation used in in Section 4.3.1.1 (Eqn. (14)) is also applicable here.

The calculation starts by finding the necessary parameters for use in Eqn. (27). In this equation, the inside and outside radii of the tube are $1.93 \mathrm{~mm}$ and $3.18 \mathrm{~mm}$, respectively. The length of the segment, $L_{\text {tube }}$, is $0.1 \mathrm{~m}$. The inside and outside heat transfer surface areas can then be calculated through:

$$
A=\pi D L_{\text {tube }}
$$

where $D$ is the relevant diameter of the cooling tube.

The material of the cooling tube is 316 stainless steel which yields a thermal conductivity of $16.3 \mathrm{~W} / \mathrm{m}{ }^{\circ} \mathrm{C}$ [18]. The convective heat transfer coefficient, $h_{\text {water }}$, can be calculated using the Nusselt number correlation (i.e. Eqn. (28)) based on water inlet temperature of the cooling tube segment in question. In theory, pressure should also be used when looking up the water properties required to evaluate the dimensionless parameters in Eqn. (28). However, due to the fact that liquid water properties barely varies within pressure range that are of interest $(23-27 \mathrm{MPa})$, this parameter is of little importance. For simplicity, a system pressure $23 \mathrm{MPa}$ is taken for all cooling tube calculations. For the first cooling-tube segment, the inlet temperature of $260^{\circ} \mathrm{C}$ is used to find the water properties. For the successive cooling-tube segments, the water properties are found based on the water temperature at the outlet of the preceding segment. The convection heat transfer coefficient on the outer surface of the cooling tube, $h_{\text {air }}$ can be found by using Eqn. (14). In this case, the water temperature of the segment inlet is used as the outside surface temperature to simplify the calculation. This temperature 
overestimation may result in a slightly large $h_{\text {air }}$. However, considering the small cross section of the tube and the high thermal conductivity of the tube wall, this overestimation should not cause serious error in the final result for the required length of the cooling tube. The combined thermal resistance for the cooling tube can then be calculated.

Based on the combined thermal resistance, the rate of heat transfer from the water to the surroundings can be calculated using Eqn. (26). Substituting the rate of heat transfer back into Eqn. (25), the outlet specific enthalpy can be calculated. The outlet specific enthalpy and the system pressure, $23 \mathrm{MPa}$, can then be used to find the inlet condition for the subsequent segment. This iterative calculation stops when the water temperature at the outlet of the segment reaches below $93^{\circ} \mathrm{C}$.

The calculation for the required cooling tube length shows that even after $10 \mathrm{~m}$ of cooling tube, the bulk temperature of the water entering the accumulator is still at $221^{\circ} \mathrm{C}$. Considering the limited space available in the laboratory, cooling the discharged water flow via natural convective heat transfer on the outside of the cooling tube is therefore not a feasible method.

It is worth noting that, in this case, the magnitude of the overall thermal resistance is found to be dictated by the external convective thermal resistance (i.e. between the ambient air and the outside of the cooling tube surface). Thus, to shorten the required cooling tube length, the key design step would be to increase the external convection heat transfer coefficient, $h_{\text {air }}$.

\section{Case 2. Cooling via forced convective heat transfer}

Forced convective heat transfer is realized on the outside of the cooling tube through the use of fans as shown schematically in Figure 16. 


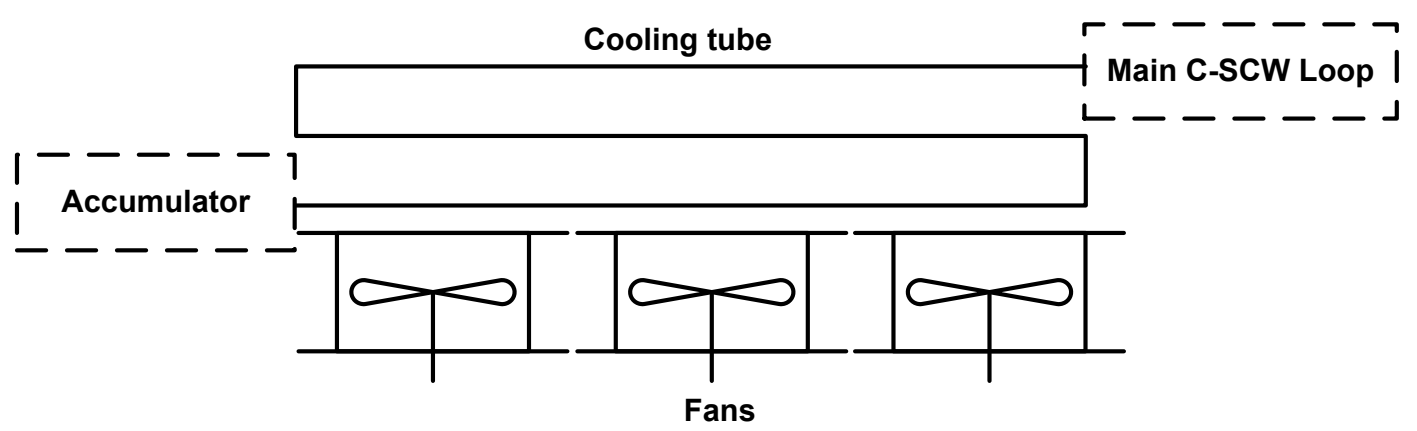

Figure 16: Layout for forced convection over the cooling tubes

Three fans manufactured by Turbo-Aire ${ }^{\circledR}$ are considered for this application. The specification sheet for the selected fan is included in Appendix 4. Each of the fans has a diameter of $0.3 \mathrm{~m}$ (12 inches) delivering air at a maximum volume flow rate of $0.64 \mathrm{~m}^{3} / \mathrm{s}$ $\left(1350 \mathrm{ft}^{3} / \mathrm{min}\right)$. The speed of the air discharging from the fan is estimated to be $8.7 \mathrm{~m} / \mathrm{s}$. Therefore, the Reynolds number for the resultant air flow over the cooling tube surface is estimated to vary between $1.9 \times 10^{3}$ (at a film surface temperature of $145^{\circ} \mathrm{C}$ corresponding to a tube surface temperature of $260^{\circ} \mathrm{C}$ ) and $2.9 \times 10^{3}$ (at a film temperature of $62^{\circ} \mathrm{C}$ corresponding to a tube surface temperature of $93^{\circ} \mathrm{C}$ ). Based on this Reynolds number range, a suitable Nusselt number correlation to evaluate the external convective heat transfer coefficient, $h_{\text {air }}$, is given as [18]:

$$
N u_{D}=0.683 \operatorname{Re}_{D}^{0.466} \operatorname{Pr}^{1 / 3}
$$

Following the calculation steps as described for Case 1, the resultant cooling tube length is determined to be $8.7 \mathrm{~m}$. Although, compared to Case 1, the required length of the cooling tube is significantly reduced, it is still considered too long for the current application. 


\section{Case 3. Forced-convection cooled cooling tube with circumferential fins}

To further improve the external heat transfer on the cooling tube, in addition to the three fans, circumferential fins are added to the cooling tube to increase the heattransfer surface area.

In order to evaluate the heat transfer performance of the finned cooling tube, detailed fin geometry must be obtained. A potential supplier, Fin Tube Products Inc., with versatile design options for the finned tube is identified. The specifications for the finned tubes are summarized in Table 11.

In this case, copper is selected as the fin material, because it has a higher thermal conductivity $\left(385 \mathrm{~W} / \mathrm{m}^{\circ} \mathrm{C}\right)$ than that of 316 stainless steel $\left(16.3 \mathrm{~W} / \mathrm{m}{ }^{\circ} \mathrm{C}\right)$ [18]. This ensures that the fin surface has a relatively uniform temperature, which is close to the temperature at the outside surface of the tube and thus facilitating the effectiveness of the forced convective heat transfer between the fin and the surrounding air. In order to have the shortest finned tube, the maximum fin density recommended by the manufacturer is chosen as indicated in Table 11. Unfortunately, for the fin thickness and the height of the fin, the manufacturer does not provide any options.

Table 11: Specifications for the finned cooling tube

\begin{tabular}{|l|c|}
\hline Material of the cooling tube & 316 stainless steel \\
\hline Material of the fin & Copper/316 stainless steel \\
\hline Type of the fin & Circular fin \\
\hline $\begin{array}{l}\text { Height of the fin (mm) } \\
\text { from tube outside surface to the } \\
\text { tip of the fin) }\end{array}$ & 4.76 \\
\hline Thickness of the fin $\mathbf{( m m )}$ & 0.381 \\
\hline $\begin{array}{l}\text { Maximum fin density } \\
\text { (number of fins per } \mathbf{1 0} \mathbf{~ c m ~ o f ~} \\
\text { straight tube) }\end{array}$ & 71 \\
\hline
\end{tabular}


As shown in Figure 17, for a finned tube, heat is released from the cooling tube to its surroundings through the finned section as well as directly from the surface of the tube between the fins. As such, the overall heat transfer calculation requires consideration of these two parallel paths of heat flow.

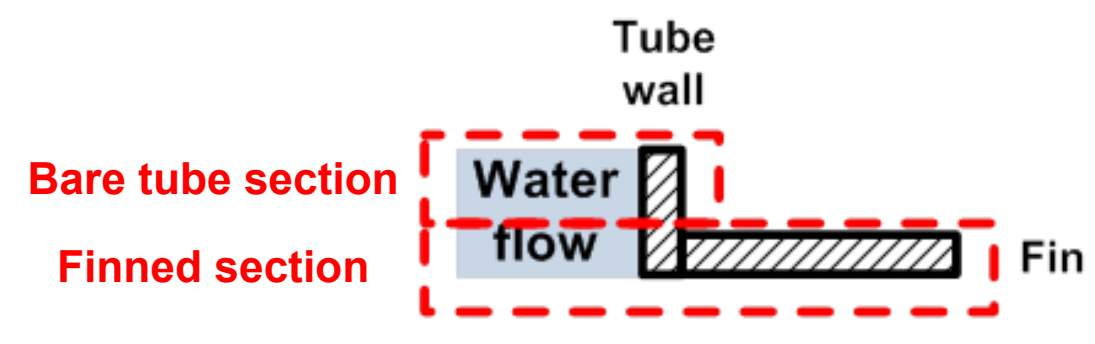

Figure 17: A finned cooling tube element

The overall thermal resistance of the finned cooling tube element, $R_{\text {element }}$, shown in Figure 17 can be evaluated through:

$$
R_{\text {element }}=\left(\frac{1}{R_{\text {bare }}}+\frac{1}{R_{\text {fin }}}\right)^{-1}
$$

where $R_{\text {bare }}$ and $R_{f i n}$ are the thermal resistances of the bare tube and finned sections, respectively $\left({ }^{\circ} \mathrm{C} / \mathrm{W}\right)$.

For the bare tube section, the thermal resistance can be evaluated using the methods explained in Case 2. For the finned section of the element, the thermal resistance can be calculated by introducing a parameter called the fin effectiveness which is defined by [18]:

$$
\varepsilon_{f}=\frac{\dot{Q}_{f i n}}{\dot{Q}_{\text {tube }}}=\frac{\tanh \left(\sqrt{\frac{H_{f i n} h_{\text {air }} A_{f i n}}{k_{f i n} A_{b, f}}}\right)}{\sqrt{\frac{h_{a i r} A_{b} H_{f i n}}{k_{f i n} A_{f i n}}}}
$$


where $\varepsilon_{f}$ is the effectiveness of the fin; $\dot{Q}_{\text {tube }}$ is the rate of convection heat transfer for the cooling tube without fins (W); $\dot{Q}_{\text {fin }}$ is the rate convection heat transfer in the presence of fin (W); $H_{\text {fin }}$ is the height of the fin $(\mathrm{m}) ; k_{\text {fin }}$ is the thermal conductivity of the fin $(\mathrm{W} / \mathrm{m}$ $\left.{ }^{\circ} \mathrm{C}\right)$ and $A_{b, f}$ is the tube surface area which is covered by the fin $\left(\mathrm{m}^{2}\right)$.

$\dot{Q}_{\text {tube }}$ can be evaluated through:

$$
\dot{Q}_{\text {tube }}=h_{\text {air }} A_{b, f}\left(T_{\text {wall }}-T_{\infty}\right)
$$

where $T_{\text {wall }}$ is the temperature on the outside surface of the cooling tube $\left({ }^{\circ} \mathrm{C}\right)$ and $T_{\infty}$ is the ambient temperature $\left({ }^{\circ} \mathrm{C}\right)$. Substituting Eqn. (33) into Eqn. (32) gives:

$$
\dot{Q}_{\text {fin }}=\varepsilon_{f} h_{\text {air }} A_{b, f}\left(T_{\text {wall }}-T_{\infty}\right)
$$

The implication of Eqn. (34) is that the finned section can be treated as a section of bare tube with a higher convection heat transfer coefficient, $h_{\text {eff: }}$

$$
h_{e f f}=\varepsilon_{f} h_{\text {air }}
$$

Based on this equation, which characterizes the external convection heat transfer of the finned section of the finned cooling tube, thermal resistance of this part of the cooling tube can be calculated through:

$$
R_{\text {fin }}=\frac{1}{h_{\text {water }} A_{\text {int } f}}+\frac{\ln \left(\frac{r_{o}}{r_{i}}\right)}{2 \pi L_{\text {tube } f} k}+\frac{1}{\varepsilon_{f} h_{\text {air }} A_{b, f}}
$$

where $A_{\text {int }, f}$ is the internal area of the finned section of the finned cooling tube $\left(\mathrm{m}^{2}\right) ; L_{\text {tube }, f}$ is the length of the fin part (m). 
Therefore, $R_{\text {element }}$ can be expressed as:

$$
R_{\text {element }}=\left(\frac{1}{\frac{1}{h_{\text {water }} A_{\text {int }, f}}+\frac{\ln \left(\frac{r_{o}}{r_{i}}\right)}{2 \pi L_{\text {tube }, f} k}+\frac{1}{h_{e f f} A_{b, f}}+\frac{1}{h_{\text {water }} A_{\text {intb }}}+\frac{\ln \left(\frac{r_{o}}{r_{i}}\right)}{2 \pi L_{\text {tube, }} k}+\frac{1}{h_{\text {air }} A_{b, b}}}\right)^{-1}
$$

where $L_{\text {tube, }}$ is the length of the bare tube section (m); $A_{\text {int }, b}$ is the tube internal area of the bare tube section $\left(\mathrm{m}^{2}\right)$ and $A_{b, b}$ is the outside tube area of the bare tube section $\left(\mathrm{m}^{2}\right)$.

Since, for a $10 \mathrm{~cm}$-long finned tube segment, there are 71 of such fin-bare tube element connected in parallel, the overall thermal resistance of the $10 \mathrm{~cm}$ long finned tube segment can be calculated by rewriting Eqn. (27) into:

$$
R_{\text {tot }}=\frac{1}{71}\left(\frac{1}{R_{\text {element }}}\right)^{-1}
$$

Taking the calculation steps described in Case 1, the total required length for the finned cooling tube can then be calculated. The resulting length of the finned cooling tube is $2 \mathrm{~m}$. This length is substantially shorter than the previous two cases. Therefore, the finned cooling tube becomes the optimal choice for the cooling tube.

\subsubsection{Numerical Computation on the Forced Convective Heat Transfer of High Temperature Water Flow inside the Finned Cooling Tube}

The purpose of performing the numerical computation is to investigate the validity of simulating a convective heat transfer flow problem using a turbulence model (Shear Stress Transport Model) developed based on the Reynolds-averaged NavierStokes Equations (RANS). The current work mainly focuses on the convective heat 
transfer of internal water flow discharged from the main C-SCW Loop under the current cooling tube design parameters as suggested by Case 3 in Section 4.3.1.3. The validation here serves to facilitate future work which can be done to simulate more advanced designs of the cooling mechanism to help improve the compactness of the pressure control module.

\subsection{Simulation Domain}

Given the axisymmetry of the water flow and the associated forced convective heat transfer in the cooling tube, for computational efficiency the computational domain is chosen as shown in Figure 18. The domain length was chosen as $10 \mathrm{~cm}$. This was done to reduce the computing memory requirements due to the high aspect ratio of the physical domain, and the simulation was then repeated for sequential segments of cooling tube with the predicted outlet flow conditions of each segment serving as the inlet conditions for the neighboring downstream segment. Figure 18 shows the geometry of the simulation domain.

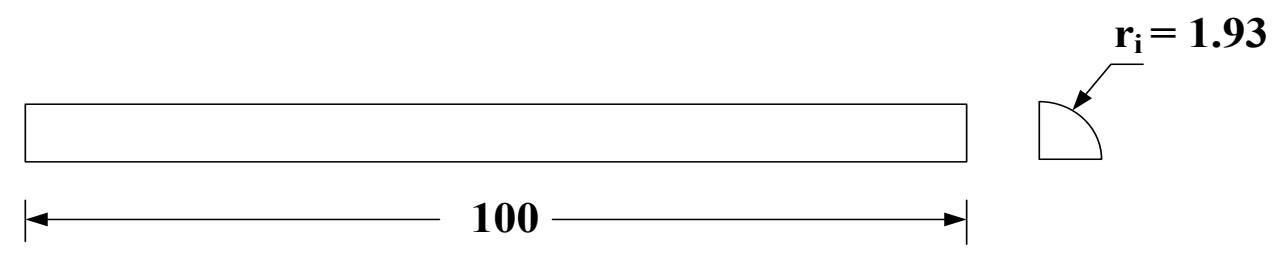

Figure 18: Simulation domain for the convective heat transfer simulation inside the cooling tube (dimension: $\mathrm{mm}$ ) 


\subsection{Governing Equations for the Heat Transfer Simulation}

The governing equations for incompressible flows written in Einstein notation are [22]:

$$
\begin{gathered}
\frac{\partial \rho}{\partial t}+\frac{\partial U_{i}}{\partial x_{i}}=0 \\
\rho \frac{\partial U_{i}}{\partial t}+\rho U_{j} \frac{\partial U_{i}}{\partial x_{j}}=-\frac{\partial P}{\partial x_{i}}+\frac{\partial}{\partial x_{j}}\left(\left(\mu+\mu_{T}\right)\left(\frac{\partial U_{i}}{\partial x_{j}}+\frac{\partial U_{j}}{\partial x_{i}}\right)-\frac{2}{3} \rho K \delta_{j i}\right) \\
\rho \frac{\partial h_{t o t}}{\partial t}-\frac{\partial P}{\partial t}+\rho \frac{\partial}{\partial x_{i}}\left(U_{i} h_{t o t}\right)=\frac{\partial}{\partial x_{i}}\left(k \frac{\partial T}{\partial x_{i}}+\frac{\mu_{T}}{P r_{T}} \frac{\partial h}{\partial x_{i}}\right)+S_{E}
\end{gathered}
$$

where $t$ is the time (s); $x_{j}$ is the spatial coordinate (m); $U_{j}$ is the velocity component of the flow $(\mathrm{m} / \mathrm{s}) ; \rho$ is the fluid density $\left(\mathrm{kg} / \mathrm{m}^{3}\right) ; k$ is the thermal conductivity $\left(\mathrm{W} / \mathrm{m}{ }^{\circ} \mathrm{C}\right) ; P$ is the pressure $(\mathrm{Pa}) ; \mu$ is the molecular viscosity $(\mathrm{Pa} \mathrm{s}) ; \mu_{T}$ is the turbulence viscosity $(\mathrm{Pa}$ $\mathrm{s}) ; K$ is the turbulence kinetic energy $\left(\mathrm{m}^{2} / \mathrm{s}^{2}\right) ; \delta_{j i}$ is the Kronecker delta; $h_{t o t}$ is the total specific enthalpy $(\mathrm{J} / \mathrm{kg}) ; T$ is the temperature $\left({ }^{\circ} \mathrm{C}\right) ; \operatorname{Pr}_{T}$ is the turbulent Prandtl number, which is defined as the ratio of the turbulent momentum diffusivity to the turbulent thermal diffusivity and it is set to 0.9 in ANSYS CFX ${ }^{\circledR} ; h$ is the static enthalpy $(\mathrm{J} / \mathrm{kg})$ and $S_{E}$ is the energy source $\left(\mathrm{W} / \mathrm{m}^{3}\right)$.

A simple correlation for estimating the turbulent Prandtl number for ducted flows is given as [25]:

$$
\operatorname{Pr}_{T}=0.9+\frac{182.4}{\operatorname{Pr} \operatorname{Re}_{d}^{0.888}}
$$


For the range of Reynolds number and Prandtl number for the cooling tube, the turbulent Prandtl number varies between 0.96 and 0.97 , which is deemed sufficiently close to the value set by the simulation software.

Eqn. (39), Eqn. (40) and Eqn. (41) are the continuity, momentum and energy equation, respectively. In these equations, the turbulence is modeled via two parameters: the turbulence viscosity, $\mu_{T}$ and the turbulence kinetic energy, $K$. The introduction of these two parameters creates a closure problem for the given set of governing equations and thus requires more equations to achieve a unique solution. The Shear-StressTransport two-equation turbulence model is chosen for this closure in the present simulations [26]:

$$
\begin{gathered}
\rho \frac{\partial K}{\partial t}+\rho U_{j} \frac{\partial K}{\partial x_{j}}=\mu_{T}\left(\frac{\partial U_{i}}{\partial x_{j}}+\frac{\partial U_{j}}{\partial x_{i}}\right) \frac{\partial U_{i}}{\partial x_{j}}-\rho \beta^{*} \omega K+\frac{\partial}{\partial x_{j}}\left[\left(\mu+\sigma_{k 3} \mu_{T}\right) \frac{\partial K}{\partial x_{j}}\right] \\
\rho \frac{\partial \omega}{\partial t}+\rho U_{j} \frac{\partial \omega}{\partial x_{j}}=\frac{\omega \gamma_{3} \mu_{T}}{k}\left(\frac{\partial U_{i}}{\partial x_{j}}+\frac{\partial U_{j}}{\partial x_{i}}\right) \frac{\partial U_{i}}{\partial x_{j}}-\rho \beta_{3} \omega^{2} \\
+\left(1-F_{1}\right) 2 \rho \sigma_{\omega 2} \frac{1}{\omega} \frac{\partial K}{\partial x_{j}} \frac{\partial \omega}{\partial x_{j}}+\frac{\partial}{\partial x_{j}}\left[\left(\mu+\sigma_{\omega 3} \mu_{T}\right) \frac{\partial K}{\partial x_{j}}\right] \\
\mu_{T}=\frac{\rho a_{1} K}{\max \left(a_{1} \omega, S F_{2}\right)}
\end{gathered}
$$

where $\omega$ is the turbulence frequency $(1 / \mathrm{s})$, related to the turbulence dissipation rate, $\varepsilon$, through:

$$
\omega=\frac{\varepsilon}{K}
$$


$S$ is the vorticity magnitude $(1 / \mathrm{s}) ; \beta$ *and $a_{1}$ are constants with values of 0.09 and 0.31 , respectively. The turbulence model constants $\beta_{3}, \sigma_{k 3}, \sigma_{\omega 3}$ and $\gamma_{3}$ in Eqn. (43) and Eqn. (44) can be evaluated using [26]:

$$
\Phi_{3}=F_{1} \Phi_{1}+\left(1-F_{1}\right) \Phi_{2}
$$

where $\Phi_{3}$ represents the model constant with subscript 3 and the values of the model constants with subscripts 1 and 2 are listed in Table 12 [26].

Table 12: Turbulence model constants for the SST turbulence model

\begin{tabular}{|c|c|c|}
\hline Model constant & $\boldsymbol{n}=\mathbf{1}$ & $\boldsymbol{n}=\mathbf{2}$ \\
\hline$\beta_{n}$ & 0.0750 & 0.0828 \\
\hline$\sigma_{k n}$ & 0.85 & 1 \\
\hline$\sigma_{\omega n}$ & 0.5 & 0.856 \\
\hline
\end{tabular}

$F_{1}$ in Eqn. (47) can be calculated through [26]:

$$
\begin{gathered}
F_{1}=\tanh \left(\arg _{1}^{4}\right) \\
\arg _{1}=\min \left[\max \left(\frac{\sqrt{K}}{0.09 \omega y}, \frac{500 \mu}{\rho y^{2} \omega}\right), \frac{4 \rho \sigma_{\omega 2} K}{C y^{2}}\right] \\
C=\max \left(\frac{2 \rho \sigma_{\omega 2}}{\omega} \frac{\partial K}{\partial x_{j}} \frac{\partial \omega}{\partial x_{j}}, 10^{-20}\right)
\end{gathered}
$$

where $y$ is the distance between the node and the nearest solid boundary in the flow field (m) and $F_{2}$ can be evaluated using [26]:

$$
F_{2}=\tanh \left(\arg _{2}^{4}\right)
$$




$$
\arg _{2}=\max \left(\frac{2 \sqrt{K}}{0.09 \omega y}, \frac{500 \mu}{\rho y^{2} \omega}\right)
$$

\subsection{Boundary Conditions}

The boundary conditions for the simulation are listed in Table 13 with the corresponding locations illustrated in Figure 19.

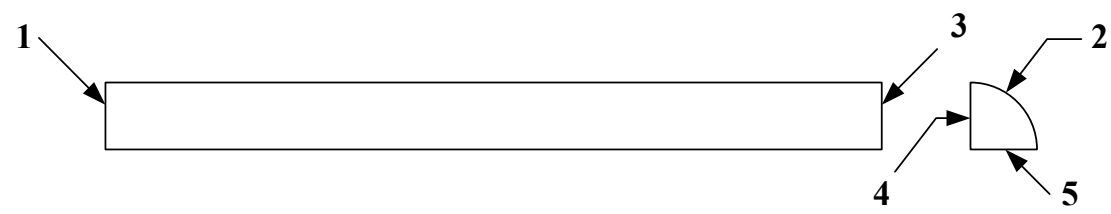

Figure 19: Labeling of the domain boundaries

A top-hat velocity is implemented at the inlet of the simulation domain. Since the water flow enters the cooling tube through a pipe reducer with a nearly sudden contraction, the exact velocity profile at the inlet would be difficult to estimate. Thus, this uniform velocity profile is assumed for the sake of simplicity. The turbulence intensity value chosen here is estimated through the following approach: for a fully developed ducted turbulent flow, turbulence intensity at the core of the flow can be estimated through:

$$
I=0.16 R e_{d}^{-0.125}
$$


Table 13: Boundary conditions for the cooling-tube water flow simulation

\begin{tabular}{|c|c|c|}
\hline Boundary & $\begin{array}{c}\text { For the first } \\
\text { computational tube } \\
\text { segment }\end{array}$ & $\begin{array}{l}\text { For the second and subsequent } \\
\text { computational tube segments }\end{array}$ \\
\hline $\begin{array}{c}1 \\
(\text { inlet })\end{array}$ & $\begin{array}{l}\text { Temperature }(T) \text { : } \\
260^{\circ} \mathrm{C} \text {; } \\
\text { Turbulence intensity: } \\
\text { set to medium }(0.05) \\
\text { Normal flow velocity: } \\
0.349 \mathrm{~m} / \mathrm{s} \text { (obtained } \\
\text { based on the mass } \\
\text { flow rate calculated in } \\
\text { Section } 4.3 .1 .3 \text { ) }\end{array}$ & $\begin{array}{l}\text { Taken from the outlet conditions of } \\
\text { the upstream neighboring } \\
\text { computational tube segment: } \\
\text { - Temperature }(T) \\
\text { - velocity components }\left(U_{j}\right) \\
\text { - Turbulence kinetic energy }(K) \\
\text { - Turbulence frequency }(\omega)\end{array}$ \\
\hline $\begin{array}{c}2 \\
\text { (wall of the } \\
\text { cooling tube) }\end{array}$ & \multicolumn{2}{|c|}{$\begin{array}{l}\text { - No slip; } \\
\text { - Convection heat transfer coefficient, } h_{e q} \text { (see the } \\
\text { explanation following this table) } \\
\text { - Turbulence kinetic energy: } K=0 \\
\text { - Turbulence frequency: calculated internally by ANSYS } \\
\mathrm{CFX}^{\circledR} \text { via } \frac{6 \mathrm{v}}{0.075(\Delta y)^{2}} \text { and } \Delta y \text { being the distance } \\
\text { between the first and second nodes from the internal } \\
\text { wall of the tube }\end{array}$} \\
\hline $\begin{array}{c}3 \\
\text { (outlet) }\end{array}$ & \multicolumn{2}{|c|}{$\begin{array}{l}\text { Average relative pressure: } 0 \mathrm{~Pa} \\
\text { (relative to the system pressure set to } 23 \mathrm{MPa} \text { ) }\end{array}$} \\
\hline $\begin{array}{c}4 \& 5 \\
\text { (symmetry plane) }\end{array}$ & \multicolumn{2}{|c|}{ Property gradients normal to the boundary set to zero } \\
\hline
\end{tabular}

Given that at the inlet of the cooling tube the Reynolds number is $10^{4}$, the resultant turbulence intensity is found to be 0.05 . In addition, for use as the inlet boundary conditions of the computational tube segment after the first one, the outlet fluid temperature, $T$, the velocity components, $U_{j}$, the turbulence kinetic energy, $k$ and the turbulence frequency, $\omega$, at each of the nodes on the outlet surface of the simulation 
domain are exported into a data file along with the coordinates of these nodes. The data file is then imported into the successive simulation and applied as the inlet flow condition. For the heat transfer boundary condition at the wall of the computational domain, as the heat transfer simulation here only simulates the internal flow, the heat conduction through the wall and the external convective heat transfer (i.e. between the ambient and the outside surface of the finned-cooling tube) are not physically included in the computation. However, to ensure that the simulation results can accurately reflect the physics of heat transfer for the finned cooling tube, the effects of these two parts of heat transfer must not be neglected. This can be achieved by transforming the thermal resistance of these two parts of the heat transfer into a dummy equivalent convection heat transfer coefficient, $h_{e q}$, and apply this convection heat transfer coefficient to the wall of the computational domain. Figure 20 illustrates how the thermal resistances are combined. Based on this illustration, the equivalent convection heat transfer coefficient, $h_{e q}$, can be calculated via:

$$
R_{e q}=\frac{1}{h_{e q} A_{i}}
$$

where $R_{e q}$ is the combined thermal resistance as illustrated in Figure $20\left({ }^{\circ} \mathrm{C} / \mathrm{W}\right) ; h_{e q}$ is the dummy equivalent convection heat transfer coefficient $\left(\mathrm{W} / \mathrm{m}^{2}{ }^{\circ} \mathrm{C}\right) ; A_{i}$ is the surface area of the internal wall $\left(\mathrm{m}^{2}\right)$. 


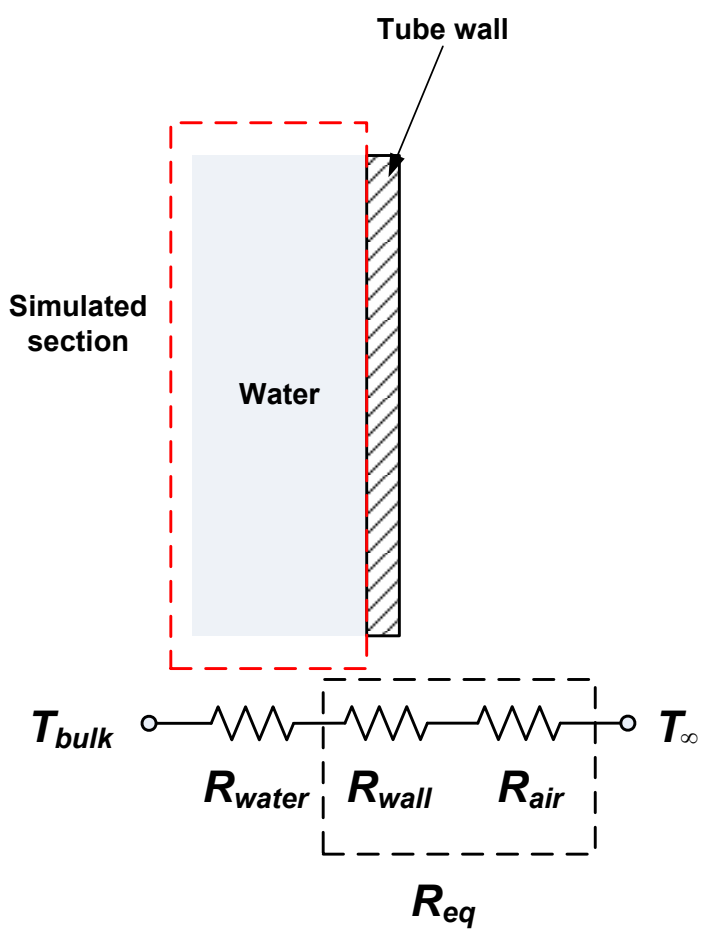

Figure 20: The combined thermal resistance for heat conduction through the wall and convective heat transfer between the ambient and the external wall of the tube

The thermal resistance of the wall of the cooling tube is easy to calculate. However, for the thermal resistance between the external surface of the cooling tube and the ambient, as discussed in Case 3 of Section 4.3.1.3, the fin part and the bare tube part each has a different convection heat transfer coefficient, namely $h_{\text {air }}$ and $\varepsilon_{f} h_{\text {air }}$, which would result in an alternating $h_{e q}$ on the surface of the wall of the computational domain. It is not convenient to generate this boundary condition. To circumvent this problem, consider the element shown in Figure 17, the average convection heat transfer coefficient can be calculated via:

$$
R_{\text {element }}=\left(\frac{1}{R_{\text {fin }}}+\frac{1}{R_{\text {bare }}}\right)^{-1}=\frac{1}{h_{e q} A_{i}}+\frac{1}{h_{\text {water }} A_{i}}
$$


where $R_{\text {element }}$ is the overall thermal resistance of the finned cooling tube element $\left({ }^{\circ} \mathrm{C} / \mathrm{W}\right)$; $R_{\text {bare }}$ and $R_{\text {fin }}$ are the thermal resistances of the bare tube section and finned section, respectively $\left({ }^{\circ} \mathrm{C} / \mathrm{W}\right)$ and $A_{i}$ is the internal surface area of the finned cooling tube element $\left(\mathrm{m}^{2}\right)$. Thus, $h_{e q}$ evaluated using Eqn. (55) becomes dependent only on the temperature.

\subsection{Spatial Mesh}

The mesh mapped onto the computational domain is shown in Figure 21.

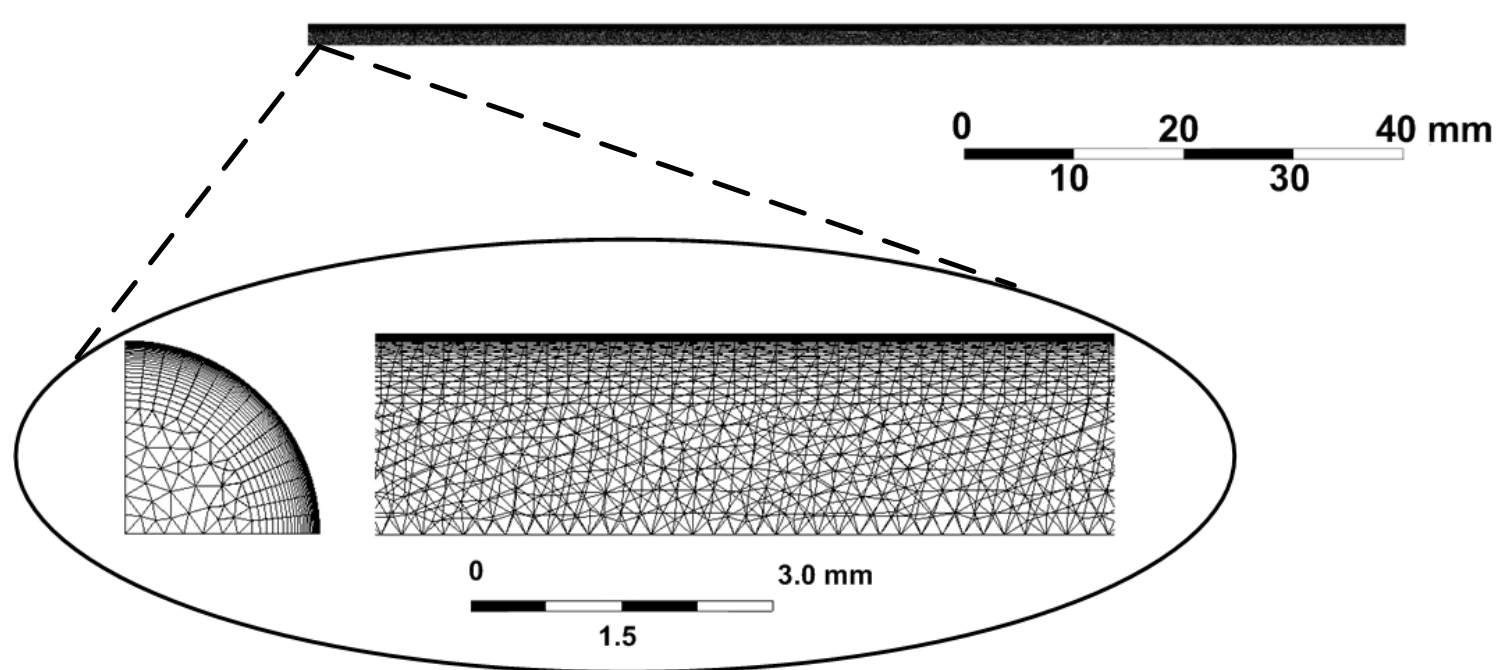

Figure 21: Mesh for convection heat transfer simulation

As shown in this figure, a hybrid mesh is used. The structured mesh is concentrated in the region near the wall of the tube to resolve large spatial gradients of velocity and temperature (normal to the tube wall), and unstructured tetrahedral mesh is implemented in regions farther away from the wall. The structured mesh is created using the "inflation layer" function provided in ANSYS CFX ${ }^{\circledR}$. Basically, the software "inflates" a two dimensional triangle into a three dimensional prism in the direction normal to the surface of the tube to create an element in an inflation layer. By implementing the inflation layers, 
the number of elements required to resolve the flow field is reduced while maintaining the quality of the mesh elements and thus the accuracy of the simulation near the cooling tube wall.

The resultant mesh has a total of 604,386 elements. The maximum edge length of the tetrahedral mesh is constrained to a value of $0.4 \mathrm{~mm}$, which is $20 \%$ of the internal radius of the tube. The first element of the structured mesh applied to the tube wall has a height of $5 \times 10^{-6} \mathrm{~m}$ such that the boundary layer of the turbulent tube flow can be properly resolved. A total of 25 inflation layers are applied in the vicinity of the wall. The justification for this mesh specification will be given in Section 4.3.1.4.6, where a benchmark simulation will be presented.

\subsection{Solution Methods}

The same element-based finite volume method described in Section 4.3.1.2.3 is used to solve the set of governing equations for the simulation of the flow field by ANSYS CFX ${ }^{\circledR}$. By integrating the governing equations over the control volume, they can be expressed as [22]:

$$
\begin{gathered}
\frac{\partial}{\partial t} \int_{V} \rho d V+\sum_{i p} \dot{m}_{i p}=0 \\
\frac{\partial}{\partial t} \int_{V} \rho U_{i} d V+\sum_{i p}\left(\dot{m}_{i p} U_{i}\right)_{i p} \\
=-\sum_{i p}\left(P_{i p} \Delta n_{i}\right)_{i p}+\sum_{i p}\left(\mu+\mu_{T}\right)\left(\frac{\partial U_{i}}{\partial x_{j}}+\frac{\partial U_{j}}{\partial x_{i}}\right) \Delta n_{j}+\sum_{i p}\left(\frac{2}{3} \rho K \delta_{j i}\right) \Delta n_{j}
\end{gathered}
$$




$$
\begin{gathered}
\frac{\partial}{\partial t} \int_{V} \rho h_{t o t} d V+\frac{\partial}{\partial t} \int_{V} P d V+\sum_{i p}\left(\dot{m}_{i p} h_{t o t}\right)_{i p} \\
=-\sum_{i p}\left(\left(k \frac{\partial T}{\partial x_{i}}+\frac{\mu_{T}}{P r_{T}} \frac{\partial h}{\partial x_{i}}\right) \Delta n_{i}\right)_{i p}+\int_{V} S_{E} d V \\
\frac{\partial}{\partial t} \int_{V} \rho K d V+\sum_{i p}\left(\dot{m}_{i p} K\right)_{i p} \\
=\sum_{i p}\left(\mu_{T}\right)\left(\frac{\partial U_{i}}{\partial x_{j}}+\frac{\partial U_{j}}{\partial x_{i}}\right)_{\Delta n_{j}}-\int_{V} \rho \beta^{*} \omega K d V+\sum_{i p}\left(\mu+\sigma_{k 3} \mu_{T}\right)\left(\frac{\partial K}{\partial x_{j}}\right) \Delta n_{j} \\
\frac{\partial}{\partial t} \int_{V} \rho \omega d V+\sum_{i p}\left(\dot{m}_{i p} \omega\right)_{i p}=\sum_{i p}\left(\frac{\omega \gamma_{3} \mu_{T}}{k}\right) U_{i}\left(\frac{\partial U_{i}}{\partial x_{j}}+\frac{\partial U_{j}}{\partial x_{i}}\right) \Delta n_{j}-\int_{V} \rho \beta_{3} \omega^{2} d V \\
+\int_{V}\left(1-F_{1}\right) 2 \rho \sigma_{\omega 2} \frac{1}{\omega} \frac{\partial K}{\partial x_{j}} \frac{\partial \omega}{\partial x_{j}} d V+\sum_{i p}\left(\mu+\sigma_{\omega 3} \mu_{T}\right) \frac{\partial K}{\partial x_{j}} \Delta n_{j}
\end{gathered}
$$

where $V$ is the control volume around the mesh node $\left(\mathrm{m}^{3}\right)$.

Discretization of the diffusion and transient terms has already being discussed in Section 4.3.1.2.3. Again, in this case, an automatic time scale is implemented by the ANSYS CFX ${ }^{\circledR}$ to march the solution toward steady state. In addition to these two terms, the advection term in Eqn. (57) through (60) also needs to be discretized. This is done via a High Resolution Scheme, under which ANSYS CFX ${ }^{\circledR}$ attempts to apply a blended scheme weighted between the Second Order Backward scheme and the First Order Backward Schemes in the computational domain [22]. The reason for employing such a blended scheme is because, while the second order scheme has an advantage in the accuracy of the solution, the first order scheme is numerically more stable. Thus, to balance the numerical stability and accuracy of the simulation results, this blended scheme is implemented. 
Again, applying the finite volume method to all the elements in the domain, the governing equations can be expressed in the form of Eqn. (24) by replacing $T$ with the relevant variables (using the generic variable $\phi$ for the purpose of discussion here). In particular, for the continuity and momentum equation, the three equations are coupled to solve the velocity and pressure field in the computational domain [22]. In this particular case, the coefficient, $a$, in Eqn. (24) becomes a $4 \times 4$ matrix; the solution, $\phi$, is a $4 \times 1$ matrix which contains the three velocity components and the pressure. The algorithm used to solve the linear systems of equations in this case is similar to that described in Section 4.3.1.2.3, except that more variables and equations are involved. The major difference is that in this case, the inner loop must first solves the coupled continuitymomentum equation set by using a W-type algebraic multi-grid algorithm and then use the obtained flow field to solve the set of transport equation for scalar variables (equations for energy and turbulence quantities). In this case, since the boundary layer of a turbulent internal flow was simulated, a stricter numerical residual criterion, $1 \times 10^{-5}$ was used [22]. In general, it takes around 100 outer loop iterations to reach convergence and since this is a steady state simulation, one inner loop iteration is performed per outer loop iteration [22]. The false time step is updated for every five outer loop iterations [22].

\subsection{Benchmark Simulation}

As described earlier, the simulation of the water flow in the cooling tube is performed in segments. At the start of these simulations, a spatial mesh was sought that would produce mesh-independent computational results for all computational segments of the cooling tube. This mesh was identified through a benchmark simulation described in this section. 
The selected Reynolds number for the benchmark simulations is 5500, because this Reynolds number is close to the arithmetic average of the maximum and minimum Reynolds number values expected for the cooling-tube water flow and direct numerical simulation (DNS) results are available in the published literature at this Reynolds number for fully-developed turbulent pipe flow [27, 28].

The total length of the computational domain for the benchmark simulation has to be sufficient to enable the simulated flow to become fully developed for comparison with results available in the literature. Eqn. (61) and Eqn. (62) give the momentum and thermal entry length for ducted turbulent flows [4, 29]:

$$
\begin{gathered}
\frac{L_{e}}{d}=4.4 R e_{d}^{1 / 6} \\
\frac{L_{e, t h}}{d}=10
\end{gathered}
$$

where $L_{e}$ is the hydrodynamic entry length $(\mathrm{m}) ; d$ is the internal diameter of the cooling tube $(\mathrm{m}) ; L_{e, t h}$ is the thermal entry length (m).

For a circular duct diameter of $0.00386 \mathrm{~m}$, the resultant hydrodynamic and thermal entry lengths are $0.0714 \mathrm{~m}$ and $0.0386 \mathrm{~m}$, respectively. Using the calculated hydrodynamic and thermal entry lengths, the total length of the benchmark simulation domain is chosen to be $0.09 \mathrm{~m}$. It has the same cross-sectional geometry as that for the heat transfer simulation for the discharged water flow as shown in Figure 18. The fluid chosen for the benchmark simulation is air at $25^{\circ} \mathrm{C}$ under atmospheric pressure transferring heat to the tube wall maintained at $15^{\circ} \mathrm{C}$.

Due to the expected large variation of temperature and velocity near the wall for turbulent pipe flows, a large amount of mesh elements must be placed within this region 
to resolve these gradients. For the selected turbulence model, a recommended distance, $y_{1}$ between the first node from the wall and the internal tube wall corresponds to a $y+$ close to 1 , where $\mathrm{y}+$ is the normalized wall coordinate, defined as:

$$
y^{+}=\frac{y_{1} \rho}{\mu} \sqrt{\frac{\tau_{\text {wall }}}{\rho}}
$$

where $\rho$ is the local fluid density $\left(\mathrm{kg} / \mathrm{m}^{3}\right) ; \mu$ is the local molecular viscosity (Pa $\mathrm{s}$ ) and $\tau_{\text {wall }}$ is the wall shear stress $(\mathrm{Pa})$, defined as:

$$
\tau_{\text {wall }}=\mu\left(\frac{\partial U}{\partial y}\right)_{y=0}
$$

where $U$ is the flow velocity along the axis of the tube $(\mathrm{m} / \mathrm{s})$ and $y$ is the normal distance in the flow field measured from the wall surface (m).

Based on the definition for $\mathrm{y}^{+}$, the distance of the first node from the wall for the benchmark simulation must be close to $9.6 \times 10^{-6} \mathrm{~m}$. Using this wall distance, three types of mesh were generated. All of them are hybrid meshes consisting of tetrahedral elements and inflated prism elements. Details about the three meshes are tabulated in Table 14, and Figure 22 shows the highest resolution mesh, which is Case 3.

Table 14: Statistics of the mesh for the three cases of the benchmark simulation

\begin{tabular}{|l|c|c|c|}
\hline & Case 1 & Case 2 & Case 3 \\
\hline Maximum element edge length (mm) & 0.63 & 0.50 & 0.4 \\
\hline Number of elements & 110,419 & 281,686 & 554,224 \\
\hline $\begin{array}{l}\text { Number of inflation layers near the } \\
\text { wall }\end{array}$ & 10 & 20 & 25 \\
\hline $\begin{array}{l}\text { Distance of the first node from the wall } \\
\text { (m) }\end{array}$ & $2 \times 10^{-5}$ & $1 \times 10^{-5}$ & $5 \times 10^{-6}$ \\
\hline
\end{tabular}




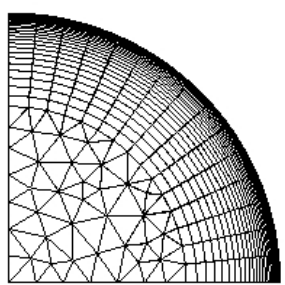

Case 3

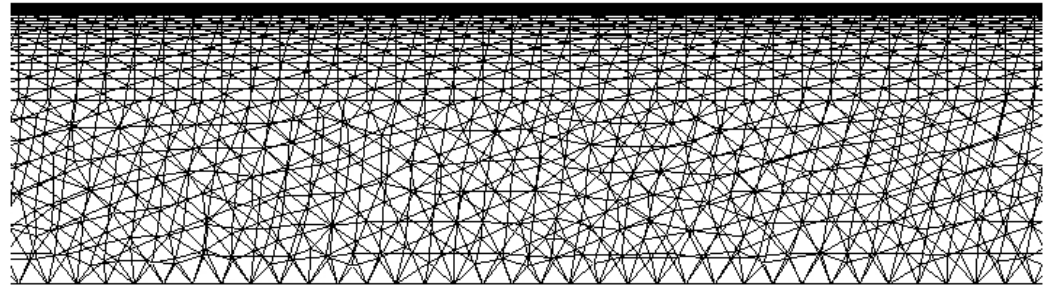

$3.0 \mathrm{~mm}$

1.5

Figure 22: A view of the mesh for Case 3 for a small section of the simulation domain used for the benchmark simulation

The boundary conditions and some important parameters for the benchmark simulations are listed in Table 15.

Table 15: Boundary conditions for the benchmark simulation

\begin{tabular}{|c|c|c|}
\hline \multirow{3}{*}{ Inlet } & Air flow velocity $(\mathrm{m} / \mathrm{s})$ & $\begin{array}{c}24.16 \\
\text { (uniform) }\end{array}$ \\
\hline & Temperature $\left({ }^{\circ} \mathrm{C}\right)$ & 25 \\
\hline & Turbulence intensity & $\begin{array}{c}\text { Medium } \\
(0.05)\end{array}$ \\
\hline Outlet & Average pressure (atm) & 1 \\
\hline \multirow[b]{3}{*}{ Wall } & Temperature $\left({ }^{\circ} \mathrm{C}\right)$ & 15 \\
\hline & Turbulence kinetic energy $\left(\mathrm{m}^{2} / \mathrm{s}^{2}\right)$ & 0 \\
\hline & \multicolumn{2}{|c|}{$\begin{array}{l}\text { - No slip; } \\
\text { - Turbulence frequency: calculated via } \frac{6 v}{0.075(y)^{2}} \\
\text { and } y \text {, in this case, being the distance between } \\
\text { the first and second nodes from the internal wall } \\
\text { of the tube }\end{array}$} \\
\hline
\end{tabular}

The resulting velocity profile at the outlet of the simulation domain is shown in Figure 23. In this figure, the local flow velocity is expressed in a normalized form: 


$$
U^{+}=U / \sqrt{\frac{\tau_{\text {wall }}}{\rho}}
$$

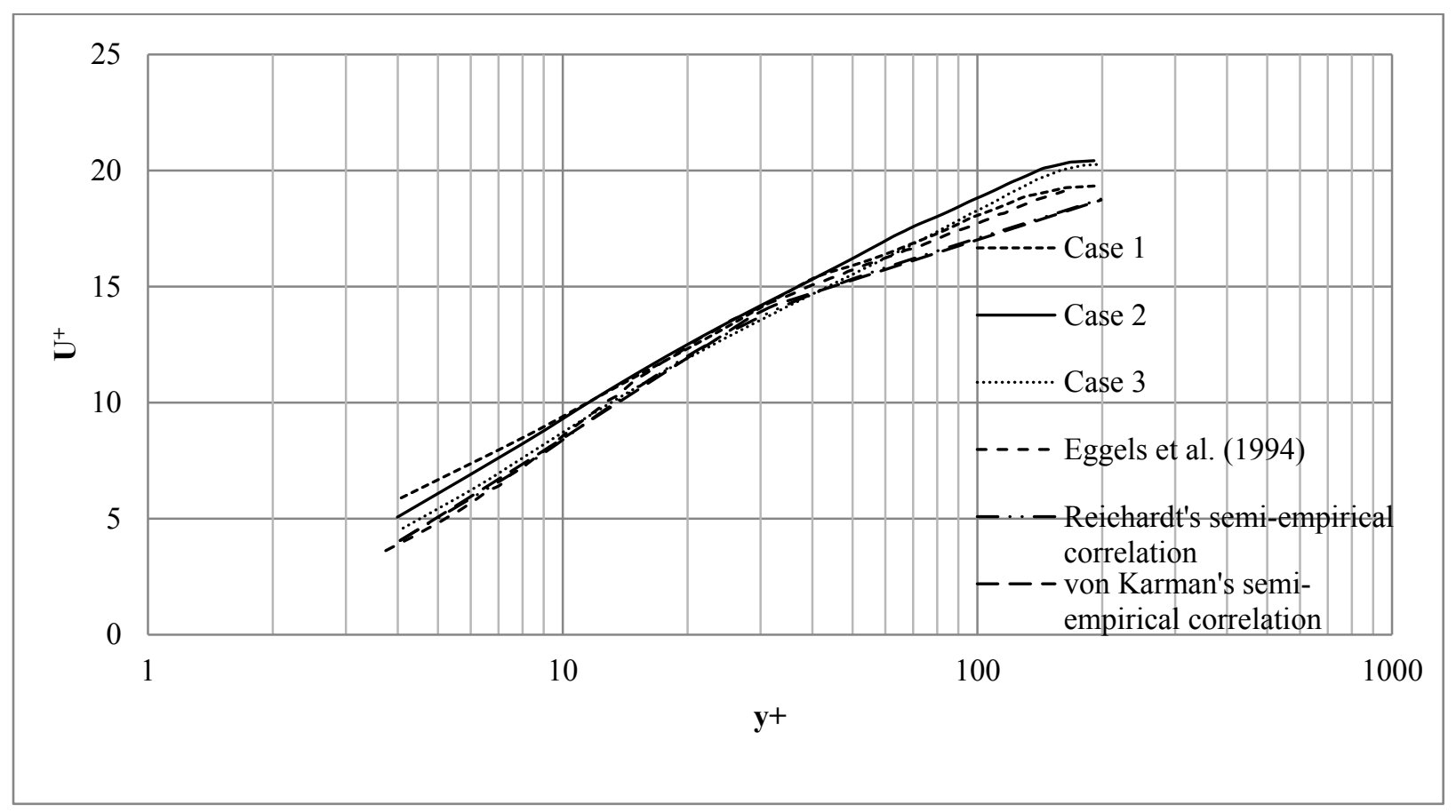

Figure 23: Comparison of benchmark simulation streamwise-velocity profile with semi-empirical and DNS results [27, 29]

The Reichardt's and von Karman's semi-empirical correlations for the turbulent velocity profile are found in a text by Kakac et al. (1987) [29]. The DNS results were produced by Eggels et al. (1994) [27]. The DNS was performed for a ducted incompressible air flow at a Reynolds number of 5300 without heat transfer [27]. As shown in Figure 23, both the benchmark simulation results and the DNS results produced by Eggels et al. (1994) are consistent with the predictions made by the correlations within the near wall region (i.e. $y^{+}$up to about 40). However, near the centerline of the pipe, the DNS and benchmark simulation results show a higher velocity compared to the velocity predicted by the correlations. This discrepancy may be caused by the fact that the 
Reynolds number of the simulated flow is very close to the critical Reynolds number, while Reichardt's and von Karman's semi-empirical correlations were developed based on the assumptions that the ducted flow is completely turbulent [27].

The predicted temperature field is compared to DNS results of Kawamura et al. (1998) in Figure 24 [28]:

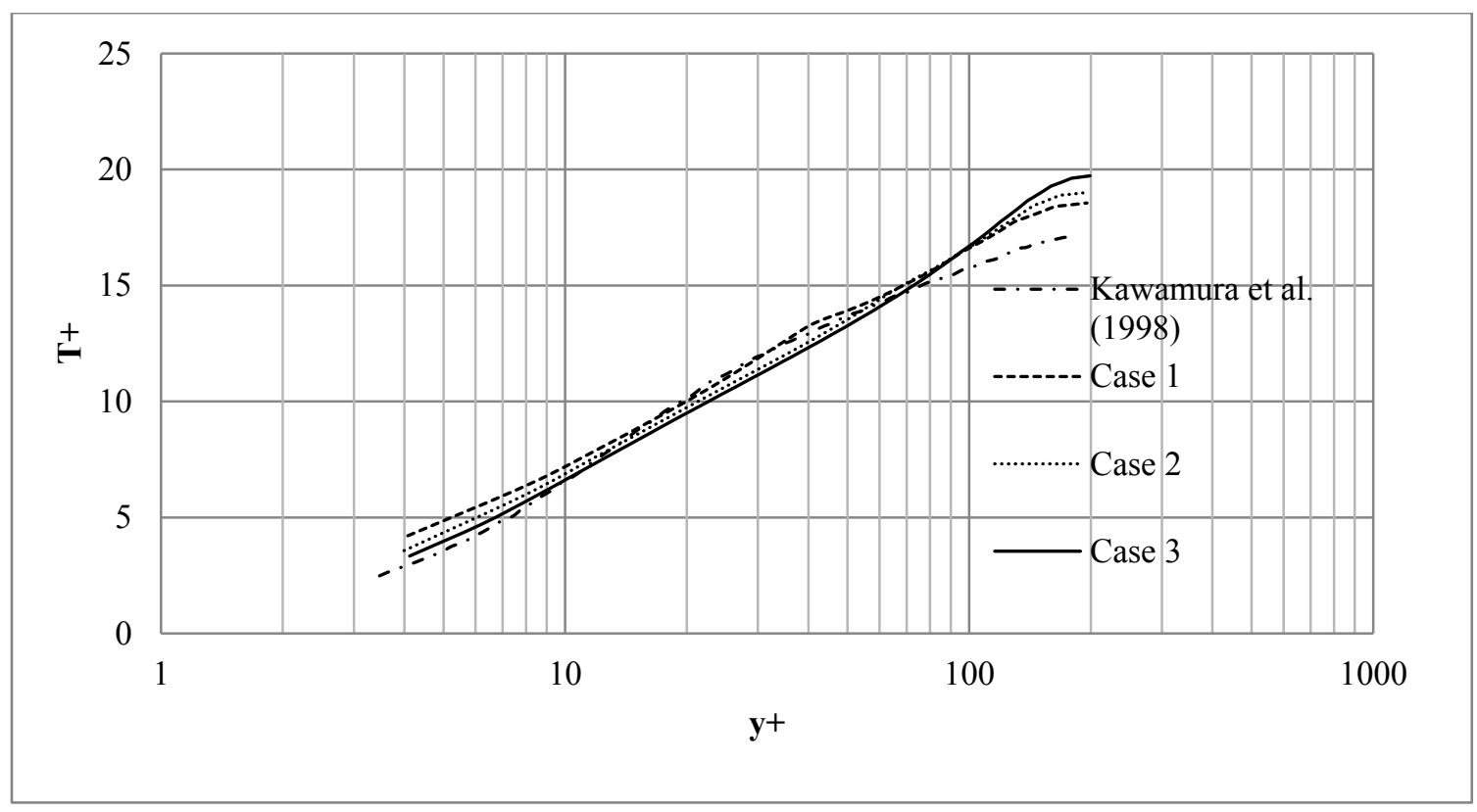

Figure 24: Comparison of benchmark simulation temperature profile results with the DNS results of Kawamura et al. (1998) [28]

In Figure 24, the local fluid temperature is expressed in a normalized form:

$$
T^{+}=\frac{T-T_{\text {wall }}}{\dot{Q}^{\prime \prime} / \rho c_{p}} \sqrt{\frac{\tau_{\text {wall }}}{\rho}}
$$

where $T$ is the local fluid temperature $\left({ }^{\circ} \mathrm{C}\right) ; \dot{Q}^{\prime \prime}$ is the wall heat flux $\left(\mathrm{W} / \mathrm{m}^{2}\right)$ and $c_{p}$ is the local specific heat at constant pressure $\left(\mathrm{J} / \mathrm{kg}{ }^{\circ} \mathrm{C}\right)$.

In Eqn. (66), the wall shear stress and the wall heat flux are obtained as part of the solution. The temperature profile obtained from the benchmark simulation is observed to 
be consistent with the DNS results though most portion of the tube, while in the core region of the tube, the temperature predicted by the benchmark simulation is slightly higher than that predicted by the DNS results. The discrepancy may be caused by the fact that the DNS results presented here are obtained based on a simulation with fully developed velocity profile throughout the simulation domain while the benchmark simulation here is simulating a ducted flow of simultaneously (both thermally and hydrodynamically) developing flow.

From Figure 23 and Figure 24, it is identified that over the majority portion of the tube crosssection, simulation results obtained in Case 3 are more consistent with the results produced by the DNS than the other two cases. Thus, the mesh specification used in Case 3 is used for the convective heat transfer simulation of the cooling tube water flow.

\subsection{Simulation Results for the Water Flow in the Cooling Tube}

Using the computational mesh identified in Case 3 of the benchmark simulations, the computations for a sufficient number of segments of the cooling tube were performed as outlined in Section 4.3.1.4.1 until the fluid bulk temperature was reduced to $93^{\circ} \mathrm{C}$. Figure 25 shows how much the Nusselt number obtained from the simulation deviates from an empirical Nusselt number correlation (Eqn. (28)) which has an uncertainty of $+/$ $10 \%$. Each of the computational data points in this figure is obtained based on the simulation results at the outlet of each of the simulated tube segment. From this figure, it appears that the Nusselt number starts to deviate from the predictions of the empirical correlation at Reynolds number values below 6000 . This inconsistency may be caused by the currently employed turbulence model: overly predicting the level of turbulence in a 
flow with a Reynolds number close to the critical Reynolds number for ducted flow (i.e. $\left.R e_{d}=2500\right)$ can lead to an over-prediction in the convective heat transfer coefficient.

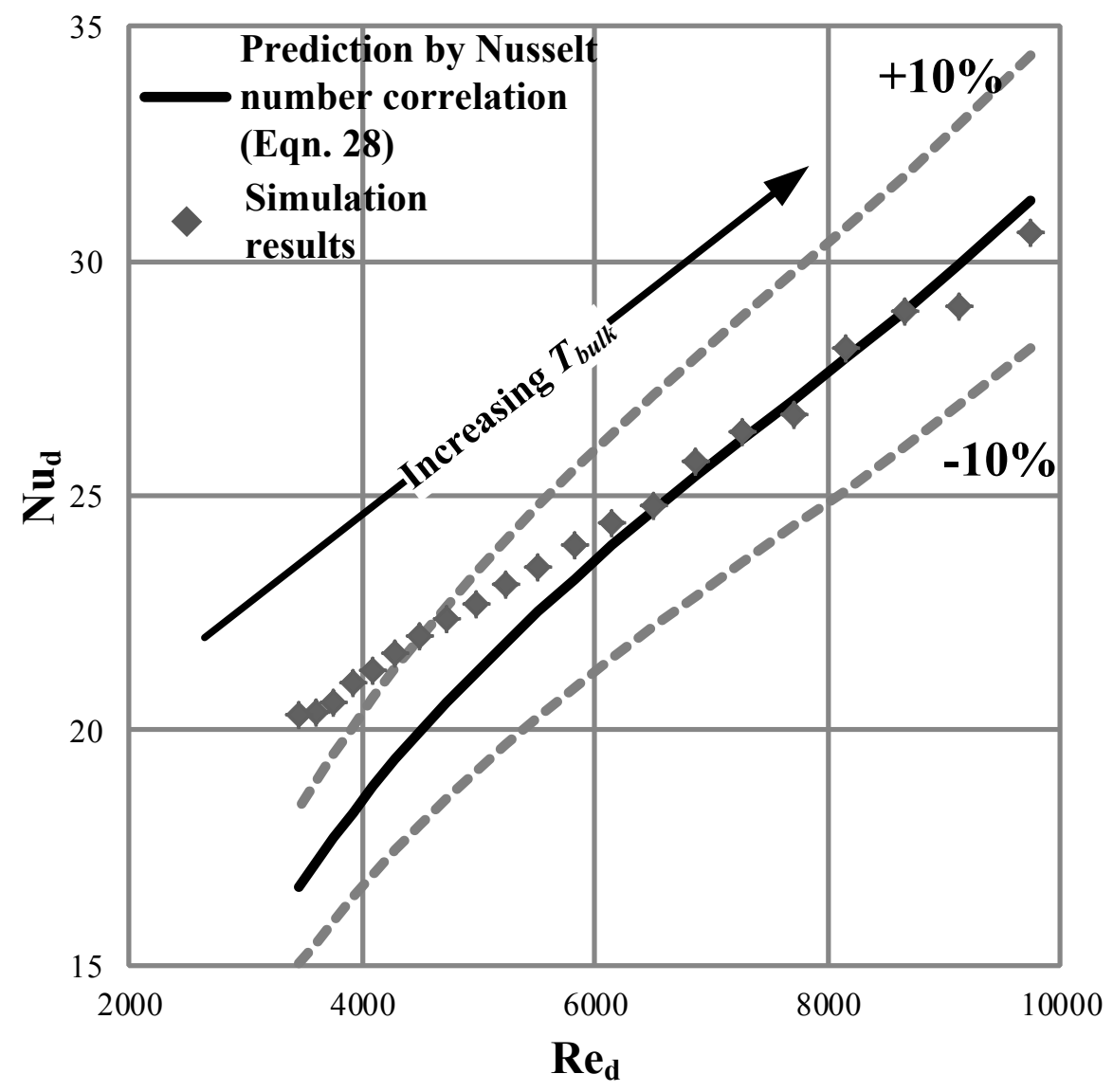

Figure 25: Comparison of the Nusselt numbers obtained from the simulation results and those from an empirical Nusselt number correlation (Eqn. (28)) 


\subsubsection{Discussion on the Selected Cooling Tube}

Table 16 summarizes the results of the heat transfer analysis for the cooling tube.

Table 16: Summary of the results on the sizing for required length of cooling tube

\begin{tabular}{|l|l|c|}
\hline \multicolumn{1}{|c|}{ Operating conditions } & \multicolumn{1}{|c|}{ Cooling method } & Length (m) \\
\hline Steady operation & $\begin{array}{l}\text { Plain tube with natural } \\
\text { convection }\end{array}$ & 0.08 \\
\hline \multirow{5}{*}{ Transient operation } & $\begin{array}{l}\text { Plain tube with natural } \\
\text { convection on exterior }\end{array}$ & $>>10$ \\
\cline { 2 - 3 } & $\begin{array}{l}\text { Plain tube with high speed } \\
\text { cooling fans }\end{array}$ & 8.7 \\
\cline { 2 - 3 } & $\begin{array}{l}\text { Finned tube with high speed } \\
\text { cooling fans }\end{array}$ & 2 \\
\hline
\end{tabular}

As seen in this table, the transient operation of the C-SCW Loop imposes a more demanding requirement on the length of cooling tube than the steady operation does. Therefore, the length of the cooling tube is decided based on the results obtained for transient operation. The solution presented in the third case for the transient loop operation would result in the shortest cooling tube length required to cool the discharged water flow $260^{\circ} \mathrm{C}$ to $93^{\circ} \mathrm{C}$ while the other two solutions would require substantially longer length to achieve the same effect. Therefore, the third method is chosen as the final solution.

Since the minimum required length of the tube is $2 \mathrm{~m}$, a longer finned cooling tube should be utilized to ensure that the water entering accumulator is conservatively below the maximum rated temperature of the accumulator. A similar heat transfer calculation taking the approach described in Case 3 of Section 4.3.1.3 shows that after passing $2.8 \mathrm{~m}$ of finned cooling tube chosen here, the bulk temperature of the discharged 
water flow would be $73^{\circ} \mathrm{C}$, which establishes a $20^{\circ} \mathrm{C}$ safety margin. The final cooling tube specification is shown in Table 17.

Table 17: Summary of the specifications for the finned cooling tube

\begin{tabular}{|l|c|}
\hline Type of fin material & Copper \\
\hline Type of tube material & Stainless steel 316 ASTM A312 \\
\hline Total length of finned cooling tube (m) & 2.8 \\
\hline Fin density (fins/inch of cooling tube) & 18 \\
\hline Outer diameter of the circular fin $(\mathbf{m m})$ & 6.35 \\
\hline Tube diameter $(\mathbf{m m})$ & 1.24 \\
\hline Tube wall thickness $(\mathbf{m m})$ & \\
\hline
\end{tabular}

It is worth noting that the fan speed is estimated through the volume flow rate claimed by the manufacturer. The volume flow rate is obtained by measuring the air speed at $0.05 \mathrm{~m}(2 \mathrm{inch})$ downstream of the fan outlet. Since some part of the cooling tube will be away from the outlet of the fan by some distance beyond $0.05 \mathrm{~m}$, the exact air flow speed should be tested at these offset distances to ensure that the actual speed of air matches the value used here. 


\section{Instrumentation, Data Acquisition System (DAQ) and Virtual \\ Control Panel Design}

Various sensors are installed on the C-R134a Loop and the C-SCW Loop to monitor the test loops' operating conditions and collect experimental data. A data acquisition (DAQ) system is developed to collect these sensor signals and to enable the operator to control and monitor the C-R134a Loop and C-SCW Loop through a computer workstation. A virtual control panel is created on the computer to allow the operator to control and monitor the test loop in real time. The following sections give the details of the design of the DAQ system and the virtual control panel.

\subsection{Sensors}

The layouts of the sensors installed on the C-R134a Loop and the C-SCW Loop are shown in Figure 26 and Figure 27, respectively.

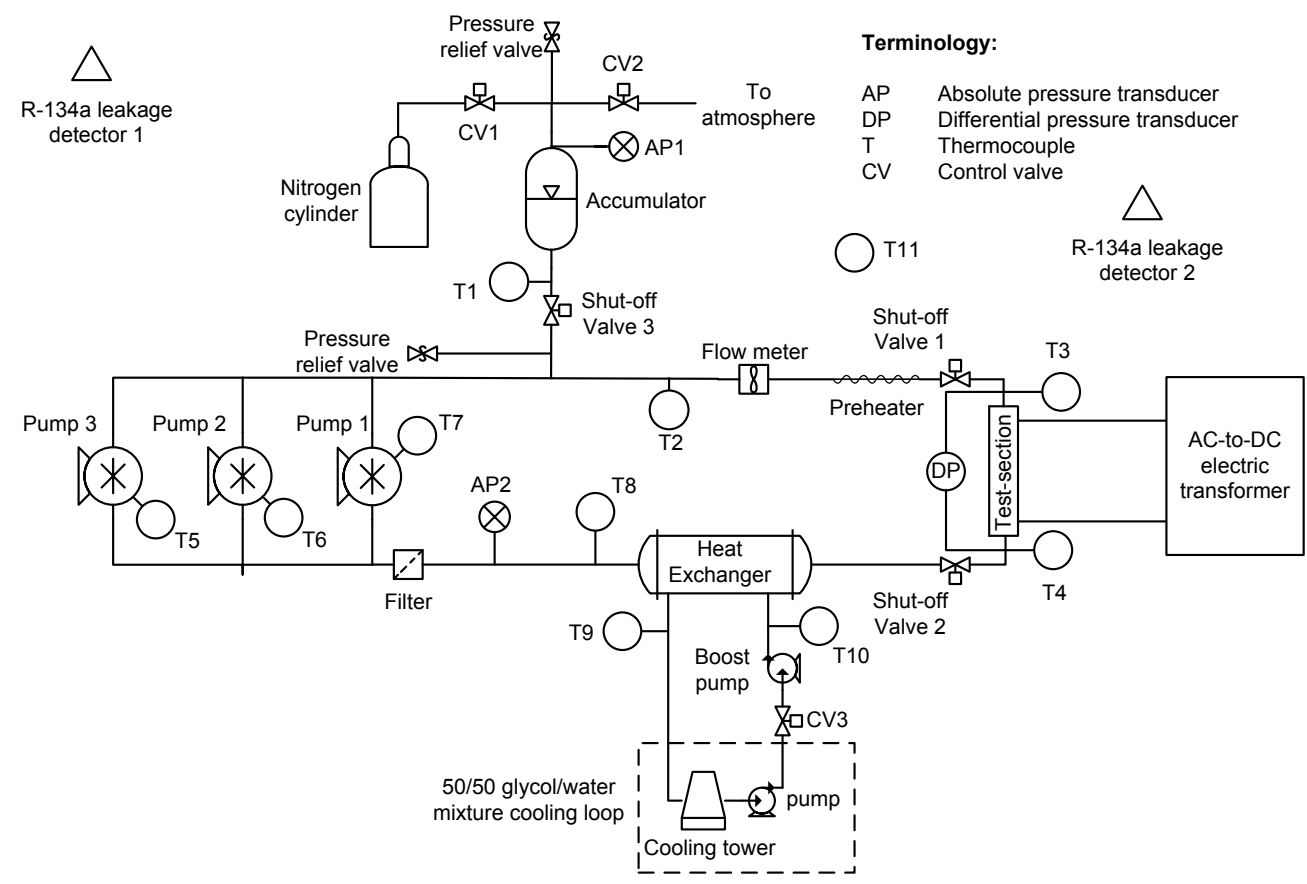

Figure 26: Sensor layout for the C-R134a Loop 


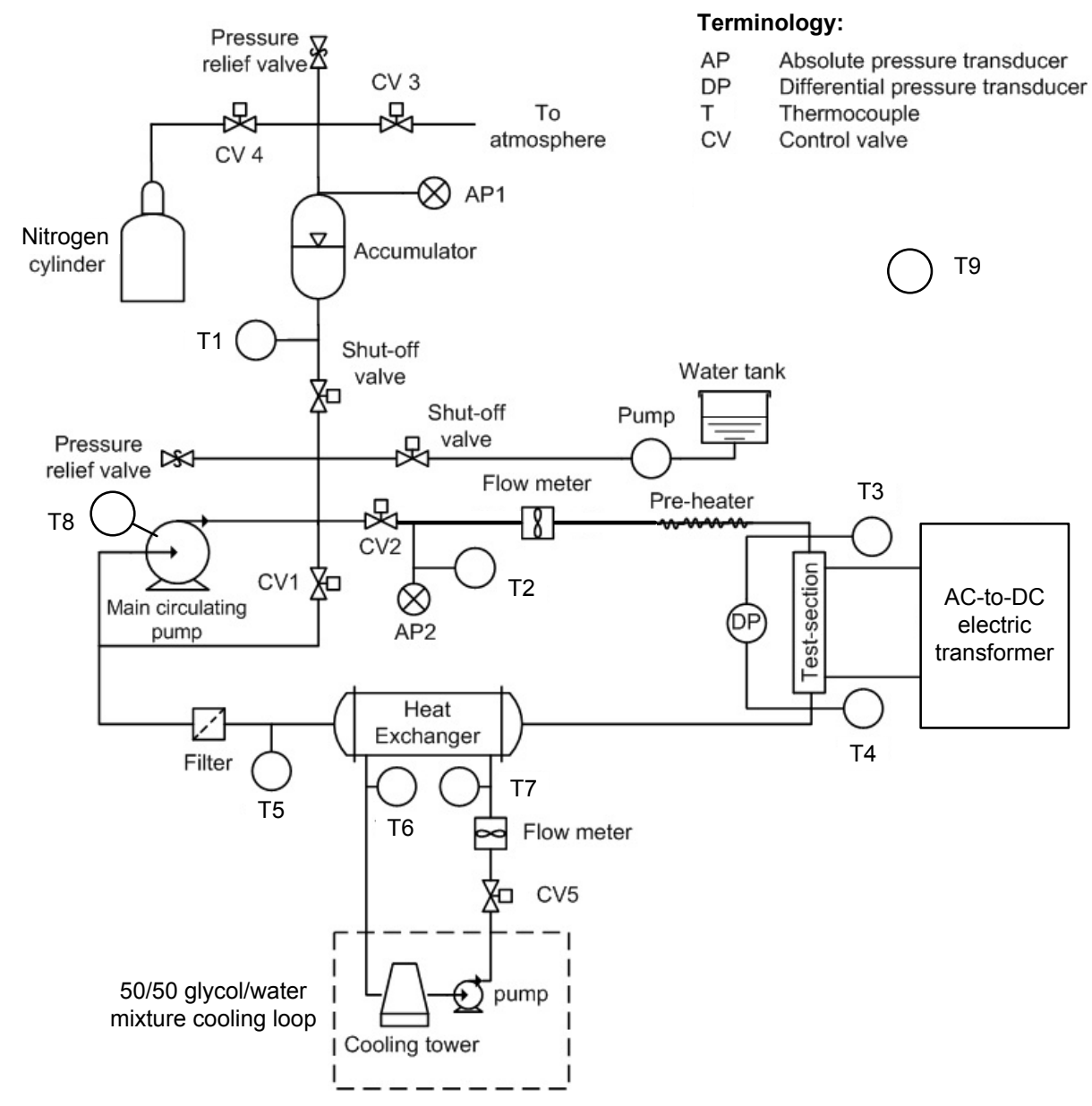

Figure 27: Sensor layout for the C-SCW Loop

There are mainly three types of sensors installed on both experimental loops: pressure transducers, thermocouples and flow meters. For the C-R134a Loop, in addition to these three types of sensors, two refrigerant (R-134a) leakage detectors are installed. The pressure transducers (differential pressure transducers and absolute pressure transducers) and flow meters were selected by a member of the author's research group and details about these sensors can be found in a contract progress report published by the author's research group [30]. A summary of specifications for these sensors is provided in Table 18. The selection of temperature sensors is discussed next. 
Table 18: Number of sensors and their signal types [31 - 37]

\begin{tabular}{|c|c|c|c|c|}
\hline $\begin{array}{c}\text { Type of } \\
\text { sensor/device }\end{array}$ & Range & $\begin{array}{c}\text { Quantity } \\
\text { of sensors }\end{array}$ & $\begin{array}{c}\text { Excitation } \\
\text { voltage }\end{array}$ & $\begin{array}{c}\text { Signal range } \\
\text { (V) }\end{array}$ \\
\hline $\begin{array}{l}\text { Absolute } \\
\text { pressure } \\
\text { transducers }\end{array}$ & $\begin{array}{c}0-27.6 \mathrm{MPa} \\
(\mathrm{C}-\mathrm{SCW}) \\
0.1-10.2 \mathrm{MPa} \\
(\mathrm{C}-\mathrm{R} 134 \mathrm{a}) \\
\end{array}$ & 2 & $\begin{array}{c}6-14 \text { V DC } \\
(\mathrm{C}-\mathrm{SCW}) \\
14-30 \mathrm{~V} \mathrm{DC} \\
(\mathrm{C}-\mathrm{R} 134 \mathrm{a}) \\
\end{array}$ & $1-5$ \\
\hline $\begin{array}{l}\text { Differential } \\
\text { pressure } \\
\text { transducers }\end{array}$ & $-0.25-0.25 \mathrm{MPa}$ & 1 & $\begin{array}{c}10.5-42.4 \mathrm{~V} \\
\mathrm{DC}\end{array}$ & $1-5$ \\
\hline $\begin{array}{l}\text { Electric } \\
\text { motor speed } \\
\text { indicator } \\
\text { (variable } \\
\text { frequency } \\
\text { drive) }\end{array}$ & $\begin{array}{c}0-1800 \mathrm{rpm} \\
(\mathrm{C}-\mathrm{SCW}) \\
0-1750 \mathrm{rpm} \\
(\mathrm{C}-\mathrm{R} 134 \mathrm{a})\end{array}$ & $\begin{array}{c}1 \\
(\mathrm{C}-\mathrm{SCW}) \\
3 \\
(\mathrm{C}-\mathrm{R} 134 \mathrm{a})\end{array}$ & $\mathrm{n} / \mathrm{a}$ & $0-10$ \\
\hline Flow meter & $\begin{array}{c}6.11 \times 10^{-6}-0.015 \mathrm{~m}^{3} / \mathrm{s} \\
(\mathrm{C}-\mathrm{SCW}) \\
0.000315-0.00315 \mathrm{~m}^{3} / \mathrm{s} \\
(\mathrm{C}-\mathrm{R} 134 \mathrm{a})\end{array}$ & 1 & $\begin{array}{c}110 \mathrm{~V} \mathrm{AC} \\
(\mathrm{C}-\mathrm{SCW}) \\
10-26 \mathrm{~V} \mathrm{DC} \\
(\mathrm{C}-\mathrm{R} 134 \mathrm{a}) \\
\end{array}$ & $\begin{array}{c}0-10 \\
(\mathrm{C}-\mathrm{SCW}) \\
0-5 \\
(\mathrm{C}-\mathrm{R} 134 \mathrm{a}) \\
\end{array}$ \\
\hline $\begin{array}{l}R-134 a \\
\text { leakage } \\
\text { detector }\end{array}$ & $\mathrm{n} / \mathrm{a}$ & $\begin{array}{c}\mathrm{n} / \mathrm{a} \\
(\mathrm{C}-\mathrm{SCW}) \\
2 \\
(\mathrm{C}-\mathrm{R} 134 \mathrm{a}) \\
\end{array}$ & $10 \mathrm{~V} \mathrm{DC}$ & 0 or 10 \\
\hline $\begin{array}{l}\text { Voltmeter } \\
\text { and ammeter } \\
\text { (On the } 300 \\
\text { kW electric } \\
\text { transformer) }\end{array}$ & $\begin{array}{c}0-150 \mathrm{~V} \\
0-2000 \mathrm{~A}\end{array}$ & 2 & $\mathrm{n} / \mathrm{a}$ & $0-10$ \\
\hline
\end{tabular}




\subsubsection{Selection of Temperature Sensors}

Temperature sensors can be divided into four categories based on four operating principles: thermal expansion of material, thermoelectric effects, change of electric resistance and measurement of thermal radiation [38].

Temperature sensors based on thermal expansion of materials include mercury thermometers and bi-metallic thermometers [38]. The working mechanism of these sensors requires the sensing element (e.g. a glass bulb containing mercury or a piece of bimetallic strip) to be immersed in the test medium (i.e. the working fluid here). As such, it is not practical to use these sensors on the present experimental loops. Temperature sensors that make use of thermal radiation are called pyrometers. These sensors are not practical for use on the experimental loops either, for the test loops are thermally insulated to minimize stray heat transfer into the surroundings. The remaining types of temperature sensors that are applicable to the loop setups are those based on the change of electric resistance and the thermoelectric type temperature sensors (i.e. thermocouples) [38].

There are two major types of temperature sensors that work based on the change in electric resistance: resistance temperature devices (RTDs) and thermistors [38]. The RTDs are made of pure metals. They are generally very stable and can reach very high accuracy (up to $0.5 \%$ of the reading) [38]. The maximum temperature for the RTDs is limited to around $800^{\circ} \mathrm{C}[37,38]$. The major disadvantage of the RTD is that the sensor is prone to the oxidation of the metallic sensing element [39]. In addition, the RTDs are usually made of platinum, which is a noble metal. Considering the maximum fluid temperature of the $\mathrm{C}-\mathrm{SCW}$ Loop is $600^{\circ} \mathrm{C}$ and that there would be a large number of 
temperature sensors to be installed on both test loops, this type of sensor is not considered for the test loops. Thermistors are made of metal oxides [38]. They are usually used for applications where high sensitivity and fast response is required [39]. The major problem with the thermistors mostly comes from the fact that the resistance change with respect to the temperature is highly non-linear [38]. This makes the application of the thermistor limited to relatively small temperature ranges (typically between $-100^{\circ} \mathrm{C}$ to $400^{\circ} \mathrm{C}$ ) [38] . In addition, they are known to have stability problems due to the change of composition of the metal oxides over time [40]. Due to this fact, they require frequent recalibration. Thus, they are not considered for the test loops.

Thermocouples operate based on the Seebeck effect [38]. They are made of two dissimilar metals, and when exposed to a temperature variation at two junctions of the metals, an electromotive force (EMF) would be generated. The temperature of the measuring junction can then be interpreted based on the measured EMF and the temperature at the other junction [39]. The measuring temperature range and the accuracy of thermocouples depend on the materials of the dissimilar metals. There are various types of thermocouples designed for different temperature ranges and applications. Due to the wide application of thermocouples, calibration and measurement uncertainty standards have been established [39]. Table 19 is a summary of common types of thermocouples with their measurement range and signal characteristics. 
Table 19: Thermocouple measurement range, uncertainty and sensor sensitivity (the relative uncertainty is expressed as the percentage of temperature reading with units in $\left.{ }^{\circ} \mathbf{C}\right)[41]$

\begin{tabular}{|c|c|c|c|}
\hline $\begin{array}{c}\text { Type of } \\
\text { thermocouple }\end{array}$ & $\begin{array}{c}\text { Approximate } \\
\text { range }\left(\mathbf{~}^{\mathbf{}} \mathbf{C}\right)\end{array}$ & $\begin{array}{c}\text { Average } \\
\text { sensitivity } \\
\left(\mu \mathbf{V} /{ }^{\circ} \mathbf{C}\right)\end{array}$ & $\begin{array}{c}\text { Uncertainty } \\
\text { (whichever is larger) }\end{array}$ \\
\hline $\boldsymbol{T}$ & $-270-400$ & 53.0 & $+/-0.5^{\circ} \mathrm{C}$ or $0.4 \%$ of reading \\
\hline $\boldsymbol{E}$ & $-270-1000$ & 78.5 & $+/-1.0^{\circ} \mathrm{C}$ or $0.4 \%$ of reading \\
\hline $\boldsymbol{J}$ & $-210-1200$ & 56.5 & $+/-1.1^{\circ} \mathrm{C}$ or $0.4 \%$ of reading \\
\hline $\boldsymbol{K}$ & $-270-1370$ & 41.6 & $+/-1.1^{\circ} \mathrm{C}$ or $0.4 \%$ of reading \\
\hline $\boldsymbol{N}$ & $-270-1300$ & 36.3 & $+/-1.1^{\circ} \mathrm{C}$ or $0.4 \%$ of reading \\
\hline $\boldsymbol{S}$ & $-50-1760$ & 9.3 & $+/-0.6^{\circ} \mathrm{C}$ or $0.1 \%$ of reading \\
\hline $\boldsymbol{R}$ & $-50-1760$ & 10.2 & $+/-0.6^{\circ} \mathrm{C}$ or $0.1 \%$ of reading \\
\hline
\end{tabular}

In the context of the pros and cons of the available temperature sensors, thermocouples are deemed to be most suitable for the C-SCW Loop and the C-R134a Loop. Since the maximum temperature occurs on the C-SCW Loop and is $723^{\circ} \mathrm{C}$ (wall surface temperature on the heated wall of the test section near the test section exit), there are six types of thermocouples that can be used for the two loops: J, N, K, E, R and S type thermocouples. $\mathrm{R}$ and $\mathrm{S}$ type thermocouples are capable of handling the temperature range here. However, since the sensors' sensitivity is much lower than the other types of thermocouples and they are made of expensive noble metals (platinum), they are not considered here. The $\mathrm{J}$ type thermocouple is not recommended to be used for temperatures above $540^{\circ} \mathrm{C}$ due to accelerated oxidation process of the thermocouple wires [41]. The $\mathrm{K}$ and $\mathrm{N}$ type thermocouples are very similar. The $\mathrm{N}$ type thermocouple is developed as an improvement to the $\mathrm{K}$ type thermocouple for its increased measurement stability and its improved resistance to oxidation [42]. The $\mathrm{K}$ type 
thermocouples are prone to measurement drift due to the irreversible material change in the sensing element at elevated temperature [42]. The E type thermocouple is developed for its high Seebeck coefficients [41]. With a higher Seebeck coefficient, when measuring the same temperature, the $\mathrm{E}$ type thermocouple produces voltage signals with higher amplitude than those produced by the $\mathrm{K}$ and $\mathrm{N}$ type thermocouples. Moreover, this type of thermocouple is more sensitive to a temperature change.

It should be noted that the upper limits of the thermocouple measurements are also affected by the size of the thermocouple sensing element [41]. Table 20 shows the temperature limits against the thickness of the thermocouple sensing element.

Table 20: Typical temperature limits for different types of thermocouples at the selected sensing element sizes (the listed wire sizes are obtained based on the standard American Wire Gage (AWG)) [41]

\begin{tabular}{|c|c|c|c|c|c|c|}
\hline \multirow{2}{*}{$\begin{array}{l}\text { Thermocouple } \\
\text { type }\end{array}$} & \multicolumn{6}{|c|}{ Upper temperature limits for various wire diameters for the sensing } \\
\cline { 2 - 7 } & $\begin{array}{c}\text { Gage } 8 \\
(3.25 \mathrm{~mm})\end{array}$ & $\begin{array}{c}\text { Gage 14 } \\
(1.63 \mathrm{~mm})\end{array}$ & $\begin{array}{c}\text { Gage 20 } \\
(0.81 \mathrm{~mm})\end{array}$ & $\begin{array}{c}\text { Gage 24 } \\
(0.51 \mathrm{~mm})\end{array}$ & $\begin{array}{c}\text { Gage 28 } \\
(0.033 \\
\mathrm{mm})\end{array}$ & $\begin{array}{c}\text { Gage 30 } \\
(0.025 \\
\mathrm{mm})\end{array}$ \\
\hline $\mathbf{T}$ & - & 370 & 260 & 200 & 200 & 150 \\
\hline $\mathbf{J}$ & 760 & 590 & 480 & 370 & 370 & 320 \\
\hline $\mathbf{E}$ & 870 & 650 & 540 & 430 & 430 & 370 \\
\hline K and N & 1260 & 1090 & 980 & 870 & 870 & 760 \\
\hline R and S & - & - & - & 1480 & - & - \\
\hline B & - & - & - & 1700 & - & - \\
\hline
\end{tabular}

Although the E type thermocouple can be used for the highest temperature on the C-SCW Loop, it requires a significantly larger sensing element than those for the $\mathrm{N}$ and $\mathrm{K}$ type thermocouples. A larger thermocouple sensing element size means a larger thermal mass and consequently, longer response time. Thus, even though the E type 
thermocouples have slightly better accuracy and a higher output signal amplitude, it is preferable to use the $\mathrm{K}$ or $\mathrm{N}$ type thermocouples for the $\mathrm{C}$-SCW Loop to reduce the response time for the thermocouples. Since the measurements of the $\mathrm{N}$ type thermocouples are more stable than those of the K type thermocouples, they are selected for the C-SCW Loop.

There are three common types of measuring junctions for thermocouples: exposed, grounded and ungrounded measuring junctions. Figure 28 shows these three types of measuring junctions.

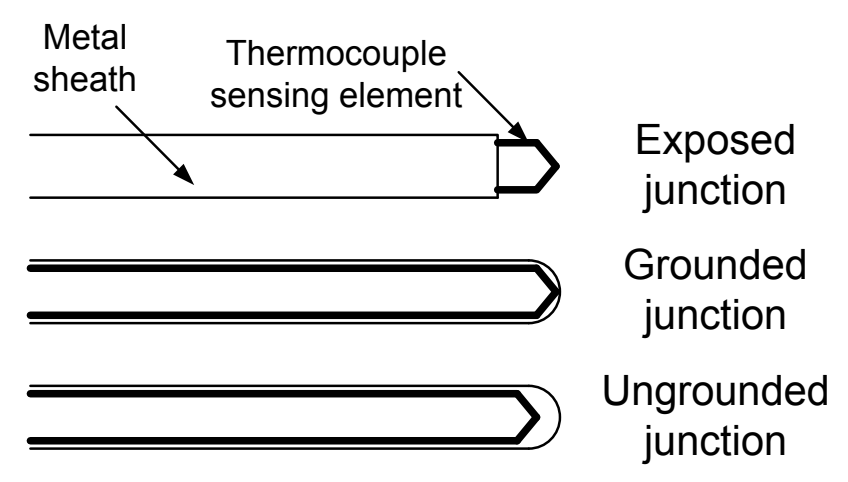

Figure 28: Three designs of thermocouple measuring junction [41]

The first two types of measuring junction designs are not suitable for the present experimental loop setups, because they are both prone to the electric noise. In addition, thermocouples with exposed measuring junctions are prone to mechanical damage and oxidation considering there is no sheath protecting the exposed thermocouple sensing element [41]. The third type of thermocouple measuring junction has the best protection against mechanical damage, oxidation and electric noise by shrouding the thermocouple sensing element in a metallic sheath filled with electrically non-conductive ceramic powders [41]. Thus, the third type of thermocouple measuring junction is chosen for the C-SCW Loop. 
For the C-R134a Loop, although E type thermocouples can be used, it is preferable to use $\mathrm{N}$ type thermocouples on both loops to allow for interchangeability of sensors and signal-conditioning circuitry between the two loops. The selected thermocouple has a sheath diameter of $1.59 \mathrm{~mm}(1 / 16 \mathrm{inch})$ and the size of the sensing element is AWG 30 (i.e. with a diameter of $0.025 \mathrm{~mm}$ as per Table 20). According to the manufacturer of the thermocouples, $\mathrm{N}$ type thermocouples of this size have a maximum measuring temperature of $920^{\circ} \mathrm{C}$ [43]. The significant improvement in the maximum measuring temperature is achieved by the incorporation of the metallic sheath and the magnesium oxide $(\mathrm{MgO})$ filling (in the sheath) which are used to protect thermocouple sensing element from being oxidized by the air at elevated temperature [43]. $\mathrm{N}$ type thermocouples with smaller sheath diameters are also available [43]. However, the next smaller size (sheath diameter of $1.0 \mathrm{~mm}$ ) has a maximum measuring temperature of $700^{\circ} \mathrm{C}$, which is lower than the maximum test section outlet wall temperature of $723^{\circ} \mathrm{C}$ [43]. Thus, $\mathrm{N}$ type thermocouples with a sheath diameter of $1.59 \mathrm{~mm}(1 / 16 \mathrm{inch})$ are selected.

For the tubular test section, the thermocouples immersed in the working fluid at the inlet and outlet of the test section are installed on two tee type tube fitting. This thermocouple installation allows the operator to directly measure the bulk temperature of the working fluid at these two locations. Based on these two temperature measurements, the bulk fluid temperature at any location along the test section can be calculated using the heat input at the test section, which can be obtained based on the electric current reading given by the electric transformer. However, to find the convection heat transfer coefficient, the wall temperatures along the length of the test section are also required. 
The thermocouples must be installed in an arrangement such that it can resolve the streamwise variation of wall temperature. Of course, it does not make sense to have the change of wall temperature between the adjacent thermocouples to be smaller than the uncertainty of the thermocouple measurements (which, for the C-SCW Loop, is typically around $+/-4^{\circ} \mathrm{C}$ and, for the C-R134a Loop, is around $+/-2^{\circ} \mathrm{C}$ ). Based on these two criteria, a total of 20 equally spaced thermocouple stations are selected along the $2 \mathrm{~m}$ long tubular test section. Under this configuration, for the operating conditions of CSCW Loop listed in Table 2, the wall temperature rise between the adjacent thermocouples stations is approximately twice the uncertainty of the thermocouple. For the C-R134a Loop, a few operating scenarios are created based on the operating envelope of the loop, and the results show a similar accuracy for the measurement of the streamwise variation of wall temperature. In addition, near the mid-span of the tubular test section (6 locations), thermocouples are mounted at three evenly-spaced locations along the circumference to measure the circumferential change of wall temperature. In total with a tubular test section, $43 \mathrm{~N}$ type thermocouples are installed on the C-R134a Loop and $41 \mathrm{~N}$ type thermocouples are installed on the C-SCW Loop. Among these thermocouples, 32 are installed on the test section for the study of thermalhydraulic phenomena.

A simple transient heat transfer analysis is carried out to find the response time of the installed thermocouple in response to a step temperature change. As will be shown in a later section, the response time of the thermocouples is an important parameter required to determine the minimum sampling rate for the DAQ system. 
As already shown, there are two methods of installing the thermocouples on the two test loops: namely, 1 . attaching the thermocouples to the surface of the piping of the test loops or 2. immersing the thermocouples into the working fluid. To find the response time for the first case is not an easy task, because it requires the knowledge of the thermal contact resistance, which in turn requires experiments to be performed. However, for the thermocouples installed using the second method, the response time of the thermocouples can be estimated using lumped-heat-capacity method, which is a common method employed in the transient heat transfer analysis [18]. Thus, for the sake of simplicity, the response time of the thermocouples installed using the second method will be used as the response time for the thermocouples selected for the two test loops.

The lumped-heat-capacity method states that when an object with a uniform initial temperature distribution of $T_{o}$ is suddenly subjected to an environment (e.g. air flow) with a temperature of $T_{\infty}$, if the Biot number meets the condition [18]:

$$
B i=\frac{h V}{k A}<0.1
$$

where $h$ is the convection heat transfer coefficient between the ambient and the surface of the object $\left(\mathrm{W} / \mathrm{m}^{2}{ }^{\circ} \mathrm{C}\right) ; V$ is the volume of the object $\left(\mathrm{m}^{3}\right) ; k$ is the thermal conductivity of the object $\left(\mathrm{W} / \mathrm{m}{ }^{\circ} \mathrm{C}\right)$ and $A$ is the heat transfer surface area $\left(\mathrm{m}^{2}\right)$, then, this object can be treated as consistently having a uniform temperature distribution during the thermal transients (i.e. as the temperature of the object $T$ gradually approaches $T_{\infty}$ ) and the variation of $T$ with respect to time, $t$, can be modeled via [18]:

$$
\frac{T-T_{\infty}}{T_{o}-T_{\infty}}=e^{-t / \tau}
$$

where $t$ is time (s) and $\tau$ is the time constant (s), which can be evaluated via [18]: 


$$
\tau=\frac{c \rho V}{h A}
$$

where $c$ is the specific heat capacity of the object $\left(\mathrm{J} / \mathrm{kg}{ }^{\circ} \mathrm{C}\right) ; \rho$ is the density of the object $\left(\mathrm{kg} / \mathrm{m}^{3}\right) ; V$ is the volume of the object $\left(\mathrm{m}^{3}\right) ; A$ is the heat transfer surface area of the object $\left(\mathrm{m}^{2}\right)$ and $h$ is the convection heat transfer coefficient between the surface of the object and its surroundings $\left(\mathrm{W} / \mathrm{m}^{2}{ }^{\circ} \mathrm{C}\right)$.

Using Eqn. (68), it can be easily shown that it takes $t=3 \tau$ for the temperature difference between the object and the ambient to settle to $5 \%$ of the initial temperature difference, $T_{o}-T_{\infty}$. As such, $3 \tau$ is taken as the response time for the transient heat transfer analysis.

In this case, a small section of the thermocouple containing the sensing junction is the object of interest in the transient heat transfer analysis. The length of this section is assumed to be $10 \mathrm{~mm}$. The volume, $V$, and the heat transfer surface area, $A$, required for evaluating Eqns. (67) and (69) can then be calculated and they are $2.01 \times 10^{-8} \mathrm{~m}^{3}$ and 5.03 $\mathrm{x} 10^{-5} \mathrm{~m}^{2}$.

As the $\mathrm{MgO}$ filling occupies most of the internal space of the metal sheath of the thermocouple, the physical properties of $\mathrm{MgO}$ (i.e. the object density, $\rho=3580 \mathrm{~kg} / \mathrm{m}^{3}$; the heat capacity of the object, $c=951 \mathrm{~J} / \mathrm{kg}{ }^{\circ} \mathrm{C}$; the thermal conductivity, $k=60 \mathrm{~W} / \mathrm{m}{ }^{\circ} \mathrm{C}$ ) are used to evaluate Eqns. (67) and (69).

The remaining unknown parameter required to evaluate Eqns. (67) and (69) is the convection heat transfer coefficient between the thermocouple and the working fluid flow around it, $h$. Since the $10 \mathrm{~mm}$-long thermocouple section modeled in this case can be viewed as a long cylinder given that the diameter of the thermocouple sheath is $1.59 \mathrm{~mm}$, 
the convection heat transfer coefficient can be found using a Nusselt number correlation applicable to a cylinder aligned in a cross flow [18]:

$$
N u_{D_{t}}=C\left(\operatorname{Re}_{D_{t}}\right)^{n} \operatorname{Pr}^{1 / 3}
$$

where $C$ and $n$ are constants, which depend on the values of the Reynolds number, $R e$, and $\operatorname{Pr}$ is the Prandtl number of the flow around the cylinder. The Nusselt number, $N u_{D_{t}}$, Prandtl number, $P r$, and Reynolds number, $R e_{D_{t}}$, are defined as:

$$
\begin{gathered}
N u_{D_{t}}=\frac{h D_{t}}{k_{\text {fluid }}} \\
R e_{D_{t}}=\frac{\rho_{\text {fluid }} v D_{t}}{\mu_{\text {fluid }}} \\
\operatorname{Pr}=\frac{c_{p \text { fluid }} \mu_{\text {fluid }}}{k_{\text {fluid }}}
\end{gathered}
$$

where $D_{t}$ is the sheath diameter of the thermocouple, which in this case is $1.59 \times 10^{-3} \mathrm{~m}$; $k_{\text {fluid }}$ is the thermal conductivity of the fluid around the cylinder $\left(\mathrm{W} / \mathrm{m}{ }^{\circ} \mathrm{C}\right) ; \rho_{\text {fuid }}$ is the fluid density $\left(\mathrm{kg} / \mathrm{m}^{3}\right) ; c_{p \text { fluid }}$ is the fluid isobaric specific heat capacity $\left(\mathrm{J} / \mathrm{kg}{ }^{\circ} \mathrm{C}\right) ; \mu_{\text {fluid }}$ is the fluid dynamic viscosity ( $\mathrm{Pa} \mathrm{s}$ ) and $v$ is the free stream velocity of the flow around the cylinder $(\mathrm{m} / \mathrm{s})$, which, in this case, is assumed to be the average velocity of the fluid in the pipe and it can be calculated based on the mass flow rate:

$$
v=\frac{4 \dot{m}}{\pi d^{2} \rho_{\text {fluid }}}
$$

where $m$ is the mass flow rate of the fluid flow $(\mathrm{kg} / \mathrm{s})$. 
All thermal physical properties of the working fluid flowing around thermocouple in the expressions presented thus far are to be evaluated at the film temperature, which, in this case, is defined as:

$$
T_{\text {film }}=\frac{T_{o}+T_{\infty}}{2}
$$

where $T_{o}$ is the initial temperature of the thermocouple at $t=0 \mathrm{~s}\left({ }^{\circ} \mathrm{C}\right)$ and $T_{\infty}$ is the fluid temperature over the thermocouple.

Clearly, the values of $\dot{m}$ and $T_{f i m}$ depends on the operating condition of the test loops. For the current analysis, a number of scenarios are created based on the operating range of the two test loops and they are listed in Table 21.

Table 21: Test loop operating scenarios created for the transient heat transfer analysis

\begin{tabular}{|l|c|c|c|}
\hline \multirow{2}{*}{} & \multirow{2}{*}{ C-SCW } & \multicolumn{2}{|c|}{ C-R134a } \\
\cline { 2 - 4 } & \multicolumn{2}{|c|}{$\begin{array}{c}\text { Subcritical } \\
\text { experiment }\end{array}$} & $\begin{array}{c}\text { Supercritical } \\
\text { experiment }\end{array}$ \\
\hline Mass flow rate (kg/s) & \multicolumn{2}{|c|}{061} & $60 / 100$ \\
\hline $\begin{array}{l}\left.\text { Film temperature ( }{ }^{\mathbf{0}} \mathbf{C}\right) \\
\text { (consider a 20 } \\
\text { change) }\end{array}$ & $270 / 610$ & $40 / 60$ & $4.4 / 6$ \\
\hline $\begin{array}{l}\text { System pressure } \\
\text { (MPa) }\end{array}$ & $23 / 27$ & $1.7 / 4$ & \\
\hline
\end{tabular}

The $20^{\circ} \mathrm{C}$ step change is considered here, because this step change in temperature is expected to be higher than the anticipated rate of change of temperature in the test loops. The film temperatures and the system pressures listed in Table 21 are the operating limits of the two test loops. It is worth noting that the mass flow rate selected here is the 
minimum mass flow rate for the two test loops. The reason for selecting the minimum mass flow rate here is that it would yield a lower heat transfer rate between thermocouple and the working fluid flow around it and thus, it would take longer for the thermocouple to equalize its temperature with the flow around it. As a result, the estimated response time for the thermocouple is a conservative estimate.

Based on the conditions listed in Table 21, the resultant Reynolds number for the flow around the thermocouple is found to vary between 1300 and 5100 for the C-SCW Loop and between 1050 and 12100 for the C-R134a Loop. The Prandtl number is found to vary between 0.8 and 2 for the C-SCW Loop and between 0.9 and 8.8 for the C-R134a Loop.

With the Reynolds number known, the constants $C$ and $n$ in Eqn. (70) can be determined and they are listed in Table 22 .

Table 22: Values of the constants $C$ and $n$ in Eqn. (70) at different Reynolds number $[18]$

\begin{tabular}{|c|c|c|}
\hline $\begin{array}{c}\text { Reynolds number } \\
\text { range }\end{array}$ & $\boldsymbol{C}$ & $\boldsymbol{n}$ \\
\hline $40-4000$ & 0.683 & 0.466 \\
\hline $4000-40,000$ & 0.193 & 0.618 \\
\hline
\end{tabular}

Thus, using Eqn. (70) and these two constants, the convection heat transfer coefficients, $h$, can be calculated and substituting the calculated values of $h$ into Eqn. (67), the Biot number can be obtained and it is found to vary between 0.01 and 0.05 for the C-SCW Loop and between 0.004 and 0.008 for the C-R134a Loop. Thus, it is valid to use the lumped-heat-capacity method to model the transient heat transfer between the small thermocouple sensor and the surrounding working fluid in the two test loops. 
Substituting the calculated convection heat transfer coefficients and the associated geometric and physical properties of the thermocouple sensor section into Eqn. (69), the time constants can be calculated and they vary between $0.2 \mathrm{~s}$ to $0.6 \mathrm{~s}$ for the $\mathrm{C}-\mathrm{SCW}$ Loop and $0.6 \mathrm{~s}$ to $1.5 \mathrm{~s}$ for the C-R134a Loop. Taking the maximum time constant, $1.5 \mathrm{~s}$, to have a conservative estimate for the response time of the thermocouple, the response time of the thermocouples are determined to be $4.5 \mathrm{~s}$.

\subsection{Controlled Devices}

There are several devices that need to be controlled on the experimental loop setups. These devices include an electric transformer, variable frequency drives (VFD) for the pumps and control valves. These devices are used to control the flow rate and the heat input to the test section on the experimental loops. Table 23 describes the control signal types for each of the devices as shown in Figure 26 and Figure 27. The data acquisition and control system is to be designed to accommodate these control signals.

Table 23: Summary of control signals [34, 37, 44]

\begin{tabular}{|l|c|c|c|}
\hline Type of device & C-SCW Loop & C-R134a Loop & Signal type \\
\hline $\begin{array}{l}\text { 300 kW AC-to-DC } \\
\text { electric transformer }\end{array}$ & 6 & 6 & $\begin{array}{c}\text { Analog } \\
(0-10 \mathrm{~V})\end{array}$ \\
\hline Pump VFD & 1 & 3 & $\begin{array}{c}\text { Digital } \\
(\text { high/low })\end{array}$ \\
\hline $\begin{array}{l}\text { Control valves on the } \\
\text { pressure control module }\end{array}$ & 2 & 2 & $\begin{array}{c}\text { Analog } \\
(1-5 \mathrm{~V})\end{array}$ \\
\hline $\begin{array}{l}\text { Control valves for the } \\
\text { loop }\end{array}$ & 2 & 2 & $\begin{array}{c}\text { Analog } \\
(4 \text { or } 20 \mathrm{~mA})\end{array}$ \\
\hline
\end{tabular}




\subsection{Data Acquisition Boards}

\subsubsection{Overview}

The data acquisition (DAQ) boards of the C-R134a and C-SCW loops are used to acquire and/or send analog and digital signals, and to provide necessary signal conditioning such that the signals can be further processed by the relevant receiving device (e.g. computer workstation or the controllers installed on the controlled devices). Such signal conditioning include: electric noise filtering to eliminate the unwanted components in the received signals, isolation to protect the DAQ boards, signal amplification to boost the sensor signals with low amplitudes, and signal conversion (i.e. from digital to analog and vice versa).

For the two experimental test loops, the selected DAQ boards should be able to accept and send the types of signals specified in Section 5.1 and 5.2. In addition, the sampling rate of the DAQ boards must be sufficient to capture the expected temporal variations in the sensor measurements.

\subsubsection{Basics of DAQ Boards}

\subsubsection{Operating Principle of DAQ Boards}

Figure 29 shows a typical data flow block diagram for a DAQ board. The analog sensor signals first go through the signal conditioning stage $[45,46]$. This stage includes processes such as filtering, amplification and isolation. The next stage is a multiplexer [45]. This device is widely used in multichannel devices [45, 47]. It is essentially a controlled switch used to connect the analog-to-digital converter to each of the channels on the board sequentially. The benefit of using this device is to allow a multi-channel 
DAQ board to have only one analog-to-digital converter to convert all the signals [45]. This can reduce the complexity and the cost of the device. When the multiplexer is connected to a channel, the analog signal is passed onto the sample-and-hold circuit. This device is similar to a capacitor. It holds the signal at a constant level (voltage) as the analog-to-digital converter digitizes the analog measurement. In some cases, each of the channels on a board would have a dedicated sample-and-hold circuit such that a high throughput can be reached. More importantly, this type of configuration enables the device to sample all the channels simultaneously, which is an important feature in some cases, where the temporal correlation of the measured quantities is of interest. 


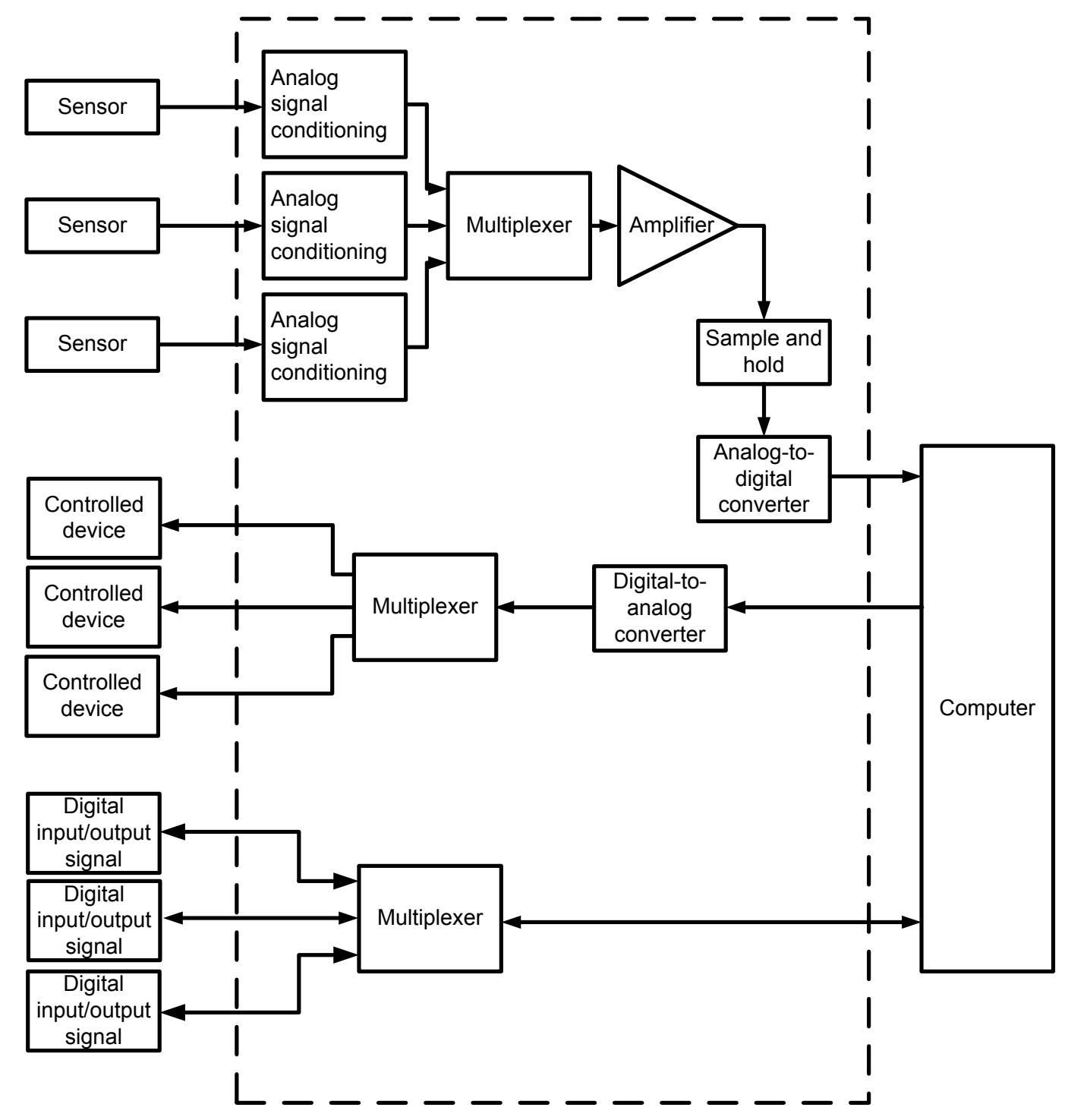

Figure 29: A typical DAQ board block diagram

For converting the digital control signals sent by the computer into analog control signals, the signal passes through a digital-to-analog converter and then each of the converted control signals is passed onto the controlled device through a multiplexer.

For digital signal communications between the computer and the device, signals simply go through a multiplexer and are then passed on to the receiving device. 


\subsubsection{Analog-to-Digital Conversion Resolution of a DAQ Board}

The resolution of a DAQ board is defined in term of the number of bits of its analog-to-digital converter. This refers to the number of binary digits that can be transmitted to the computer by the DAQ board to represent a sample of an analog signal that is received as input by the analog-to-digital converter. The measureable voltage range of the analog-to-digital converter is interpreted into binary representations of the voltage amplitude and an increment of 1 bit would correspond to a certain level of increment of voltage of the input analog signal. This minimum increment can be calculated using:

$$
\text { resolution }=\frac{\text { Range }}{2^{n}}
$$

where Range refers to the analog signal input range; $n$ is the number of bits that can be processed by the analog-to-digital converter and the resulting uncertainties for the ranges of the inputs are shown in Table 24.

\section{Table 24: Uncertainties resulted from the digitization of the analog input signals}

\begin{tabular}{|l|c|}
\hline \multicolumn{1}{|c|}{ Analog input range } & Uncertainty (V) \\
\hline $0-5 \mathrm{~V}$ & $3.0 \times 10^{-7}$ \\
\hline $0-10 \mathrm{~V}$ & $6.0 \times 10^{-7}$ \\
\hline Thermocouple inputs & $4.7 \times 10^{-9}$ \\
\hline
\end{tabular}

The DAQ board cannot interpret an analog signal increment that is smaller than the one calculated using Eqn. (76). Stated in another way, the quantity calculated through Eqn. (76) corresponds to the least significant bit (LSB) in the binary representation of the analog signal. A smaller increment is essentially rounded off by the analog-to-digital converter [45]. The same rule can be applied to the digital to analog converter: regardless 
of the value specified by the operator at the computer workstation, the digital-to-analog converter can only send limited number of digital signals.

\subsubsection{Determination of Sampling Rate for a DAQ Board}

By the Nyquist sampling theorem, in order to reconstruct a proper representation of an incoming analog signal, the sampling rate (i.e. the rate at which the analog signal is converted into the digital signal by the analog-to-digital converter) of the DAQ board should be at least twice of the highest frequency of the actual signal $[44,47]$. This required minimum sampling frequency is called the Nyquist frequency. If a signal is sampled below the Nyquist frequency, the signal reconstructed using the sampled data would deviate from the actual signal as illustrated in Figure 30 and this phenomenon is called aliasing.

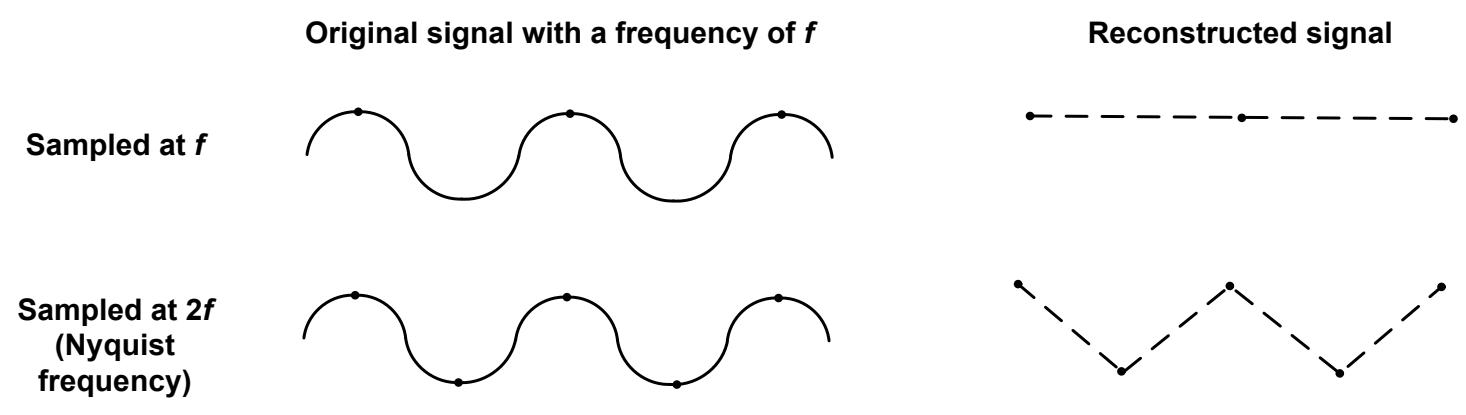

Figure 30: Illustration of an aliased signal due to undersampling

\subsubsection{Selection of DAQ Boards for Use with the C-SCW and C-R134a Loops}

The preceding introduction to the basic operation theories for the DAQ boards establishes the criteria for the selection of the DAQ board for use with the two test loops: the type of the analog/digital signals, the resolution of the data acquisition boards and the required minimum sampling rate. 


\subsubsection{Type and Number of Analog/Digital Signals}

The type and number of signals to be processed are already indicated in Table 18 and Table 23. Among these signals, the thermocouple temperature measurements have slightly different signal conditioning requirements. As mentioned in Section 5.1.1, to find the temperature at the measuring junction, the temperature at the other junction must also be measured. This latter junction is called the reference junction and it is illustrated in Figure 31 [49].

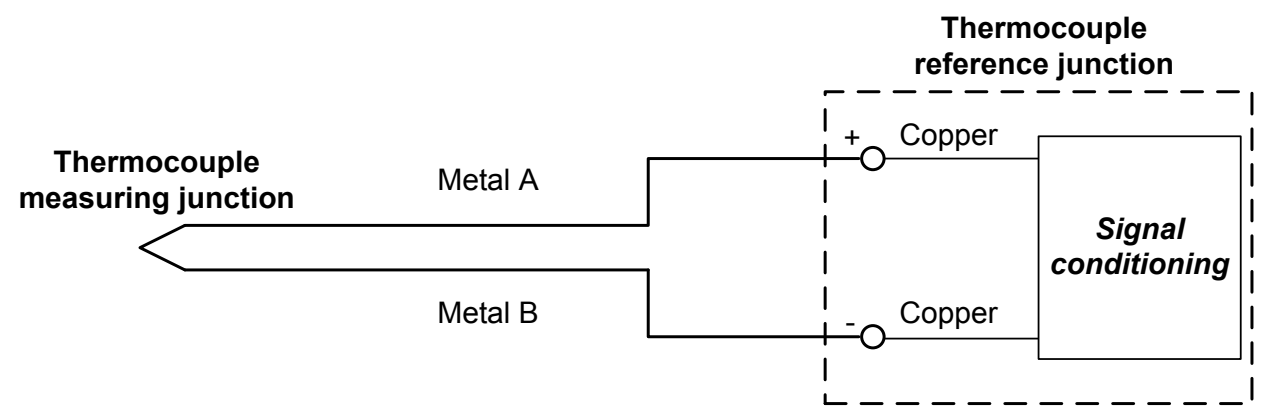

Figure 31: Thermocouple reference junction

Effectively, this means that that the internal temperature of the DAQ board must be measured. Some of the commercially available DAQ boards have onboard temperature sensors which can measure the internal temperature of the DAQ board.

\subsubsection{Required Resolution for the DAQ Boards}

As shown in Section 5.3.2.2, the resolution of the DAQ boards affects the accuracy of the sensor measurements. The resolution must be sufficiently high to ensure that the quantization error does not contribute in a significant way to the overall measurement error. The criteria chosen here is that the quantization error is small enough such that it does not affect the least significant digit of the actual sensor measurements (e.g. if a pressure transducer has an uncertainty of $+/-0.1 \mathrm{~Pa}$, then the required resolution 
of the DAQ board is such that that the quantization uncertainty is less than $+/-0.01 \mathrm{~Pa}$ ). The uncertainties of the sensors are listed in Table 25.

Table 25: Uncertainties for the sensors [31 - 37, 44]

\begin{tabular}{|c|c|c|}
\hline \multirow{2}{*}{$\begin{array}{c}\text { Type of } \\
\text { sensor/device }\end{array}$} & \multicolumn{2}{|c|}{ Uncertainties of the sensors } \\
\hline & C-SCW & C-R134a \\
\hline $\begin{array}{l}\text { Absolute pressure } \\
\text { transducers }\end{array}$ & $\begin{array}{l}+/-0.5 \% \text { of the full scale } \\
(+/-0.02 \mathrm{~V})\end{array}$ & $\begin{array}{c}+/-0.1 \% \text { of the full scale } \\
(+/-0.004 \mathrm{~V})\end{array}$ \\
\hline $\begin{array}{l}\text { Differential } \\
\text { pressure } \\
\text { transducers }\end{array}$ & \multicolumn{2}{|c|}{$\begin{array}{l}+/-0.15 \% \text { of the full scale } \\
\quad\left(+/-7.5 \times 10^{-4} \mathrm{~V}\right)\end{array}$} \\
\hline Flow meters & $+/-1.6 \%$ of the reading & $+/-1 \%$ of the reading \\
\hline $\begin{array}{l}\text { N type } \\
\text { thermocouples }\end{array}$ & \multicolumn{2}{|c|}{$+/-1.1^{\circ} \mathrm{C}$ or $0.4 \%$ of the reading $\left(\right.$ in ${ }^{\circ} \mathrm{C}$ ) whichever is higher } \\
\hline $\begin{array}{l}\text { Voltmeter and } \\
\text { ammeter } \\
(300 \mathrm{~kW} \text { AC-to- } \\
\text { DC electric } \\
\text { transformer) }\end{array}$ & \multicolumn{2}{|c|}{$\begin{array}{c}+/-1 \% \text { of the full scale } \\
(1.5 \mathrm{~V} / 20 \mathrm{~A})\end{array}$} \\
\hline
\end{tabular}

Based on the signal ranges and the uncertainties of the sensor measurements listed in Table 18 and Table 25, the minimum resolution is found to be 9 bit.

The resolution for the digital-to-analog converter is of less importance than that for the analog-to-digital converter. This is because the uncertainties of these signals do not directly affect the experimental results, i.e. the convective heat transfer coefficients and total pressure losses of the working fluid flow inside the test section, both of which are to be calculated solely based on the sensor measurements as will be shown in a later section where the uncertainty analysis for these two important physical parameters is performed. As will be shown in a later section, the selected digital-to-analog converter 
has a resolution of 16 bits. For the $300 \mathrm{~kW}$ AC-to-DC electric transformer, this resolution theoretically allows the operator to control a $0.002 \mathrm{~V}$ change in DC voltage output or a 0.03 A change in DC current output, both of which are smaller than uncertainties of the voltage and current meters installed on the electric transformer. Therefore, this resolution should be more than sufficient for the operator to have a fine control over the electric transformer. Similarly, for the control valves listed in Table 23, the selected digital-toanalog converter allows the user to adjust the valve opening resulting in a flow coefficient $\left(C_{v}\right)$ change of $0.0015 \%$ of the maximum valve flow coefficient, which should also be more than sufficient for fine control over the flow through these valves.

\subsubsection{Required Sampling Rate for the DAQ Boards}

There are two criteria that determine the required sampling rate for the DAQ board: the response time of the sensors and the smallest time scale of the physical phenomena that is expected to be captured by the sensor measurements.

On the C-SCW and C-R134a loops, the convective heat transfer experiments are to be performed under steady system pressure and working fluid temperature, and under transient flow rates and heat flux conditions that are expected to cause time variations in temperature of the order of a few degree Celsius per second. Such transients are significantly greater than the time response of the measurement sensors selected for the test loops. Thus, the response time of the sensors becomes the sole criterion for determining the DAQ board sampling rate. For the pressure transducers and the flow meters, they are listed in Table 26. 
Table 26: Response time of the pressure transducers and the flow meters $[31-33$, 36]

\begin{tabular}{|l|c|}
\hline Type of sensor/device & Response time (s) \\
\hline $\begin{array}{l}\text { Absolute pressure } \\
\text { transducers }\end{array}$ & $\begin{array}{c}0.2(\mathrm{C}-\mathrm{SCW}) \\
<0.01(\mathrm{C}-\mathrm{R} 134 \mathrm{a})\end{array}$ \\
\hline $\begin{array}{l}\text { Differential pressure } \\
\text { transducers }\end{array}$ & 0.1 \\
\hline Flow meters & $1.0(\mathrm{C}-\mathrm{SCW})$ \\
$0.02(\mathrm{C}-\mathrm{R} 134 \mathrm{a})$
\end{tabular}

For the response time of the thermocouples, it has already been shown that the selected $\mathrm{N}$ type thermocouples have a maximum response time of $4.5 \mathrm{~s}$. Although the pressure transducers and the flow meters allow the operator to sample at a faster rate (as indicated in Table 26), in the absence of proper temperature measurements, the additional measurements sampled from these sensors would be useless for the convection heat transfer analysis. Thus, to meet the Nyquist criteria, the required minimum sampling frequency, $f_{\min }$ for the DAQ boards is:

$$
f_{\min }=2 \times \frac{1}{4.5}=0.4 \mathrm{~Hz}
$$

\subsubsection{Selected DAQ Boards}

Based on the criteria established in Sections 5.3.3.1 through 5.3.3.3, two types of DAQ boards were selected from the inventory of the Measurement Computing Corporation: USB-2416 DAQ board and USB-3106 DAQ board. The USB-3106 is used as a supplement to the USB-2416 as the latter does not have a digital-to-analog converter and thus cannot send analog signals to the controlled devices on the experimental loops as indicated by the control signal requirements established in Table 23 . 
Each USB-2416 DAQ board can accommodate up to 32 sensors with singleended input connection configuration or 16 sensors with differential input connection [49]. The single-ended input connection allows the user to have all the sensors share a common ground connection on a DAQ board and thus allows the DAQ board to accommodate more sensors [46]. On the other hand, differential input connection can help eliminate the electric noise picked up by the wires connecting the sensor and DAQ boards and thus it is more suitable for connecting sensors producing low amplitude signals (such as thermocouples in the present application). Each USB-2416 DAQ board has a 24-bit analog-to-digital converter which is above the minimum required resolution of 9 bits as specified in Section 5.3.3.2 [49]. It also provides a special signal conditioning mode designed for thermocouple measurements [49]. It has an onboard thermistor to measure the DAQ board internal temperature (i.e. the temperature at the reference junction) and driver software installed on the computer that is interfaced with the DAQ board then interprets the thermocouple voltage measurements into temperature measurements based on this reference junction temperature [49]. To utilize this mode for thermocouple measurements, the thermocouples must be connected to the DAQ board using differential connection [49]. The remaining sensors listed in Table 18 can be connected to the USB-2416 DAQ boards through single-ended connection.

There are uncertainties introduced by the analog-to-digital (A/D) converter when it is converting the analog signals into digital signals. Based on the specifications given by the manufacturer of the DAQ board, these uncertainties are shown in Figures 32 through 36 for the expected measurement range of the sensor for the two test loops [49]. 


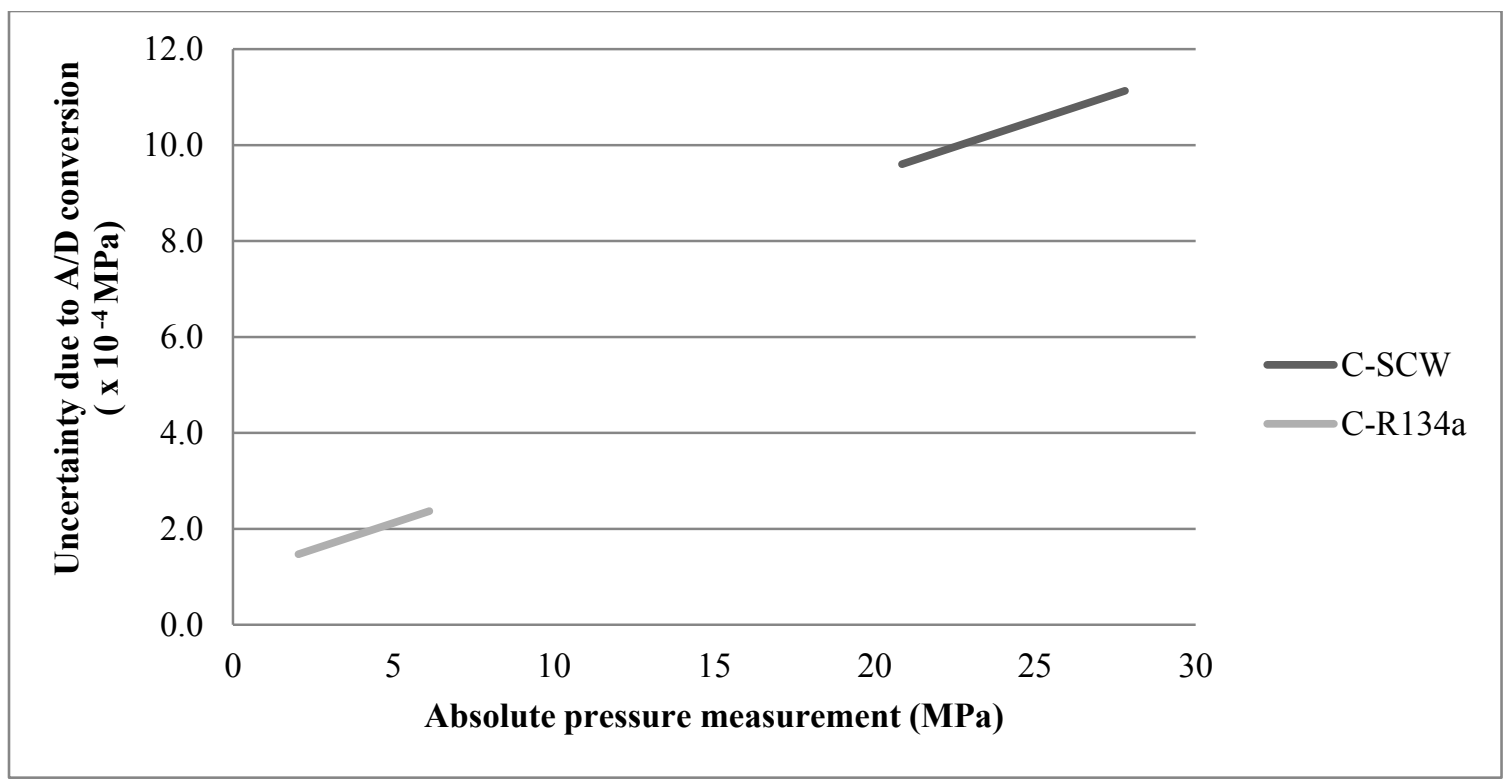

Figure 32: Uncertainty in the absolute pressure measurements due to signal conditioning

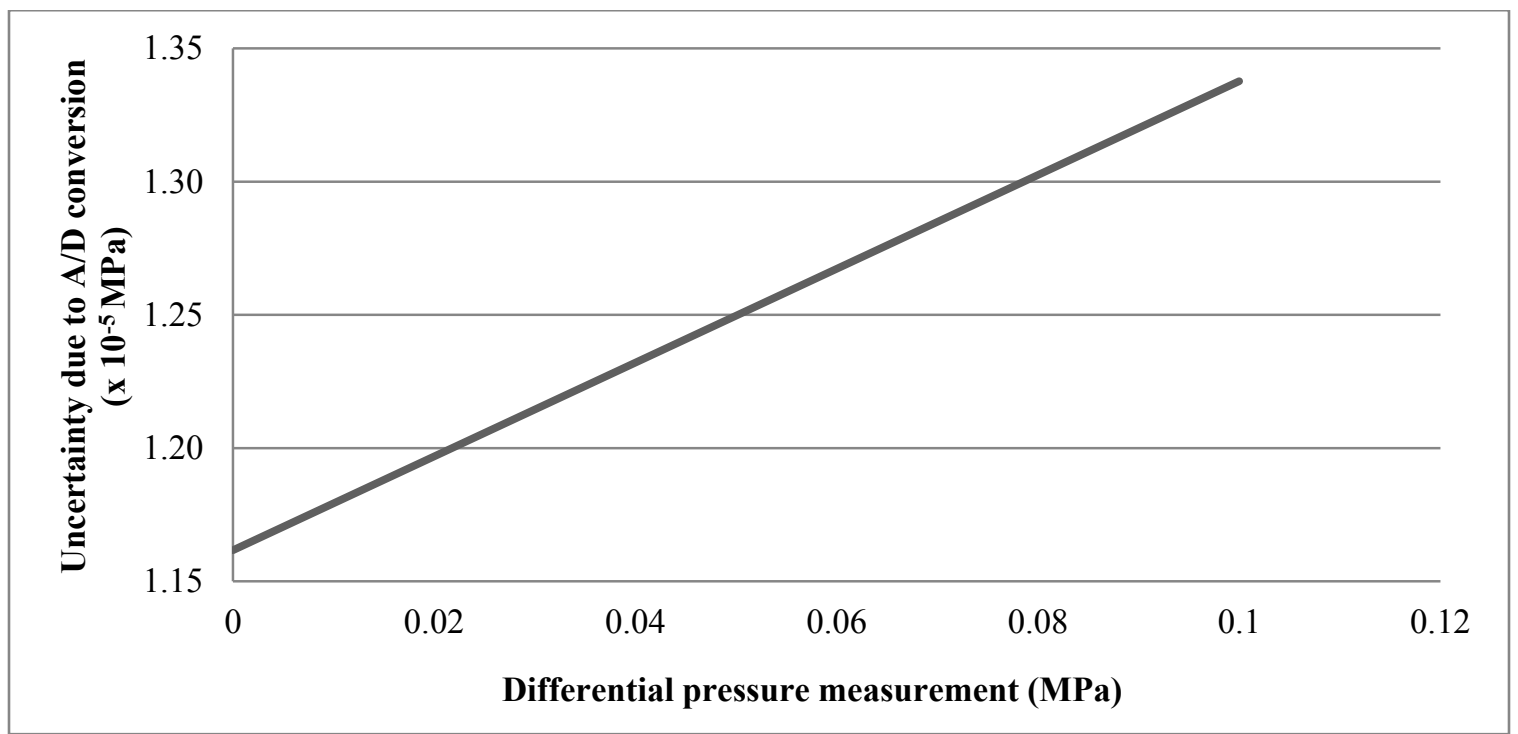

Figure 33: Uncertainty in the differential pressure measurements due to signal conditioning 


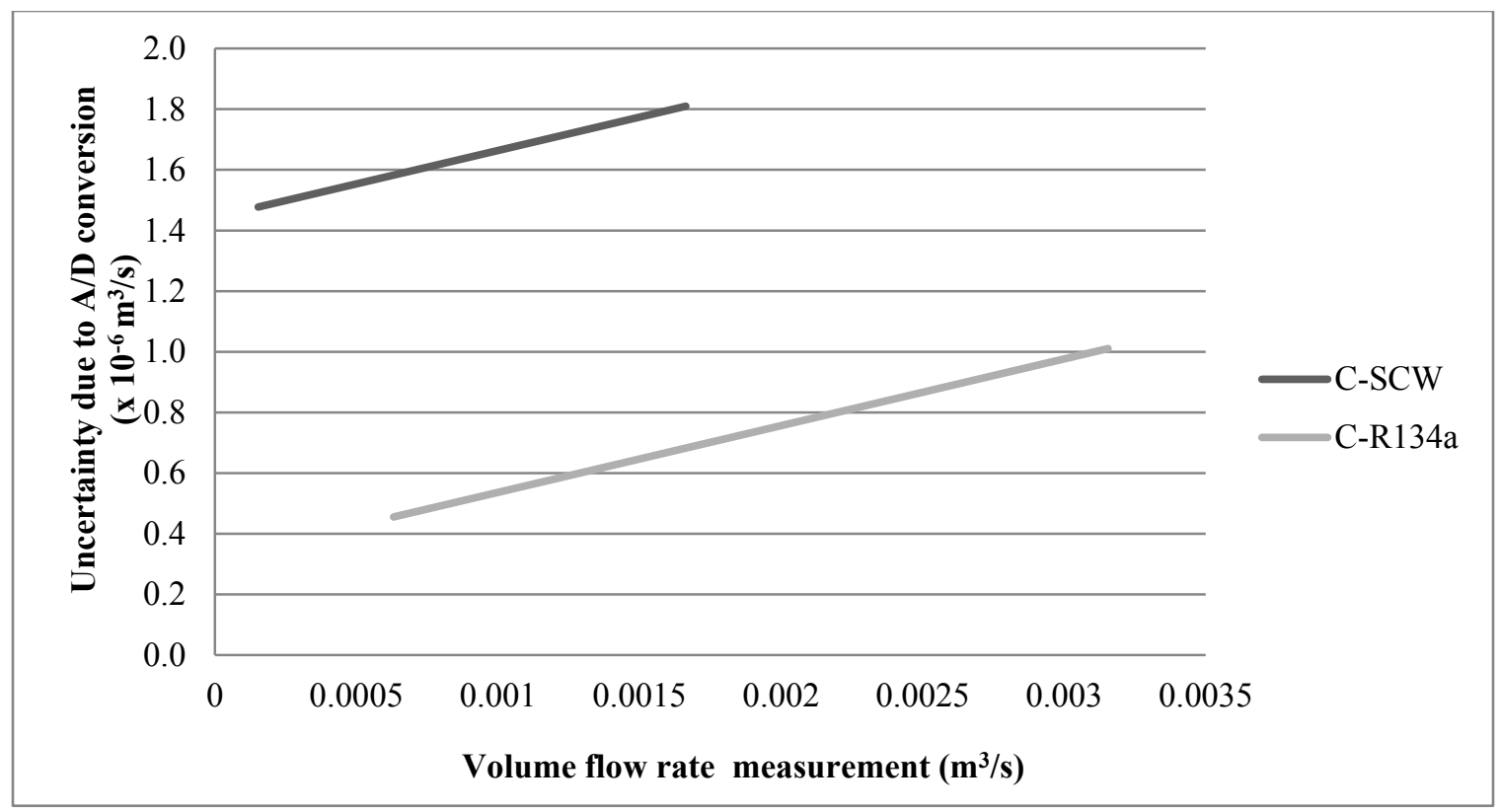

Figure 34: Uncertainty in the flow rate measurements due to signal conditioning

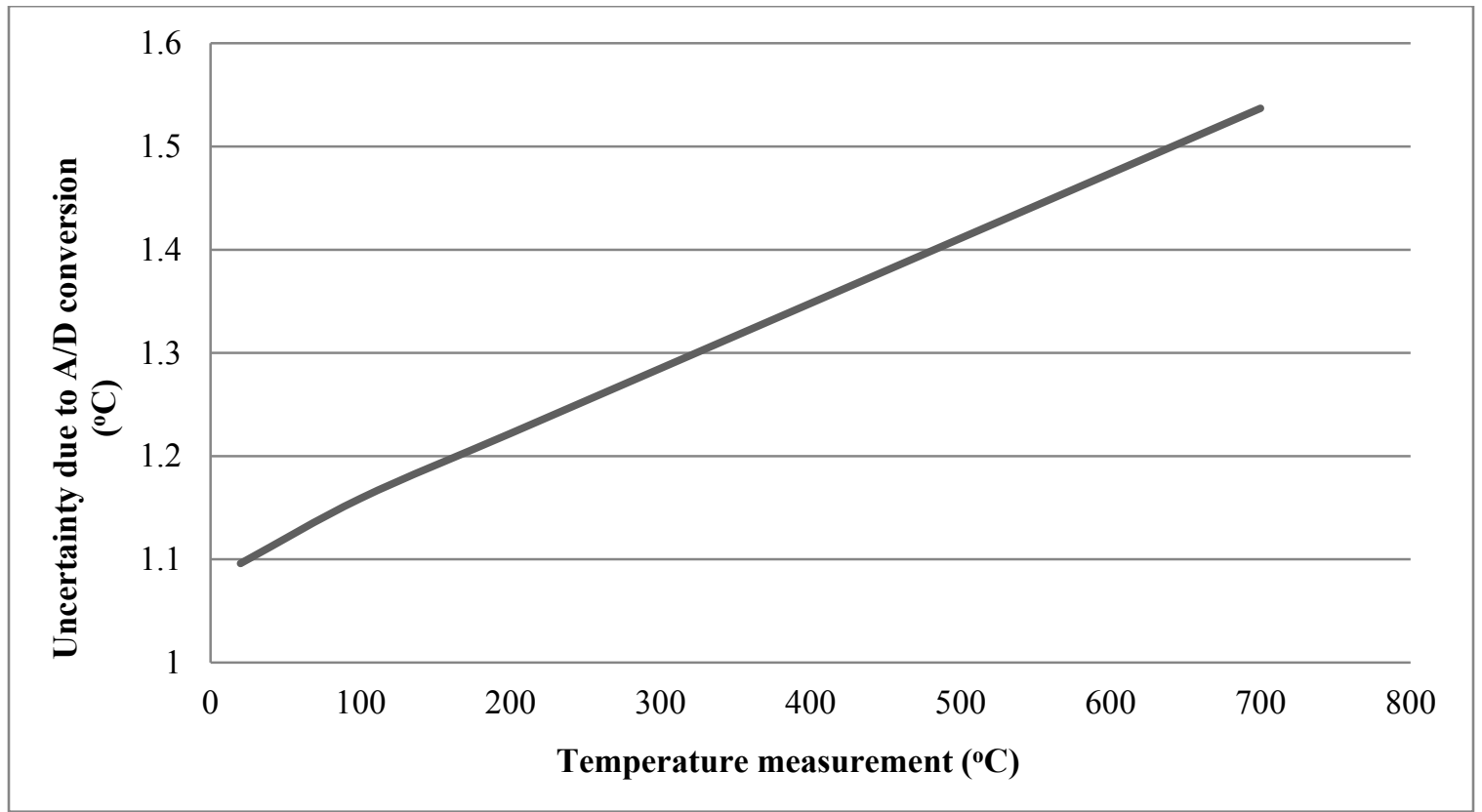

Figure 35: Uncertainty in temperature measurements due to signal conditioning 


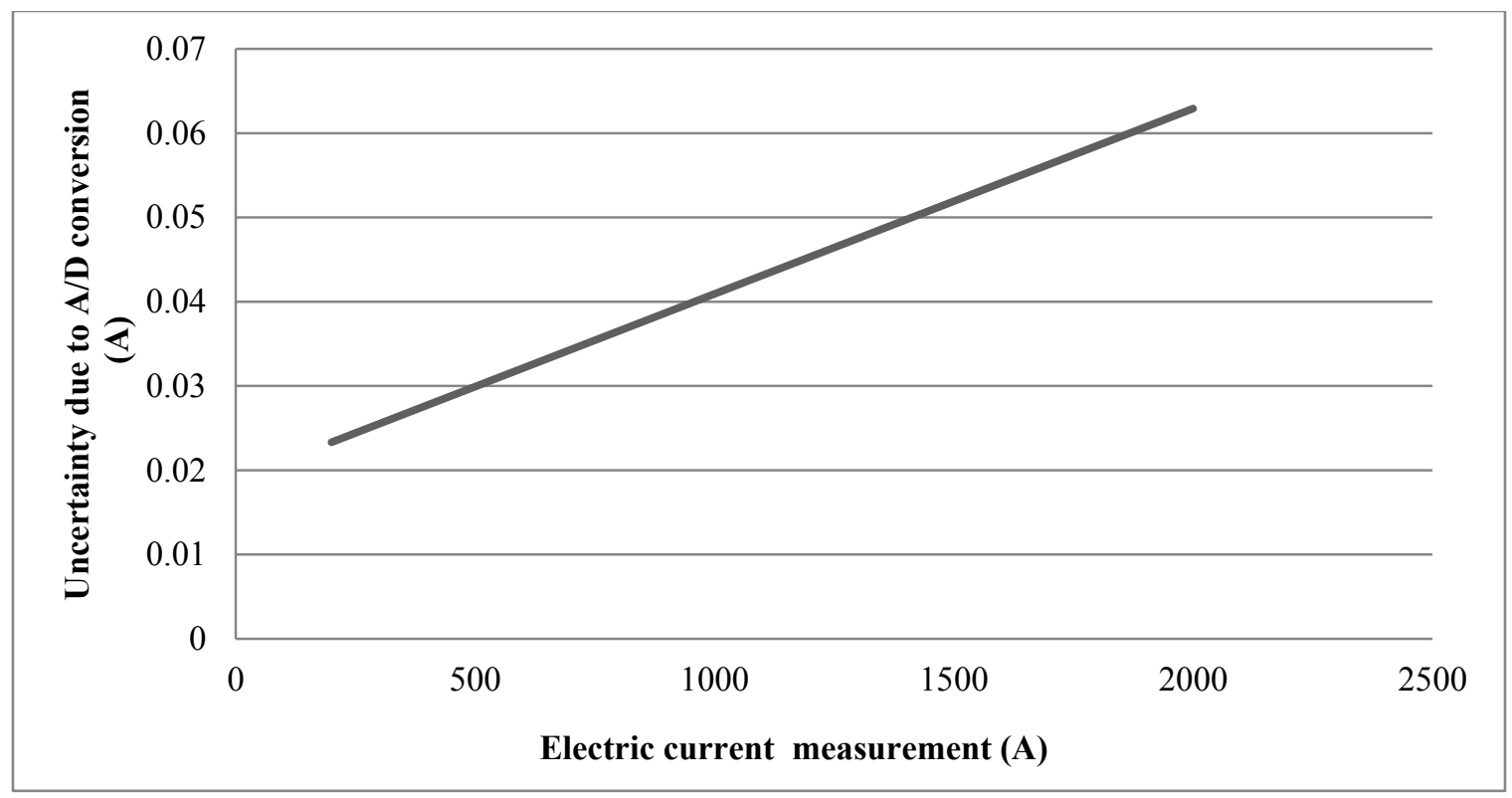

Figure 36: Uncertainty in electric current measurements of the $300 \mathrm{~kW}$ AC-to-DC electric transformer due to signal conditioning

The USB-2416 DAQ board consistently samples the input analog signals at 30000 $\mathrm{Hz}$ [49]. This sampling rate is much higher than the required sampling rate $0.4 \mathrm{~Hz}$. These samples are automatically averaged by the DAQ boards based on the output rate (i.e. the rate at which the DAQ board sends measurements to the computer workstation) specified by the user. The relationship between the output rate and the sampling rate is given by [49]:

$$
n=30000 \frac{1}{p}
$$

where $n$ is the number of samples taken to be averaged to form one output and $p$ is the output rate specified by the user. The averaging of the samples can help to eliminate electric noises at certain frequency (e.g. averaging measurements sampled at $60 \mathrm{~Hz}$ can help eliminating a sinusoidal noise at the same frequency, which is commonly generated by the AC power lines). 
The throughput rate, $N$, can be calculated using [49]:

$$
N=\frac{1}{\sum_{i}\left(\frac{1}{p}+640 \mu s\right)}
$$

where $i$ is the number of input signals and $640 \mu s$ is the amount of time required for the DAQ board to switch from one channel to another.

In conclusion, at the maximum output rate, $p=3750$ outputs per second, the USB-2416 DAQ board has a maximum throughput rate $69 \mathrm{~Hz}$ (16 differential channels), which should be high enough to be used for the experimental test loops [49].

To control the devices listed in Table 23, a 16-bit USB-3106 DAQ boards is selected. It is capable of sending the types of signals listed in Table 23 at a throughput rate of $100 \mathrm{~Hz}$, which should be more than sufficient for controlling the operation of the test loops [50].

\subsubsection{Wiring for the DAQ Boards}

The wiring of the sensors to the DAQ boards has been designed to enable switching of the DAQ boards' connections to the sensors from one loop (or test section) to another. Figure 37 shows the components used for this purpose. 


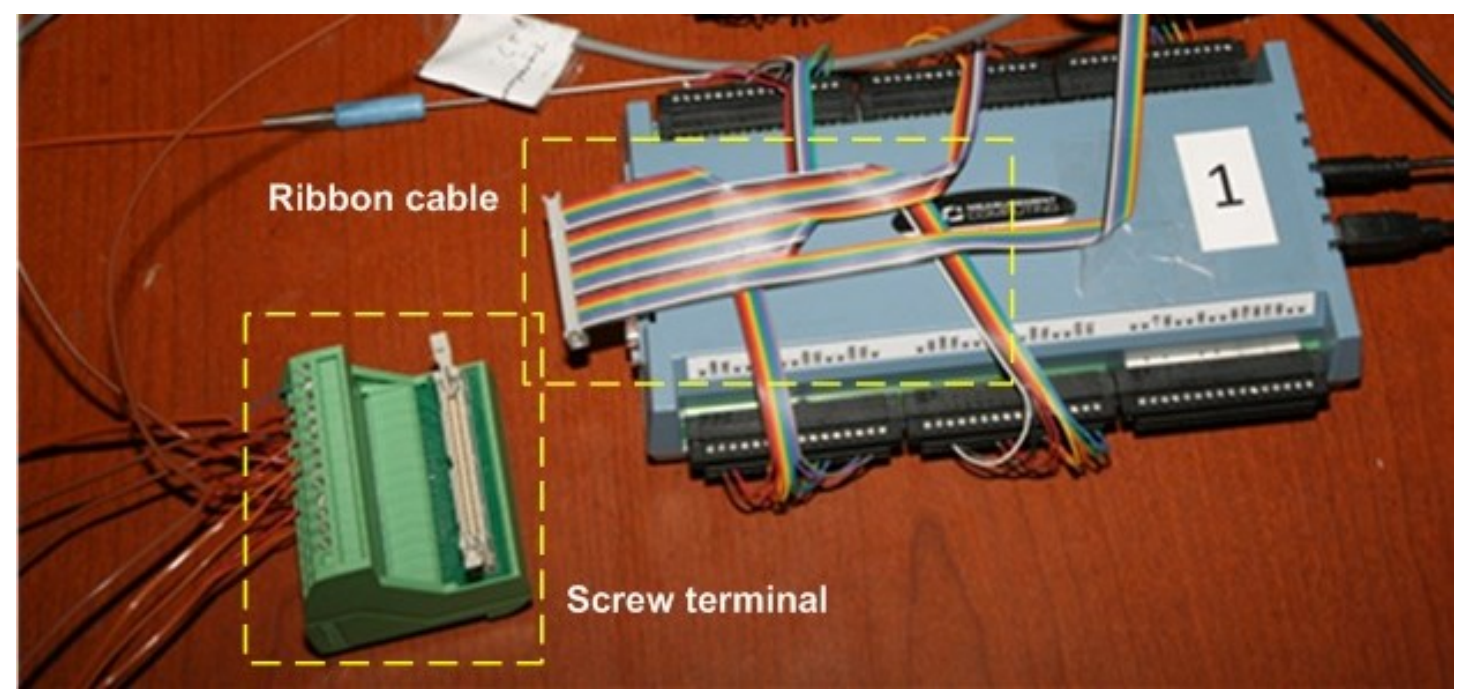

Figure 37: Screw terminal and the ribbon cable with multi-pin connector

The sensors are not connected to the DAQ board directly. Instead, several green screw terminal blocks are used and all the sensors are connected to the screw terminal blocks. Each of the screw terminal blocks has a multi-pin connector with each pin of this connector connected to one of the screw terminals on the block. A ribbon cable with a multi-pin connector that can be mated with the multi-pin connector on the screw terminal block is used to connect the screw terminal to the DAQ board. This arrangement allows the DAQ boards to be quickly detached from the sensors installed on one loop (or test section) and switch to the sensors installed on another loop (or test section). Twisted and shielded cables are used to connect the sensors and the DAQ boards to minimize the effects of electric noise on the signals.

\subsection{Measurement Uncertainties and Propagated Uncertainties for the Selected Thermalhydraulic Parameters}

The measurement uncertainty is a measure of how the measurements deviate from the true values of a physical quantity [48]. The discussion on the uncertainties presented 
here mainly focuses on the measurements related to the thermalhydraulic characteristics of the working fluid flow through the test section (shown in Table 27). Uncertainties of the sensor measurements for health monitoring purposes are of secondary importance and thus are not discussed here.

The estimation of the uncertainties of the parameters listed in Table 27 consists of two parts: estimating the total uncertainties of sensor measurements and using uncertainty propagation methods to estimate the errors for the two important physical parameters calculated using these direct sensor measurements: the total pressure loss of the working fluid through the test section and the convection heat transfer coefficient between the tubular wall of the test section and the working fluid.

Table 27: Parameters of interest for the experiments performed on the C-SCW and C-R134a Loops

\begin{tabular}{|c|c|}
\hline Parameters of interest & Source \\
\hline System pressure & Absolute pressure transducer \\
\hline $\begin{array}{l}\text { Pressure difference across } \\
\text { the test section }\end{array}$ & Differential pressure transducer \\
\hline Temperature & $\begin{array}{l}\text { Thermocouples installed on the test } \\
\text { section: } \\
\text { - } 34 \text { for the tubular test section }\end{array}$ \\
\hline Flow rates & Flow meter \\
\hline $\begin{array}{l}\text { Electric current through the } \\
\text { test section }\end{array}$ & $\begin{array}{l}\text { Amperage output by the } 300 \mathrm{~kW} \text { electric } \\
\text { transformer }\end{array}$ \\
\hline Heat input at the test section & \multirow{2}{*}{$\begin{array}{l}\text { No direct measurements; calculated } \\
\text { based on other measured quantities }\end{array}$} \\
\hline $\begin{array}{l}\text { Heat transfer coefficient } \\
\text { Total pressure loss }\end{array}$ & \\
\hline
\end{tabular}




\subsubsection{Uncertainties for the Sensor Measurements}

The uncertainties for the sensor measurements originate from two sources: uncertainties caused by the design of the sensors and uncertainties caused during the signal conditioning. They can be combined through [48]:

$$
e_{\text {total }}=\sqrt{\sum_{j} e_{j}^{2}}
$$

where $e_{j}$ is the absolute measurement uncertainty from source $j$ and $e_{\text {total }}$ is the combined uncertainty for the measurement. The uncertainties for the sensors installed on the test loops are listed in Table 25 and the uncertainties caused during the signal conditioning process of the USB-2416 DAQ boards are shown in Figures 32 through 36.

The total measurement uncertainties for the sensor measurements were calculated via Eqn. (80). It was found that the uncertainty for the current measurement of AC-to-DC electric transformer is consistently $20 \mathrm{~A}$. The total uncertainties of the measurements of the remaining parameters are plotted against the sensor measurements which are expected to be encountered during the test loop operation as shown in Figures 38 through 41.

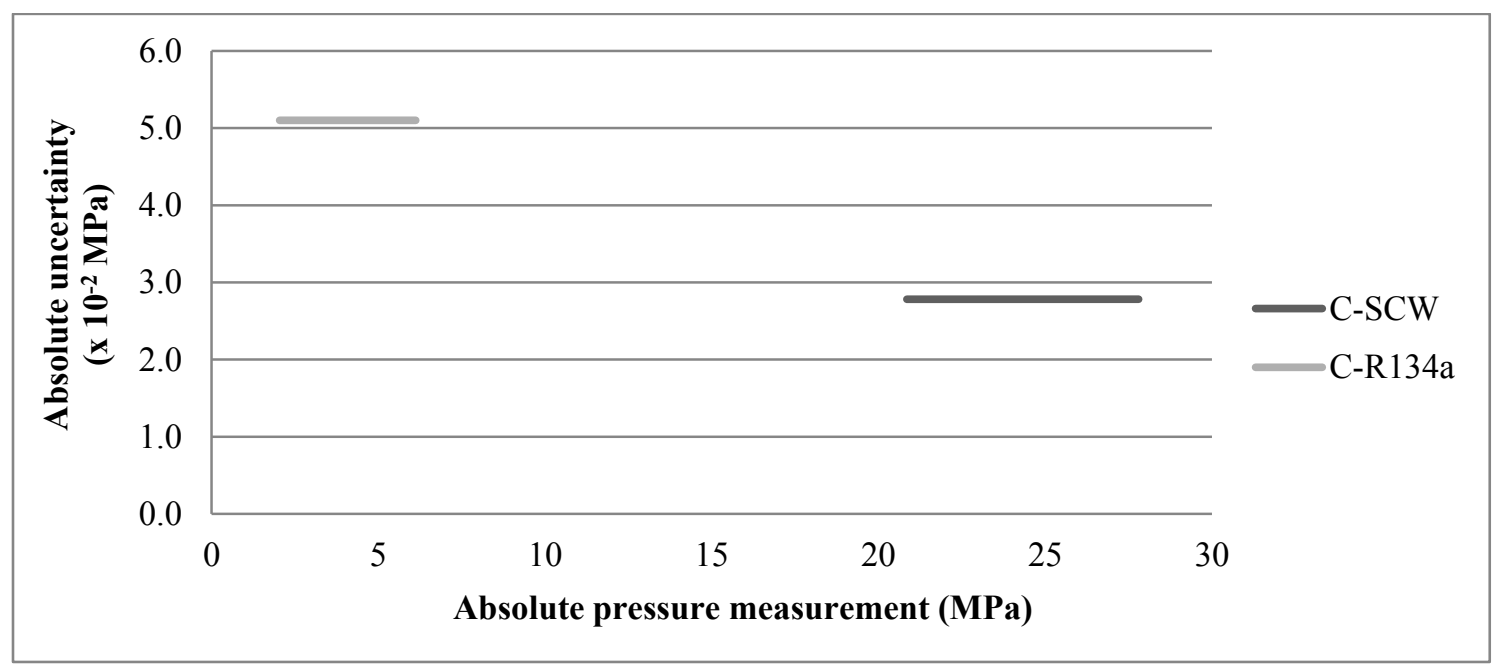

Figure 38: Total uncertainty of the absolute pressure measurement of the working fluid 


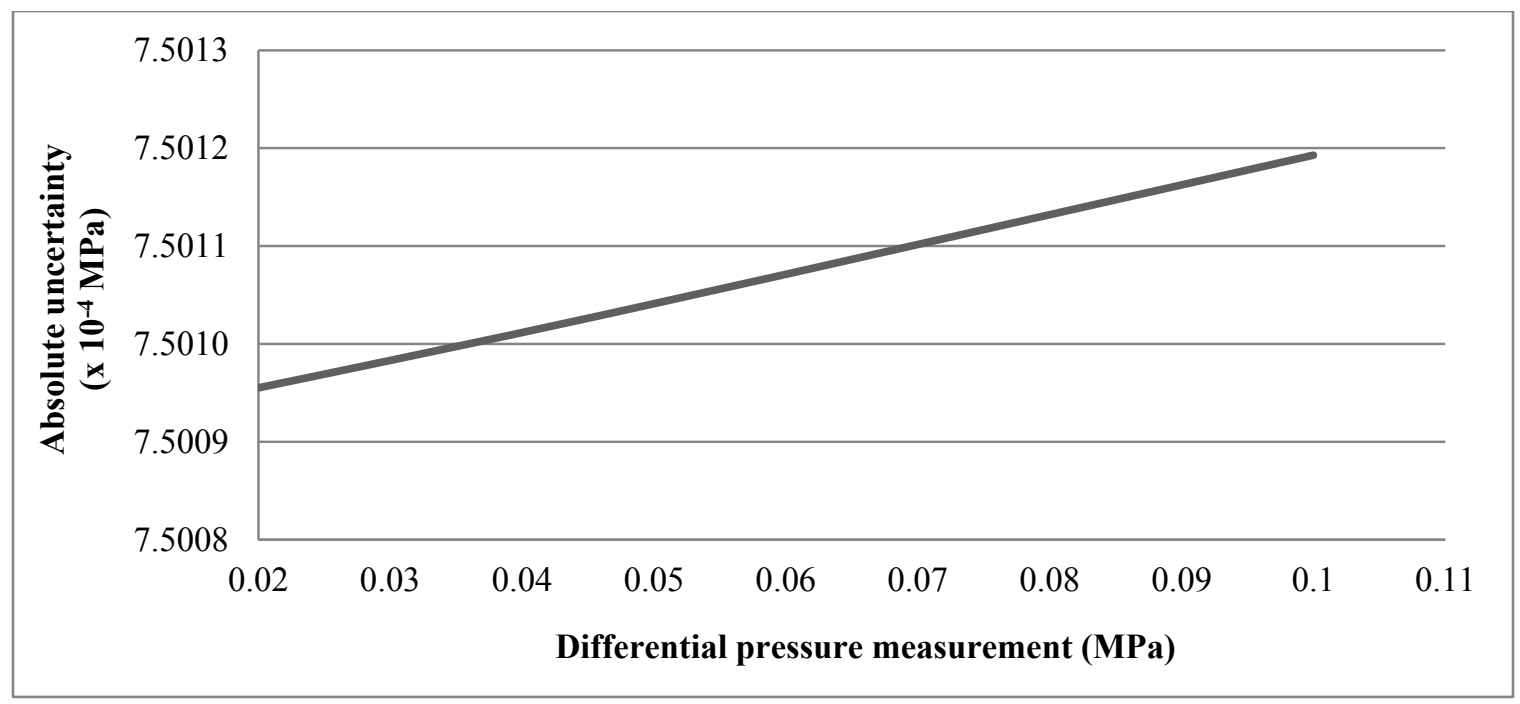

Figure 39: Total uncertainty in differential pressure measurements across the tubular test section

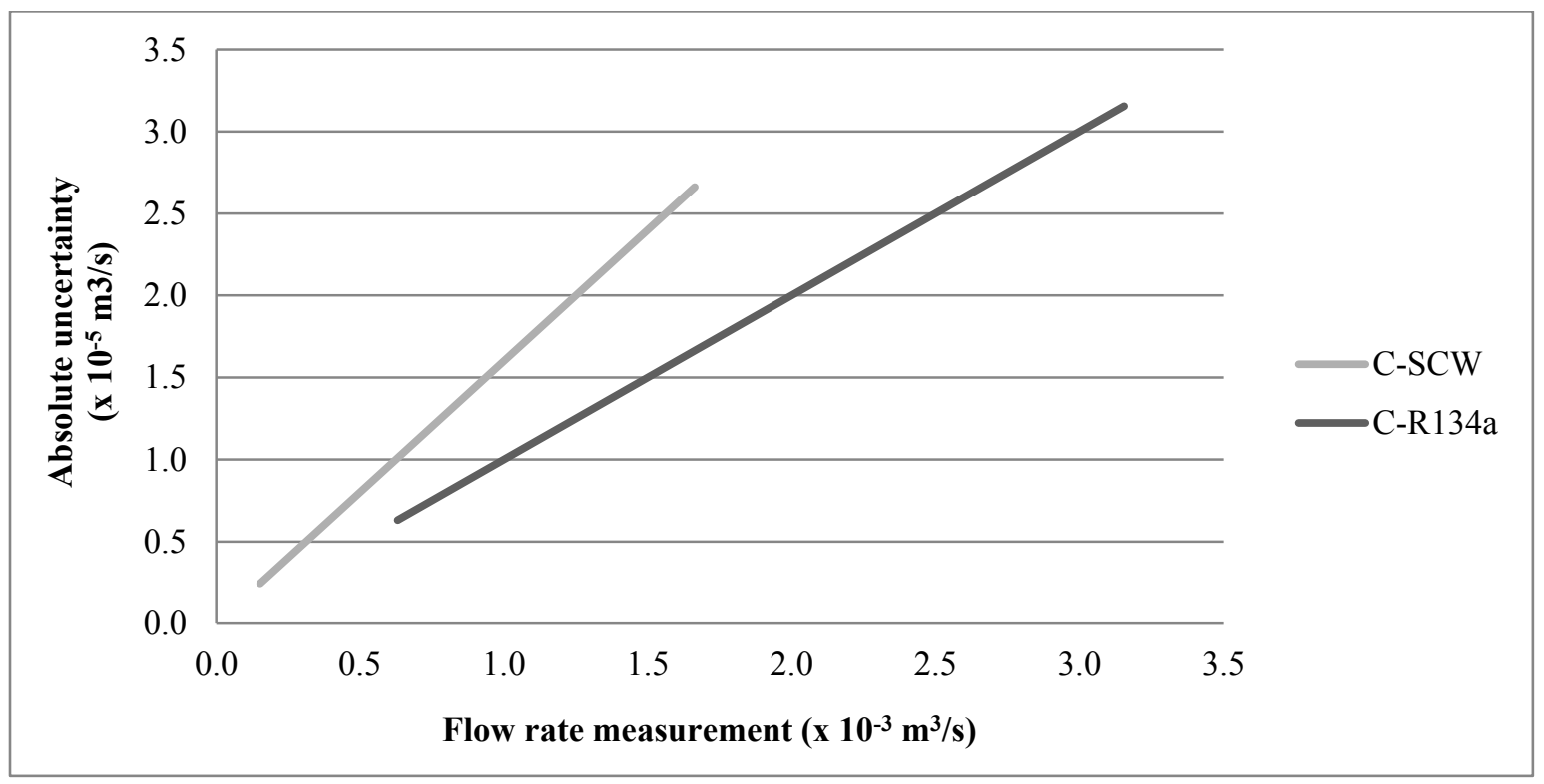

Figure 40: Total uncertainty in flow-rate measurements 


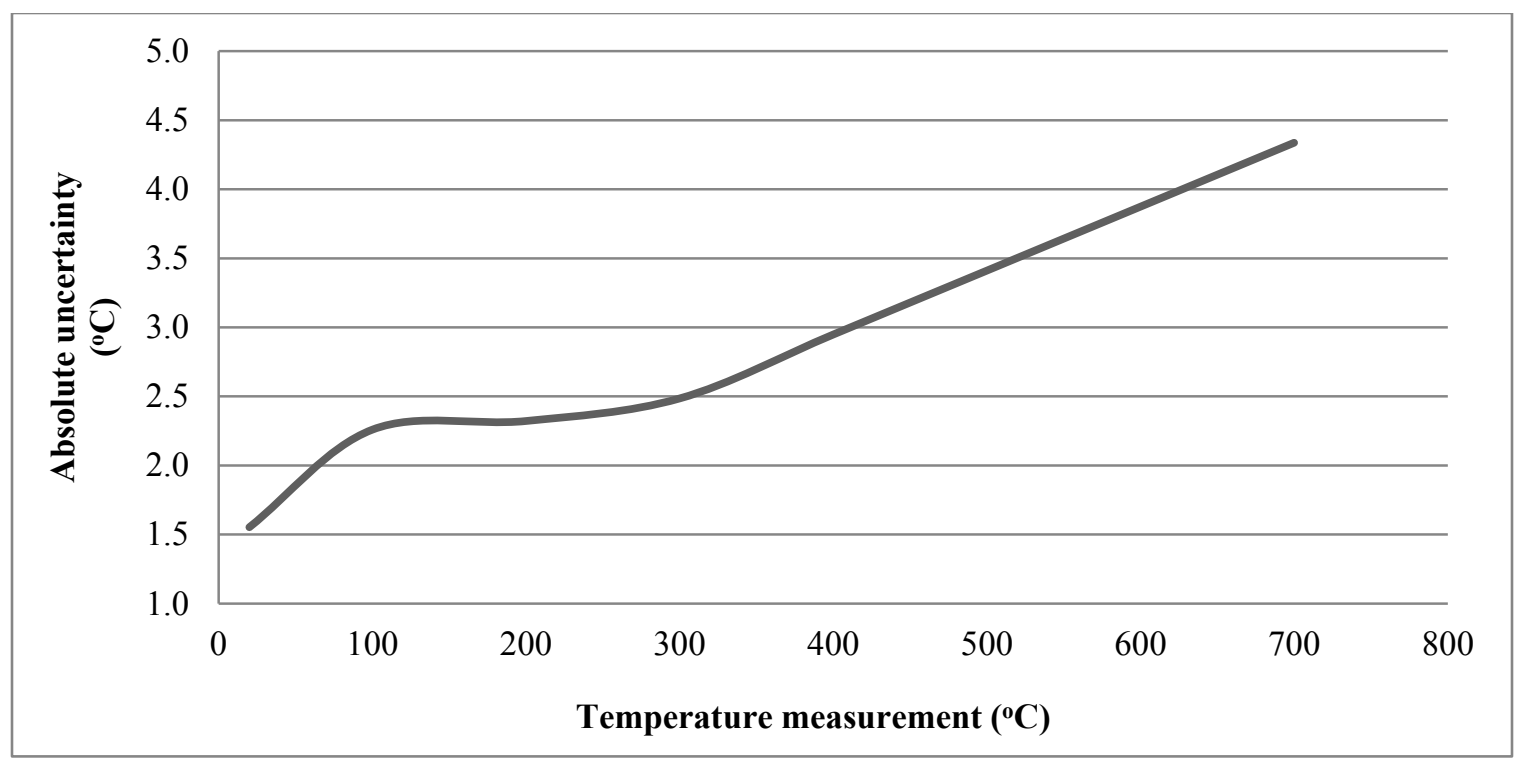

Figure 41: Total uncertainty of the temperature measurements

\subsubsection{Error Propagation for the Convection Heat Transfer Coefficient}

If a physical parameter, $Y$, is a function of a series of independent variables, $X_{j}$, then the uncertainty of this parameter can be estimated through [48]:

$$
e_{p}=\sqrt{\left(\frac{\partial Y}{\partial X_{j}} e_{j}\right)^{2}}
$$

where $e_{p}$ is the propagated absolute uncertainty for the physical parameter of interest, $Y$, and $e_{j}$ is the absolute uncertainty for the independent variable, $X_{j}$.

Here, the physical parameters of interest are the convection heat transfer coefficient, $h$, and the total pressure loss within the test section, $\Delta P_{o, t e s t}$. The independent variables affecting these two physical parameters can be identified by establishing governing equations which relate the sensor measurements listed in Table 27 and these 
two parameters of interest. Then, the absolute uncertainties, $e_{j}$, and the derivatives, $\frac{\partial Y}{\partial X_{j}}$, can be found.

The convection heat transfer coefficient of the working fluid at the test section can be calculated through:

$$
h=\frac{I^{2} R}{A\left(T_{\text {wall }}-T_{\text {bulk }}\right)}
$$

where $h$ is the forced convection heat transfer coefficient $\left(\mathrm{W} / \mathrm{m}^{2}{ }^{\circ} \mathrm{C}\right) ; T_{\text {wall }}$ is the wall surface temperature of the heater at the test section $\left({ }^{\circ} \mathrm{C}\right) ; T_{\text {bulk }}$ is the bulk temperature of the working fluid $\left({ }^{\circ} \mathrm{C}\right) ; I$ is the electric current through the heated wall of the test section (A); $R$ is the electric resistance of the heated wall of the test section $(\Omega)$ and $A$ is the heat transfer surface area $\left(\mathrm{m}^{2}\right)$.

Based on this governing equation, the independent variables and the corresponding partial derivatives are found and they are listed in Table 28.

Table 28: Independent variables and partial derivatives for evaluating the propagated uncertainties for convection heat transfer coefficient

\begin{tabular}{|c|c|}
\hline $\begin{array}{c}\text { Independent } \\
\text { variables }\end{array}$ & Partial derivatives \\
\hline $\boldsymbol{I}$ & $\frac{2 I R}{A\left(T_{\text {wall }}-T_{\text {bulk }}\right)}$ \\
\hline $\boldsymbol{T}_{\text {wall }}$ & $\frac{-I^{2} R}{A\left(T_{\text {wall }}-T_{\text {bulk }}\right)^{2}}$ \\
\hline $\boldsymbol{T}_{\text {bulk }}$ & $\frac{I^{2} R}{A\left(T_{\text {wall }}-T_{\text {bulk }}\right)^{2}}$ \\
\hline
\end{tabular}


Based on Table 28, the values for several independent parameters are required to complete the error propagation. Thus, a series of operating conditions for the C-R134a Loop were selected for the purpose of the error propagation as shown in Table 29. For the C-SCW Loop, the selected operating conditions are those listed in Table 2.

The absolute uncertainty of the electric current, $I$, is $20 \mathrm{~A}$. The bulk fluid temperature can be calculated by applying the conservations of energy principle:

$$
T_{b u l k}=T_{i n}+\frac{I^{2} R}{c_{p} \rho Q}
$$

where $T_{\text {bulk }}$ is the local bulk fluid temperature $\left({ }^{\circ} \mathrm{C}\right) ; T_{\text {in }}$ is the bulk fluid temperature at the inlet of the test section $\left({ }^{\circ} \mathrm{C}\right) ; c_{p}$ is the isobaric specific enthalpy $\left(\mathrm{J} / \mathrm{kg}{ }^{\circ} \mathrm{C}\right) ; \rho$ is the density of the working fluid at the flow meter $\left(\mathrm{kg} / \mathrm{m}^{3}\right)$ and $Q$ is the volume flow rate measured by the flow meter $\left(\mathrm{m}^{3} / \mathrm{s}\right)$.

Using this equation, the bulk fluid temperature at any location where the thermocouples are installed can be obtained. The system pressure is considered as constant through the test section. In this case, the uncertainty for estimated bulk fluid temperature is obtained using the method as that described for calculating the uncertainty for the convection heat transfer coefficient (i.e. obtaining the partial derivative of $T_{b u l k}$ with respect to $T_{i n}, I, c_{p}, \rho$ and $Q$ ). 
Table 29: C-R134a Loop operating scenarios considered for the error propagation

\begin{tabular}{|c|c|c|c|}
\hline & & Subcritical & Supercritical \\
\hline Test section $t$ & & All three & st section \\
\hline System presst & MPa) & $1.7 / 4$ & $4.4 / 6$ \\
\hline Test section & Inlet & 40 & 100 \\
\hline$\left({ }^{\circ} \mathrm{C}\right)$ & Outlet & $80 / 90 / 100$ & $110 / 125 / 140$ \\
\hline $\begin{array}{l}\text { Heat input at } \\
\text { section/flow } r\end{array}$ & & $\begin{array}{l}\text { Maximum } \\
\text { established } \\
\text { limits (whi } \\
\text { possible flc } \\
\text { the test sec } \\
\text { outlet temp } \\
\text { - Minimum } \mathrm{f} \\
\text { established } \\
\text { flux }(500 \mathrm{k} \\
\text { minimum } \mathrm{p} \\
\text { through the } \\
\text { the desired } \\
\text { temperatur }\end{array}$ & $\begin{array}{l}\text { d on the } \\
\mathrm{n} \text { temperature } \\
\text { esult in maximum } \\
\text { can be heated by } \\
\text { desired test section } \\
\text { ased on the } \\
\text { test section mass } \\
\text { hich would result in } \\
\text { ired so that the flow } \\
\text { n can be heated to } \\
\text { n outlet }\end{array}$ \\
\hline
\end{tabular}

During the experiments, $T_{\text {wall }}$ is measured by the thermocouples. However, since there are no temperature measurements available at the time of writing of this manuscript, these measurements must be estimated for the purpose of error propagation. As the heat input and the bulk fluid temperature are already determined based on the scenarios listed in Table 2 and Table 29, the heater wall surface temperature can be obtained using a Nusselt number correlation [18]:

$$
N u_{D_{h}}=0.023 \operatorname{Re}_{D_{h}}^{0.8} \operatorname{Pr}^{0.4}
$$

where $N u_{D_{h}}, R e_{D_{h}}$ and $P r$ are the Nusselt number, the Reynolds number and the Prandtl number for the working fluid flow through the test section, respectively; the subscript, $D_{h}$, 
indicates that the affixed parameters are evaluated based on the hydraulic diameter of the test section, which was defined in Section 3.2.1.

This equation can be used to find the convection heat transfer coefficient, which in turn can be used to calculate the wall temperature. It should be noted that this correlation is chosen as a compromise to predict the wall temperature of the heated surface, because there is no accurate Nusselt number correlation available for flow with bulk fluid temperature within critical/pseudo-critical region. Outside the critical/pseudocritical region, this correlation can produce relatively reliable results. Using the convection heat transfer coefficient calculated here and the bulk fluid temperature calculated based on the fore-mentioned method in this section, the wall temperature can be calculated using Eqn. (82). The absolute uncertainty of the wall temperature measurements can then be calculated based on the thermocouple manufacturer's specifications listed in Table 25 and the results are shown in Figure 41. It should also be noted that the convection heat transfer coefficient, $h$, hereby calculated is also used to calculate the relative uncertainty defined as:

$$
e_{r p, h} \%=100 \% \times \frac{e_{p, h}}{h}
$$

where $e_{r p, h}$ is the relative uncertainty of the convection heat transfer coefficient and $e_{p, h}$ is the propagated uncertainty for the convection heat transfer coefficient $\left(\mathrm{W} / \mathrm{m}^{2}{ }^{\circ} \mathrm{C}\right)$. The results of the error propagation for the convection heat transfer coefficient are shown in Figure 42 to Figure 47. 


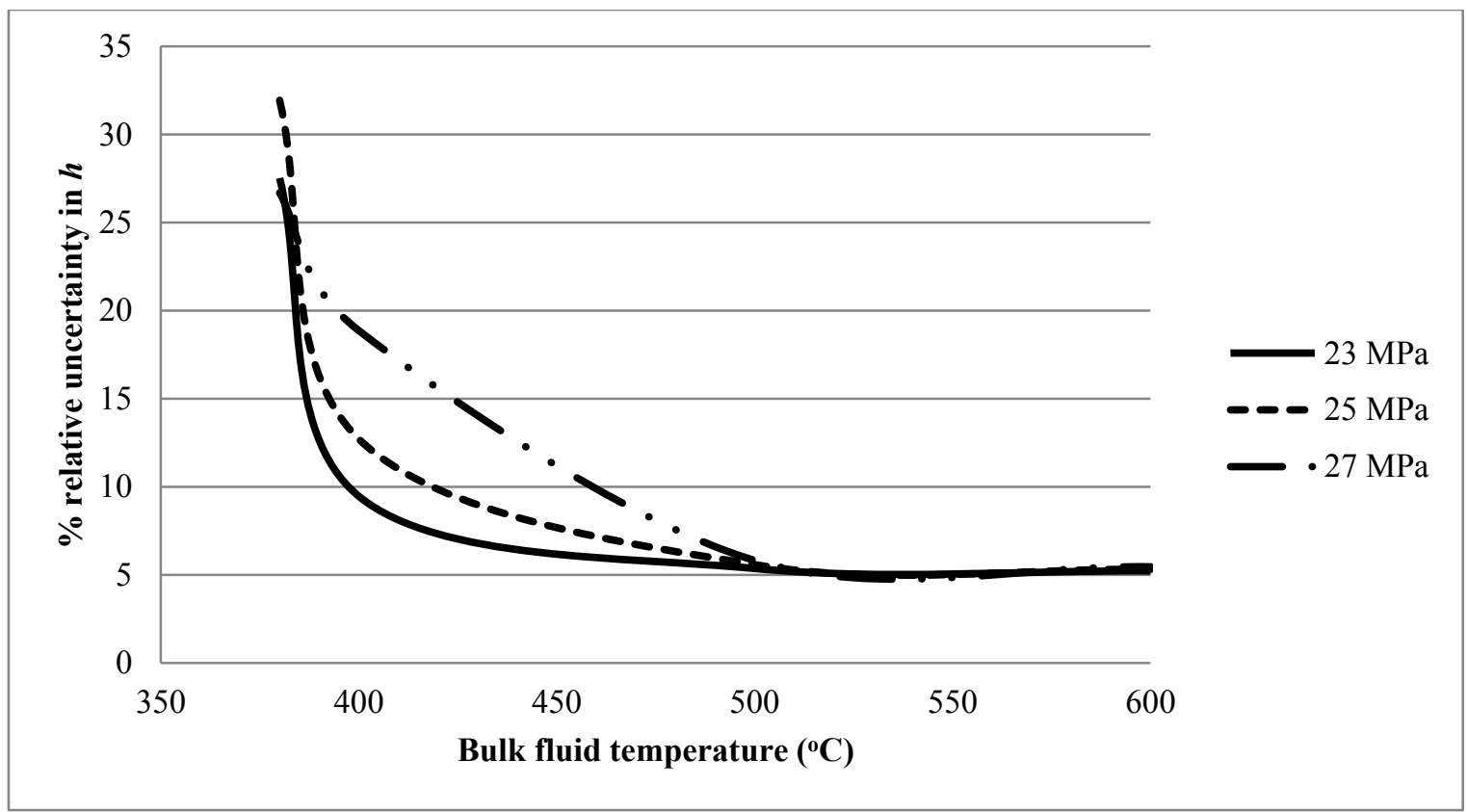

Figure 42: Relative uncertainty for the convection heat transfer coefficient in the test section for the C-SCW Loop with the tubular test section installed

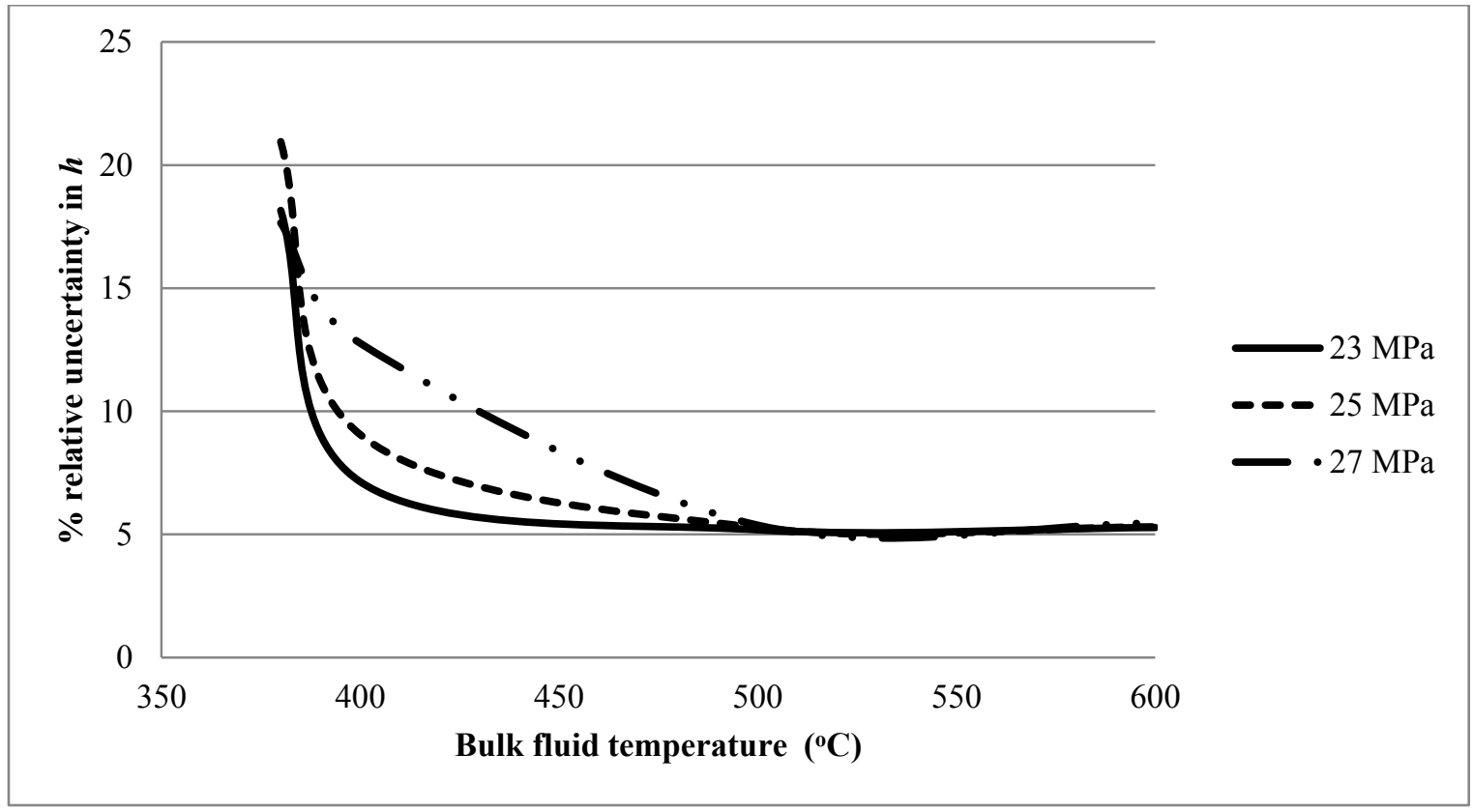

Figure 43: Relative uncertainty for the convection heat transfer coefficient in the test section for the C-SCW Loop with the annular test section installed 


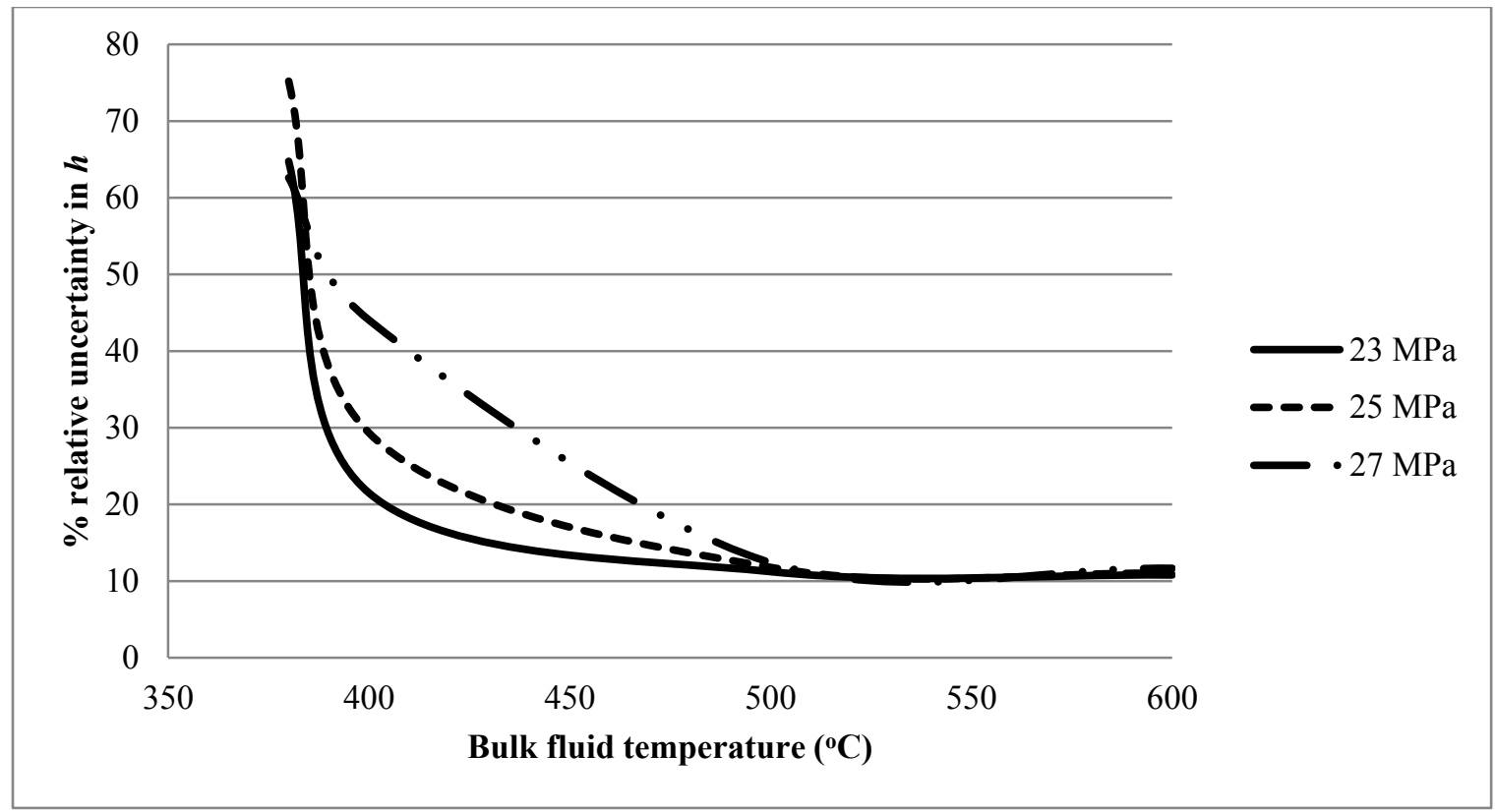

Figure 44: Relative uncertainty for the convection heat transfer coefficient in the test section for the C-SCW Loop with the 7-rod bundle test section installed

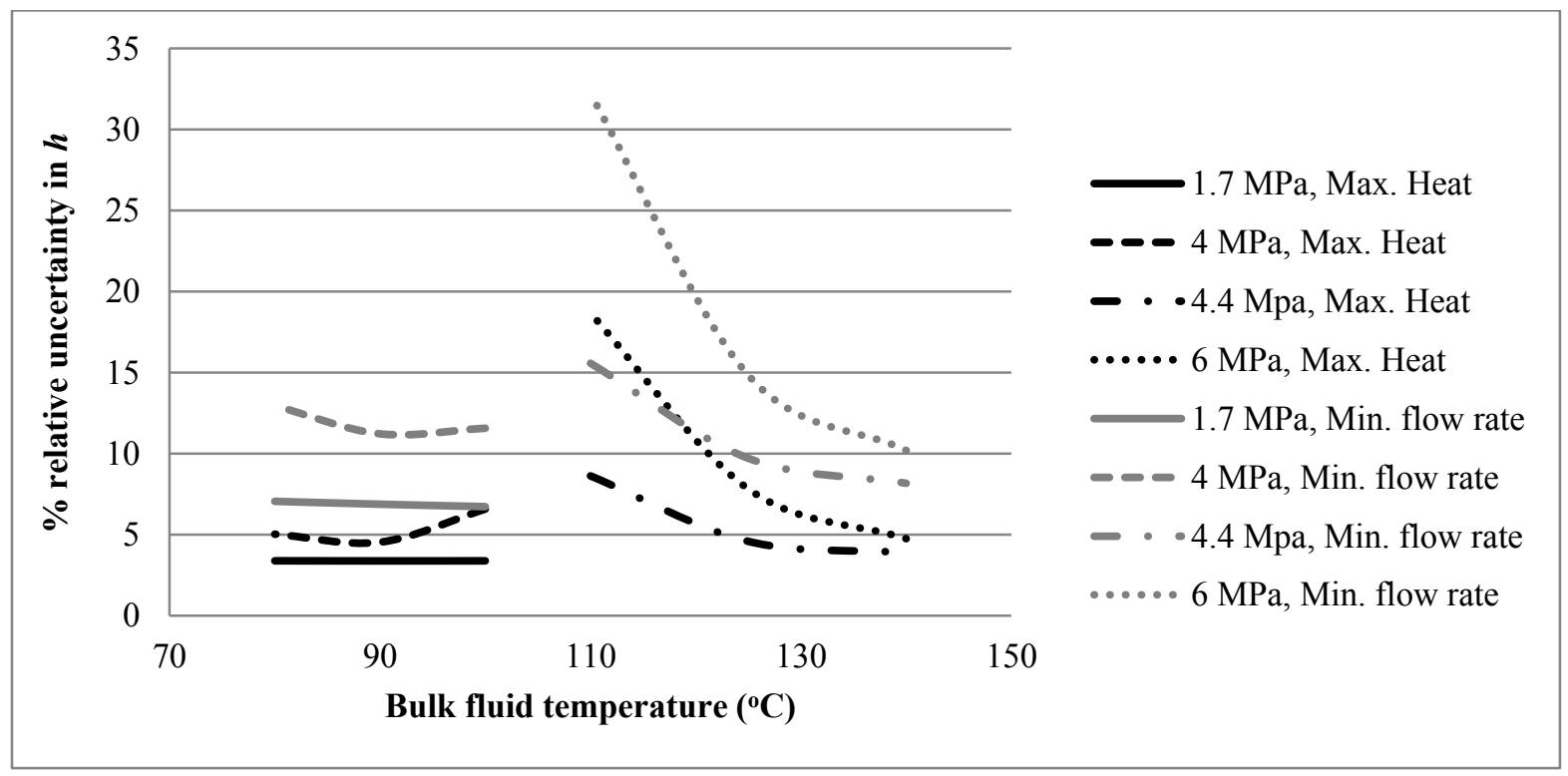

Figure 45: Relative uncertainty for the convection heat transfer coefficient in the test section for the C-R134a Loop with the tubular test section installed 


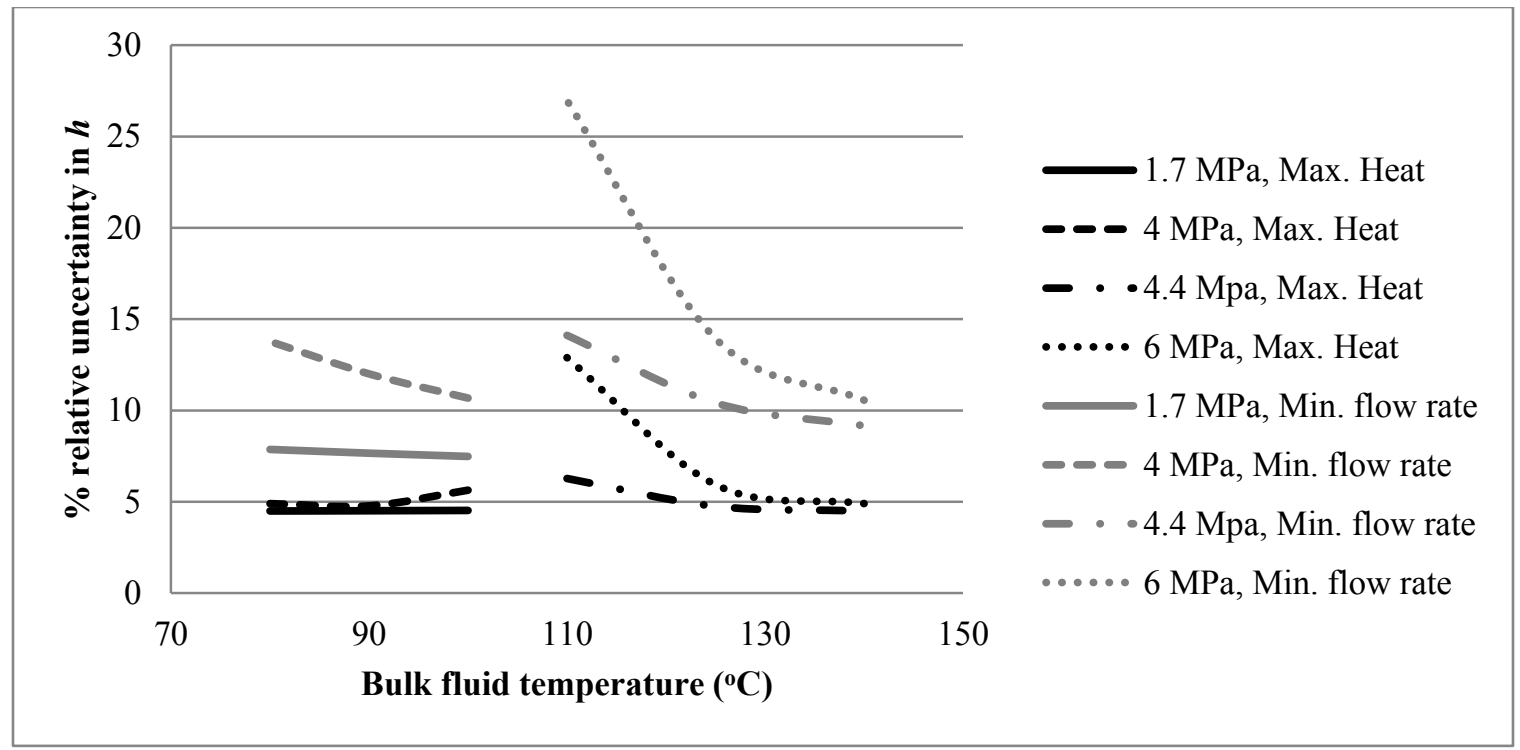

Figure 46: Relative uncertainty for the convection heat transfer coefficient in the test section for the C-R134a Loop with the annular test section installed

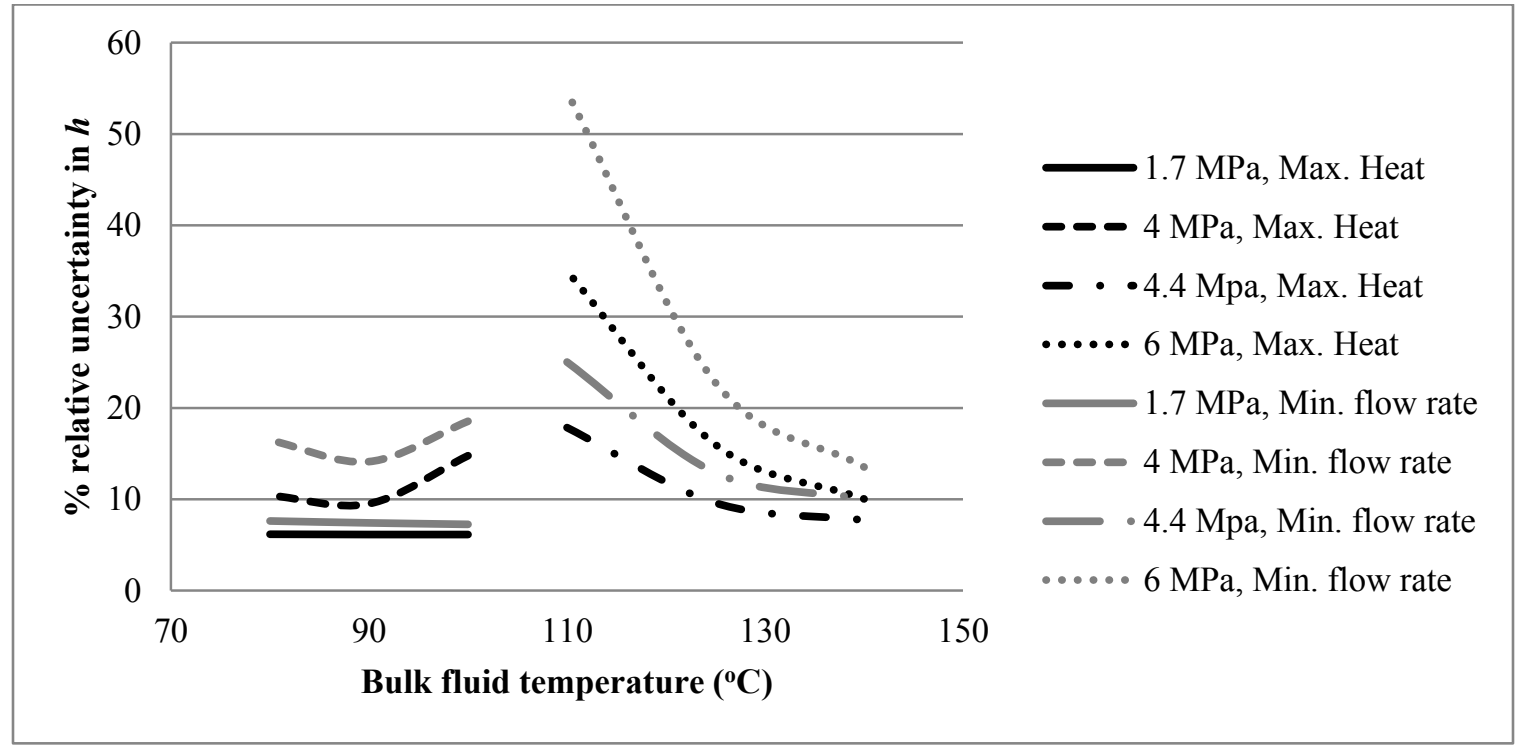

Figure 47: Relative uncertainty for the convection heat transfer coefficient in the test section for the C-R134a Loop with the 7-rod bundle test section installed

In these figures, the system pressures are indicated in the data legends. The data legend, Max.Heat, indicates that the error propagation is performed based on the 
operating condition where the heated wall in the test section is imparting maximum amount heat into the fluid and, similarly, the data label, Min. flow rate, indicates that the error propagation is done using a flow rate calculated based on the minimum test section mass flux (500 kg/m $\mathrm{m}^{2} \mathrm{~s}$ for both test loops) specified by the designer of the main loop [2]. As shown in these figures, as the temperature approaches the critical/pseudo-critical point of the fluids (which is around $380^{\circ} \mathrm{C}$ for water and around $100^{\circ} \mathrm{C}$ for $\mathrm{R}-134 \mathrm{a}$ depending on the system pressure), the propagated uncertainty of the heat transfer coefficient becomes significant. The reason can be explained as follows: when the bulk fluid temperature approaches the critical/pseudo-critical temperature, the heat transfer coefficient predicted by the Nusselt number correlation used here (Eqn. (84)) tends to become large to the point where the difference between the wall temperature and the bulk fluid temperature becomes small enough to be comparable with the uncertainty of the bulk fluid/wall temperature (e.g. at a system pressure of $23 \mathrm{MPa}$ with the tubular test section installed, the uncertainty for $T_{\text {bulk }}=380^{\circ} \mathrm{C}$ is $+/-2.8^{\circ} \mathrm{C}$ and the uncertainty for corresponding wall temperature, $T_{\text {wall }}=386^{\circ} \mathrm{C}$ is $+/-2.9^{\circ} \mathrm{C}$, while the difference between $T_{\text {bulk }}$ and $T_{\text {wall }}$ is only $6^{\circ} \mathrm{C}$ ). This can incur huge relative uncertainty in the resulting convection heat transfer coefficient.

The uncertainty for the total pressure loss is estimated in a similar way. Figure 48 shows the setup of the differential pressure transducer on the two test loops. The differential pressure transducer is installed on an impulse tube, which connects to the inlet and outlet of the test section. The impulse tube is installed to prevent the sensor from being overheated by the high temperature of the working fluid flowing in the test section. In this figure, the angular position, $\theta$, is measured from the horizontal plane. In 
this particular orientation of the test section shown in Figure 48, the working fluid in the test section is flowing upward against gravity and in this case, the angular position, $\theta$, is defined on the range between 0 and $90^{\circ}$ (i.e. 0 being the horizontal position and $90^{\circ}$ being the working fluid flowing in a vertically upward direction). In a similar way, when the flow is flowing downward, the corresponding angular position is defined from 0 to $-90^{\circ}$ (i.e. $-90^{\circ}$ being the working fluid flowing in a vertically downward direction).

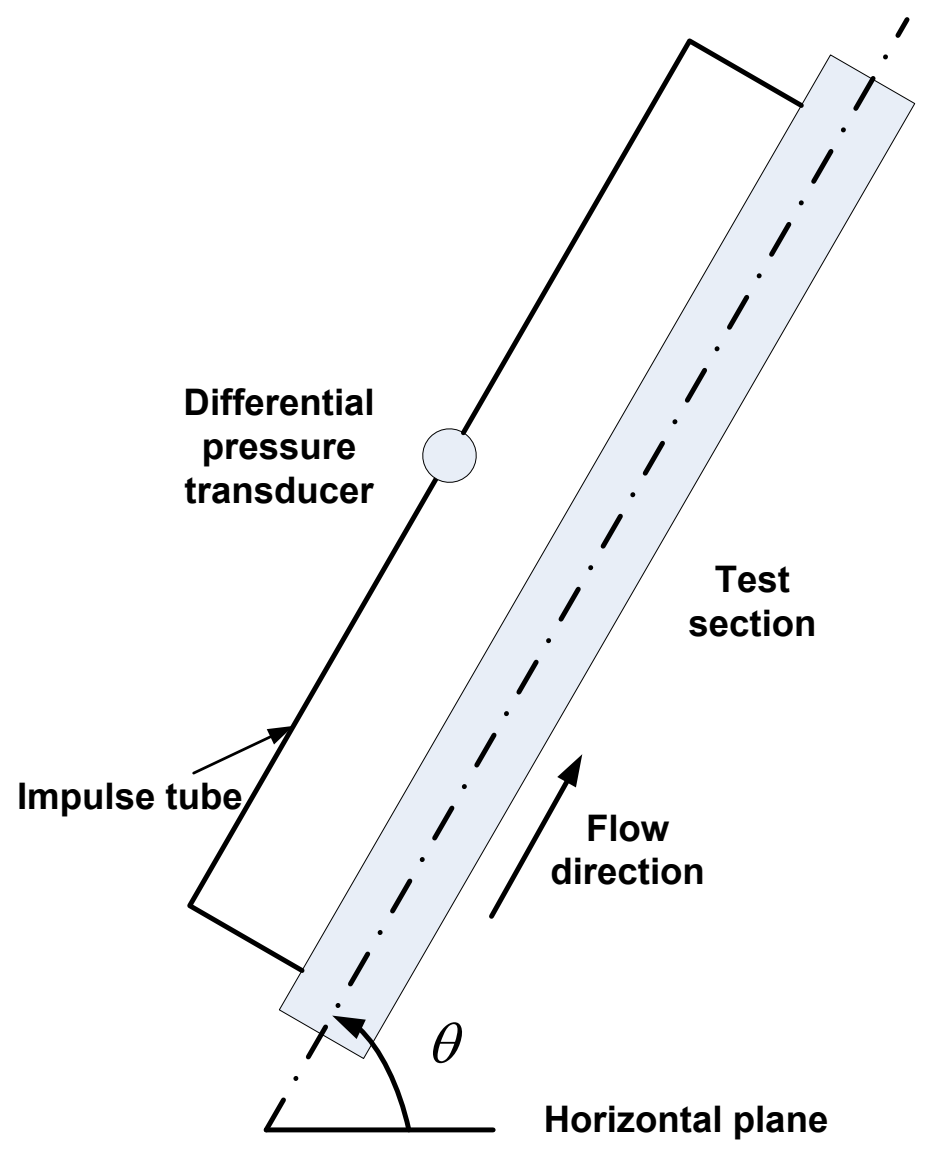

Figure 48: Setup of the differential pressure transducer on the two test loops

Based on setup shown in this figure, a governing equation relating the total pressure loss and the differential pressure transducer reading can be written: 


$$
\begin{aligned}
& \Delta P_{\text {o test }}=\Delta P_{\text {measured }}+\rho_{\text {impulse }} g L \sin \theta-\frac{\rho_{\text {in }}+\rho_{\text {out }}}{2} g L \sin \theta \\
& -\left(\frac{1}{\rho_{\text {out }}}\left(\frac{\rho_{f} Q}{A_{\text {flow }}}\right)^{2}-\frac{1}{\rho_{\text {in }}}\left(\frac{\rho_{f} Q}{A_{\text {flow }}}\right)^{2}\right)
\end{aligned}
$$

where $g$ is the gravitational acceleration $\left(\mathrm{m} / \mathrm{s}^{2}\right) ; L$ is the length of the test section $(\mathrm{m}) ; \rho_{\text {in }}$ and $\rho_{\text {out }}$ are the bulk fluid density at the inlet and outlet of the test section respectively $\left(\mathrm{kg} / \mathrm{m}^{3}\right) ; \rho_{f}$ is the bulk fluid density at the location where the flow meter is installed $\left(\mathrm{kg} / \mathrm{m}^{3}\right) ; Q$ is the volume flow rate measured by the flow meter $\left(\mathrm{m}^{3} / \mathrm{s}\right) ; A_{\text {flow }}$ is the flow area of the test section $\left(\mathrm{m}^{2}\right) ; \rho_{\text {impulse }}$ is the density of the working fluid in the impulse tube $\left(\mathrm{kg} / \mathrm{m}^{3}\right)$ and $\Delta P_{\text {measured }}$ is the reading of differential pressure transducer, which can be expressed as:

$$
\Delta P_{\text {measured }}=P_{\text {in }}-P_{\text {out }}
$$

where $P_{\text {in }}$ and $P_{\text {out }}$ are the pressures at the sensing ports of the differential pressure transducer measuring the static pressure at the inlet and outlet of the test section, respectively $(\mathrm{Pa})$. To simplify the analysis, it is assumed that the water in the impulse tube of the C-SCW Loop is at constant temperature, $200^{\circ} \mathrm{C}$. Based on the calculation carried out by another member of the research team and for the C-R134a Loop, since the operating temperature of this test loop is significantly lower than that for the $\mathrm{C}-\mathrm{SCW}$ Loop, it is assumed that the R-134a fluid in the impulse tube is at room temperature, which is conservatively taken as $30^{\circ} \mathrm{C}[2]$.

The resultant independent variables and their partial derivatives are identified in Table 30. Similar to the uncertainty propagation for the heat transfer coefficient, the 
values and the uncertainties for the parameters listed in Table 30 must be obtained. The values of these parameters are obtained based on the scenarios presented in Table 29 and the uncertainties for these parameters are either obtained from the NIST tables or from those reported in Figure 38 through Figure 41 [6]. In addition, since the angular position, $\theta$, is involved, 3 angular positions, $\theta=0^{\circ}, 90^{\circ}$ and $-90^{\circ}$, are selected for studying the effect of the variation of $\theta$ on the total uncertainty for the pressure loss. It was found that the angular position has negligible effects on the propagated error for the pressure loss. As such, only the results of the error propagation for horizontally oriented test sections are included in the presentation of the final results here and they are shown in Figure 49 through Figure 54. Again, in this set of figures, relative uncertainties are used and they are defined as:

$$
e_{r p, p} \%=100 \% \times \frac{e_{p, p}}{\Delta P_{o \text { test }}}
$$

where $e_{r p, p}$ is the relative uncertainty for the total pressure loss in the test section; $e_{p, p}$ is the propagated uncertainty for the total pressure loss in the test section $(\mathrm{Pa})$. 
Table 30: List of independent variables and their partial derivatives

\begin{tabular}{|c|c|}
\hline $\begin{array}{c}\text { Independent } \\
\text { variables }\end{array}$ & Equations for partial derivatives \\
\hline$\rho_{\text {impulse }}$ & $g L \sin \theta$ \\
\hline$\rho_{\text {out }}$ & $-\frac{g L \sin \theta}{2}+\frac{1}{\rho_{\text {out }}^{2}}\left(\frac{\rho_{f} Q}{A_{\text {flow }}}\right)^{2}$ \\
\hline$\rho_{\text {in }}$ & $-\frac{g L \sin \theta}{2}-\frac{1}{\rho_{\text {in }}^{2}}\left(\frac{\rho_{f} Q}{A_{\text {flow }}}\right)^{2}$ \\
\hline$\rho_{f}$ & $-\left(\frac{1}{\rho_{\text {out }}}-\frac{1}{\rho_{\text {in }}}\right)\left(\frac{2 \rho_{f} Q^{2}}{A_{\text {flow }}^{2}}\right)$ \\
\hline$\Delta P_{\text {measured }}$ & $-\left(\frac{1}{\rho_{\text {out }}}-\frac{1}{\rho_{\text {in }}}\right)\left(\frac{2 \rho_{f}^{2} Q}{A_{\text {flow }}^{2}}\right)$ \\
\hline$Q$ & \\
\hline
\end{tabular}

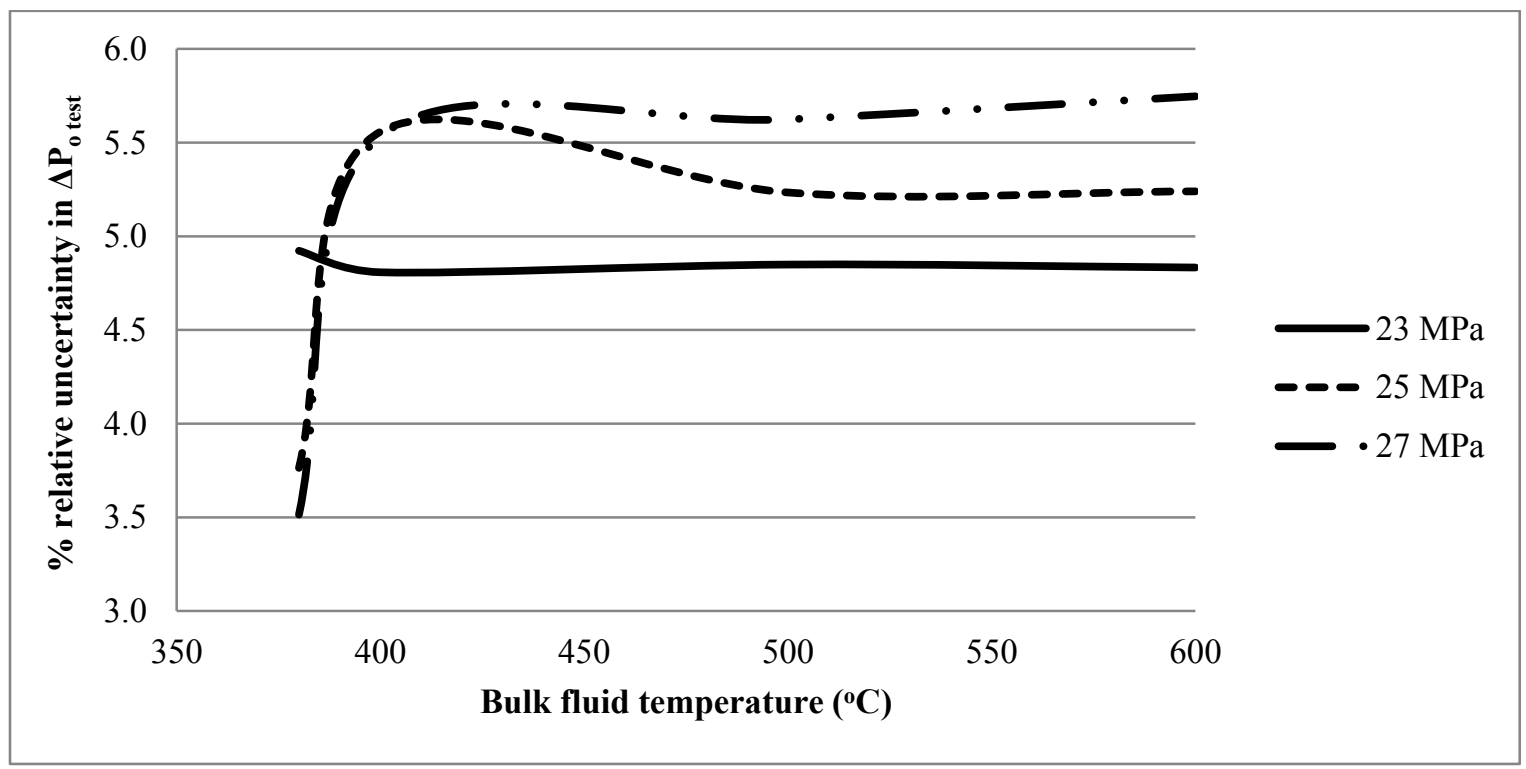

Figure 49: Relative uncertainty for the total pressure loss in the test section for the C-SCW Loop with the tubular test section installed 


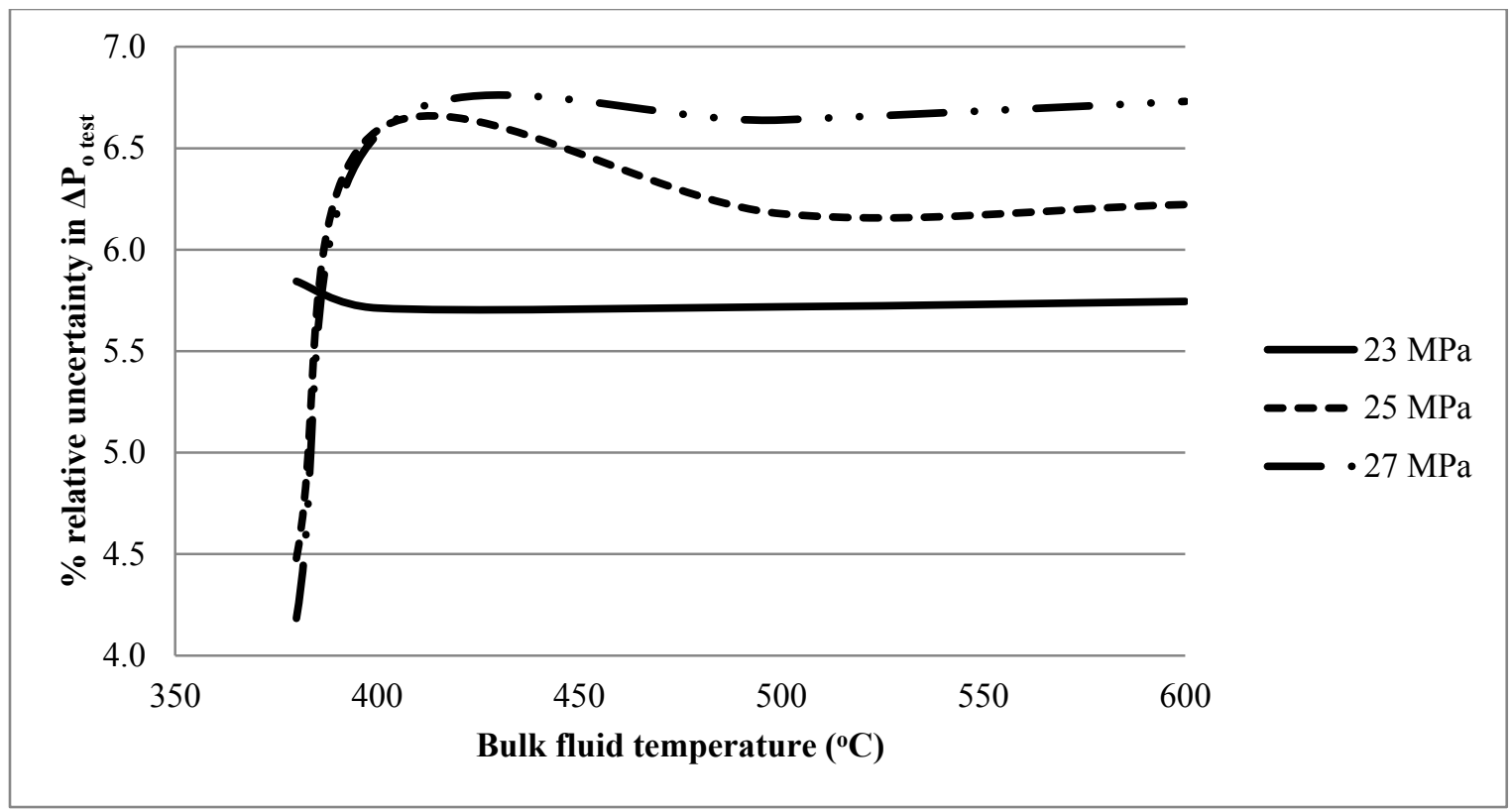

Figure 50: Relative uncertainty for the total pressure loss in the test section for the C-SCW Loop with the annular test section installed

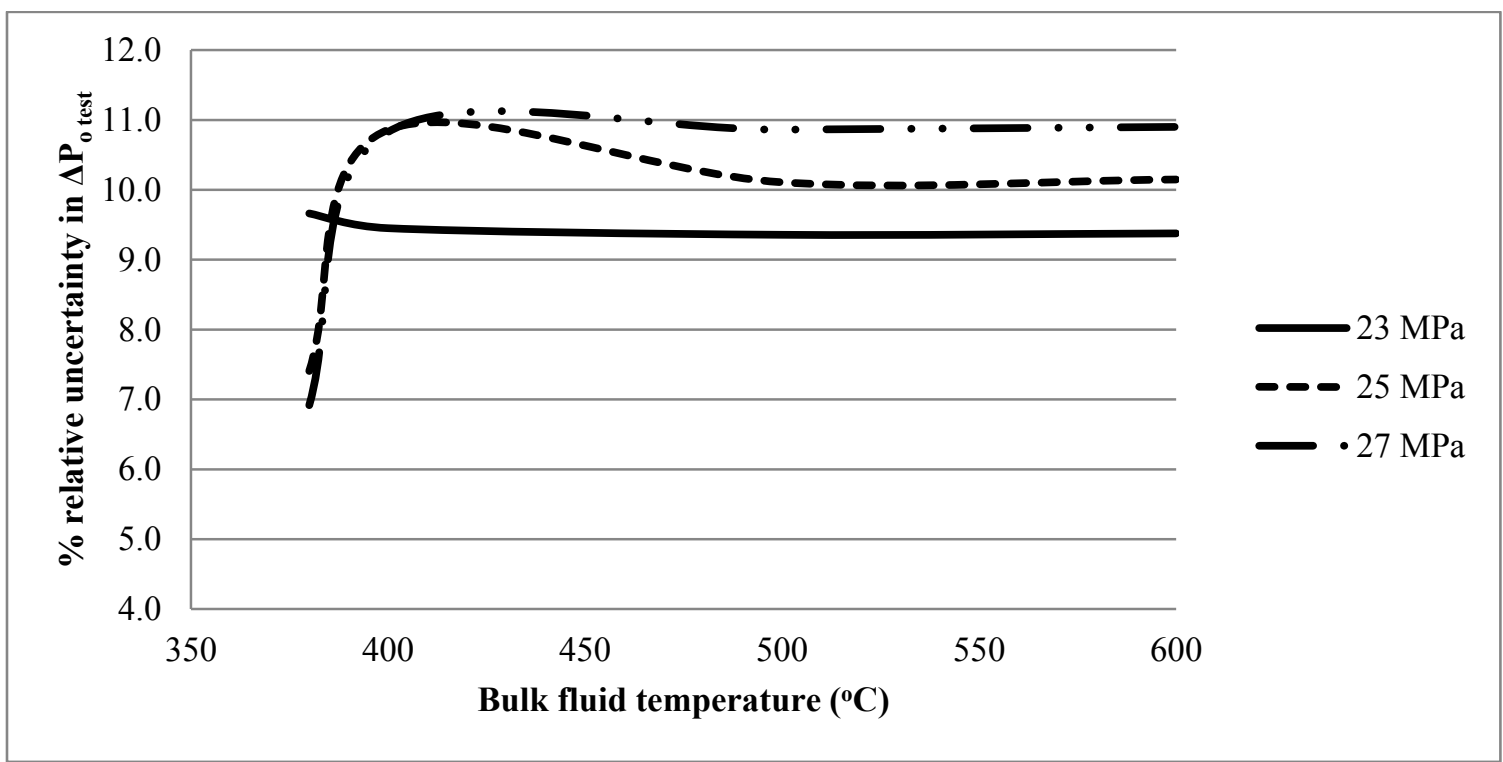

Figure 51: Relative uncertainty for the total pressure loss in the test section for the C-SCW Loop with the 7-rod bundle test section installed 


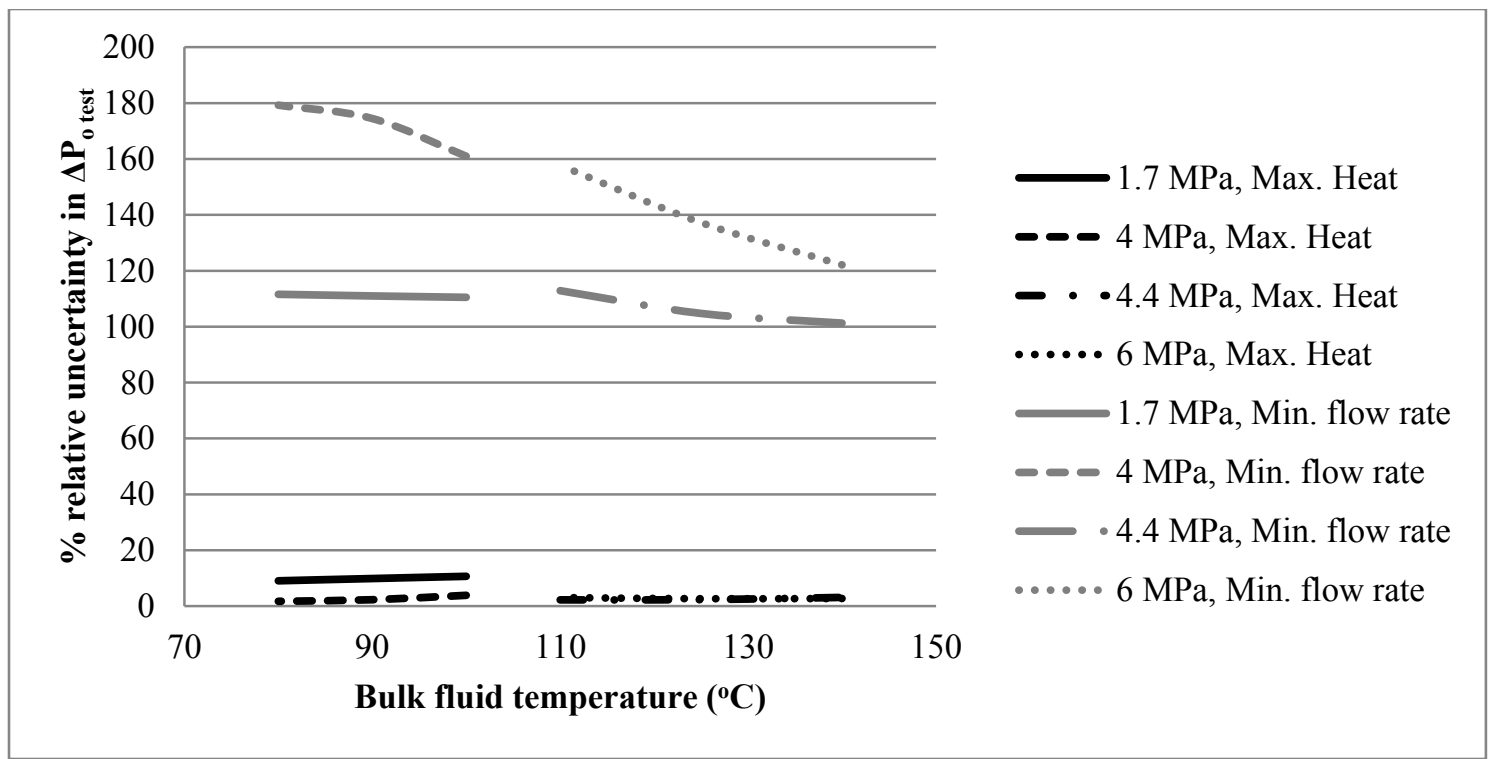

Figure 52: Relative uncertainty for the total pressure loss in the test section for the C-R134a Loop with the tubular test section installed

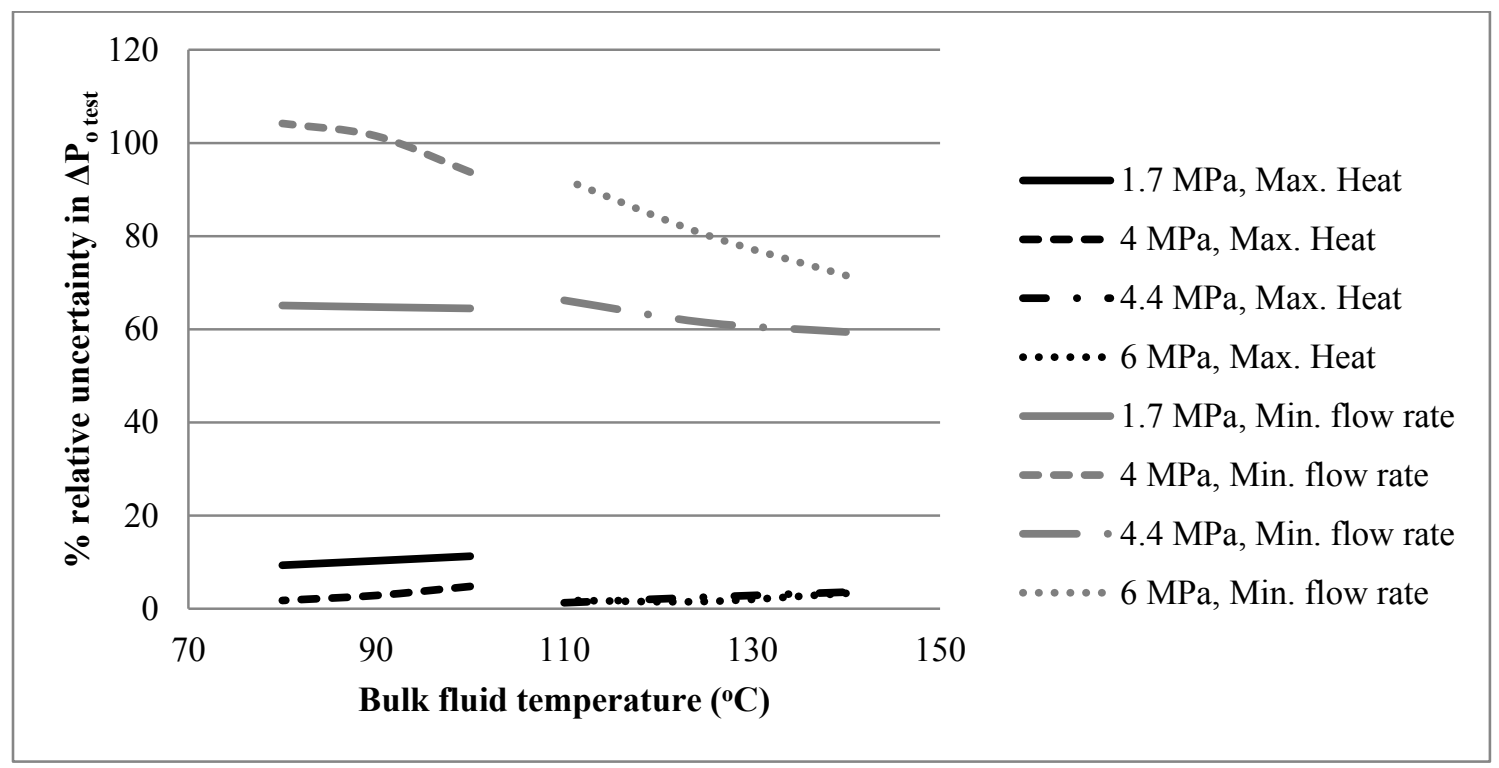

Figure 53: Relative uncertainty for the total pressure loss in the test section for the C-R134a Loop with the annular test section installed 


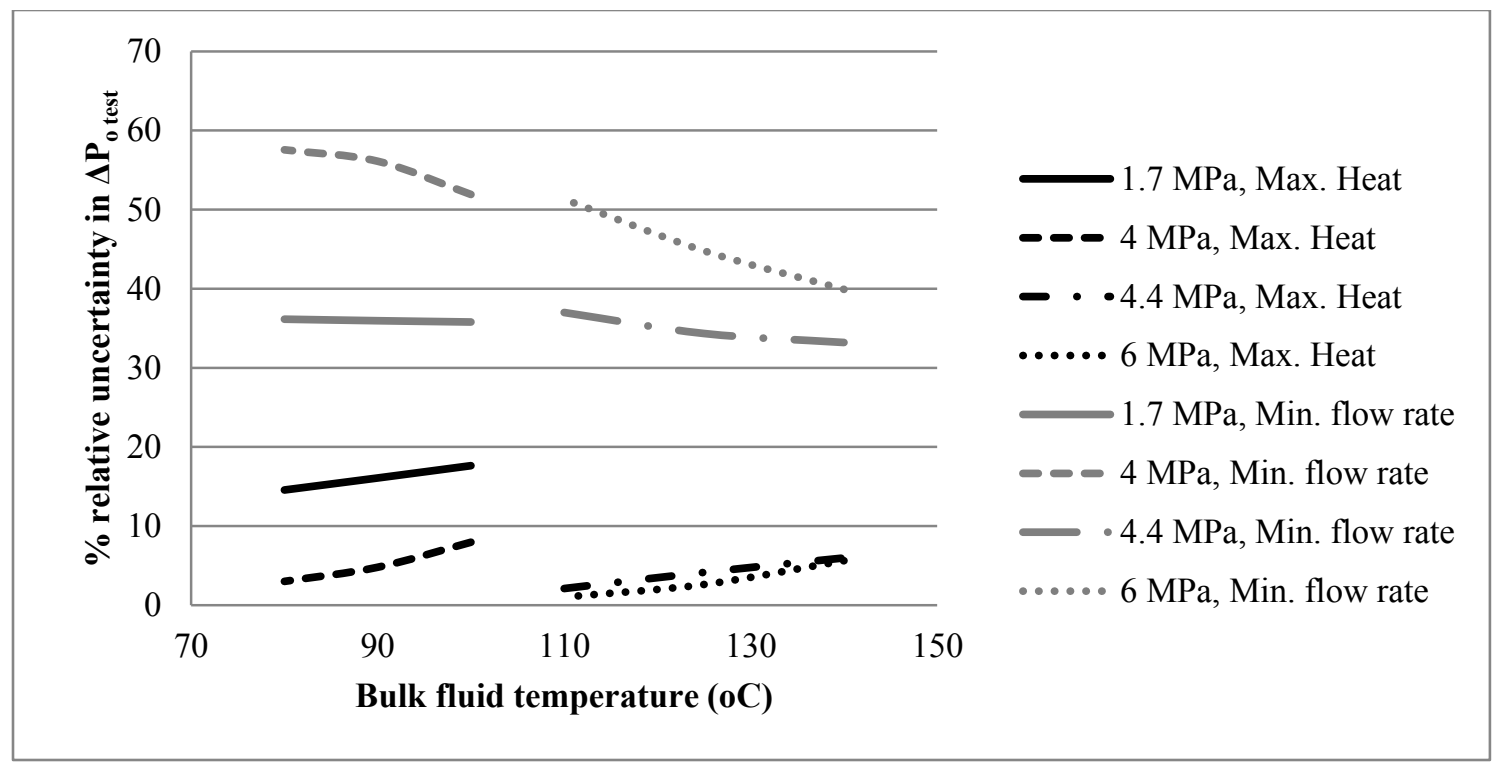

Figure 54: Relative uncertainty for the total pressure loss in the test section for the

\section{C-R134a Loop with the 7-rod bundle test section installed}

It is worth noting that for the C-R134a Loop, the relative uncertainties in all minimum flow cases are very high. This is because the differential pressure transducer installed on the C-R134a Loop has an inherent measurement uncertainty of $+/-750 \mathrm{~Pa}$, while in cases where the C-R134a Loop is running at its minimum flow rate, the total pressure loss of the flow inside the test section tends to approach this uncertainty value or even becomes smaller than this value. This yields a very large relative uncertainty for the predicted total pressure loss of the flow in the test section.

\subsection{Design of the Virtual Control Panel}

\subsubsection{Overview}

The virtual control panel is designed to allow the operator to monitor and control the test loops through a computer workstation. The control panel is created using National Instruments ${ }^{\circledR}$ LabVIEW $^{\mathrm{TM}}$ 2010. The design of the control panel has brought the 
human factor into consideration to minimize human error and confusion when the test loop is operated.

\subsubsection{Literature review}

Computers have been used for control and process automation for a long time. In modern control and process systems, increasing involvement of computers has changed the role of the human operator. More and more routine tasks have been assigned to the computers as the computers are less prone to errors in performing repetitive tasks. The following reviews the basic concepts in the design of a graphical user interface for controlling purposes.

\subsubsection{Supervisory Control}

Removing some of the tasks from human operators shifts their role from being in direct control to being in supervisory control. The term, "supervisory" is a mimic of the relationship between human operator and the automated controller: the human operators are acting as supervisors; the automated controllers and their subsystems are acting as the intelligent subordinates $[51,52,53]$. The "staff subordinates" use their computer algorithms to execute the inputs from the "supervisors". After the actions are carried out, the "staff subordinates" collect and translate the data which infers the result of the action and the state of the system and then feed this package of information back to their "supervisors" for further instructions [52].

\subsubsection{Design Philosophy of Human-Computer Interface}

Designing of a human-computer interface (HCI) is a multidisciplinary task which requires the designer to have knowledge of social science, human psychology, cognitive 
engineering, and system engineering $[52,54,55]$. A poorly designed HCI will quickly overwhelm the operator and can result in catastrophic system failures. The scope of this survey is to obtain the design guidelines involving human-computer interactions, especially on the design of visual display terminals (VDT).

Guidelines and principles are presented in most of the control design books dedicated to ergonomics and human factors. Extensive survey works have been done on the study of human factors and usability of the control features on VDT. These references present the results of case studies conducted on real world HCI designs. The findings of such literature are summarized in the following sections.

\subsection{System and Task Analysis}

In order to design a working automated control system, the designer has to first translate the design requirements into a list of small tasks both for the computers and for the operators. This important procedure is called system and task analysis $[54,56]$. Nachreiner, et al (2005) referred to this procedure as task interface design [51].

Depending on the scenarios, the tasks could be roughly divided into two categories:

- Tasks for normal operations (routine operations)

- Tasks for situations where anomaly is detected (e.g. alarms are triggered; non-routine operations)

Each of these two broad categories could be further divided into two sub-categories:

- Tasks for human operators; and

- Tasks for automation controllers

Once the tasks are set up, they should be used as the basis for the design of the graphical user interface (GUI). This can substantially help the designer to simplify the interface design. 


\subsection{Layout and Features of a Properly Designed Virtual Control Panel}

A good control panel is self-explanatory. There are numerous methods that lead to an effective design of a control panel. The following section describes the guidelines that are suggested by the literatures.

\section{Visual Attraction and Rest Points}

Visual attraction points are the physical points on the computer monitors that human eyes naturally pay more attention to. In contrast, when human eyes reach the visual rest points, the mind of the user tends to calm down. The following is a list of visual attraction points and rest points suggested in [57]:

- Visual attraction points

○ Corners of the screen

$\circ$ Tilted lines

○ Moving objects or objects with complicated shape

- Objects with outstanding sizes or colors

- Visual rest points

○ Horizontal lines

- Calming color

○ Blanks and margins

For users, visual attraction points are "easier to find" than visual rest points. Designers can use these points to establish the contrast between the important and secondary features of a virtual control panel [57]. The results of the system and task 
analysis can then be used to help in deciding on the locations of the control objects. Designers should place the most important or most used feature (i.e. high priority objects) in visually attractive regions. On the other hand, the visual rest points could be used to present important explanatory texts or warning messages that require users to read patiently [57].

To take advantage of the visual attraction and rest points, one has to prioritize the objects and features that are to be laid on the control panels [57]. This can be used as the starting point for the design of a virtual control panel.

\section{Visibility of the Objects and Texts}

One of the common design mistakes is that designers often place a series of control elements on the control panel without introducing any visual discrimination [51, 55]. This practice not only undermines the appearance of the control panel, but more importantly also jeopardizes the response time of the human operators.

For a designer, there are numerous ways to help the operator effectively identify and locate the control elements. Apart from using the visual attraction and rest points, the designer could use strategies such as assigning different colors, object shapes, sizes, creating animations to introduce additional attractive points that can call for users' attention [57].

The most common practice is to use colors and shapes to differentiate the objects on the control panel [57]. However, it is important that when using colors or shapes to distinguish objects, the designer should follow the cultural convention. Improper usage of color may cause confusion to the operator. 
Grouping and alignment is another commonly used method to distinguish different groups of controls [57]. A more structured control panel allows the user to easily identify the controls and tends to cause less stress [57].

\subsubsection{Design of the Virtual Control and Monitoring panel}

Based on the review on the design methods of a GUI, a virtual control and monitoring panel design was carried out for the C-R134a and C-SCW Loops. Basically, for each of the test loops, the operation tasks of a human operator can be divided into three categories: monitoring the operating status of the loop, inputting control parameters, and taking experimental measurements at the test section. As such, three different control panels are designed with each performing one of these tasks. Each of the panels is displayed on a dedicated computer monitor. The virtual panel for loop control is located in the middle monitor and the virtual panels for health monitoring and taking and monitoring the experimental data are located on the left and right monitors, respectively. The following section discusses the design of these panels in greater detail.

\subsubsection{Health Monitoring Virtual Panel}

The health monitoring panels designed for the two test loops are shown in Figure 55 and Figure 56. The health monitoring panels for both loops share a similar layout. On this panel, the operator would be able to visually monitor the sensor readings. Instead of giving out a table with a list of sensors and their locations in texts, the loop block diagrams are used here. On the diagrams, all the sensors have been clearly marked with a virtual diode. These diodes are used as indicators for the sensor readings. When the readings of the sensors are within the safe margin of the loop's operating envelope, the indicators would light up as green. However, when the control program detects that a 
sensor's reading is at an abnormal level, it turns the color of the indicator to red. The red indicators would create visual attraction points through their color and would stand out against the white background color of the block diagram.

However, simply having the indicators is not enough, as a red indicator would not be able to tell the operator what kind of malfunction the loop is experiencing. Therefore, the readings of the sensors are provided to the operator. They are shown in the form of a list of numerical indicators. In addition to this list, three graphical plots are added to the right side of the health monitoring virtual panel. Each of them would plot a different kind of reading (in this case, the readings would be temperature, pressure and flow rates) against time. In case of emergency, these plots allow the operator to track the history of the sensor measurements and get a sense of how fast a parameter changes. In case of multiple sensors returning values exceeding their thresholds, the operator can prioritize his response based on the trends shown on the plot. To avoid confusion, the sensor readings would not be plotted on these three graphical plots unless the operator clicks on the indicator on the block diagram. A red circle around the indicator would appear in this case to indicate that the sensor readings are being plotted on the three graphical plots. 


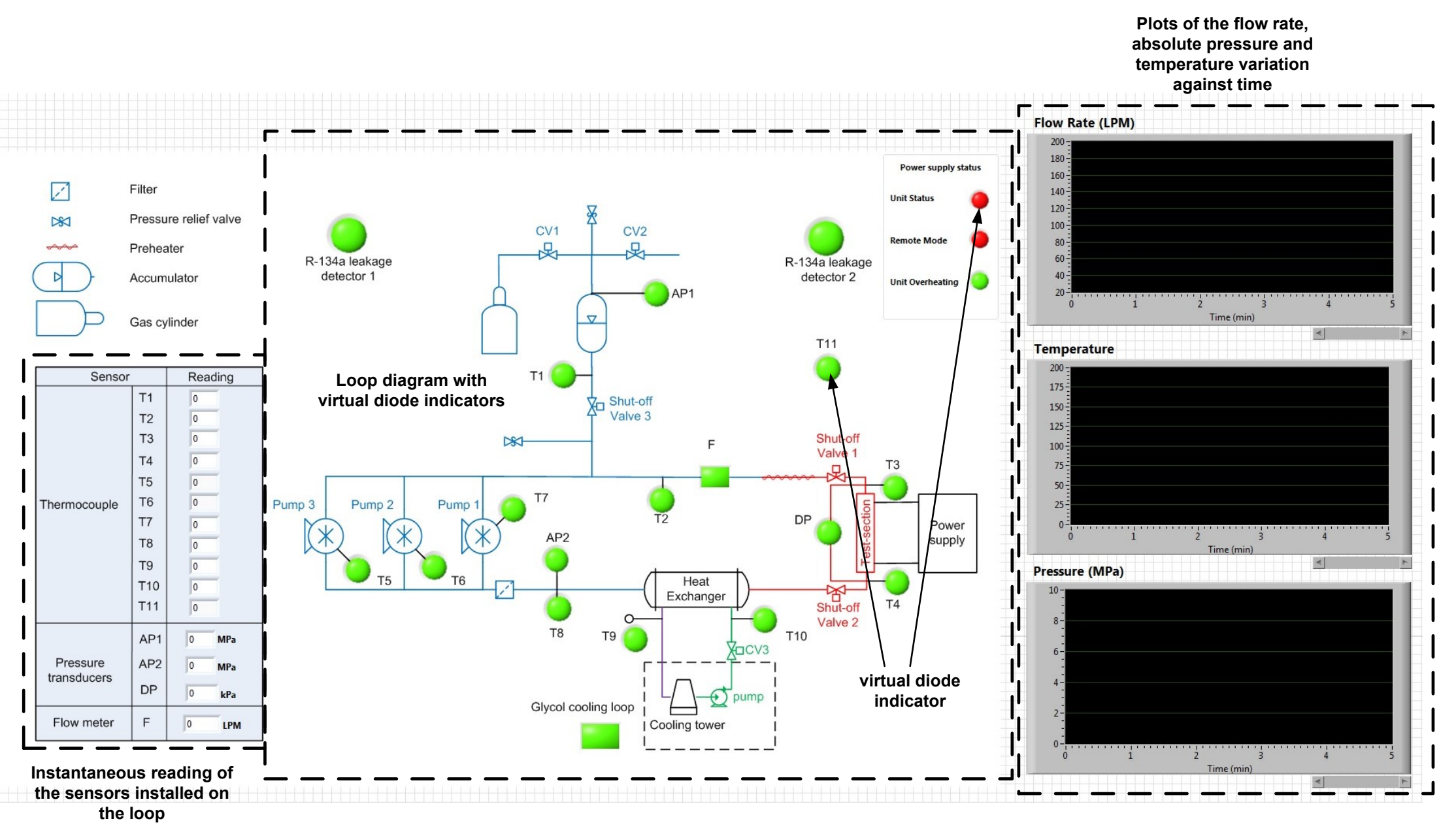

Figure 55: Health monitoring virtual panel for the C-R134a Loop 


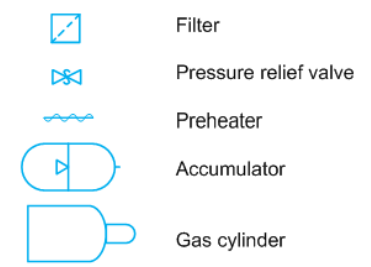

\begin{tabular}{|c|c|c|}
\hline \multicolumn{2}{|l|}{ Sensor } & Reading \\
\hline \multirow{9}{*}{$\begin{array}{c}\text { Thermocouple } \\
\text { (degC) }\end{array}$} & $\mathrm{T} 1$ & 0 \\
\hline & $\mathrm{T} 2$ & 0 \\
\hline & T3 & 0 \\
\hline & T4 & 0 \\
\hline & T5 & 0 \\
\hline & T6 & 0 \\
\hline & T7 & 0 \\
\hline & T8 & 0 \\
\hline & T9 & 0 \\
\hline \multirow{3}{*}{$\begin{array}{l}\text { Pressure } \\
\text { transducers }\end{array}$} & AP1 & $\sqrt{0} \mathrm{MPa}$ \\
\hline & AP2 & $\sqrt{0} \mathrm{MPa}$ \\
\hline & DP & $\sqrt{0} \mathbf{k P a}$ \\
\hline Flow meter & $\mathrm{F}$ & LPM \\
\hline
\end{tabular}
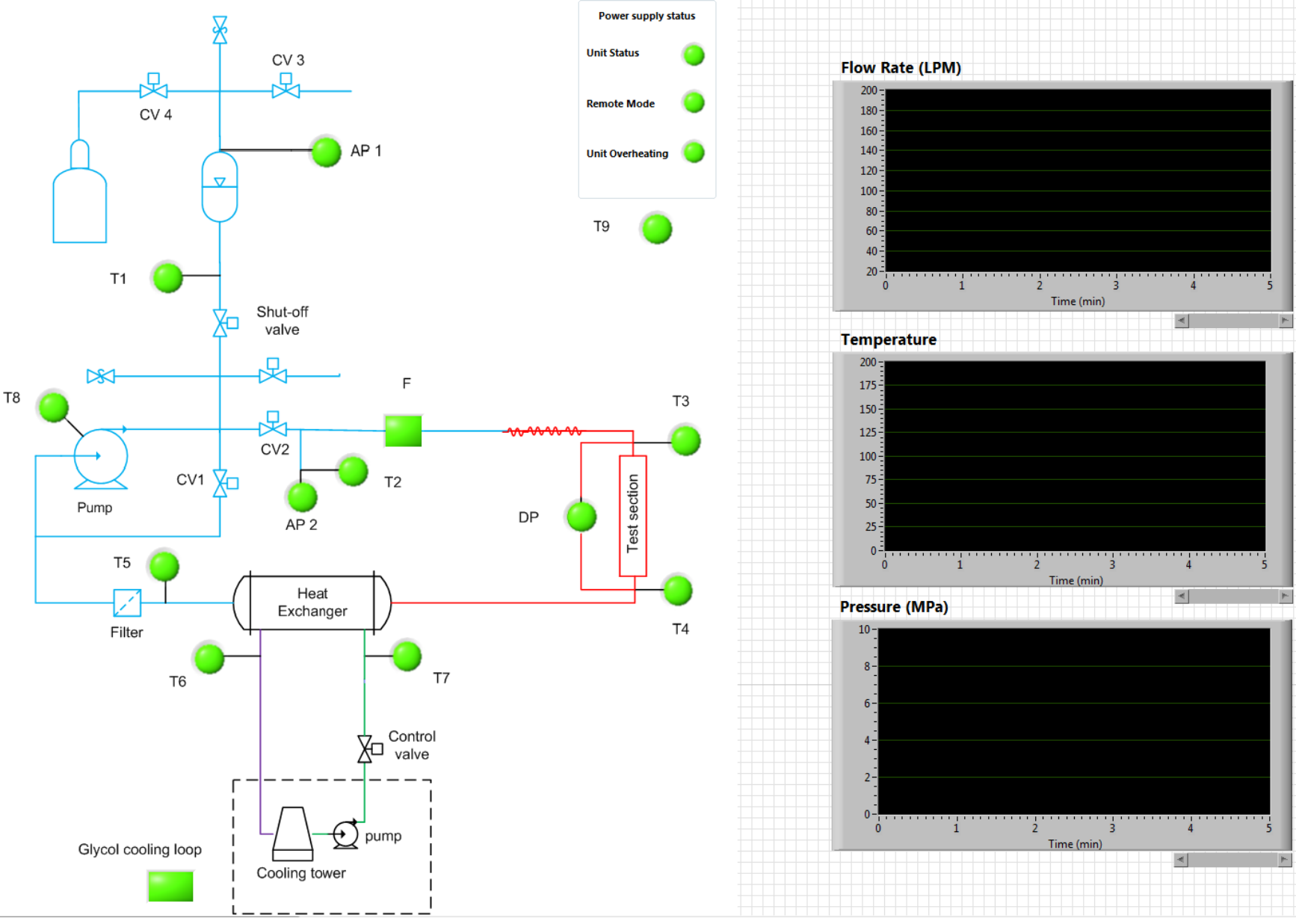

Temperature

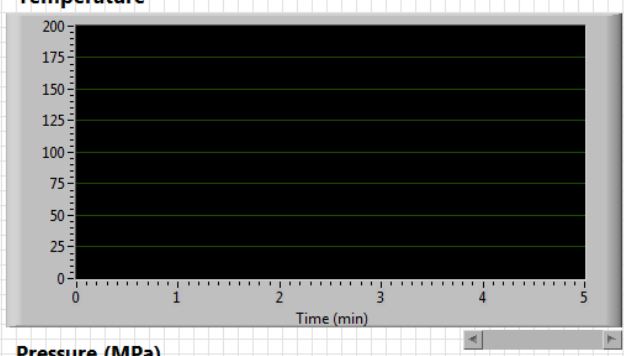

Pressure (MPa)

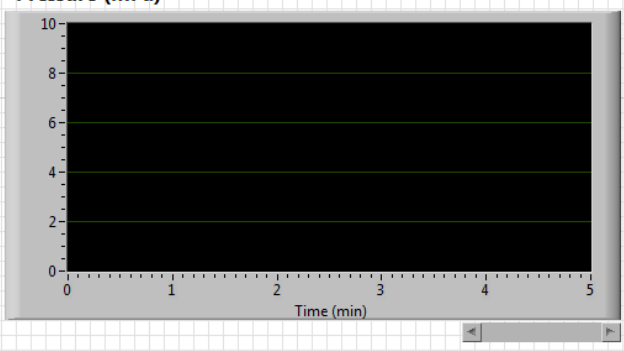

Figure 56: Health monitoring virtual panel for the C-SCW Loop 


\subsubsection{Virtual Panel for Loop Control}

The two virtual panels for loop control for the two test loops are shown in Figure 57 and Figure 58. This panel is divided into five sub-sections based on the tasks of each of the controllers of the test loops. There are three rows of controls and two independent sections on this panel. The first row includes all of the flow controls. These controls include the pump speed control and the valve controls. The controls in the second row control the total heat input to the working fluid in the loop. These include controls for the coolant flow rates through the heat exchanger and the output voltage and current of the electric transformer. The controls in the bottom row control the system pressure. This category of controls include the controls for the globe valves installed on the nitrogen gas side of the loop pressure control module and the shut-off valve installed between the accumulator and the test loop.

A warning message box and an emergency stop button are located at the top right corner of this panel. In case of an incorrect operation or system error, the type of error would be shown in this message box to assist the operator to correct the error. The red emergency stop button is to be used to shut down the power to the loop in case of loop malfunction. These two sections are deemed to be the most important sections on this panel as they are related to the safety of this loop. Therefore, they are placed at the corner of the monitor screen, as the corners of the screens are usually the visual attraction points. In particular, the red stop button is intentionally made to be the largest button on the entire panel. Both the color and the size of this button should make it the easiest button to find even when the operator is under stress. At the bottom right corner of this panel lies the room temperature controllers for the lab. 


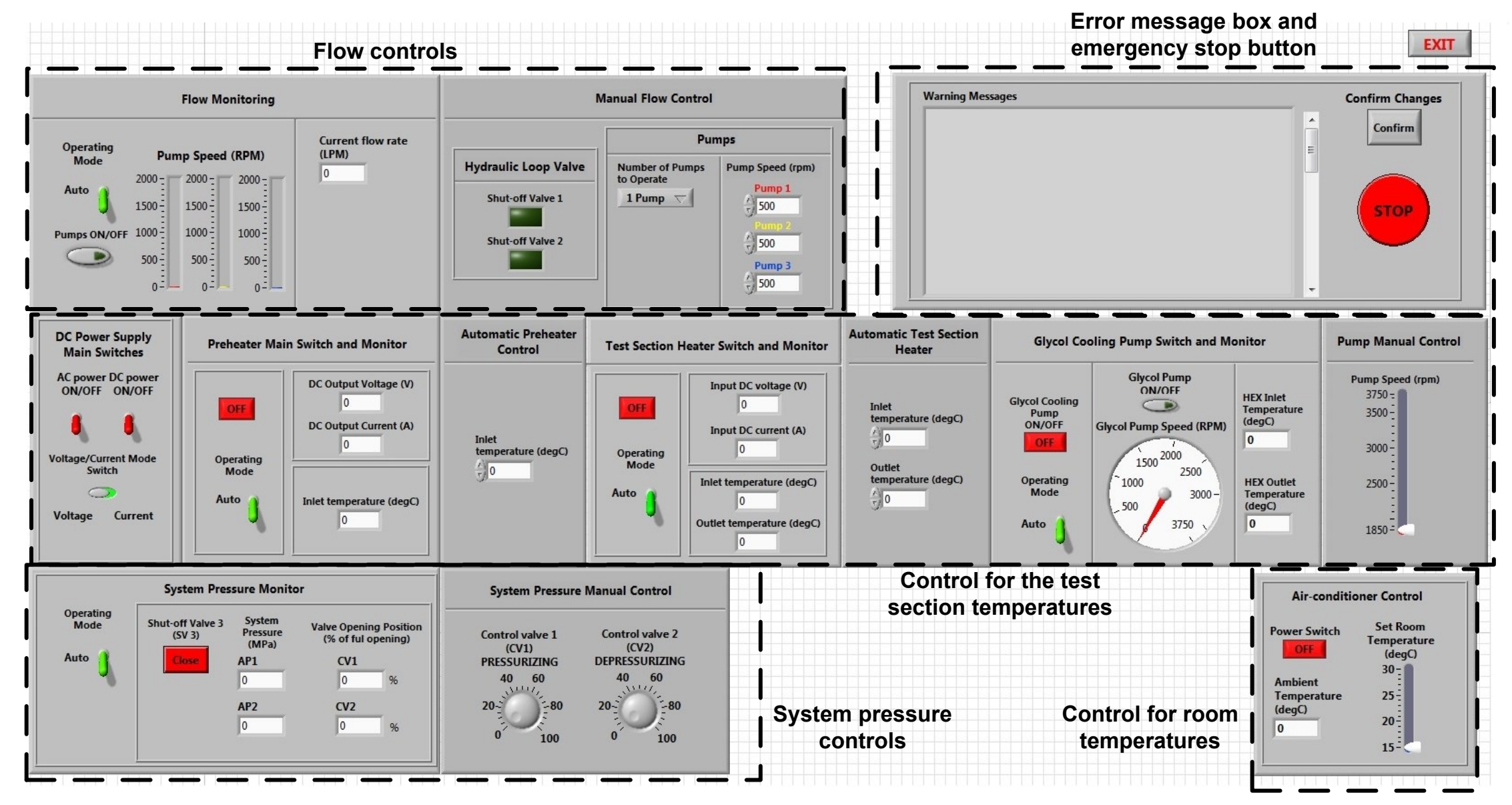

Figure 57: Virtual control panel for the C-R134a Loop 


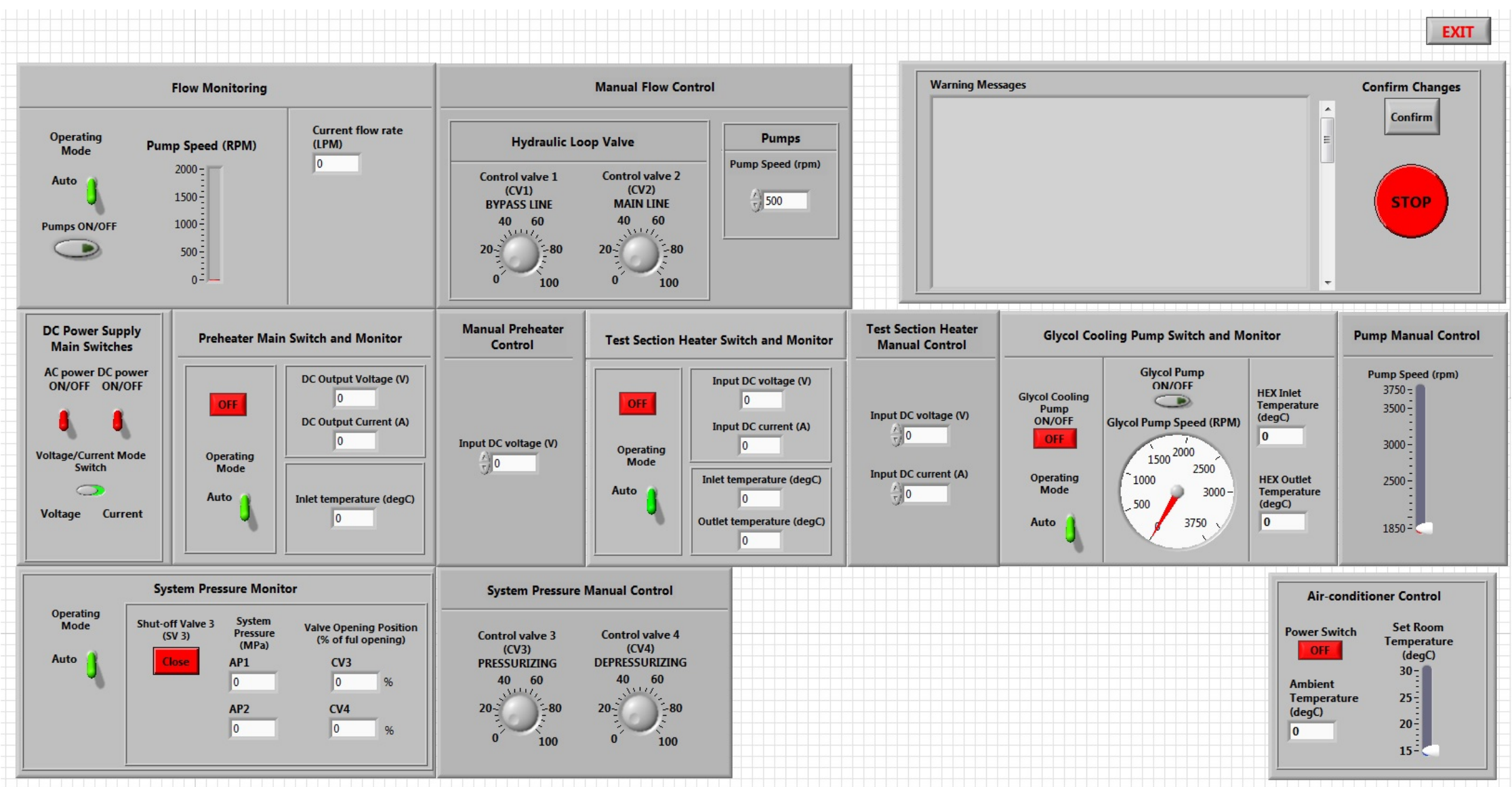

Figure 58: Virtual control panel for the C-SCW Loop 
As explained above, the set of controllers grouped together mostly perform the same control task, and lines/blank spaces are added between these groups such that the operator can easily find the desired controller.

For every type of controller, there would be two modes of control: automated control and manual control. As explained earlier, modern control designs should be a supervisory control design meaning that simple and repetitive control tasks should be completed by the computer. The purpose of setting up the automated control mode is to realize the supervisory control design. In the automated control mode, the input data type is more closely related to the experiments: water/R-134a flow rates, test section inlet and outlet temperature and system pressure. Based on the operator's inputs, the control algorithm would regulate these loop parameters accordingly.

However, occasionally, there might be instances when an operator has to take over the control over the loop. Under these circumstances, the operator can engage the manual control mode by toggling the mode switches. Toggling these switches would hide the automated controls and show the manual controllers at the place where the automated control was. To reach the desired loop operating condition under this mode, the operator would have to closely observe the sensors' readings. For every set of control, there is a sensor reading panel placed right beside the controls. These readings are placed such that the operator does not have to turn to the monitoring panel which is located on the leftside monitor while using the controls shown on the middle monitor.

The color code for this panel follows that set for the health monitoring panel. When the loop is operating, no controller or indicator should be found in red color on this 
panel other than the emergency stop button. This way, if there is a switch that is not turned on, the operator can easily identify it.

\subsubsection{Virtual Panel for Experimental Data}

The virtual panel for experimental data for both test loops is shown in Figure 59. The experimental data mainly include the absolute and differential pressure transducer readings, the temperature readings from the thermocouples installed on the test section and the flow meter readings.

On the upper left corner is a selector for the type of test section installed on the loop. Since each of the test section designs is different, the control program would have to load a different algorithm based on the selected type of test section.

Depending on the selected test section type, the controls shown in this section would also be different. When a specific test section is selected, the controls for the other two types of test section would be hidden. The reason for implementing this technique is again to avoid the panel becoming cluttered with irrelevant controllers during the loop operation, which may cause distraction and confusion to the operator. For the annular and 7-rod bundle test sections, two slider bars are incorporated to control the axial location of the sensors.

On the right side of the panel, there are two graphical plots showing the differential pressure transducer reading and temperature readings along the test section with respect to time. These are the two key measurements of the experiments. The absolute pressure and the flow rates are shown at the upper left corner of the monitor.

The differential pressure transducer reading would always be plotted on the graph, while for the temperature reading plot, to avoid confusion, the operator is offered the 
option to turn on and off the plot for the individual thermocouple readings. The switches controlling the on and off of the temperature graphical plot are placed at the lower left corner of the panel. 
Real time plots for temperature and

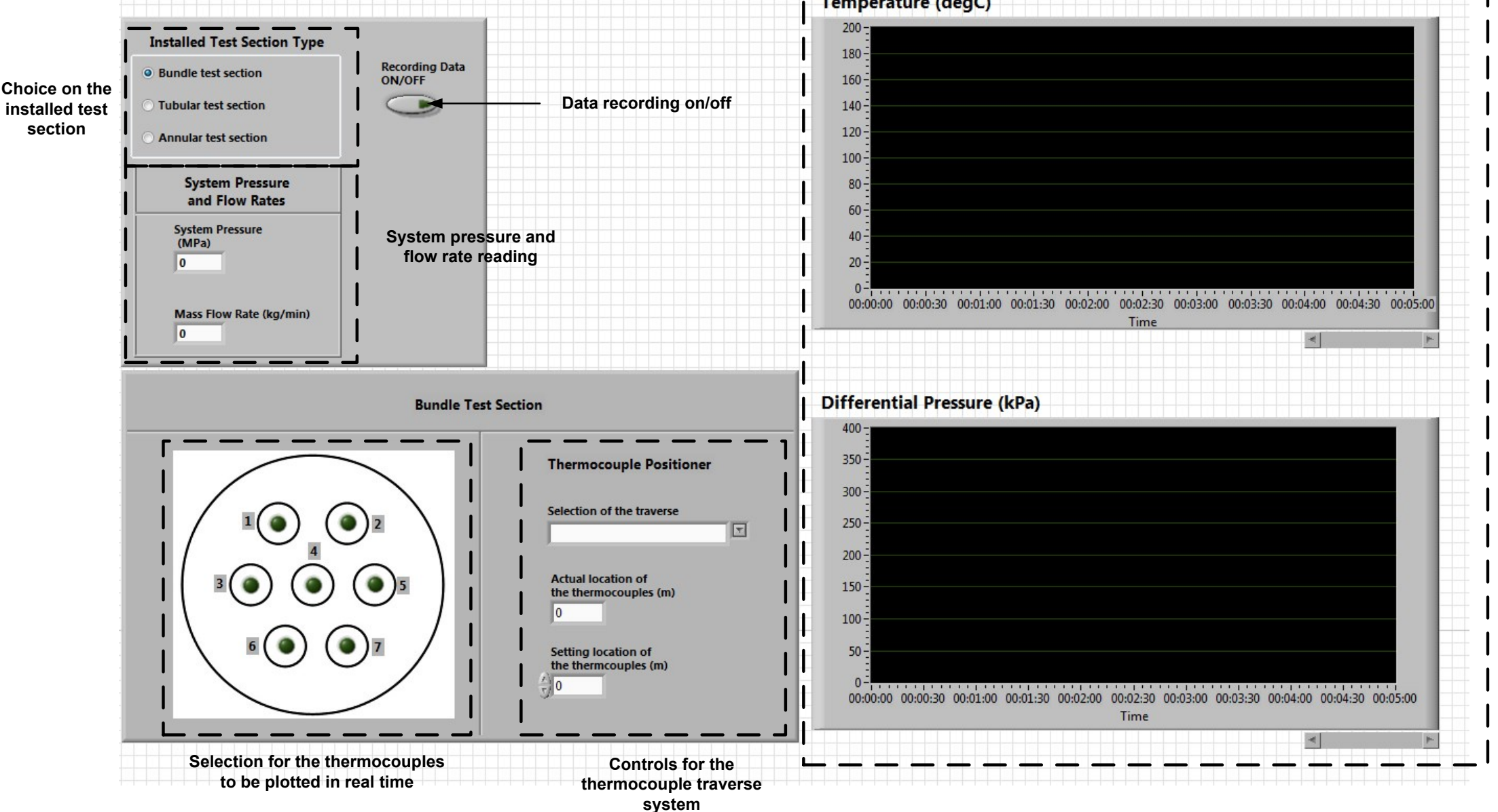

Figure 59: Display for experimental data 


\section{Conclusions}

This thesis work involves a wide range of areas contributions to the development of experimental setups for the study of heat transfer in supercritical fluids. Invaluable experience has been earned from such a multi-disciplinary design effort. This chapter summarizes the highlights of this work.

\subsection{Flow Control Devices on the C-SCW Loop}

This effort focuses on the selection a pump and two control valves for the C-SCW Loop. The pump is installed to compensate for the total pressure losses of water incurred during the operation of the C-SCW Loop. The pump is required to have a total pressure rise of $72.1 \mathrm{kPa}$ at a water mass flow rate of $4.51 \times 10^{-4} \mathrm{~m}^{3} / \mathrm{s}$. At these conditions, the pump is estimated to require a shaft power input of $113 \mathrm{~W}$. The selected pump is manufactured by Klaus Union Gmbh \& Co. It is a centrifugal pump capable of delivering a maximum total pressure rise of $101 \mathrm{kPa}$ with a flow rate range from $5 \times 10^{-4}$ to $2.0 \times 10^{-3} \mathrm{~m}^{3} / \mathrm{s}$. The pump is connected to an electric motor with a shaft power output of $1.1 \mathrm{~kW}$, which is substantially higher than the estimation. There are two reasons for the difference between the predicted and final pump designs: 1 . The final pump was designed by the manufacturer to operate at a flow rate notably greater than required on the test loop, thus necessitating the use of a bypass line and 2 . The pump designed by the manufacturer was coupled to its motor via a magnetic coupling, which introduces an additional source of power dissipation. Thus, the overall efficiency of the final pump design is substantially lower than the estimation made in the preliminary pump sizing. 
To regulate the water flow rate through the test section of the C-SCW Loop, two control valves (globe valves) are installed on the bypass line and the main branch of the loop, respectively. Globe valves are selected for their flow controllability over a wide range of valve opening. Both of the valves have a maximum flow coefficient of 6 , which is a value determined based on the operating flow coefficients of the two control valves: from 2.1 to 4.3 for the valve on the bypass line and from 1.07 to 4.87 for the valve on the main flow path.

\subsection{Pressurization Modules for the Two Test Loops}

Two pressure control modules are designed to regulate the system pressure in the C-SCW and C-R134a Loops and to store the excessive working fluid discharged from the main loop during the loop operation. Each of the modules contains a bladder type accumulator with a total internal volume of $18.9 \mathrm{~L}$, which should be appropriate to hold the working fluids discharged from the respective test loop (a maximum 5.9 $\mathrm{L}$ for the $\mathrm{C}$ SCW Loop and 15 L for C-R134a Loop). For each of the test loops, the inert gas port of the accumulator is connected to a nitrogen gas cylinder and atmosphere so as to achieve dynamic control over the system pressure of the two test loops. Two electrically actuated valves are used to control the rate of pressurization and depressurization. Tubes and compression fittings are used to connect all these components. In order to withstand the pressure exerted by the working fluids and the nitrogen gas, these tubes are made of 316 stainless steel and have an outer diameter of $6.25 \mathrm{~mm}$ with a wall thickness of $1.24 \mathrm{~mm}$.

In particular, for the C-SCW Loop, a section of $2.8 \mathrm{~m}$ long cooling tube is designed to ensure that the accumulator, rated for a maximum temperature of $93^{\circ} \mathrm{C}$, would not be overheated by the discharged water of $260^{\circ} \mathrm{C}$. The cooling tube is made of 316 stainless 
steel with copper fins. Copper is used as the fin material for its high thermal conductivity. Three fans are placed on one side of the cooling tube to facilitate forced-convection heat transfer from the fins. This setup would cool the water discharged into the accumulator from $260^{\circ} \mathrm{C}$ to $73^{\circ} \mathrm{C}$, which gives a $20^{\circ} \mathrm{C}$ safety margin.

A numerical simulation is carried out to investigate ability of solving a convective heat transfer problem using state-of-the-art turbulence models. The simulation is carried out in ANSYS CFX ${ }^{\circledR}$. The results of the simulation show that for cooling tube flow Reynolds number above 6000 , the predicted convective heat transfer coefficient is consistent with that predicted by existing empirical correlations. As the Reynolds number falls below 6000 , the prediction by the numerical simulation tends to over-predict the rate of heat transfer.

\subsection{Design of the DAQ System}

Various sensors are installed on the two test loops to monitor the test loop's operating conditions and collect experimental data. The selection of the temperature sensors is a part of this thesis work. Based on specifications of the test loops and the pros and cons of various commercially available temperature sensors, $\mathrm{N}$ type thermocouples are selected for the two test loops. The smallest possible thermocouple is desired in this case, because a smaller sensor size would give a faster time response. As such, the selected $\mathrm{N}$ type thermocouple has a sheath diameter of $1.59 \mathrm{~mm}$ giving a rated maximum temperature of $920^{\circ} \mathrm{C}$, which is higher than the maximum temperature that could possibly be encountered on the two test loops $\left(723^{\circ} \mathrm{C}\right)$.

There are a total of 7 voltage-based sensor signals $(0-5 \mathrm{~V}$ or $0-10 \mathrm{~V})$ for the $\mathrm{C}$ SCW Loop and 11 such signals for the C-R134a Loop (excluding the sensors installed on 
the test section). For the test section, a maximum of 32 thermocouple sensor signals are utilized. The required resolution for analog-to-digital converter is 9 bit and the required minimum sampling rate is $0.4 \mathrm{~Hz}$. To accommodate these criteria, four 24 bit, USB-2416 DAQ boards manufactured by Measurement Computing Corporation are selected, with each of the board capable of accommodating 32 sensors with single-ended input connection configuration (or 16 sensors with differential input connection) with a maximum input voltage of $20 \mathrm{~V}$. Each of the DAQ board has a throughput rate of $69 \mathrm{~Hz}$.

For the controlled devices installed on the two test loops, there are a total of 11 control signals for the C-SCW Loop and 13 control signals for the C-R134a Loop. The types of the control signals consists of: analog voltage (maximum of $10 \mathrm{~V}$ ), current signals $(4-20 \mathrm{~mA})$ and digital signals. The DAQ board's sampling rate and resolution of the digital-to-analog converter are determined to be of less importance in this case as these two parameters are not the primary factors affecting the accuracy of the critical measurements of the heat transfer experiment. As a result, a USB-3106 DAQ board manufactured by Measurement Computing Corporation is selected. It offers 16 signal connections with each of these connections capable of sending digital signals or analog voltage signals with a maximum amplitude of $20 \mathrm{~V}$ or analog current signals at $4-20$ $\mathrm{mA}$.

A measurement uncertainty analysis on the chosen setup of the DAQ system is carried out to estimate the uncertainties for the critical outcomes of the experiments: the convective heat transfer coefficients and total pressure losses within the test section. It is found that the uncertainties for both of the parameters reach their peak when the bulk fluid is under a thermodynamic state in the vicinity of the pseudo-critical point of the 
working fluid. As the fluid's bulk thermodynamic state moves away from the pseudocritical point, the uncertainties for the fore-mentioned two parameters start to fall back to around $+/-10 \%$ of the reading.

In order to control and monitor the operation of the two test loops from a remote computer workstation, two virtual control panels are designed base on ergonomic principles. Each of these two control panels contains three sub-panels, namely the health monitoring virtual panel, the virtual panel for loop control and the virtual panel for experimental data, with each of these three sub-panels shown on a dedicated computer monitor. The controls and health monitoring features on these three panels are differentiated by implementing ergonomic principles regarding color codes, size manipulations and placements of objects. Implementation of these principles allows the operator to quickly identify a control or health monitoring feature on the virtual control panel. 


\section{References}

[1] S. Baindur, "Materials challenges for the supercritical water-cooled reactor," in Proceedings of the 28th Annual Conference of the Canadian Nuclear Society, St. John, New Brunswick, 2007.

[2] M. N. Balouch, "Design of Test Loops for Forced Convection Heat Transfer Studies at Pseudo-critical state," Carleton University, Ottawa, 2011.

[3] M.N. Balouch, R. Alena, A. Mason, J. Goldak, M. Yaras, "Design and thermal/structural analysis of a supercritical water thermohydraulics loop," in The 5th International Symposium on Supercritical-Water-Cooled-Reactors, Vancouver, 2011.

[4] F. White, Fluid Mechanics, 5 ed., New York, NY: McGraw-Hill Companies, Inc., 2003.

[5] M.L Nayyar, et al., Piping Handbook, New York: McGraw-Hill Companies, Inc., 2000.

[6] "Thermalphysical Properties of Fluid Systems," NIST, 2011. [Online]. Available: http://webbook.nist.gov/chemistry/fluid/.

[7] I.J. Karassik et al., Pump Handbook, 4 ed., New York, NY: McGraw-Hill Companies, Inc., 2008.

[8] W. Peng, Fundamentals of Turbomachinery, Hoboken, NJ: John Wiley \& Sons, Inc., 2008. 
[9] B. Nesbitt, Handbook of Valves and Actuators: Valve Manual International, Elsevier Ltd., 2007.

[10] R.W. Zappe, P. Smith, Valve Selection Handbook, 5 ed., Burlinton, MA: Gulf Professional Publishing, 2004.

[11] G. Towler, R. Sinnott, Chemical Engineering Design: Principles, Practice and Economics of Plant and Process Design, 5 ed., Burlinton, MA: ButterworthHeinemann, 2009.

[12] Pipe Flanges and Flanged Fittings, ASME B16.5, American Society of Mechanical Engineers (ASME), 1996.

[13] R. Warring, The Hydraulic Handbook, 8 ed., Surrey: Trade \& Technical Press Ltd., 1983.

[14] J. Johnson, Introduction to Fluid Power, Delmer Publisher Inc., 2002.

[15] M. Rabie, Fluid Power Engineering, New York, NY: McGraw-Hill, 2009.

[16] API RP 520, Sizing, Selection, and Installation of Pressure-Relieving Devices in Refineries: Part I - Sizing and Selection, American Petroleum Institute (API), 2000.

[17] ASME B 31.1, Power Piping, American Society of Mechanical Engineers (ASME), 2001.

[18] J. Holman, Heat Transfer, New York, NY: McGraw-Hill Companies, Inc., 2002.

[19] T.H. Kuehn, R.J. Goldstein, "Numerical solution to the Navier-Stokes equations for laminar natural convection about a horizontal isothermal circular cylinder," Int. J. Heat Mass Transfer,, vol. 23, pp. 971 - 979, 1980. 
[20] T. Saitoh, T.Sajiki, K. Maruhara, "Benchmark solutions to natural convection heat transfer problem around a horizontal circular cylinder," Int. J. Heat Mass Transfer,, vol. 36, no. 5, pp. $1251-1259,1993$.

[21] P. Wang, R. Kahawita, T.H. Nguyen, "Numerical computation of the natural convection about a horizontal cylinder using splines, Part A," Num. Heat Transfer,, vol. 17, pp. 191 - 215, 1990.

[22] "ANSYS CFX-Solver Theory Guide," ANSYS, Inc., 2009.

[23] J.R. Licht, M.H. Anderson, M.L. Gorradini, R. Bonazza, "Heat Transfer Phenomena in Supercritical Water Nuclear Reactors," 2007.

[24] F.P. Incropera, D.P. DeWitt, T.L. Bergman, A.S. Lavine, Fundamentals of Heat and Mass Transfer, 6 ed., John Wiley \& Sons, Inc., 2007.

[25] B. Weigand, Analytical Methods for Heat Transfer and Fluid Flow Problems, Berlin: Springer, 2004.

[26] F. Menter, "Two-equation eddy-viscosity turbulence models for engineering applications," AIAA Journal, vol. 32, no. 8, pp. 1598 - 1605, 1994.

[27] J.G.M Eggels, F. Unger, M.H. Weiss, J. Westerweel, R.J. Adrian, R. Friedrich, F.T.M. Nieuwstadt, "Fully developed turbulent pipe flow: a comparison between direct numerical simulation and experiment," Journal of Fluid Mechanics, vol. 268, pp. $175-210,1994$.

[28] H. Kawamura, K. Ohsaka, H. Abe, K. Yamamoto, "DNS of turbulent heat transfer in channel flow with low to medium-high Prandtl number fluid," Int. J. of Heat and Fluid Flow, vol. 19, no. 5, pp. 482 - 491, 1998. 
[29] S. Kakac, Y. Yener, Convective Heat Transfer, 2 ed., Boca Raton, FL: CRC Press LLC, 1995.

[30] M.N. Balouch, A. Mason, R. Alena, Y.L. Jin, "Supercritical Water Loop Design Report," Ottawa, 2010.

[31] "Rosemount 2088 Absolute and Gage Pressure Transmitter: Product Data Sheet," Rosemount Inc., 2013.

[32] "Industrial Pressure Transducers," Swagelok Company, 2011.

[33] "Rosemount 3051 Pressure Transmitter: Product Data Sheet," Rosemount Inc., 2008.

[34] "CFW-08 Frequency Inverter Manual," WEG Automacao S.A., 2006.

[35] "Model 1100 Series Turbine Flow Meter," Racine Federated Inc., 2010. [Online]. Available: http://www.blancett.com/1100_TFM.php. [Accessed 2011].

[36] "FLUXUS ADM 7X07 Technical Specification," FLEXIM Americas Corporation, 2010.

[37] "Type DTLG 600-150/2000 with Analog Programming: Instruction \& Operating Manual for Carleton University," MAGNAVOLT Technologies Inc., 2010.

[38] G. Barney, Intelligent Instrumentation: Microprocessor Applications in Measurement and Control, New York: Prentice Hall Inc., 1988.

[39] W. Dunn, Introduction to Instrumentation, Sensors and Process Control, Boston, MA: Artch House, 2006.

[40] F. Mazada, Discrete Electronic Components, New York, NY: Cambridge University Press, 1981. 
[41] Manual on the Use of Thermocouples in Temperature Measurement, 4 ed., ASTM International, 1993.

[42] R. Bentley, Handbook of Temperature Measurement, vol. 3, Springer, 1998.

[43] "Reference Guide," OMEGA, [Online]. Available: http://www.omega.com/temperature/pdf/tc_temp_limits_range.pdf. [Accessed 2013].

[44] "Dimensions and Technical Details Electric Actuator M-Series," HANBY Inc., [Online]. Available: http://www.hanbayinc.com/dataSheets/Mxx-spec.pdf. [Accessed 2013].

[45] R. Malaric, Instrumentation and Measurement in Electrical Engineering, Boca Raton, FL: Brown Walker Press, 2011.

[46] G. Johnson, R. Jennings, LabVIEW Graphical Programming, New York, NY: McGraw-Hill Companies Inc., 2006.

[47] U.A. Bakshi, A.V. Bakshi, Measurements and Instrumentation, Technical Publications, 2009.

[48] W. Bolton, Measurement and Instrumentation Systems, Oxford: Newnes, 1996. [49] "USB-2416 USB-based Multi-function I/O Module User's Guide," Measurement Computing Corporation, 2011.

[50] "USB-3106 USB-based Analog Output User's Guide," Measurement Computing Corporation, 2009.

[51] F. Nachreiner, P. Nickel, I. Meyer, "Human factors in process control systems: the design of human-machine interfaces," Safety Science, vol. 44, no. 1, pp. 5 - 26, 2006. 
[52] T. Sheridan, "Telerobotics, automation and human supervisory control," Automatica, vol. 30, no. 6, pp. 1072 - 1073, 1994.

[53] C. Wittenberg, "A pictorial human-computer interface concept for supervisory control," Control Engineering Practice, vol. 12, no. 7, pp. 865 - 878, 2004.

[54] C. Sandom and R. Harvey, Eds., Human Factors for Engineers, London: Institute of Eletrical Engineers, 2004.

[55] E. K. Company, Ergonomic Design for People at Work, Toronto: Lifetime Learning, 1983.

[56] S.H. Han, H. Yang, D.G. Im, "Designing a human-computer interface for a process control room: a case study of a steel manufacturing company," Int. J. of Industrial Ergonomics, vol. 37, no. 5, pp. 383 - 393, 2007.

[57] G. Shin, S. Hegde, "User-preferred position of computer displays: effects of display size," Human Factors, vol. 52, no. 5, pp. 574 - 585, 2010. 


\section{Appendix 1: Total Pressure Loss in the Subsections of the C-SCW}

\section{Loop}

Table A1-1: Total pressure loss within each of the subsections on the C-SCW Loop

\begin{tabular}{|c|c|c|c|c|c|}
\hline Subsection & $\begin{array}{c}\text { Installed test } \\
\text { sections }\end{array}$ & & $23 \mathrm{MPa}$ & $25 \mathrm{MPa}$ & $27 \mathrm{MPa}$ \\
\hline \multirow{12}{*}{ Section 1} & \multirow{4}{*}{$\begin{array}{l}\text { 7-rod bundle } \\
\text { test section }\end{array}$} & $380^{\circ} \mathrm{C}$ & 239 & 540 & 621 \\
\hline & & $400^{\circ} \mathrm{C}$ & 154 & 177 & 217 \\
\hline & & $500^{\circ} \mathrm{C}$ & 90 & 93 & 95 \\
\hline & & $600^{\circ} \mathrm{C}$ & 69 & 70 & 71 \\
\hline & \multirow{4}{*}{$\begin{array}{l}\text { Annular test } \\
\text { section }\end{array}$} & $380^{\circ} \mathrm{C}$ & 240 & 543 & 623 \\
\hline & & $400^{\circ} \mathrm{C}$ & 155 & 177 & 217 \\
\hline & & $500^{\circ} \mathrm{C}$ & 91 & 93 & 96 \\
\hline & & $600^{\circ} \mathrm{C}$ & 69 & 70 & 71 \\
\hline & \multirow{4}{*}{$\begin{array}{l}\text { Tubular test } \\
\text { section }\end{array}$} & $380^{\circ} \mathrm{C}$ & 243 & 549 & 630 \\
\hline & & $400^{\circ} \mathrm{C}$ & 156 & 179 & 220 \\
\hline & & $500^{\circ} \mathrm{C}$ & 92 & 94 & 97 \\
\hline & & $600^{\circ} \mathrm{C}$ & 70 & 71 & 72 \\
\hline \multirow{12}{*}{ Section 2} & \multirow{4}{*}{$\begin{array}{l}\text { 7-rod bundle } \\
\text { test section }\end{array}$} & $380^{\circ} \mathrm{C}$ & 185 & 423 & 486 \\
\hline & & $400^{\circ} \mathrm{C}$ & 118 & 136 & 167 \\
\hline & & $500^{\circ} \mathrm{C}$ & 69 & 71 & 73 \\
\hline & & $600^{\circ} \mathrm{C}$ & 52 & 53 & 54 \\
\hline & \multirow{4}{*}{$\begin{array}{l}\text { Annular test } \\
\text { section }\end{array}$} & $380^{\circ} \mathrm{C}$ & 186 & 425 & 488 \\
\hline & & $400^{\circ} \mathrm{C}$ & 119 & 137 & 168 \\
\hline & & $500^{\circ} \mathrm{C}$ & 69 & 71 & 73 \\
\hline & & $600^{\circ} \mathrm{C}$ & 53 & 53 & 54 \\
\hline & \multirow{4}{*}{$\begin{array}{l}\text { Tubular test } \\
\text { section }\end{array}$} & $380^{\circ} \mathrm{C}$ & 187 & 429 & 494 \\
\hline & & $400^{\circ} \mathrm{C}$ & 120 & 138 & 170 \\
\hline & & $500^{\circ} \mathrm{C}$ & 70 & 72 & 74 \\
\hline & & $600^{\circ} \mathrm{C}$ & 53 & 54 & 55 \\
\hline
\end{tabular}




\begin{tabular}{|c|c|c|c|c|c|}
\hline \multirow{12}{*}{ Section 3A } & \multirow{4}{*}{$\begin{array}{l}\text { 7-rod bundle } \\
\text { test section }\end{array}$} & $380^{\circ} \mathrm{C}$ & 595 & 1039 & 1155 \\
\hline & & $400^{\circ} \mathrm{C}$ & 502 & 493 & 542 \\
\hline & & $500^{\circ} \mathrm{C}$ & 463 & 415 & 417 \\
\hline & & $600^{\circ} \mathrm{C}$ & 444 & 420 & 395 \\
\hline & \multirow{4}{*}{$\begin{array}{l}\text { Annular test } \\
\text { section }\end{array}$} & $380^{\circ} \mathrm{C}$ & 597 & 1043 & 1161 \\
\hline & & $400^{\circ} \mathrm{C}$ & 503 & 494 & 543 \\
\hline & & $500^{\circ} \mathrm{C}$ & 463 & 415 & 417 \\
\hline & & $600^{\circ} \mathrm{C}$ & 445 & 421 & 396 \\
\hline & \multirow{4}{*}{$\begin{array}{c}\text { Tubular test } \\
\text { section }\end{array}$} & $380^{\circ} \mathrm{C}$ & 602 & 1053 & 1172 \\
\hline & & $400^{\circ} \mathrm{C}$ & 506 & 498 & 547 \\
\hline & & $500^{\circ} \mathrm{C}$ & 466 & 417 & 418 \\
\hline & & $600^{\circ} \mathrm{C}$ & 446 & 423 & 397 \\
\hline \multirow{12}{*}{ Section 3B } & \multirow{4}{*}{$\begin{array}{l}\text { 7-rod bundle } \\
\text { test section }\end{array}$} & $380^{\circ} \mathrm{C}$ & 7760 & $1.01 \mathrm{E} 4$ & $1.08 \mathrm{E} 4$ \\
\hline & & $400^{\circ} \mathrm{C}$ & 7940 & 6910 & 6930 \\
\hline & & $500^{\circ} \mathrm{C}$ & 8020 & 7420 & 6910 \\
\hline & & $600^{\circ} \mathrm{C}$ & 8000 & 7390 & 6880 \\
\hline & \multirow{4}{*}{$\begin{array}{l}\text { Annular test } \\
\text { section }\end{array}$} & $380^{\circ} \mathrm{C}$ & $1.28 \mathrm{E} 4$ & $1.68 \mathrm{E} 4$ & $1.79 \mathrm{E} 4$ \\
\hline & & $400^{\circ} \mathrm{C}$ & $1.31 \mathrm{E} 4$ & $1.14 \mathrm{E} 4$ & $1.14 \mathrm{E} 4$ \\
\hline & & $500^{\circ} \mathrm{C}$ & $1.31 \mathrm{E} 4$ & $1.22 \mathrm{E} 4$ & $1.13 \mathrm{E} 4$ \\
\hline & & $600^{\circ} \mathrm{C}$ & $1.31 \mathrm{E} 4$ & $1.21 \mathrm{E} 4$ & $1.12 \mathrm{E} 4$ \\
\hline & \multirow{4}{*}{$\begin{array}{c}\text { Tubular test } \\
\text { section }\end{array}$} & $380^{\circ} \mathrm{C}$ & $1.53 \mathrm{E} 4$ & $2.00 \mathrm{E} 4$ & $2.14 \mathrm{E} 4$ \\
\hline & & $400^{\circ} \mathrm{C}$ & $1.57 \mathrm{E} 4$ & $1.36 \mathrm{E} 4$ & $1.36 \mathrm{E} 4$ \\
\hline & & $500^{\circ} \mathrm{C}$ & $1.56 \mathrm{E} 4$ & $1.44 \mathrm{E} 4$ & $1.34 \mathrm{E} 4$ \\
\hline & & $600^{\circ} \mathrm{C}$ & $1.56 \mathrm{E} 4$ & $1.44 \mathrm{E} 4$ & $1.31 \mathrm{E} 4$ \\
\hline
\end{tabular}




\begin{tabular}{|c|c|c|c|c|c|}
\hline \multirow{12}{*}{ Section 4A } & \multirow{4}{*}{$\begin{array}{l}\text { 7-rod bundle } \\
\text { test section }\end{array}$} & $380^{\circ} \mathrm{C}$ & 447 & 493 & 517 \\
\hline & & $400^{\circ} \mathrm{C}$ & 441 & 411 & 388 \\
\hline & & $500^{\circ} \mathrm{C}$ & 428 & 397 & 369 \\
\hline & & $600^{\circ} \mathrm{C}$ & 413 & 382 & 355 \\
\hline & \multirow{4}{*}{$\begin{array}{l}\text { Annular test } \\
\text { section }\end{array}$} & $380^{\circ} \mathrm{C}$ & 449 & 495 & 520 \\
\hline & & $400^{\circ} \mathrm{C}$ & 444 & 413 & 390 \\
\hline & & $500^{\circ} \mathrm{C}$ & 431 & 399 & 371 \\
\hline & & $600^{\circ} \mathrm{C}$ & 415 & 384 & 357 \\
\hline & \multirow{4}{*}{$\begin{array}{c}\text { Tubular test } \\
\text { section }\end{array}$} & $380^{\circ} \mathrm{C}$ & 454 & 500 & 526 \\
\hline & & $400^{\circ} \mathrm{C}$ & 448 & 417 & 394 \\
\hline & & $500^{\circ} \mathrm{C}$ & 436 & 402 & 375 \\
\hline & & $600^{\circ} \mathrm{C}$ & 420 & 388 & 361 \\
\hline \multirow{12}{*}{ Section 4B } & \multirow{4}{*}{$\begin{array}{l}\text { 7-rod bundle } \\
\text { test section }\end{array}$} & $380^{\circ} \mathrm{C}$ & $2.16 \mathrm{E} 4$ & $4.12 \mathrm{E} 4$ & $4.60 \mathrm{E} 4$ \\
\hline & & $400^{\circ} \mathrm{C}$ & $1.47 \mathrm{E} 4$ & $1.64 \mathrm{E} 4$ & $1.93 \mathrm{E} 4$ \\
\hline & & $500^{\circ} \mathrm{C}$ & 8840 & 9000 & 9170 \\
\hline & & $600^{\circ} \mathrm{C}$ & 6780 & 6820 & 6860 \\
\hline & \multirow{4}{*}{$\begin{array}{c}\text { Annular test } \\
\text { section }\end{array}$} & $380^{\circ} \mathrm{C}$ & $2.17 \mathrm{E} 4$ & $4.14 \mathrm{E} 4$ & $4.62 \mathrm{E} 4$ \\
\hline & & $400^{\circ} \mathrm{C}$ & $1.47 \mathrm{E} 4$ & $1.65 \mathrm{E} 4$ & $1.94 \mathrm{E} 4$ \\
\hline & & $500^{\circ} \mathrm{C}$ & 8890 & 9040 & 9210 \\
\hline & & $600^{\circ} \mathrm{C}$ & 6810 & 6850 & 6890 \\
\hline & \multirow{4}{*}{$\begin{array}{c}\text { Tubular test } \\
\text { section }\end{array}$} & $380^{\circ} \mathrm{C}$ & $2.20 \mathrm{E} 4$ & 4.19E4 & $4.67 \mathrm{E} 4$ \\
\hline & & $400^{\circ} \mathrm{C}$ & $1.49 \mathrm{E} 4$ & $1.67 \mathrm{E} 4$ & $1.96 \mathrm{E} 4$ \\
\hline & & $500^{\circ} \mathrm{C}$ & 8990 & 9140 & 9320 \\
\hline & & $600^{\circ} \mathrm{C}$ & 6890 & 6930 & 6970 \\
\hline
\end{tabular}




\begin{tabular}{|c|c|c|c|c|c|}
\hline \multirow{12}{*}{ Section 4C } & \multirow{4}{*}{$\begin{array}{l}\text { 7-rod bundle } \\
\text { test section }\end{array}$} & $380^{\circ} \mathrm{C}$ & 879 & 1092 & 1150 \\
\hline & & $400^{\circ} \mathrm{C}$ & 819 & 835 & 863 \\
\hline & & $500^{\circ} \mathrm{C}$ & 775 & 777 & 778 \\
\hline & & $600^{\circ} \mathrm{C}$ & 760 & 761 & 762 \\
\hline & \multirow{4}{*}{$\begin{array}{c}\text { Annular test } \\
\text { section }\end{array}$} & $380^{\circ} \mathrm{C}$ & 879 & 1094 & 1151 \\
\hline & & $400^{\circ} \mathrm{C}$ & 820 & 836 & 864 \\
\hline & & $500^{\circ} \mathrm{C}$ & 775 & 777 & 779 \\
\hline & & $600^{\circ} \mathrm{C}$ & 761 & 761 & 762 \\
\hline & \multirow{4}{*}{$\begin{array}{c}\text { Tubular test } \\
\text { section }\end{array}$} & $380^{\circ} \mathrm{C}$ & 881 & 1098 & 1157 \\
\hline & & $400^{\circ} \mathrm{C}$ & 821 & 837 & 865 \\
\hline & & $500^{\circ} \mathrm{C}$ & 776 & 778 & 780 \\
\hline & & $600^{\circ} \mathrm{C}$ & 761 & 762 & 762 \\
\hline
\end{tabular}




\section{Appendix 2: Operating Flow Coefficients of the Two Control Valves}

\section{Installed on the C-SCW Loop}

The operating conditions under which the calculations for the data presented in Table A2-1 were carried out are the ones indicated in Section 3.2. The data entries highlighted with yellow color are the operating $C_{v}$ 's for the two control valves. The type of the installed test section and the corresponding loop operating conditions are also indicated in the table.

Table A2-1: Operating flow coefficients $\left(C_{v}\right)$ for the control valves installed on the

\section{C-SCW Loop}

\begin{tabular}{|c|c|c|c|c|c|c|c|c|c|c|c|}
\hline \multirow[t]{2}{*}{ Type of test section } & \multirow{2}{*}{$\begin{array}{l}\text { Test section outlet } \\
\text { temperature (degC) }\end{array}$} & \multirow{2}{*}{$\begin{array}{l}\text { Pressure } \\
\text { (MPa) }\end{array}$} & \multicolumn{8}{|c|}{$\mathrm{Cv}$ of the valve in the bypassline } & \multirow[b]{2}{*}{$\begin{array}{c}\text { Cv of the valve in the main } \\
\text { line }\end{array}$} \\
\hline & & & $\begin{array}{c}\begin{array}{c}\text { Pump flow } \\
\text { rate } \\
\left(m^{\wedge} 3 / \mathrm{hr}\right)\end{array} \\
\end{array}$ & 1.79 & 2.12 & 2.46 & 2.79 & 3.12 & 3.46 & 3.79 & \\
\hline \multirow{15}{*}{ TUBULAR } & \multirow{3}{*}{380} & 23 & & 1.96 & 2.77 & 3.58 & 4.38 & 5.19 & 6.00 & 6.81 & 1.99 \\
\hline & & 25 & & 0.58 & 1.28 & 1.98 & 2.68 & 3.38 & 4.08 & 4.78 & 3.50 \\
\hline & & 27 & & 0.34 & 1.01 & 1.69 & 2.36 & 3.04 & 3.72 & 4.39 & 3.94 \\
\hline & \multirow{4}{*}{400} & & & & & & & & & & \\
\hline & & 23 & & 2.45 & 3.26 & 4.08 & 4.89 & 5.70 & 6.51 & 7.32 & 1.58 \\
\hline & & 25 & & 2.47 & 3.33 & 4.20 & 5.06 & 5.93 & 6.79 & 7.65 & 1.63 \\
\hline & & 27 & & 2.20 & 3.06 & 3.92 & 4.77 & 5.63 & 6.49 & 7.35 & 1.83 \\
\hline & \multirow{4}{*}{500} & & & & & & & & & & \\
\hline & & 23 & & 2.95 & 3.78 & 4.60 & 5.42 & 6.24 & 7.06 & 7.88 & 1.18 \\
\hline & & 25 & & 3.05 & 3.90 & 4.75 & 5.60 & 6.45 & 7.30 & 8.15 & 1.17 \\
\hline & & 27 & & 3.13 & 4.01 & 4.89 & 5.77 & 6.65 & 7.53 & 8.41 & 1.17 \\
\hline & & & & & & & & & & & - \\
\hline & \multirow{3}{*}{600} & 23 & & 3.15 & 3.97 & 4.79 & 5.61 & 6.43 & 7.25 & 8.07 & 1.02 \\
\hline & & 25 & & 3.27 & 4.13 & 4.98 & 5.83 & 6.69 & 7.54 & 8.39 & 1.00 \\
\hline & & 27 & & 3.41 & 4.30 & 5.19 & 6.08 & 6.97 & 7.86 & 8.76 & 0.99 \\
\hline & & & & & & & & & & & \\
\hline \multirow{15}{*}{ ANNULAR } & \multirow{3}{*}{380} & 23 & & 2.12 & 2.99 & 3.86 & 4.74 & 5.61 & 6.48 & 7.35 & 1.89 \\
\hline & & 25 & & 0.65 & 1.40 & 2.15 & 2.90 & 3.65 & 4.40 & 5.16 & 3.23 \\
\hline & & 27 & & 0.38 & 1.11 & 1.84 & 2.56 & 3.29 & 4.02 & 4.74 & 3.59 \\
\hline & \multirow{4}{*}{400} & & & & & & & & & & \\
\hline & & 23 & & 2.66 & 3.53 & 4.41 & 5.28 & 6.15 & 7.03 & 7.90 & 1.50 \\
\hline & & 25 & & 2.66 & 3.59 & 4.52 & 5.45 & 6.38 & 7.30 & 8.23 & 1.56 \\
\hline & & 27 & & 2.40 & 3.32 & 4.24 & 5.16 & 6.09 & 7.01 & 7.93 & 1.74 \\
\hline & & & & & & & & & & & \\
\hline & \multirow{3}{*}{500} & 23 & & 3.19 & 4.08 & 4.96 & 5.84 & 6.72 & 7.61 & 8.49 & 1.12 \\
\hline & & 25 & & 3.30 & 4.22 & 5.14 & 6.05 & 6.97 & 7.89 & 8.81 & 1.12 \\
\hline & & 27 & & 3.38 & 4.33 & 5.28 & 6.22 & 7.17 & 8.12 & 9.06 & 1.12 \\
\hline & & & & & & & & & & & \\
\hline & \multirow{3}{*}{600} & 23 & & 3.42 & 4.31 & 5.19 & 6.08 & 6.97 & 7.86 & 8.75 & 0.97 \\
\hline & & 25 & & 3.55 & 4.47 & 5.39 & 6.31 & 7.23 & 8.15 & 9.07 & 0.96 \\
\hline & & 27 & & 3.68 & 4.63 & 5.59 & 6.55 & 7.51 & 8.47 & 9.42 & 0.95 \\
\hline \multirow{14}{*}{ 7-ROD BUNDLE } & \multirow{3}{*}{380} & 23 & & 2.25 & 3.31 & 4.37 & 5.44 & 6.50 & 7.57 & 8.63 & 1.93 \\
\hline & & 25 & & 0.32 & 1.23 & 2.14 & 3.06 & 3.97 & 4.88 & 5.79 & 3.16 \\
\hline & & 27 & & 0.00 & 0.88 & 1.76 & 2.64 & 3.52 & 4.40 & 5.28 & 3.45 \\
\hline & & & & & & & & & & & \\
\hline & \multirow{3}{*}{400} & 23 & & 3.00 & 4.08 & 5.15 & 6.23 & 7.30 & 8.38 & 9.45 & 1.52 \\
\hline & & 25 & & 2.94 & 4.07 & 5.20 & 6.34 & 7.47 & 8.60 & 9.74 & 1.62 \\
\hline & & 27 & & 2.57 & 3.70 & 4.82 & 5.95 & 7.07 & 8.20 & 9.32 & 1.80 \\
\hline & \multirow{4}{*}{500} & & & & & & & & & & \\
\hline & & 23 & & 3.73 & 4.81 & 5.90 & 6.98 & 8.07 & 9.16 & 10.24 & 1.15 \\
\hline & & 25 & & 3.84 & 4.96 & 6.09 & 7.22 & 8.34 & 9.47 & 10.60 & 1.15 \\
\hline & & 27 & & 3.92 & 5.08 & 6.24 & 7.40 & 8.56 & 9.72 & 10.88 & 1.16 \\
\hline & \multirow{3}{*}{600} & & & 403 & 512 & 6.22 & 7.31 & 840 & 9.50 & 10.59 & 0.99 \\
\hline & & 25 & & 4.03 & 5.30 & 6.43 & 7.57 & 8.70 & 9.83 & 10.97 & 0.99 \\
\hline & & 27 & & 4.29 & 5.47 & 6.64 & 7.81 & 8.98 & 10.15 & 11.32 & 0.99 \\
\hline
\end{tabular}




\section{Appendix 3: Sizing of the Cooling Tube and the Pressure Relief}

\section{Valves}

\section{Sizing for the Cooling Tube Wall Thickness}

\section{Design data:}

\begin{tabular}{|l|c|}
\hline Tube outside diameter $\left.\left(\mathbf{D}_{\mathbf{0}}\right) \mathbf{( m m}\right)$ & 6.35 \\
\hline Wall thickness $(\boldsymbol{t})(\mathbf{m m})$ & 1.24 \\
\hline Service temperature $\left({ }^{\mathbf{0}} \mathbf{C}\right)$ & $260 / 30$ \\
\hline Service pressure $(\boldsymbol{P})(\mathbf{M P a})$ & $27 / 40.8$ \\
\hline
\end{tabular}

\section{Calculation:}

As per ASME B31.1, paragraph 104.1.2, the minimum wall thickness $\left(t_{m}\right)$ for the tube should not be lower than [1]:

$$
t_{m}=\frac{P D_{o}}{2(S E+y P)}
$$

where $S E$ is the maximum allowable stress for stainless steel $316(\mathrm{kPa})$. Values of this parameter can be found in Table 3 of Appendix A of the ASME B31.1 Power Piping Code [1].

For service condition 1: $\mathrm{P}=27 \mathrm{MPa}$ and service temperature of $260^{\circ} \mathrm{C}$, Eqn. $\mathrm{A} 3-1$ gives:

$$
t_{m}=\frac{27 \times 10^{3} \mathrm{kPa} \times 6.35 \mathrm{~mm}}{2\left(86184+1.0 \times 27 \times 10^{3}\right)}=0.75 \mathrm{~mm}
$$

For service condition 2: $\mathrm{P}=40.8 \mathrm{MPa}$ and service temperature of $30^{\circ} \mathrm{C}$, Eqn. $\mathrm{A} 3-1$ gives:

$$
t_{m}=\frac{40.8 \times 10^{3} \mathrm{kPa} \times 6.35 \mathrm{~mm}}{2\left(129621 \mathrm{kPa}+1.0 \times 40.8 \times 10^{3} \mathrm{kPa}\right)}=0.76 \mathrm{~mm}
$$


Since in both cases, the minimum required wall thickness is smaller than the selected wall thickness $1.24 \mathrm{~mm}$, the design selection can be considered safe.

\section{Sizing of the Pressure Relief Valve (PRV)}

Sizing calculation for the PRV to be installed on the Gas Side of the C-R134a Loop and the C-SCW Loop

Relief condition: Taking C-R134a Loop as an example, CV 4 (gas charging valve) on the C-R134a Loop is fully open with a flow coefficient $\left(C_{v}\right)$ of 0.09 . The upstream pressure of this valve is at $40.8 \mathrm{MPa}$ and the downstream pressure is $6.8 \mathrm{MPa}$ (which is $110 \%$ of MAWP (or the set pressure) of the C-R134a Loop, as per API RP 520) [2].

\section{a. Maximum Discharge Flow Rate}

The mass flow rate of compressible fluid through the $\mathrm{CV} 4, \dot{m}$, can be calculated via [3]:

$$
C_{v}=\frac{\dot{m}}{N_{8} F_{p} P_{g a s} Y \sqrt{\frac{x M}{T_{g a s} Z}}}
$$

where $N_{8}$ is a constant, which is given as $0.948 \mathrm{~kg} / \mathrm{h} ; P_{\text {gas }}$ is the nitrogen pressure at the upstream of the gas charging valve $(\mathrm{kPa}) ; F_{p}$ is the geometric factor and it is 1.0 in this case; $T_{\text {gas }}$ is the nitrogen temperature at the upstream of the gas charging valve, which is taken as $303 \mathrm{~K}$ in this case; $M$ is the molar mass of the fluid, which is $28 \mathrm{~kg} / \mathrm{kmol}$ for nitrogen in this case; $Z$ is the compressibility factor and for the given condition, the value is found to be 1.25 and $x$ is the pressure drop ratio:

$$
x=\frac{\Delta P}{P_{g a s}}
$$


where $\Delta P$ is the pressure drop across the valve $(\mathrm{kPa})$ and $Y$ is the expansion factor is 0.67 in this case. This value should never exceed the critical pressure ratio, under which the flow through the valve is choked (with the ratio of the specific heat capacity being 1.7 for nitrogen gas at the upstream of the gas charging valve under a pressure of $40.8 \mathrm{MPa}$ $\left.30^{\circ} \mathrm{C}\right)$

$$
x=1-\left(\frac{2}{1.7+1}\right)^{(1.7 / 0.7)}=0.5
$$

In other words, at the relief condition, the PRV should be large enough to relief the nitrogen gas a rate of $\dot{m}$ (i.e. the discharge rate). For the given relief condition, the discharge rate is found to be $448 \mathrm{~kg} / \mathrm{hr}$.

\section{b. Required Size of the Discharge Area of the PRV}

For gas services, the required orifice area for the PRV can be calculated through [2]:

$$
A=\frac{13160 \dot{m}}{C k_{d} k_{b} k_{c} P_{u p}} \sqrt{\frac{T_{u p} Z}{M}}
$$

where $C$ is an equation constant, which is 343 in this case; $P_{u p}$ is $110 \%$ of the set pressure $(\mathrm{kPa}) ; T_{u p}$ is the temperature of the fluid at the inlet of the PRV $(\mathrm{K}) ; A$ is the orifice area $\left(\mathrm{mm}^{2}\right)$ and $k_{d}, k_{b}$ and $k_{c}$ are the equation constants, whose values, in this case, are 0.62, 1.0 and 1.0 , respectively.

The resulting required discharge area is $15 \mathrm{~mm}^{2}$. Considering the smallest ASME certified PRV (D type) has an orifice size of $70 \mathrm{~mm}^{2}$, the smallest PRV should be sufficient to perform the duty here [4]. 
For C-SCW Loop, since the loop is operating at a substantially higher pressure, the discharge rate is expected to be smaller considering same gas charging valve is used (because the pressure differential across the gas charging valve is smaller). The required discharge port size is expected to be even smaller. Thus, the D-type PRV should also be fit for duty on the gas side of the pressure control module installed for C-SCW Loop.

Sizing calculation for the PRV to be installed on the working fluid side of the C-R134a Loop and the C-SCW Loop

Relief condition (for the C-R134a Loop): Flow is stopped and the test section is operating at its maximum power input, $51.5 \mathrm{~kW}$. At the time of discharge, the R-134a at the test section is at its maximum temperature (i.e $100^{\circ} \mathrm{C}$ at the inlet and $140^{\circ} \mathrm{C}$ at the outlet). The discharge pressure is again, 6.8 MPa. A similar approach is taken to find the required size for the discharge area of the PRV.

\section{a. Maximum Discharge Flow Rate}

The maximum discharge flow rate can be calculated by:

$$
\dot{m}_{\text {discharge }}=\rho_{\text {discharge }} \frac{d V}{d t}
$$

where $V$ is the volume of the test section $\left(\mathrm{m}^{3}\right) ; \rho_{\text {discharge }}$ is the density of $\mathrm{R}-134 \mathrm{a}$ discharged through the PRV, which in this case is $1088 \mathrm{~kg} / \mathrm{m}^{3}$ (at $6.8 \mathrm{MPa}$ and $65^{\circ} \mathrm{C}$ ) and $t$ is time (s). The temperature, $65^{\circ} \mathrm{C}$, is the average temperature of the ambient temperature $30^{\circ} \mathrm{C}$ and the temperature of the $\mathrm{R}-134 \mathrm{a}$ in the low temperature section of the C-R134a Loop.

By conservation of mass, $\frac{d V}{d t}$ can be calculated through: 


$$
\left(\rho+\frac{d \rho}{d t} d t\right)\left(V+\frac{d V}{d t} d t\right)=\rho V
$$

where $\rho$ is the density of R-134a in the test section at the time of discharging $\left(\mathrm{kg} / \mathrm{m}^{3}\right)$ and $V$ is the volume of the fluid initially stayed in the test section $\left(\mathrm{m}^{3}\right)$.

Reducing Eqn. A3-9 gives:

$$
\frac{d V}{d t}=-\frac{V}{\rho}\left(\frac{d \rho}{d t}\right)
$$

Therefore, Eqn. A3-8 can be rewritten as:

$$
\dot{m}_{\text {discharge }}=-\rho_{\text {discharge }} \frac{V}{\rho}\left(\frac{d \rho}{d t}\right)
$$

For the $\frac{d \rho}{d t}$ term, it can be expressed as by assuming the discharge pressure is maintained at constant which is $6.8 \mathrm{MPa}$ :

$$
\frac{d \rho}{d t}=\left.\frac{\partial \rho}{\partial u}\right|_{p=6.8 M P a, T=120^{\circ} C} \frac{d u}{d t}
$$

where $u$ is the specific internal energy of the R-134a at the test setion $(\mathrm{J} / \mathrm{kg})$. In this case, $\left.\frac{\partial \rho}{\partial u}\right|_{p=6.8 M P a, T=120^{\circ} \mathrm{C}}$ only depends on the fluid properties and it is found to be $-5.4 \times 10^{-3}$ $\mathrm{kg}^{2} / \mathrm{J}-\mathrm{m}^{3}$. The temperature, $120^{\circ} \mathrm{C}$ here is the average of the inlet and the outlet of the test section at the start of discharge. The second term $\frac{d u}{d t}$ can be found by:

$$
\frac{d u}{d t}=\frac{\dot{Q}}{m_{t e s t}}
$$

Therefore, Eqn. A3-11 can be further reduced to: 


$$
\dot{m}_{\text {discharge }}=-\rho_{\text {discharge }} \frac{V}{\rho} \frac{d \rho}{d u} \frac{\dot{Q}}{m_{\text {test }}}
$$

Assuming that, at the start of discharge, the volume of the fluid is close to that of the test section, Eqn. A3-14 can further be reduced to:

$$
\dot{m}_{\text {discharge }}=-\rho_{\text {discharge }} \frac{d \rho}{d u} \frac{\dot{Q}}{\rho^{2}}
$$

The discharge mass flow is found to be $0.61 \mathrm{~kg} / \mathrm{s}$.

\section{b. Required Size of the Discharge Area of the PRV}

For R-134a, the fluid is in gas phase under ambient temperature and pressure $\left(30^{\circ} \mathrm{C}\right.$ and $\left.1 \times 10^{5} \mathrm{~Pa}\right)$. Thus, there is a potential phase change, which the R-134a may undergo during its discharge through the PRV. Under such scenario, procedures outlined in Section D2.2 of the API RP 520 are applicable to the sizing of the PRV [2].

It is necessary to determine where the R-134a starts its phase change and it can be determined by introducing a parameter called the Saturated Omega Parameter, $\omega_{s}$, which is defined by:

$$
\omega_{s}=9\left(\frac{\rho_{l o}}{\rho_{9}}-1\right)
$$

where $\rho_{l o}$ is the density of the fluid at the inlet of the PRV, which in this case is 1088 $\mathrm{kg} / \mathrm{m}^{3}$ and $\rho_{9}$ is the density of the fluid evaluated at $90 \%$ of the saturation pressure $\left(P_{s}=\right.$ 1.9 $\mathrm{MPa}$ ) corresponding to the PRV inlet temperature $\left(65^{\circ} \mathrm{C}\right)$, which in this case is 84 $\mathrm{kg} / \mathrm{m}^{3}$. The value of this parameter is found to be 107 . 
With the help of this parameter, the location of phase change can be found by using the comparison between the $P_{s}$ and $\eta_{s t} P_{1}$, of which $P_{l}$ is the pressure of the fluid at the inlet of the PRV and $\eta_{s t}$ is the transition saturation pressure ratio, which is defined by:

It was found that:

$$
\eta_{s t}=\frac{2 \omega_{s}}{1+2 \omega_{s}}
$$

$$
P_{s}<\eta_{s t} P_{1}
$$

Therefore, the phase change occurs at the throat of the discharge port.

Based on this result, an equation is given for calculating the required size for discharge port:

$$
A=\frac{0.3208 Q \rho_{\text {discharge }}}{K_{d} K_{b} K_{c} G}
$$

The unit in this equation is based on empirical unit system: the discharge area is given the unit of in ${ }^{2}$; the volume flow rate, $Q$, is given as US gallon per minute; $\rho_{\text {discharge }}$ is given as $1 \mathrm{~b} / \mathrm{ft}^{3} ; G$ is the mass flux, which is given the unit of $1 \mathrm{~b} / \mathrm{s} \mathrm{ft}^{2}$ and it can be calculated through:

$$
G=96.3 \sqrt{\rho_{l o}\left(P_{u p}-P_{a}\right)}
$$

where $\rho_{l o}$ is given the unit of $\mathrm{lb} / \mathrm{ft}^{3} ; P_{u p}$ is also given the unit of psi and $P_{a}$ is the atmospheric pressure, which is 14.7 psi. $K_{d}, K_{b}$ and $K_{c}$ are equation constants, which are $0.65,1$ and 0.9 , respectively.

The resultant size of the discharge port is $0.013 \mathrm{in}^{2}$, which is $8.4 \mathrm{~mm}^{2}$. Thus, the ASME D-type PRV should be used [4]. 
Since the discharge temperature of the water is the average of the ambient temperature, $30^{\circ} \mathrm{C}$ and the temperature of the water in the cold section of the loop, $260^{\circ} \mathrm{C}$, water will also undergo a phase change through the PRV. The MAWP for the C-SCW Loop is $27.07 \mathrm{MPa}$. Thus, the sizing procedure for the PRV to be installed on the water loop is the same to that used for the C-R134a Loop. The resulting size of the discharge port is $16 \mathrm{~mm}^{2}$. Therefore, ASME D-type PRV should be used on the working fluid side of the C-SCW Loop [4]. 


\section{References}

[1] ASME B 31.1, Power Piping, American Society of Mechanical Engineers (ASME), 2001.

[2] API RP 520, Sizing, Selection, and Installation of Pressure-Relieving Devices in Refineries: Part I - Sizing and Selection, American Petroleum Institute (API), 2000.

[3] “Control Valve Handbook,” Emerson Process Management, 2005

[4] API Standard 526, Flanged Steel Pressure Relief Valves, American Petroleum Institute (API), 1995 


\section{Appendix 4: Specifications for the Fans Selected of the Pressure}

\section{Control Module of the C-SCW Loop}

"Turbo-Aire ${ }^{T M "}$ Specifications

- $1 / 50$ th Horsepower motor

- 5 blades with air straighteners

- Slide control: Off, Low, Medium, High

- Pearl grey housing with charcoal ABS protective grilles

- U.L. Listed and CSA approved

- Two year limited warranty

- Hassock type fan: floor, table or wall mount

\begin{tabular}{|c|c|c|c|c|c|}
\hline \multicolumn{6}{|c|}{ Unmatched C.F.M. Performance } \\
\hline Switch Setting & CFM* & RPM & Amp Rating & Watts & CFM per Watt \\
\hline High & 1340 & 1160 & .953 & 109.6 & 12.23 \\
\hline Medium & 1154 & 870 & .733 & 84.3 & 13.69 \\
\hline Low & 602 & 615 & .568 & 65.3 & 10.59 \\
\hline \multicolumn{6}{|c|}{ *Test Method: Measured with velometer 2 inches from fan face } \\
\hline \multicolumn{2}{|c|}{ Distance from fan face } & \multicolumn{2}{|c|}{ CFM } & \multicolumn{2}{|c|}{ Switch Setting } \\
\hline \multicolumn{2}{|l|}{2 inches } & \multicolumn{2}{|c|}{1,350} & \multicolumn{2}{|c|}{ High } \\
\hline \multicolumn{2}{|l|}{10 feet } & \multicolumn{2}{|c|}{8,513} & \multicolumn{2}{|c|}{ High } \\
\hline \multicolumn{2}{|l|}{20 feet } & \multicolumn{2}{|c|}{11,225} & \multicolumn{2}{|c|}{ High } \\
\hline
\end{tabular}

Ordering Information

- Model Number: \#3200

- UPC Code: 6363503200

- Pack: 1 per carton

- Carton Dimensions: $19^{\prime \prime}$ x $18^{\text {"h }}$ x $9^{1 / 4 "} \mathrm{~d}$

- Carton Cube: 1.7 cubic feet

- Fan blade size: $12^{\prime \prime}$

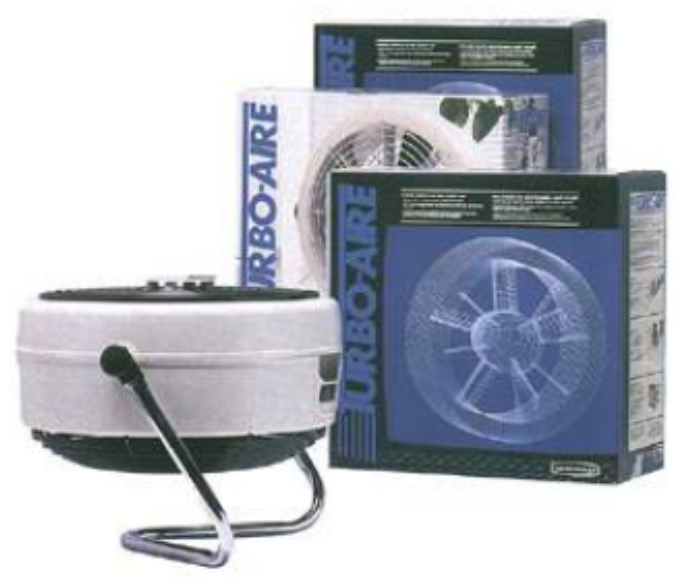

